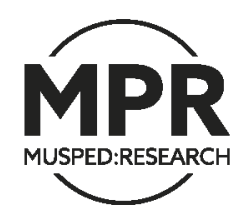

NO. 42022

Robin Rolfhamre \& Elin Angelo (Eds.)

\title{
Views on Early Music as Representation
}

\section{INVITATIONS, CONGRUITY, PERFORMANCE}




\section{Views on Early Music as Representation}



Robin Rolfhamre and Elin Angelo (Eds.)

\section{Views on Early Music as Representation} INVITATIONS, CONGRUITY, PERFORMANCE 
(C) 2022 Elin Angelo, Jorge Salgado Correia, Randi Margrethe Eidsaa, Frida Forsgren, Rolf Lislevand, Inga Marie Nesmann-Aas, Robin Rolfhamre and Daniel Henry Øvrebø.

This work is protected under the provisions of the Norwegian Copyright Act (Act No. 2 of May 12, 1961, relating to Copyright in Literary, Scientific and Artistic Works) and published Open Access under the terms of a Creative Commons Attribution-NonCommercialNoDerivatives 4.0 International (CC BY-NC-ND 4.0) License (https://creativecommons. org/licenses/by-nc-nd/4.o/). This license allows third parties to copy and redistribute the material in any medium or format for non-commercial purposes only. If you remix, transform, or build upon the material, you may not distribute the modified material.

Third parties are prohibited from applying legal terms or technological measures that restrict others from doing anything permitted under the terms of the license. Note that the license may not provide all of the permissions necessary for an intended reuse; other rights, for example publicity, privacy, or moral rights, may limit third party use of the material.

This book has been made possible with support from the University of Agder.

ISSN: $2703-7843$

ISBN PDF: 978-82-02-75537-9

ISBN EPUB: 978-82-02-75873-8

ISBN HTML: 978-82-02-75538-6

ISBN XML: $978-82-02-75874-5$

ISBN Print Edition: 978-82-02-75619-2

DOI: https://doi.org/10.23865/noasp.157

This is a peer-reviewed anthology.

Cover Design: Cappelen Damm AS

Cappelen Damm Akademisk/NOASP

www.noasp.no

noasp@cappelendamm.no 


\section{Innhold}

Chapter 1 Introduction: Making History Through Music

Performance and Education

Robin Rolfhamre and Elin Angelo

Chapter 2 Performative Musicology and HIP as Rhetoric and

Pedagogy for the Past in Present and Future.

Robin Rolfhamre

Chapter 3 Contextual In-Depth Knowledge as a Liberating Force

in Artistic and Pedagogical Communication of Early

Modern Material

Inga Marie Nesmann-Aas

Chapter 4 Hearing Early Modern Music Through the Contemporary 119

Daniel Henry Øvrebø

Chapter 5 Rolf Lislevand in Conversation with Randi Margrethe Eidsaa and Daniel Henry Øvrebø 139

Daniel Henry Øvrebø, Randi Margrethe Eidsaa and Rolf Lislevand

Chapter 6 Early Music in an Interdisciplinary Artistic Production:

The Project Pluvinel's Academy

Randi Margrethe Eidsaa

Chapter 7 Re-Enacting Beat Art: An Aesthetic and Pedagogical

Approach to Re-Living History.

Frida Forsgren

Chapter 8 Rhetorically Performative Early Music: YouTube Videos as Statements 199

Robin Rolfhamre and Daniel H. Øvrebø

Chapter 9 From Researcher/Performer to Artistic Researcher:

Looking Back at the Past in Search of New Possibilities

Jorge Salgado Correia

About the Authors. 



\title{
Introduction: Making History Through Music Performance and Education
}

\author{
Robin Rolfhamre
}

Professor of Music Education, University of Agder

\section{Elin Angelo}

Professor of Music Education, NTNU - Norwegian University of Science and Technology

Generally, schoolteachers educate their pupils in the early Baroque era as a school project in one way or another. They may listen to music, discuss literature, politics, historical events, watch a theme-related film and present a YouTube clip with an excerpt from a (perhaps randomly selected) performance of a canonical opera. Through such a project something important happens. The pupils form a conception of what the Baroque era was, based on the teacher's structured guidance (a person who may have no formal musical training whatsoever, cf. Statistisk sentralbyrå, 2019). This concept will follow the pupils as they grow - some will pursue a future in the arts or the humanities, and some will not - and will lay a foundation for how they perceive their cultural heritage. Of course, this understanding of the Baroque era develops further over time and space, and finally results in a general public conception of who we are and where we come from. Hence, there is a pedagogical mandate in caring

Citation: Rolfhamre, R. \& Angelo, E. (2022). Introduction: Making history through music performance and education. In R. Rolfhamre \& E. Angelo (Eds.), Views on early music as representation: Invitations, congruity, performance (MusPed:Research No. 4, Ch. 1, pp. 7-19). Cappelen Damm Akademisk. https:// doi.org/10.23865/noasp.157.ch1

Licens: CC BY-NC-ND 4.0 
for and promoting a cultural heritage, particularly through education. An important question for future endeavours within the historical arts, then, is what we as music teachers actively do and can do to manage and care for our cultural heritage within various educational settings. For example, establish a dialogue of scholarship and artistic practice in line with Article 3 of the Treaty on European Union (EU, 2012). In this volume, therefore, we have invited colleagues from higher music education to examine education, pedagogical settings and early music in combination rather than as separate discourses. The approaches and chapters in this anthology will thus contribute to and bridge the research fields of early music, musicology and music education. With this motivation, the authors of this anthology explore their own educational practices through philosophical and inquiring approaches, rooted in their everyday practice as music teachers and music performers. Therefore, pedagogy is neither the necessary starting point nor a central part of the authors' and educators' own professional understanding. Instead, the word pedagogy points to what arises from the authors' practices rather than what constitutes a defined, path-delineating starting point for that same practice.

Musicians who spend their lives teaching students how to play and interact with music do not necessarily consider themselves pedagogues. Previous research reveals great variations in music educators' self-understanding and conception of their professional responsibilities and expertise (Angelo, 2016; Dobroven, 2020; Kaschub \& Smith 2014; Krüger, 2000; Mills, 2004; Nerland, 2003; Nielsen \& Karlsen, 2020; Roberts 2002; Schei, 2007). For example, a music teacher might first and foremost percieve him/herself as a professional musician. Accordingly, this self-perception guides their intentions and habitual parameters differently from other musicians, who may consider themselves teachers with a designated, pedagogical mandate with certain responsibilities (particularly flavoured by general educational practices). Moreover, different music performance educators may represent various self-perceptions based on their musical style preferences and affiliations (e.g., from classical music, contemporary music or jazz). This would also be reflected in their terms of employment and what expectations they must meet as teachers in different contexts and traditions. Music education can be said to be of a different 
nature than other occupations, as musicians are often allowed more selfregulated teaching activities (within the set boundaries of a course syllabus) where teaching aims, repertoire and teaching and learning designs may differ considerably from individual to individual. What constitutes an often conflicting additional duty, as a result of the Bologna process (The European Higher Education Area, 1999, n.d.) and the merging of higher education in Norway, is an increasing demand for research activities, entrepreneurship and academic skills. Obviously, in higher education these factors influence how music educators perceive their mandate and expertise, as well as how they develop and conduct their music teaching activities (Angelo et al., 2019, 2021b; Bowman, 2007; Ferm Thorgersen et al., 2016). So far, early music seems to have dodged the dedicated focus of researchers within contemporary music education and professionalism, who problematise music institutions and their teachers' self-understanding, mandates and expertise. This volume wishes to contribute to introducing new perspectives to the educational agenda by discussing the accompanying mandates as well as the premises for music education in the twenty-first century through perhaps (at least to some) surprising pathways provided by early music in practice.

\section{An educational canvas}

To approach an exploration of educational practice and pedagogy from the outside-in we decided not to settle on any common understanding of what "education" or "pedagogy" would entail beforehand, nor did we agree on any well-construed definition. What we did agree on, however, was that each contributor should base their work on their own practice, from their own perspective, and look at the use of historical music in various educational or pedagogical-by-effect settings. This enabled, as the volume will show, an interesting sort of fuzzy terminological space driven by an implicit understanding of terminologies often contrasting with their professional understanding as higher music education teachers and employees. We hope that our efforts will contribute to broadening the pedagogical and educational fields of study by offering additional outside-in pathways to the subjects. 
Moreover, in a defined benefit-driven educational system - kept in place by quality assurance procedures, policies, funding schemes and performance indicators - it is easily assumed that education is, and should be, for a specific purpose. Education and pedagogy, in this perspective, make themselves relevant by achieving something defined, a specific state of being. It can be addressed differently, however. In the Norwegian language we have two similar, but still very different, words that both relate to education: utdanning (education) and danning (formation). The first educates for a specific end or a particular occupation, while the latter represents the formation of knowledge. Hence, the first leans somewhat towards instrumental operationality while the second towards epistemology, learning for learning's sake and, sometimes, also for leisure and pleasure. Cutting off the $u t$ - from utdanning thus allows new ways of approaching pedagogical practices.

Early music performance in its broadest capacity presents a compelling case for being something in the present representing, presenting, enacting, reenacting, living and reliving, concretising and fantasising a historical past. It includes perspectives ranging from familiar phenomena such as the early music revival, authenticity and the HIP (historically informed performance), to less frequent efforts related to cultural heritage sustainability. Moreover, and more recently, it also implies historical films, neo-isms, re-composing, and re-formations. It is both what it is and something entirely other. Inspiring countless efforts to come to terms with its nature, one way of approaching the act of conveying or doing history is through pedagogy and music education. This anthology deals with the challenge of conveying or doing history through educational approaches. These approaches aim towards learning and training, specific knowledge and specific subjects, as well as broader and more philosophical perspectives relating to humanity, values, ethics and the role of history in nurturing future generations and communities. If we maintain the previous divide between pedagogy and pedagogy-by-effect as two separate categories, the first is more familiar in Northwestern European societies' conception of music education, and has its roots in Scandinavian and German teacher education and teacher education research (Angelo et al., 2021b; Ferm Thorgersen et al., 2016; Georgii-Hemming \& Lilliedahl, 
2014; Kertz-Welzel, 2004, 2014; Nielsen, 2005, 2006, 2007). It particularly emphasises the German bildung and didaktik (distinct from the English, didactics). Here, music education arose from making music a subject to be studied according to general teacher educational views, highlighting didaktik, teaching and learning (Angelo et al., 2021a).

The second, pedagogy-by-effect, differs in that it turns the hierarchy upside-down. Music performers and theoreticians are now approaching educational practice without necessarily imagining themselves as Pedagogues (capital P intended). They rather focus on communicating and maintaining a certain craft, and they gain experience over time in how to do so effectively. Although this would be readily categorised as pedagogy and education by many, that does not perhaps correspond to the experience of the individual teacher. "I am only a musician passing on a craft to others the way I know how to do it," they may think, while compartmentalising pedagogy as something dependent on having formal tuition, a certain vocabulary, and perhaps even some mystical ethos that may or may not be understood as compatible with music performance training. Rather than consciously experimenting with constructive alignment (e.g., Biggs, 1996), gamification (such as Fulton, 2019; Hung, 2018; Smith \& Abrams, 2019), flipped classroom (for instance, Arslan, 2020; Julia et al., 2020; Ozdamli \& Asiksoy, 2016; Rabidoux, 2018) and/or ICT-supported tuition, only to mention a few perspectives, they may be more concerned with preserving a particular tradition of (teaching) practice. In this case, that tradition would often be construed as a master-apprentice model. What is interesting to note in the present context is the very name of the Department of Classical Music and Music Education (University of Agder) where Rolfhamre is currently employed. Setting up "classical music" and "music education" as separate entities in the department's title very much embodies this twofold understanding where the one is not the other, and subsequently invites one to ask why it is so. And, what happens if we remove this separation, substituting it with a different option? Although both questions need a more dedicated focus than what this present volume can offer, they serve as a catalytic incentive through which this anthology enters the field of higher music performance education and pedagogy. 
The general uses of the word "pedagogy" in this anthology, therefore, cover different, more or less clearly defined interpretations in the various chapters, and stretch from methodological concerns in teaching and training to concerns about formational and communicative aspects in artistic performances, and to more complex views of the role of history in developing democratic, respectful and sustainable lives and societies. Pedagogy, here, is then multifaceted as it is placed and displaced in learning, acting, mediating, communicating, perceiving, conveying and persuading historically remote, cultural practices.

\section{Project background}

A more general driving force behind the project is: When sustaining and managing a certain European cultural heritage, how do we do so and to what effect? It is easy to deduce that to approach this question, the insider historical, musicological, early modernist perspectives, or similar ideas, may not be enough on their own. The subject calls for both insider and outsider perspectives. More precisely, it calls for both insider-outsider (insider early music studies scholars who study a lost practice they cannot revisit) and outsider-outsider positions (someone more or less alien to early music scholarship being confronted with and reacting to its present artistic expressions). The project led to the formation of the research group REMP: Reconfiguring Early Modern Performance, which assembled scholars and artists from both domains to produce this present volume. As a means of taking a fresh look at traditional early music performance studies, we soon saw its pedagogical potential. The project would not only function as an instrument to be used within an educational setting (higher education degrees, primary school history, pre-concert talks, Facebook-forums, etc.), but also as something primarily pedagogical in its formation and re-formation. The way early music is construed and portrayed just to fulfil the official boundary of its terminology, is also a pedagogical act utilised in multiple ways by artists, historians, musicians, film-makers, social media enthusiasts, etc. Somewhere in all this, there are many past-present congruences and mismatches to be found that are easily neglected in non-interdisciplinary settings. It is 
not a question of regarding early music scholarship and artistry as binary presentism versus historicism, but rather as historicism in presentism and presentism in historicism. That is precisely what this volume is all about and to which it seeks to contribute.

Robin Rolfhamre initiated the project and formed the research group behind this anthology back in 2018 as a reaction to a thought-provoking personal experience when he contributed to starting up the University of Agder, Faculty of Fine Arts $\mathrm{PhD}$-specialisation, Art in Context. As an interdisciplinary doctoral study programme, the fields of classical music, music pedagogy, theatre and drama as well as visual arts were taught together, and the curriculum highlighted each individual field of study contextually in relation to the others and to society. In the preparatory work leading to the start-up, teachers representing each of the main fields worked together to find common ground and to better understand each other's scholarly context and legacy. What had earlier seemed given and axiomatic was no longer so, and Rolfhamre was inspired to follow up the critical questions he received from these very competent "outsiders". He then formed the research group based on two questions which he had been pondering for some time: (1) What happens when non-dedicated early modern music scholars are asked to study it from their perspective? (2) What can the outsider perspective contribute to the field itself? The contributing scholars from the University of Agder based research group REMP are: Professor of Music Education and early music performer, Robin Rolfhamre; Professor of Music Education, Randi Margrethe Eidsaa (Music Education); Associate Professor Frida Forsgren (Visual Arts); Research Fellows and performing artists, Inga Marie Nesmann-Aas and Daniel Henry Øvrebø (the latter obtained his $\mathrm{PhD}$ late in 2021); as well as the internationally acclaimed lutenist, pedagogue and early music specialist Professor Rolf Lislevand, Dr hc. To secure non University of Agder based perspectives, Rolfhamre was also glad to be able to join forces with co-editor, Professor of Music Education, Elin Angelo (NTNU, Norwegian University of Science and Technology), as well as to welcome Associate Professor Jorge Salgado Correia (University of Aveiro) in order to review the project output with a fresh set of eyes through to the anthology's concluding chapter. 
The work compiles a variety of chapters highlighting spectatorship, experience, theory, rhetoric, philosophy, representation, performance, performativity, literature, visual arts, pedagogy, education, pragmatism and also new materialism. It treats music that is readily categorised as early music (in a canonical, orthodox sense), and music that is bordering on, or even becoming, something else entirely, but with evident roots in the early music repertoire.

\section{Chapters}

This volume presents nine chapters. First, Robin Rolfhamre's extensive and thorough chapter two (almost in a Wagnerian musical drama sense) "Performative Musicology and HIP as Rhetoric and Pedagogy for the Past in Present and Future" examines early music performance, musicology and music pedagogy to propose moving from what he argues to be an understanding of the HIP (historically informed performance) as something analogous to a learning outcome, to one utilising its potential as a pedagogical and rhetorical practice, and makes a first attempt at proposing a dedicated performative musicology to make HIP more pronounced as a pedagogy for the past in the present and future.

Second, in chapter three, "Contextual In-Depth Knowledge as a Liberating Force in Artistic and Pedagogical Communication of Early Modern Material", Inga Marie Nesmann-Aas, based in her ongoing PhD project on Henry Purcell's opera Dido and Aeneas (1689), wishes to elucidate the process of an in-depth study of sources and contextual analysis functioning as a knowledge basis for artistic integrity, while focusing on the aria "Dido's Lament". From a topomorphological perspective, she seeks to explain some possible interconnections, interpretations and inspiration for an embodied artistic approach to the material, as well as the implications this approach can have for performers in proposing new, meaningful ways of studying and approaching the artistic experience of the work.

Next, Daniel Henry Øvrebø’s “Hearing Early Modern Music Through the Contemporary" focuses on how contemporary music practice engages with early modern aesthetics. Based on two works by Felix Renggli and 
Aisha Orazbayeva in which Telemann's Solo Fantasias are interspersed with contemporary techniques and repertoire, he studies how Baroque music exemplified by Telemann can be communicated to a modern audience without relying upon conceptions of historically informed performance, but instead attempts to communicate what can be called the fantasias' genuine aesthetic content.

The fifth chapter presents a conversation between Rolf Lislevand and scholars Randi Margrethe Eidsaa and Daniel Henry Øvrebø. The theme for the conversation centres on early modern music as a distinct practice in classical music, and its relationship to research, pedagogy and education. Lislevand, one of the leading early music performers of recent decades, shares his views on how performers can find meaningful ways to study, rehearse and perform early modern music. Particularly, they aim to respond to an intrinsic need for the music to communicate with an audience in a way that modern listeners find meaningful, and that also does not lose itself in the authenticity debate.

In the sixth chapter, "Early Modern Music in an Interdisciplinary Artistic Production: The Project Pluvinel's Academy", Randi Margrethe Eidsaa presents and reflects on a small-scale interdisciplinary artistic project designed in 2016, as part of a university degree programme. Performed in 2017 by enrolled students and a group of young riders at a local equestrian centre, the show lasted for 75 minutes and combined narration, acting and movement, costumes and equestrian sports activities with music repertoires primarily selected from early modern music. By highlighting the development of the performance components and her exploration of the learning outcomes after the artistic part of the project was completed, she emphasises how the anthology work inspired a framework for knowledge production related to historical, aesthetic, didactic and production issues. Experiences from the two versions of the artistic project, and the reflective thinking process, fostered an in-depth learning process which may be transferable to projects in various formats in a wide range of educational environments.

In chapter seven, visual arts scholar Frida Forsgren offers a pedagogical model for working with early modern culture derived from much later Beat art pedagogical practices. In "Re-Enacting California Beat 
Art: An Aesthetic and Pedagogical Approach to Re-Living History”, she draws on a 10-credit course combining artistic work with an academic curriculum at the University of Agder, dedicated to the teaching of American Beat culture. The chapter proposes that the methodology associated with the course may be applicable to the early modern field as a pedagogical method to present, enact, reenact, live, relive and fantasise a historical past.

The eighth chapter, "Rhetorically Performative Early Music: YouTube Videos as Statements" by Robin Rolfhamre and Daniel H. Øvrebø, addresses increasing history consumption in today's society, which in different social formations, creates a common expectation of what historical music is, can and should be. Drawing on music education and Baradian new materialism perspectives, they offer what they perceive as a promising procedure for studying early music performance from a less anthropocentric viewpoint by asking: How do we intra-act with early music performance as represented through online videos in ways that convey different subject positions?

Finally, building on the previous chapters of this volume, Jorge Salgado Correia draws attention to how musicians involved in historically informed performance (HIP) are drawn in two different directions, motivated to observe and analyse the past (i.e., to contribute to historical knowledge) as well as to conceive a pertinent artistic intervention (i.e., to contribute to an artistic domain). Correia invites the reader to go beyond an understanding of musical practice as simple 'artefact-performance-reception'. When embracing a sense of possibility, a specific territory becomes available to HIP performers, a territory constituted by an embodied intersubjective amalgam of beliefs, convictions, and mythopoetic configurations, in which the performers, as artistic researchers, can intervene, creating new realities and provoking changes and reconfigurations - rhetorically, pedagogically, and above all artistically.

\section{Acknowledgements}

To conclude, we would like to extend our sincere gratitude to the anthology contributors and peer reviewers who made this volume possible. 
Furthermore, we are also grateful for the financial support provided by the University of Agder.

Robin Rolfhamre and Elin Angelo, May 2021

\section{References}

Angelo, E. (2016). Music educators' expertise and mandate: Who decides, based on what? Action, Criticism and Theory in Music Education 15(2), 178-203. https:// ntnuopen.ntnu.no/ntnu-xmlui/handle/11250/2566637

Angelo, E., Knigge, J., Sæther, M. \& Waagen, W. (2021a). Higher education as context for music pedagogy research. In E. Angelo, J. Knigge, M. Sæther \& W. Waagen (Eds.), Higher education as context for music pedagogy research (pp. 7-17). Cappelen Damm Akademisk. https://doi.org/10.23865/noasp.119.choo

Angelo, E., Knigge, J., Sæther, M. \& Waagen, W. (2021b). The discursive terms of music/teacher education at four higher educational institutions. In E. Angelo, J. Knigge, M. Sæther \&W. Waagen (Eds.), Higher education as context for music pedagogy research (pp. 351-385). Cappelen Damm Akademisk. https://doi. org/10.23865/noasp.119.ch14

Angelo, E., Varkøy, Ø. \& Georgii-Hemming, E. (2019). Notions of mandate, knowledge and research in Norwegian classical music performance studies. Journal for Research in Arts and Sports Education, Special Issue Community Arts / Arts Education, 3(1), 78-10o. https://jased.net/index.php/jased/article/view/1284

Arslan, A. (2020). Instructional design considerations for flipped classroom.

International Journal of Progressive Education, 16(6), 33-59. https://doi. org/10.29329/ijpe.2020.280.3

Biggs, J. (1996). Enhancing teaching through constructive alignment. Higher Education, 32, 347-364. https://link.springer.com/article/10.1007/BFoo138871

Bowman, W. (2007). Who is the "we"? Rethinking professionalism in music education. Action, Criticism and Theory for Music Education 6(4), 109-131.

Dobrowen, L. (2020). Musikk på barnetrinnet. En studie av loereres forståelser av profesjonalitet $i$ musikkundervisning [Doctoral dissertation, The Norwegian Academy of Music]. https://nmh.brage.unit.no/nmh-xmlui/ handle/11250/2672795?locale-attribute=en

EU. (2012). Consolidated version of the treaty on European Union. Official Journal of the European Union. https://eur-lex.europa.eu/resource.html?uri=cellar:2bf14obfa3f8-4ab2-b5o6-fd71826e6da6.0023.02/DOC_1\&format=PDF

Ferm Thorgersen, C., Johansen, G. \& Juntunen, M. L. (2016). Music teacher educators' visions of music teacher preparation in Finland, Norway and Sweden. 
International Journal of Music Education, 34(1), 49-63. https://doi.org/10.1177/ O255761415584300

Fulton, J. (2019). Theory of gamification - motivation [Doctoral dissertation, William Howard Taft University].

Georgii-Hemming, E. \& Lilliedahl, J. (2014). Why “what" matters: On the context dimensions of music didactics. Philosophy of Music Education Review, 22(2), 132-155. https://www.jstor.org/stable/10.2979/philmusieducrevi.22.2.132

Hung, A. C. Y. (2018). Gamification as design thinking. International Journal of Teaching and Learning in Higher Education, 30(3), 549-559.

Julia, J., Afrianti, N., Soomoro, K. A., Supriyadi, T., Dolifah, D., Isrokatun, I., Erhamwilda, E. \& Ningrum, D. (2020). Flipped classroom educational model (2010-2019): A bibliometric study. European Journal of Educational Research, 9(4), 1377-1392. https://doi.org/10.12973/eu-jer.9.4.1377

Kaschub, M. \& Smith, J. (Eds.). (2014). Promising practices in 21st century music teacher education. Oxford University Press.

Krüger, T. (2000). Teacher practice, pedagogical discourses and the construction of knowledge: Two case studies of teachers at work [Doctoral dissertation, Bergen University College].

Kertz-Welzel, A. (2004). Didaktik of music: A German concept and its comparison to American music pedagogy. International Journal of Music Education, 22(3), 277-286.

Kertz-Welzel, A. (2014). Musikpädagogische grundbegriffe und die internationalisierung der musikpädagogik. Ein unlösbares dilemma? [Basic concepts of music education and the internationalization of music education. An unsolvable dilemma?] In J. Vogt, M. Brenk, \& F. Heß (Eds.), (Grund-)begriffe musikpädagogischen nachdenkens. Entstehung, bedeutung, gebrauch (pp. 19-35). LIT.

Mills, J. (2004). Working in music: Becoming a performer-teacher. Music Education Research, 6(3), 245-261.

Nerland, M. (2003). Instrumentalundervisning som kulturell praksis: En diskursorientert studie av hovedinstrumentundervisning i høyere musikkutdanning [Doctoral dissertation, University of Oslo].

NESH. (2016). Forskningsetiske retningslinjer for samfunnsvitenskap, humaniora, juss og teologi. Den nasjonale forskningsetiske komité for samfunnsfag og humaniora (NESH). https://www.etikkom.no/forskningsetiskeretningslinjer/ Samfunnsvitenskap-jus-og-humaniora/

Nielsen, F. V. (2007). Music (and arts) education from the point of view of didaktik and bildung. In L. Bresler (Ed.), International handbook of research in arts education (pp. 265-286). Springer. 
Nielsen, F. V. (2005). Didactology as a field of theory and research in music education. Philosophy of Music Education Review, 13(1), 5-19.

Nielsen, F. V. (2006). A view on the future of an international philosophy of music education: A plea for a comparative strategy. Philosophy of Music Education Review, 14(1), 7-14.

Nielsen, S. G. \& Karlsen, S. (2020). The case of Norway: A microcosm of global issues in music teacher professional development. Arts Education Policy Review. https://doi.org/10.1080/10632913.2020.1746714

Ozdamli, F. \& Asiksoy, G. (2016). Flipped classroom approach. World Journal on Educational Technology: Current Issues, 8(2), 98-105.

Rabidoux, S. (2018). Re-envisioning the archaic higher education learning environment: Implementation processes for flipped classrooms. International Journal on E-Learning, 17(1), 85-93.

Roberts, B. A (2002). Gatekeepers and the reproduction of institutional realities: The case of music education in Canadian universities. Musical Performance 2(3), 63-80.

Schei, T. B. (2007). Vokal identitet: En diskursteoretisk analyse av profesjonelle sangeres identitetsdannelse [Doctoral dissertation, University of Bergen]. http:// hdl.handle.net/1956/2549

Smith, K. \& Abrams, S. S. (2019). Gamification and accessibility. The International Journal of Information and Learning Technology, 36(2), 104-123.

Statistisk sentralbyrå. (2019). Lærerkompetanse i grunnskolen. https://www.ssb.no/ utdanning/artikler-og-publikasjoner/laererkompetanse-i-grunnskolen--390746

Sætre, J. H. (2018). Why school music teachers teach the way they do: A search for statistical Regularities. Music Education Research, 20(5), 546-559. https:// doi.org/10.1080/14613808.2018.1433149

The European Higher Education Area. (n.d.). Bologna Process - European Higher Education Area. https://www.ehea.info

The European Higher Education Area. (1999). Ministerial Conference Bologna 1999. http://www.ehea.info/cid10o21o/ministerial-conference-bologna-1999.html

Varkøy, Ø., Angelo, E. \& Rolle, C. (2020). Artist or crafts(wo)man? European Journal of Philosophy in Arts Education, 5(1), 7-32. http://www.ejpae.com/index.php/ EJPAE/article/view/41 



\title{
Performative Musicology and HIP as Rhetoric and Pedagogy for the Past in Present and Future
}

\author{
Robin Rolfhamre \\ Professor of Music Education, University of Agder
}

\begin{abstract}
In this chapter, I examine early music performance, musicology and music pedagogy in order to propose moving from what I argue to be an understanding of HIP (historically informed performance) as something analogous to a learning outcome, to the idea of utilising its potential as a pedagogical and rhetorical practice, providing a different context in which to develop its potential. First, I present a canvas on which HIP is delineated. Next, I engage in a logical exercise to unlock and explore HIP's inner workings. Expanding on John Hillis Miller's (2009) performativity sub one and sub two, I proceed to propose four different types of performativity (i.e., performativities ${ }_{0-3}$ ) centred on John Langshaw Austin, Jacques Derrida and Judith Butler respectively. Providing some foundation for this exercise is a survey based on 132 music research journal articles published over the last five years in six representative, refereed journals. This leads me to a first attempt at proposing a dedicated performative musicology. Here, I introduce a rhetorical perspective on the past in the present based on the work of Antonis Liakos and Mitsos Bilalis (2017), Rivers and Weber (2011) and Rueger (2011). This ultimately leads to a final perspective of regarding HIP as a pedagogical activity providing a space for future ethical concerns. Or, more descriptively phrased: a pedagogy for the past in the present and future.
\end{abstract}

Keywords: historically informed performance (HIP), early music, performativity, rhetoric, pedagogy, ethics

Citation: Rolfhamre, R. (2022). Performative musicology and HIP as rhetoric and pedagogy for the past in present and future. In R. Rolfhamre \& E. Angelo (Eds.), Views on early music as representation: Invitations, congruity, performance (MusPed:Research No. 4, Ch. 2, pp. 21-95). Cappelen Damm Akademisk. https://doi.org/10.23865/noasp.157.ch2

Licens: CC BY-NC-ND 4.0 


\section{Introduction}

In this chapter, I will propose a possible framework for approaching historical musicology performance as an active and productive phenomenon - one that acts and facilitates human growth - rather than one that merely represents the past in a museum-like manner. I will work from the hypothesis that the historically informed music performance, when re-situated and re-contextualised, can indeed offer to do more than provide an opportunity to re-experience or even fantasise a reliving of the past. To do so, I examine early music performance, historical musicology and music pedagogy to propose moving from what I argue to be an understanding of HIP, that is, the historically informed performance, as something analogous to a learning outcome (see below), to the idea of utilising its potential as a pedagogical and rhetorical practice, providing a different context in which to develop its potential. This has led me to explore the inner workings of the HIP concept from a performative perspective - one such approach among many - and thus to propose an analytical-methodological research practice from a foremost pedagogical and rhetorical perspective. I will through philosophy aim both to distinguish various operative concepts of performativity, and clarify what they offer to a historical music discourse. In addition, I will argue for an HIP understood not so much as a set epistemological apparatus, but as a pedagogical potential for learning and doing early music contextually, for utilising the past to learn about the present and future, as well as for introducing ethics (or at least a first incentive to do so in future research) into traditionally historical object-driven discourses in music. It is, of course, quite an undertaking, an emprise, that cannot be accomplished all at once, but I will attempt to present a satisfying framework from which future discourse can evolve.

From a safe harbour in music pedagogy, rhetoric and performativity, the chapter seeks to offer contributions within musicology that come to terms with and expand the potential of performativity-driven discourses within musicology. Notably it also seeks to contribute to music pedagogy and historical music research by introducing alternative views on HIP as an activity that does something. First, I present a canvas on which HIP is delineated. Following, I engage in a logical exercise to unlock and explore 
HIP's inner workings. Expanding on John Hillis Miller's (2009) performativity sub one and sub two, I proceed to propose four different, selected types of performativities (performativities ${ }_{0-3}$ ), which are then discussed comparatively through various perspectives. The multiple concepts are, here, centred on John Langshaw Austin, Jacques Derrida and Judith Butler respectively. Providing some foundation for this exercise is a survey based on 132 music research journal articles published over the last five years in the refereed journals: Journal of the American Musicological Society, Journal of the Royal Musical Association, Journal of Seventeenth-Century Music, Music Performance Research, International Journal of Music and Performing Arts, and Journal of Research in Music Performance. The survey, as a representative sample, and the differentiation of various performativities leads me to a first attempt to propose deliberate modes of discourse based on such operatives - a dedicated performative musicology, one could say. In proposing a performative musicology, I am not necessarily introducing anything new, but merely drawing on already present impulses from neighbouring fields of study. This actually verbalises and directs attention to a specific phenomenon and possible cause-and-effect turn of events deduced thereof. A dedicated nomenclature can more effectively help to identify what perspective we are pursuing, also in the future. From here, I introduce a rhetorical perspective on the past in the present based on the work of Antonis Liakos and Mitsos Bilalis (2017), Rivers and Weber (2011) and Rueger (2011). I pursue this line of reasoning not only to understand the rhetoric, design and intention of the past aesthetic object/ event, but to make rhetoric the prime operative itself within a performativities-centred setting. This then offers, perhaps, an equal opportunity to implement performativities ${ }_{1-3}$, both for music as artefact and as practice. This ultimately leads to a final perspective regarding HIP as a pedagogical activity providing a space for future ethical concerns. Or, more descriptively phrased: A pedagogy for the past in the present and future.

\section{HIP}

The early music revival arose in the second half of the twentieth century following an increase in dedicated academic publishing activities, 
expanding academic music departments and, more recently, through offering degree programs focusing specifically on early music (Echols, 2013). It was particularly following World War II, Dorottya Fabian informs us, that the impetus to revive early music indeed appeared (Fabian, 2016, p. 12). The focus was first directed towards the music of the Western Baroque and earlier. Still, the term early music has since expanded to include more or less all music whose performance practice needs to be reconstructed through various sorts of surviving material, also known as contemporary evidence (Haskell, 2001). By the 1970s, the new ideal to be sought was the truly authentic performance. It required an understanding of the musical work to be seen as some sort of artefact, that is to make the text come to life once more in a representative manner. This sort of artefact way of thinking is perhaps symptomatic of our society in general. As John Butt puts it: "In an age that has experienced both the catastrophic destruction of cultural artefacts and a phenomenal expansion of technological production and reproduction, there is a definite craving for the 'original' and 'authentic' in many areas of Western society". I doubt, however, that many current early music academics would readily subscribe to this worldview, and fewer still would do so publicly. The authentic performance of music is not an easy issue to settle in this context. When the search for the authentic becomes an imperative, it must also respond to a cultural need. The "authentic" as a truth function, therefore, is dangerous because "it implies some standard of transhistorical truth, to be valid whatever the era" (Butt, 2001).

The use of the term "authenticity" has, therefore, decreased considerably since the early 1990s, to be replaced by terminologies such as HIP (historically informed performance), historically aware, and period performance. These newer terminologies emphasise the "informed and aware" rather than the "true and correct", and have become significant movements in recent fields of study and activities dedicated to music performance. "It has opened up a wide range of possibilities", Butt comments, "for new ways of performing and hearing and, shorn of its claims to 'authenticity', represents an attitude to performance that, at its best, is both vital and invigorating." Yet, HIP does not reject authenticity entirely as it instead follows the same tradition, only adding the postscript " $\ldots$ as 
far as we know and from what is manageable". Butt suggests that the historically informed performance should involve certain premises (some or all):

1) Use of instruments from the composer's own era; 2) Use of performing techniques documented in the composer's era; 3) Performance based on the implications of the original sources for a particular work; 4) Fidelity to the composer's intentions for performance or to the type of performance a composer desired or achieved $;^{1}$ 5) An attempt to re-create the context of the original performance; and 6) An attempt to re-create the musical experience of the original audience. (Butt, 2001)

Categories 1-3 relate to the artefact-centred approach where we turn to objects (instruments, technical execution and original sources) to reconstruct an ontology. Categories 4-6 naturally withhold an aesthetics-based approach shared by general historical musicology, ethnomusicology and music theory from which the early music movement grew. A typical approach to historical music performance is displayed in an online article by Michael Graubart, entitled "Musical Hermeneutics: The 'Authentic' Performance of Early Music" (200o). Here, the historical music performance is solely discussed from the perspective of hermeneutics. There is no mention of the phenomenological, intuitional and empirical (e.g., scientific studies of acoustics, instrument performance, psychological responses, etc.). Neither does he refer to past sociocultural practices and the music's original functions. Moreover, the music practice he describes is fundamentally rooted in the score, and he continuously refers to the "listeners" and, as such, rules out all other senses. Finally, instruments are mentioned only insofar as they relate to "their" realisation of the score and not the score's realisation of the instruments. He also makes no mention of the performer-instrument relationship found outside the realms of the mere "realisation of the score", which should be of interest to a philosophical website. We should not, however, simply accept the understanding of HIP as a uniform activity. In fact, research indicates that there is no generalised true view of what HIP is in practice: "because

1 Today, however, most would probably reject composer intention as anything meaningful. 
practices never stand still," Fabian reminds us (Fabian, 2016, pp. 13-15). As such, continued attention to the phenomenon can contribute to even further theoretical and artistic developments.

HIP can be said to function in different ways. It can be a goal, something to strive towards to gain authority as a historical performer. It can also be a beginning, a sort of driving licence to qualify as an early music performer, for instance. (This, of course, follows the same cultural mechanisms as those of the earlier authenticity movement, although it appears more nuanced in its present state.) But what happens in the liminal space between HIP and not HIP, as well as between HIP as goal or beginning? What is the inner functionality of the historically informed performance? Despite the fact that HIP looks past the idea of absolute truth, it still works within the boundaries of right and wrong. One performance could be more historically informed than another. The same performance could be more authentic in some of its features than in others (Kania, 2017). Yet, there is a consistent mode of operation accompanying the HIP movement, in which the authenticity of a performance is directly related to the authenticity of the sources from which it has developed, and in various degrees can cause what is absent to negate the subjective attempts to fill the gaps (Butt, 2001). This, in turn, relates intimately to the fundamentalist approaches to the ontology of what constitutes a musical work (Kania, 2017). This sort of divide between data and subjectivity has traditionally caused music performers and scholars to walk different, parallel paths representing different ambitions and agendas. Kartomi suggests that scholars' activities centre around writing academic articles, books and editions. Performers are more preoccupied with performing (live or in recorded formats) what they have analysed and prepared, sometimes with liner notes or annotated texts. Performer scholars have to deliver both (Kartomi, 2014, p. 193). According to Anna Maria Friman, early music scholars tend to seek some sort of objective reliability and critical distance, while performers, naturally, are more obliged to cultivate the subjective and emotional. Or, put differently, scholars seek strong arguments to acquire reputation through publishing activities, and performers seek some sort of "likeability" (in the sense of their reliance on a loyal audience to pursue a performance career) 
(Friman, 2008, p. 112). There is, then, some sort of epistemological divide between a paradigmatic mode based on propositional meaning (relating to a lineage from mythical thought, to abstraction, to concepts, to reason, to sciences, to paradigmatic knowledge), and embodied meaning (from mythical thought to narratives, to gestures, to know-how, to arts, and to material thinking). Problems and conflicts often arise when trying to translate the artistic and embodied domains into the declarative and discursive modes (Correia, 2020). From John Butt's perspective:

If some tend to assume that musical works are objects that are basically nonhuman and thus stable in character (those on the side of analytical philosophy and music analysis), others have surely gone too far in the direction of social constructivism and assumed that pieces of music exist only by virtue of the attitudes of a particular society - that there is nothing essentially "there" beyond the cultural norms at hand. (Butt, 2015, p. 4)

From a pedagogical perspective, I perceive HIP as a somewhat normative, ontologically focused learning outcome. That is, it is something to be achieved if one knows enough of a specific historical musical practice and repertoire, and channels it through the integrity and artistic ideal of the performing artist. It not only entails nomenclature for describing an artistic movement or aesthetic ideal, but also has pedagogical implications. First, this is because of its preference for the objective and empirical, as well as its emphasis on the recreation of the past, rather than the present, which is something else than the present-ness and subjectivity of the music teaching situation. Second, it relies on someone holding the power of definition (e.g., judging when something is authentic or not). When the idea of what HIP effectively entails, and what qualifies as a successful practice is not settled, and in some way becomes part of a general agreement, it becomes too vague to be pedagogically useful by itself. We must then leave it to the individual pedagogue to decide. Third, as we will see below, there is a lack of conformity in relation to knowledge, practice, appearance and perception. With this as a background, during my time as music performance teacher and scholar I have come to question how useful HIP - that is, the stylistic movement dedicated to the historically informed performance - indeed is from a pedagogical perspective, 
focusing on the performance itself rather than the theory and data to which it owes its credibility. When used in the sense of quality, assuring that a historical music performance is true to its epistemological preferences and research foundation, for instance, it fails as pedagogy and rather becomes a learning outcome. "If you learn all this and do all that, then your performance becomes an HIP," one may say to the student. It comes with a sort of readymade answer related to its canon and codes of proper conduct, and leads to achieving a status of belonging rather than fully welcoming alternative practices (Bergeron, 1992, pp. 1-2, 4-5). On the other hand, if one does not celebrate the past and historical evidence, there is no "historical music performance", only "music performance".

\section{How HIP operates (logically)}

A discourse on what constitutes an HIP relates strongly to what is considered to be the work performed, that is, its ontology. Most prominent among music ontologists is perhaps the fundamentalist debate on the metaphysics of classical music and what constitutes an authentic performance of a musical work. The most popular stance is to accept the existence of a musical work (realists) while others deny this (anti-realists). Among the realists, some deny that musical works are mental entities (idealists), others that they are actions. Some prefer a platonist (musical works are abstract objects) framework, while others cling to the nominalists (music is a collection of concrete particulars), or those preferring a culturally-based position. The latter may very well be perceived as the most dominant position these days, rooted in continental, rather than Anglo-American, philosophical traditions. Regardless of the philosopher's individual preference, the fundamentalist debate is quite heavily concerned with technicalities, whereas the related authenticity debate discusses how performers relate to such entities (Kania, 2017). That means how we can, should or sometimes must relate to different ontologies, and what sort of mandate and quality criteria they impose on the performer.

Although there is much pedagogical potential in historical artefacts (Barty, 2004), I choose a different path. Due to my present concern with early music as practice, rather than as a collection of technicalities and 
artefacts understood as forms of measurable learning outcomes, I will employ a rhetorical, communicative entrance to the musical work comprehended through a given situation. In the following discussion, therefore, there is an underlying assumption that the "musical work" exists as an agreement between the performer and the audience within a certain context. I use logic to develop this relationship through an agenda of identifying certain mechanisms and rhetorical scaffolds, which can support the later turns of my argument towards a pedagogy for the past in the present.

If the musical work performed is a result of an in situ communication, or negotiated through social interaction, then it should follow that HIP can be somewhat similar. When the performer acknowledges the audience's expectation of what constitutes a "performance" and a "work" by performing it, they also acknowledge that same understanding of the "musical work" within that particular context. Hence, If the performer does not meet the audience's expectations, the latter may be left confused or troubled as to what exactly the performance was that they had witnessed: "I did not understand the performance; I found it rather confusing". Naturally, any placement of the "work" can function - be it the music, the performance, the audience's experience of it, the film documentation of it, or whatever - as long as the audience and performer agree on the conditions for the performance and what to expect. (The element of surprise is not in consideration at the moment.) The "work" then is part of a communicational agreement between the performer and the audience, that is, even at the time when the audience decide to go to a concert venue, for instance, they create an expectation of: what they will experience beforehand according to the venue itself; who the performer is; what music is being played; and in what context the event takes place. The performer enters this communicational agreement when they present their event (or when accepting the conditions of the booking agents, for instance). The audience enters the communicational agreement when they attend the event at a given venue, and within a certain context. For instance, if I choose to go to the Royal Albert Hall to listen to some symphony orchestra's performance of Mahler (both maintaining a romantic tradition that is quite different from the early modern concepts of music 
making), I soon create expectations of details, such as how the performers will dress, the rituals related to the conductors entering the stage, how I should behave as an audience, etc. My initial judgement of the event itself will be strongly influenced by my expectations, and if the performers perform what I expect them to, I am ready to understand what they seek to communicate to me from the very start. However, if I meet a situation that is very much different from what I expected beforehand, I may find myself surprised, or perhaps even overwhelmed, and my emotional response to that reaction is very much decided by how persuasive the performers are when presenting it. Whether I agree on the terms of the "work", and to being part of the communication they offer through their performance, is entirely up to me as an auditor, and it may not be either/or. I may accept some parts of the performance, but not all. Let us, furthermore, assume that I do not know much about historical music performance - I may even be an early modern novice - then at what point of the musical event does the historically informed performance, that is HIP, qualify as HIP?

For a performer to be historically informed, which in this early modern context means being informed about music that by far precedes ourselves and any sound recording system, there are certain features that must be considered. The historically informed musician (M) can only perform early modern music according to their understanding of certain historical data $(d)$, certain literature $(l)$, their intuitive imagination of the unknown $(q)$, as well as their artistic skill and integrity $(s)$ : ( $\exists \mathrm{d} \& \exists \mathrm{l} \& \mathrm{q} \& \mathrm{~s}) \rightarrow \mathrm{M}$. (Of course, the reader is advised to remember that all these features are in themselves complexes with their own elaborate discourses.) In this sense, the historically informed musician performs their understanding of a certain historical musical practice as HIP, and as such, the "HIP" does not, in this context, refer to a normative, general HIP per se, but to their specific version of it. That is, "It is HIP because I say it is, I have done my homework". HIP is, therefore, an agential concept - "I say that my performance is HIP, and therefore it is" - and if the audience accepts it as HIP in that particular context, then all parties agree to the terms of the agreement and the music becomes HIP. This argument is easy to criticise because there are no conditions, whatsoever, of the quality of the historical knowledge, 
but this is exactly the point of my argument. A scholarly audience and a historically informed musician may very well disagree on the music performance, either rightfully so because of a lack of knowledge, or because they simply belong to different scholarly perspectives. But when the audience does not consist entirely of trained scholars or music professionals, there is no way to decide the truth in relation to what HIP is, only the validity of the performer's and audience's agreement as to what constitutes $\mathrm{HIP}$ at that present moment. Just as A (audience) expects Wx (work $x$ ) $\rightarrow$ $\mathrm{P}$ (performer) performs $\mathrm{Wx}=\mathrm{Wx}$, earlier, then $\mathrm{A}$ accepts ${ }^{\mathrm{HIP}} \mathrm{Wx} \& \mathrm{M}$ performs ${ }^{\text {HIP }} \mathrm{Wx} \rightarrow{ }^{\text {HIP } W x}$. For the historically informed performance to take place (at least communicatively) the audience and performer must have an agreement both as to what the work is, and how HIP is being acknowledged within the specific context.

Continuing in relation to the novice audience, the only way for them to accept and experience HIP is to rely on the performer's offering: "The performer presents the music as historically informed and I accept it. They certainly play on some rather peculiar instruments, and it sounds like something I have never heard before. Surely, they must be historically informed". How easily the novice audience accepts and trusts the performer's ethos and historical informed-ness is proportional to how skilled and persuasive the performer appears, at least that is my hypothesis (see Fig. 1 below). The performer's ethos plays a crucial part here.

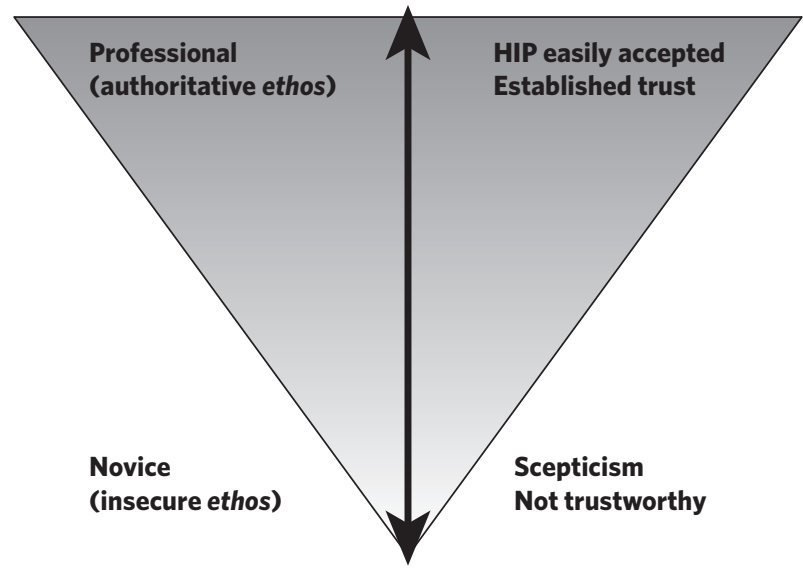

Figure 1. The Relationship Between the Acceptance of an HIP and the Performer's Ethos. My illustration. 
Take a highly esteemed Renaissance musician who is internationally renowned for their competence in a certain kind of music as an example. The threshold for what they can present musically without having their HIP-ness brought in for questioning is vastly higher than it would be for an insecure, young music student performing their first few concerts. Furthermore, when the novice audience attends a concert or listens to a recording of highly esteemed musicians, just because they have heard of their competence, their initial reaction to music that is new to them may not be one of scepticism at all, but rather a simple, "Aha! So this is Renaissance music! Now I have learned something new”. HIP, as performed by the performer, then, is not only an agential concept in the sense of how it constitutes itself, but it is also as a pedagogical tool. It mediates how the historically informed sounds to a novice audience, and they learn. The success of this pedagogical activity relates to the audience's response to the performer's ethos. Here, we must recall how HIP is performed by $M$ according to their understanding of historical musical practice: ( $\exists \mathrm{d} \&$ $\exists l \&$ q \& a) $\rightarrow$ M. As a continuation of this argument, HIP is verified by the audience's acceptance of the performer's performed knowledge and artistic integrity, and their mutual understanding of what the musical work is within a certain situation. From the audience's repeated acceptance of, in terms of the performance's repeated insistence on, a certain understanding of the "work" and what is accepted as HIP in a given situation, HIP is agentially normalised as a general concept. It is how we relate to that concept that ultimately decides whether we are HIP or not. Furthermore, this general concept spreads the knowledge of historically informed knowledge without necessarily having to relate very much to cutting edge academic research. HIP is a "mutual understanding and agreement of" rather than a proven fact. This is an important feature of historically informed performance practice, because, although it relies on academic research to evolve (cf., M above) it does not rely on it to keep existing. My version of HIP may be grounded figuratively on theoretical work I did 20 years ago that I have not compared to any more recent research ever since. Nonetheless, until I am disproved by my audience (or some individual part of it), my concept of HIP is still valid as long as the audience accepts it, regardless of it being up to speed with current research or not. 
From another perspective, the historically informed performance relates very strongly to what it is not (in the sense that, for instance, "day" relies on its opposite "night" to be "day"), and it exerts a certain otherness in today's more mainstream musical climate (here, relating to the collected fields of more general portions of the music market including generalisations such as classical, rock and popular). But in what sense is it something other? This question facilitates numerous strategies, ranging from Aristotelian syllogisms with all the logical risks, to the reductio in absurdum (reduction to absurdity; e.g., "HIP is not a hamburger." Then does "hamburger" really relate to "HIP" in the same manner as the aforementioned "day" to "night"? Does "HIP" rely on "hamburger" to be "HIP"?), to other deconstructionist arguments, and many more. In this present context, I will keep it simple and effective by focusing on "otherness" as "what it is not".

Early modern music is certainly different from many other genres, or at least that is what we are often led to believe. Baroque improvisation is somewhat unattainable because we have to improvise in a baroque fashion. However Baroque composers certainly did not do that; they simply improvised according to contemporary traditions and taste, like we do today. Rather than humanising the musical practice, today's baroque improvisation is often featured as a display of a musician's genius. How often do I hear in conversations with others how brilliant Johann Sebastian Bach was, being such a gifted improviser? But this focus on genius, originality and otherness (the musician is brilliant, and I am not; that is why they perform, and I listen) is not something very early modern at all. It is a much more modern invention, a romantic ideal of the acclaimed artist, that is not compatible with seventeenth or early eighteenth-century aesthetics (Potolsky 2006, locs. 294-296).

Furthermore, how often have I had conversations with audiences, family and new acquaintances (usually starting with ritualistic phrases like, "What do you do for a living?") in which the early modern is described as mystical because it is very different from today's genres. But, as I have argued elsewhere, the early modern concept of music making is, in fact, more akin to many current popular music practices than it is, indeed, to the romantic, "classical music" tradition (Rolfhamre, 2014). It was 
pragmatic: they borrowed musical ideas from each other; dance was for a long period of time, in several parts of Europe, central to musical expression; one used the instruments at hand and if the music did not fit the new instrument, they made the necessary adjustments; solmization was a bodily experience, not only theoretical, as the hands were used to illustrate pitch (Early Music Sources, 2017b); the act of transposing a highpitched melodic line notated with a G-clef was an automatic response because the idiomatic voice trumped the score (Early Music Sources, 2017a); etc. Even further, depending on period, genre and region, singing was about making the text clear, telling a story and not merely displaying tone qualities and technique. To me, at least, this shows that early modern music was closer to what popular musicians do today than what is often assumed. The "otherness" in this situation is not situated at the far end of a dichotomous scale, but operates gradually on that scale depending on the focus of our discussion. When does "early modern" music cease to be just that? In Graham Priest's Introduction to Logic, we read a comparable example of "fuzzy logic", where he proposes that a child is still a child one second later. This is also true three seconds later and ten seconds later. By repeating this one-second-later argument for 630,720,000 seconds, we could still assert that the child is still a child, but that is no longer true because the child could, by now, have reached an age of 25. "[...] Being a child seems to fade out, gradually, just as being a (biological) adult seems to fade in gradually. It seems natural to suppose that the truth value of 'Jack is a child' also fades from true to false" (Priest, 2000, pp. 68-70).

We could easily apply the same type of argument to the early modern music being performed today through the binary relationship of "early modern" to "not early modern". This brings us neatly to another perspective prompted by scholars such as Derrida: When criticising something, we are inevitably part of what we are criticising (Collins \& Mayblin, 2012, locs. 398-399). For HIP, this is true in the sense that HIP, as I have repeatedly made clear, is an imaginative construct: one that cannot exist without being filtered out from our modern assumptions of what good aesthetics are. No matter how historically correct we are, we are still living and performing the music today. Thus, criticising how HIP something is, is a rather tiresome affair unless one also acknowledges the modernity of it 
within a given context. By presenting “old” music (in layman's terms), we are also reinventing it and creating something new (cf., $\mathrm{M}$ above), which is quite paradoxical, as our historical attempts only result in innovation and alternative music to contrast, so to speak, other more modern genres.

However, the repeated formalisation of both the "work" and HIP creates a normative, general expectation of what is historically informed. Let us say that I have discovered a groundbreaking fact that widely contradicts our knowledge of how music from, for instance, the Renaissance is to be performed. I decide to bring this new knowledge to life through a performance without any additional persuasion involved. I neither write any descriptive notes in the programme nor present my findings verbally to the audience. It is not difficult to assume that I may be met with well-founded scepticism from those who have an idea of the music. By contradicting the normative HIP-practice, I become what it is not. I am not historically informed. Even if I am the only one who is "right" and everyone else is mistaken, that is irrelevant in this context because I break the terms of agreement of the communicative contract between me and the audience of what HIP is in a certain situation. I am counteracting, rather than reaffirming, my ethos. Hence the truth value of HIP is only secondary because the communicative agreement and acceptance of my agential presentation of my knowledge precede it. The historically informed performance, then, is a concept and general practice. It is neither truth, nor falsehood, but an agreement between the producing and the receiving parties.

\section{Performativity}

Performativity has developed into an ambiguous umbrella terminology with different applications in relation to what field of study one refers to and who utilises it. It has inspired various interpretations, applications and more or less competing and related derivative concepts (Kattenbeldt, 2010; Madrid, 2009; Parker \& Sedgwick, 1995, p. 2). Scholar Morten Kyndrup argues, in 2006, that "performativity", as a terminology, has become ambivalent to the extent that it is, in fact, in danger of dissolving itself. It demands to be "situated within [, and differentiated 
from,] the theoretical landscape and its processes of displacement. If this does not happen, we risk the term bursting like a bubble, replaced by an empty "umbrella" with neither distinctive power nor analytical potential” (Kyndrup, 2006, pp. 39 and 43-44, my translation). According to Ruitenberg, "The signifier 'performative' has no single meaning that could be called 'true' or 'original' and is always open to (intentional or unintentional) reinscription with new meaning" (Ruitenberg, 2007, p. 260). Axel Englund further suggests that:

On the most basic level, the turn toward the performative designates a shift of attention from closed structures to an open-ended process, which in itself resists the linearity of a turn. As such, it cannot be conclusively dated or located, but has been detected retrospectively and proclaimed programmatically many times over. In this sense, what we need to get beyond is perhaps just the definite article: rather than a unified paradigm shift, "the" performative turn is a meandering network of movements from artefact to action. (Englund, 2019, p. 1)

Performativity, however, seems to have a common trait in that it seeks to highlight and review otherwise overlooked aspects of texts within arts and culture research (Böhnisch, 2010, pp. 28). This could range from intricate socio-political readings of events and actions to merely acknowledging that a musical text is indeed performed, and that it offers something else than the artefact it represents (see below). Camilla Jalving reminds us that performance, performative and performativity are not the same. Although they represent different elements, they share many features. One can compare them accordingly: Performativity encapsulates, collectively both performance and the performative (Jalving, 2011, pp. 29 and 62; see also a related remark in Butler, 1990/2006, pp. 71 and 74). To Sommerfeldt, Caine and Molzahn, "The suffix -ity [onto performativ,] indicates a condition or state of the noun. Hence, performativity is the condition or state that accomplishes or indicates the future accomplishment of the statement" (Sommerfeldt et al., 2014, p. 5). For the remainder of this chapter, I will keep this sort of division in mind. Moreover, Jalving also points out that the performative is a constantly developing concept that will not easily be presented once and for all, schematically (Jalving, 2011, p. 65). Because performativity seems not as developed and 
integrated into general historical musicology as it is in theatre studies and the visual arts, for instance. I find it necessary to be somewhat schematic, nonetheless. The ambition, however, is not to provide a final answer to what it is, but to establish a starting point. For such a starting point to be of use, it must also provide some clarity (which I hope will be developed further in the future for the specific purpose of historical music performance studies).

To utilise performativity in a manner that enlightens a subject, rather than confuses it, we must understand what it offers and why. As the demarcation between various concepts can be unclear, Böhnish asks to what extent is a performative theory a reaction (Böhnisch, 2010, pp. 30 and 32)? Chiel Kattenbeldt, for instance, places the epicentre of performativity in general within theatre studies, and suggests that neighbouring art forms (such as music and visual arts) in reality return to theatre studies through a radicalisation of their performativity. "This paradigm [, he continues, ] may be experienced as a counter-movement in which the arts refer to, and reflect upon, themselves in order to take up a critical position in the larger context of the performative turn in a culture in which mediatisation represents a strong exponent" (Kattenbeldt, 2010, p. 37). Following this logic, it seems that an analysis of music performance as something that happens on a stage, for instance, belongs in theatre studies, that theatre has the authority of and claims the stage. Indeed, looking at the institutionalisation of the arts in the Western world, this has become somewhat naturalised as the various academic departments claim one of the senses as their domain. Music departments claim and deal with the sonic and the auditory; touch and movement belong to dance; and the visual arts devote themselves to what we can see and sense (Eidsheim, 2015, loc. 342).

While I confess that it was through theatre that I found the inspiration for the present approach, I have some difficulty accepting the theatre as the singular centre around which all performativity revolves. I am more interested in finding a performativity, an enactment of the artefact, that infuses the musicology to which it seeks to contribute from within, rather than alienating itself by approaching it from the outside. In this sense, in the present chapter, I somewhat neglect the current developments of 
performativity within theatre and visual arts studies in favour of returning to the roots, focusing particularly on Austin, Derrida (who both theorise within linguistics) and Butler (who approaches gender, feminist and queer performance from a socio-political and psychoanalytic framework). Below, I delineate other concepts and uses of terminology within musicology that differ from what Kattenbeldt describes, and which seem to exist in a quite different developmental stage, more or less detached from recent developments in theatre studies. What remains unclear, however, is whether different ideas of performativities are situated parallel to other pathways to the subject being studied, or above them. That is, whether they comment on, contribute to or consume other analytical approaches and, in all cases, what their ranges are (Böhnisch, 2010, p. 32). This is perhaps why numerous concepts of performativity's diverse implementation within the various art discourses are natural. They all rely on different premises and agendas that demand appropriate analytical tools and, as Sara Salih reminds us, there is always the risk of collapsing performativity into performance (Salih, 2002, p. 59).

The question is whether performativity's insistence on what has been systematically overseen in the analytical approaches from which it distances itself implies a competing, incompatible alternative to artefact-driven discourse. This would imply a difference imposing an opposition between action and sign, where the focus on one rules out the other. Furthermore, a focus on action looks past, and ultimately hides the knowledge derived from the research artefact itself, and as such becomes just as limited as the approach it opposes. This would abandon the idea that one analytical approach could fully embrace a field of study, and would be substituted by the performative approach, as well as the ones to which it finds itself in opposition (Böhnisch, 2010, p. 33). In HIP, the historical artefact is pivotal to what we do. It is what is left for us to theorise and to perform. It is the very reason why so many of us enter the field in the first place. This would perhaps suggest that the sort of performativity discourse seen in contemporary theatre and art performance (such as those of Marina Abramović, Joseph Beuys, Carolee Schneemann, etc.) would need considerable adaptation before being validated for a mainstream historical-musicological audience. Indeed, a historically informed 
performance without history is merely an informed performance, while history is provided by the historical artefact.

To bring about a performativity appropriate for HIP - that does not seek to divide and conquer but to develop what we already have - we must crystallise an approach that naturally fits, extends and challenges its ambition and interest while transforming how it was understood before. As such, Böhnisch advises, we must ask how the two, the performative and what it opposes, relate to each other and what they seek to contribute. "This necessarily leads us to the question of whether the dichotomies used to introduce performativity ultimately dissolve themselves when implementing a performative theoretical-methodological perspective" (Böhnisch, 2010, pp. 34-36, my translation). This brings us to a central, possible function of what performativity (however it is conceptualised) can offer, as Sommerfeldt, Caine and Molzahne put it: "How performativity can open spaces for inquiry" (Sommerfeldt et al., 2014, p. 1). Or, from the Böhnisch perspective: "A vessel for transformation until the change it prescribes becomes naturalized and habituated" (Böhnisch, 2010, p. 37). This latter view is what interests me in the present context: its methodological potential. However, what needs to be determined is from what perspective and to what end it will operate.

If a performativity appropriate for HIP will function, it needs to be transparent in terms of what it offers, how it offers it, and for what purpose it offers what it offers. For instance, three articles all use the word performativity with an implied meaning and little delineation: one uses it as a synonym for performance; one in reference to Butler; and a third referring to recent derivatives within theatre studies. Confusion can lead to a less functional and effective concept. This would result in a less attractive analytical approach. As simple as this logic is, I attempt to show below that this is, in fact, the current status within historical musicology and that this may be the reason why performativity, as a theoretical-methodological activity, has not yet flourished within the field as it has done within other fields. Additionally, as music researchers have traditionally favoured the "the idealized and abstract at the expense of the sensible, unrepeatable experience," as Nina Eidsheim puts it (Eidsheim, 2011, p. 134), it is somewhat easy to grasp why unclear, internally conflicting approaches struggle to 
persuade, whereas established practices are already operating satisfactorily. We need, then, a way of verbalising our efforts. This is provided by Böhnisch (2010) and Kyndrup (2006). According to Böhnisch, confusion can possibly be avoided if one first clarifies whether performativity is used as an analytical-methodological approach, or is a quality inherent in the subject or object being studied. Secondly, one must reflectively subscribe to one of the following mentalities: 1) Is the concept of performativity a non-compatible alternative to what it opposes, a binary entity: performative/not performative?; 2) Is it a compatible extension of what it opposes where we also deal with gradients: more or less performative?; 3) Does performativity suggest an attempt to impose transformation where the difference between performativity and the other is neither binary nor gradual, but transcendent? (Böhnisch, 2010, p. 39). Furthermore, while asking "[w]hat is [performativity] and [what] does it want, and what can it do and [what] will it not", Kyndrup proposes five approaches to a discourse of performativity (Kyndrup, 2006, p. 38, my translation):

1) Types of art and whether performativity is type specific and type dependant.

2) Aesthetic artefacts and their qualification as performative, either in a binary or gradual sense.

3) Where performativity stands in relation to perception, that is, if performativity comes from the perception or the artefact.

4) Where performativity stands in relation to various analytical approaches and if it represents a specific type of analysis.

5) The historical status of performativity. Is performativity only relevant to specific instances within the performative turn, or can it qualify for other uses in earlier historical instances? (Kyndrup, 2006, p. 38)

Finally, while contributing to a theoretical-analytical approach, Böhnisch offers three ways of understanding the artistic event:

1) A work-centric mindset. The (theatrical) work is on the stage, and the audience functions as passive receivers. The work is understood as an artefact with a designated meaning. 
2) A reception aesthetic mindset. The work is to be found in the audience's consciousness. They are now individually active contributors to various meanings of the work. The work is understood as dynamic and open.

3) A performative mindset. The artistic event is neither claimed by the work nor by the audience as an artefact, but exists between the two where meaning is created through collective interaction. The work as artefact dissolves, to be replaced by the event.

Within these three mindsets we can detect a shift "from passive to active, from static to dynamic, from constant to variable, from individual to collective, from addressee to participant" (Böhnisch, 2010, pp. 40 and 87-88, my translation). Böhnisch and Kyndrup together provide a solid scaffold on which performativity can conceptualise with transparency.

My present project assumes a theoretical-analytical position addressing both the current and historical status of performativity. I seek to contribute an activity-based understanding of cause and effect within both historical musicology as practice and its artefacts, to expand on current historico-musicological and historically informed performance practices. The aim is to help promote a transformation from a representative, detached way of portraying historical music to an active pedagogically and rhetorically centred view of its formation and operation. Hopefully, this will help unite historical musicology and practising performers, in finding other ways to work together rather than working parallel. Naturally, what should now be asked is what status performativity has within the musicological discourse?

\section{Performativities $_{0-3}:$ A survey and a move towards a performative musicology}

I have already implied that performativity has gained an increasingly strong foothold in, for instance, identity, feminist, gender, queer, LGHBT focused music studies (Hawkins, 2017; Green, 1997; Morrison, 2019; Spohr, 2019; Thurman, 2019), and within other fine arts discourses (Auslander, 2006; Fischer-Lichte, 2008; Jalving, 2011; Kyndryp, 2006). 
It is my impression, however, that there is still a struggle to gain widespread general acceptance within some discourses, particularly those focusing on general Western classical music and early music (outside feminist and gender studies). Perhaps this is because it has not yet been properly defined, delineated or differentiated in these contexts, so as to offer something beyond what is already offered by established practices. Margaret Kartomi (2014) presents what seems to be a promising effort in her article "Concepts, Terminology and Methodology in Music Performativity Research". But Kartomian performativity seems, through its reliance on and approach to a music performance's many stakeholders, to be more in line with Christopher Small's term "musicking" (1998), than with Austinian performativity serving as the foundation for her argument (Kartomi, 2014, p. 191, I give Austin's performativity more attention below). Here is why. When proposing a "comprehensive methodology for research into performativity (i.e., the condition and behaviour of musicians while performing) and ultimately into the whole musical and socio-cultural process of bringing performance to fruition," she proposes a model based on "[...] adapting Austin's three-level framework and adding Sedgwick's level as a fourth". This results in four categories, including:

1. The actual music performed, including the rationale behind repertoire choice.

2. The execution of the music and factors that affect it, such as performance style and the performers' persona, competence, ensemble interaction, cueing techniques, entrainment, and attitudes to tempo, tone colour, intonation, and so forth.

3. The effects of the performers on the audience and vice versa.

4. The contributions of all stakeholders to the success of the event, including the roles of the event organisers, technicians in charge of the venue's spatial and acoustic conditions, private and public fundraisers, publicists, entrepreneurs, technicians, and the media.

Through a systematic comparison of findings related to the four categories, and by connecting them to suitable performances, one may "draw general conclusions about performative issues and, eventually, about the 
nature of music performativity itself" (Kartomi, 2014, p. 192). But she does so only by focusing on the action as "to act", rather than what it establishes or constitutes as a direct result of it being acted. They are both closely related, of course, but there is a difference in emphasis. Whereas the first approaches issues from within the action in a descriptive manner, through a contextual reading of something leading up to an event, the latter favours the result of the actions (I declare you married; I promise). It makes me wonder whether her reference to Austin is indeed properly grounded in his Harvard lectures, or if it is out of mere habit that she refers to him (as the "founder" of speech act theory), given that she focuses more on the action of performing rather than its constituting effect (Kartomi, 2014, p. 191).

This disconnection of the theory she ascribes to from what she argues for begs several questions. In what sense does she move beyond a classical descriptive field note written by an outsider (as she is not part of the group serving as her case)? And in what way does her "performative" within an ethnomusicological context differ from the rich tradition and the basic modus operandi of other fields of study, such as music performance studies? The latter springs to mind when she identifies three types of performativity research: "that which performers themselves believe or write about their performances; that which music scholars - most of whom are former or current performers - write or say about others' performances; and that of performer-scholars who write about their work" (Kartomi, 2014, p. 207). In no way, do these categories provide any premise for judging what act or truth they constitute merely by being performed, rather they refer to production, the being in an action and performing. Consider her Acehnese case study "which describes the music and dance performed, comments on its execution, refers to interaction between performers and audience (including judges), and describes the contributions of the many stakeholders" (Kartomi, 2014, p. 207). Here she poses no evaluative judgement on whether the performative act indeed constitutes what it intended to do (in the Austinian sense), but rather shares with us a descriptive process unveiling comparable data, that is field notes subject to analysis with an emphasis on the outsider position. Consider, for instance, comments such as: "Many also felt the need to experience a culture's music from 
the inside-by learning to perform it, thereby coming vividly to appreciate the social, emotional, and rational affects embedded in its practices" (Kartomi, 2014, p. 195). Kartomi's performativity, then, is perhaps more a matter of "performance" and "performing". Although I do agree with her that the "limited amount of research into music performativity carried out to date has drawn attention to the need to develop a potentially comprehensive methodology with which to document and analyse the complex issues involved" (Kartomi, 2014, p. 207), I still think we need a fresh beginning, a ground zero, from which the various potentials of "performativity" can evolve starting with the concept, rather than ascribing nomenclature to a situation. Indeed, by applying performativity to music research, or HIP in the present context, we must take care not to reinvent already established, parallel practices, which already have advanced procedures and traditions, but are only called something else (Kyndrup, 2006, p. 44).

Another, more promising and in-depth approach to performativity comes from music theorist Andrew J. Chung who presents what he calls a use-theoretical notion of "meaning"' (Chung, 2019). Drawing on Austin and Wittgenstein, he promotes a performative perspective on the musical work as an artefact, as "an invitation to set down momentarily a certain tool we are accustomed to wielding as part of our sense-making circumspection toward the sounding, musicking. That tool is the conceptual framework underwritten by meaning-as-mapping". It employs speech act theory as a conceptual tool for registering meaning in musical sound and sonic environments, as well as bridging musical and linguistic thinking. But what limits Chung's efforts is his seeming reliance on music as an artefact, and as sound (cf., Eidsheim's remarks about the institutionalisation of the senses above; Chung, 2019), a matter that I seek to contribute to through my proposal. The strength of his contribution, I would argue, resides both in his theoretical detail and depth, as well as his maintaining that "[u]se and efficacy are not merely affordances of musical semantics; use and efficacy stand beneath musical semantics as the ground out of which semantic claims can even emerge at all". This is perhaps what we now need in order to make performativity count as something worthwhile in transitioning the performance of early music, 
for instance, from mere representation to a "pragmatics-first" concept, not only of musical "meaning-as-use" as Chung proposes (2019), but of early music performance and "research-as-use", so to speak. The important approach furthered by Chung is what he identifies as a less represented perspective in music scholarship: "[W]hat it is for music to be meaningful". Chung identifies two types of performativity: $\mathrm{P}_{1}$-Performativity and $\mathrm{P}_{2}$-Performativity. The first addresses the aliveness of performances as bodily acts, as well as "the materiality or eventhood of performing". The latter "highlights semiotic efficacy" focusing on the artefact (be it, e.g., the score, the staged performance, a painting or a sculpture).

What then is the current status of the word "performative" in music research beyond Chung and Kartomi? A search through the articles (round tables, editorials and book reviews excluded) of the Open Access volumes over the past five years in the refereed journals Journal of the American Musicological Society, Journal of the Royal Musical Association, Journal of Seventeenth-Century Music, Music Performance Research, International Journal of Music and Performing Arts, Journal of Research in Music Performance reveal a very restricted use of the word performativity. ${ }^{2}$ Only 46 articles out of 132 (i.e., approximately 35\%) employ the word at all. The articles surveyed in the Journal of Seventeenth-Century Music revealed no use of "performative" or "performativity" at all. (I will refer to the individual articles when relevant below.) A survey of this sort has an apparent weakness, as it only focuses on the appearance and implementation of a single word within limited source data. Although the aim here is merely to provide an indication based on a sample, further research is needed to provide a fuller metaperspective of the issue.

2 There are of course several other journals that would have been relevant here, particularly those focusing more explicitly on early music, but to access the more general musicological debate and to provide some sort of selection criteria to restrict the data into a manageable format for this project, I chose to focus on more generally framed, fully Open Access journals. Several excluded journals were considered beyond the Open Access criteria, but, at least it was my impression at the time that although these would certainly enrich the discussion and provide an even more realistic representation of the field, they still would not significantly alter the results. I hope to pursue the representation of performativity and other related issues in future research based on a broader data foundation. 
I would like to embrace and expand John Hillis Miller's (in addition to A.J. Chung's similar effort) approach distinguishing between Performativity sub 1 (the performative speech act) and Performativity sub 2 (performing something). Performative sub 1 and performative sub 2, Miller argues, are often but not always mistakenly confused by "those in 'performance studies"' (Miller, 2009, p. 308). Janelle Reinelt goes further within theatre-focused research, ascribing performance and performativity as "central organizing concepts" to Anglo-American theorists, and theatrically to their European colleagues (Reinelt, 2002, p. 207). In music scholarship, I find that the confusion is far more critical than what Miller portrays, and I would like to suggest a new set of categorisation for this present context. In an effort to sort things out in the context of a music discourse, at least briefly and superficially, I will try to backtrack the term through four perspectives: first, ground zero, Performativity sub zero (Performativity ${ }_{0}$ ), to perform in general (i.e., I perform music, therefore I am performative); second, the often-claimed founding father, John Lewis Austin (Performativity); third, Derrida's concept of the phenomenon (Performativity ${ }_{2}$ ); and finally, Butler's influential and popular performativity (Performativity ${ }_{3}$. Often, discourse is grounded in later scholars' theories while only automatically, for the sake of tradition and genealogy (so it may seem), referring to Austin as the founding father, so to speak, without thinking much about the consequences of heritage as speech acts transferred from one ontology to the next, while operating in different contexts and with different aims and concerns. Some even argue that this lineage from Austin to Derrida to Butler is faulty, a mistake because they aim at different things in separate contexts (McKinlay, 2010, p. 120; Miller, 2009, p. 307). As McKinlay puts it: "There is a real danger that doing things with words is morphing into doing anything - everything - with [Austin's] word, performativity" (McKinlay, 2010, p. 139). For the sake of clarity, I will centre this survey around the three mentioned philosophers, fully aware that by doing so, I overlook other competing concepts of the term. To separate the Austinian, Derridean and Butlerian discourses figuratively, I suggest that Austin's is a kind of temporal, situation-focused in situ, acted here-andnow performativity, while Derrida's is a linear sort connecting several 
instances over time and space. Butler, I argue, presents a circular alternative in which an act upholds the phenomena's insistence on its later repetition and, as such, both acts out and causes its own performance (see Figure 2 below). The aim of this figurative exercise is not foremost one of explanation and coming to terms with, but rather separating and organising the following argument to avoid confusion, and pinpointing their individual operational potentials more equally and individually than merely serving the discursive route from one to the other (for the latter see e.g., Parker \& Sedgwick, 1995, p. 2). The performativities ${ }_{\mathrm{O}-3}$ portrayed here are in no way conclusive, nor do they satisfyingly pay respect to the fuller dimensions of their operation and potential, rather what I offer is a landscape. This landscape may help us understand enough to navigate and see different performativities through their contributions, in order to suggest other perspectives on historical musicology, and how we understand and utilise historical music performance. To paraphrase Miller, I aim to distinguish carefully between several kinds of performativity and show their helpfulness in reading historical music, music performance, and HIP (Miller, 2009). Numerous publications describe the developmental aspects of the theories of Austin, Derrida and Butler (Hall, 200o; Hollywood, 2002; Kohli, 1999; Loxley, 2006; Loxley \& Robson, 2013; Marshall, 1999; McKinlay, 2010; Parker \& Sedgwick, 1995; Potter 2001; Sommerfeldt et al., 2014; Ruitenberg, 2007; Reinelt, 2002). I see no point in offering yet another exhaustive historiography in the present context, but will rather focus on their core methodological potential.

Before I proceed, it should be noted, however, that other performativities centred on other contributors are both possible and present. One obvious example would be Jean-Francois Lyotard, who utilises a performativity based on a quest for efficiency: "the best possible input/output equation" (Lyotard cited in Locke, 2015; see e.g., Jalving, 2011, p. 53; Koopman 2005; Locke 2015; Parker \& Sedgwick, 1995, p. 2). As such, Lyotard could possibly represent a Performativity ${ }_{4}$ category operative within, for instance, educational research scholarship. This type of performativity would directly address the situation introducing this chapter, but which I judge to be somewhat premature until the framework proposed here has been 
sketched out fully. I hope to pursue these perspectives in future research to expand the approach presented below.

\section{$\bullet$}
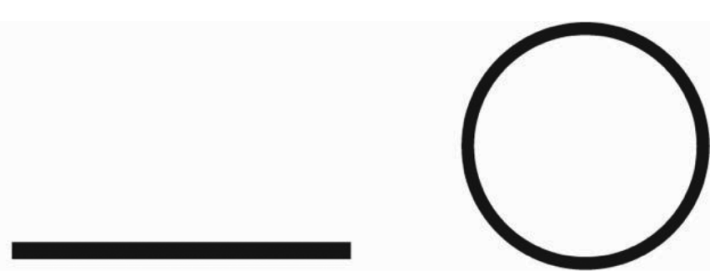

Figure 2. A Visual Representation of In Situ, Linear and Circular Performativities. These figures can be understood as visual aids in conceptualising the time domain of each phenomenon, and how they differ from each other in this respect. Time is represented by the horizontal axis. My illustration.

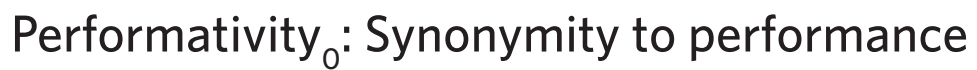 (noun or adjective)}

This level refers to uses of the word performativity in its simplest form. I perform music, therefore I am performative. A song lyric is performative if someone sings it, poetry if it is vocalised and sheet music when someone plays it. In this sense "performativity" functions as a synonym for performance, an alternative nomenclature. As such, performative/ performativity functions as an opposite or alternative to something else. We could, for instance, distinguish between: performance/not performance (Kennaway, 2015; Llorens, 2017); performance practice/work/ performance (Golomb 2017); work analysis/performance (Curry, 2017; Korhonen-Björkman, 2019); performance/narrative (Clarke et al., 2016); oral/text/performance (Caldwell, 2018); interpretative/performative (Williams, 2016); poetry/performance (Weaver, 2017); sign and notation in representation/performance in the sense of live presentation (Schuiling, 2019); and aesthetic object/activity (Zanovello, 2016).

Although it comes in handy as an adjective, I would personally advise against "performative" use simply because the inherited connotations and applications merely result in confusion and ineffectiveness. As I will show below, Austinian, Derridean and Butlerian performatives take us on different paths. This is not to mention other derivatives which will 
not be given much attention here, such as Cavell, Searle, Felman, Fish, Turner, Sedgwick and Lyotard's concepts of the performative (Koopman, 2005; Loxley, 2006; Marshall, 1999; Sommerfeldt et al., 2014, p. 5).

\section{Performativity ${ }_{1}$ : John Langshaw Austin}

In my opinion, Austin's lecture series at Harvard in 1955 (1962) represents an in situ, here and now type of performativity, which confines itself to a specific, delineated situation. Concerned with pragmatic, applied views on the philosophy of successful and flawed language, particularly utterances (Potter, 2001; Ruitenberg, 2007, p. 262), he proceeds to unveil the capacity of spoken language in everyday life through a very focused and narrow perspective (Loxley, 2013, p. 2-3). Using Oxford "house-style" plain prose he reduces complex philosophical issues - those identified by logical positivists in particular - to simple statements about everyday and commonplace situations to better understand, as Alan McKinlay puts it, "the social embeddedness of everyday language" (Hall, 200o, p. 184; McKinlay, 2010, pp. 125 and 137;). As such, his "performative" has attracted much attention from scholars who read and criticise him in different ways, to which the long dispute between Jacques Derrida and John Searle testifies, as well as the many variants of performativity that have been developed since (for an account of the Derrida-Searle debate see e.g., Loxley, 2006). To James Loxley, "[i]t is the assumption that Austin's work presents no real challenge to its readers, that its philosophical or theoretical status is swiftly registered, that has engendered the confidence with which that work is then summed up and criticised in many accounts of performativity" (Loxley, 2006, pp. 1-4). (It should be noted that none of the surveyed journal articles above cite Austin in their bibliographies.) In short, we can boil down his contribution to three main features:

1. Constatives and performatives

2. Locutionary, illocutionary, perlocutionary utterances

3. A known and accepted conventional procedure (Marshall, 1999, pp. 312-314) 
Constatives and performatives differ in that the first refers to statements that are descriptive in a verifiable or falsifiable sense, and the latter simply does what it says. The performative utterance does not describe or report, it does something actively in the present by someone authorised (Austin, 1962, pp. 3, 5-6, 60, 67 and 139; Loxley, 2006, pp. 2 and 8; Ruitenberg, 2007, pp. 319-320). But "to do something" is a vague expression, and the performative is not always easy to distinguish from the constative (pp. 91 and 94). This could explain, at least in part, how quick superficial readings of his work - or even merely citing him as the founding father of performativity through other authors - give rise to competing interpretations of what performativity is, and how it is something more than performance in general (see below). Performatives are bound by intention, not truth, and for them to work successfully, certain conditions must be met and key, authorised participants must play their part (Loxley, 2006, pp. 9-10 and 26; Sommerfeldt et al., 2014, p. 5). Moreover, the conditions must be met in a contractual fashion between utterer and recipient, which emphasises the situation's participants, as well as the one doing the uttering (Jalving, 2011, p. 49):

(A. I) There must exist an accepted conventional procedure having a certain conventional effect, that procedure to include the uttering of certain words by certain persons in certain circumstances, and further,

(A. 2) the particular persons and circumstances in a given case must be appropriate for the invocation of the particular procedure invoked.

(B. I) The procedure must be executed by all participants both correctly and

(B. 2) completely.

$(\Gamma$. I) Where, as often, the procedure is designed for use by persons having certain thoughts or feelings, or for the inauguration of certain consequential conduct on the part of any participant, then a person participating in and so invoking the procedure must, in fact, have those thoughts or feelings, and the participants must intend so to conduct themselves, and further

(Г.2) must actually so conduct themselves subsequently. (Austin, 1962, pp. 14-15) 
There are numerous ways in which each individual step can misfire and, if unlucky - depending on how much authority is assigned to them cancel the act performed. James Loxley points out that "performative utterances are exposed to trouble because they are conventional [and in some way institutional] - ritual, ceremonial - performances", which "can be quoted, cited, or repeated beyond their normal conditions of employment". A proper, sustained account from Austin on what he means by convention, however, is missing (Loxley, 2006, pp. 11-12, 51-52; for one possible account of the ritual of the performative, see Hollywood, 2002, as well as Loxley, 2006).

Next, Austin distinguishes between "locutionary" (which has a traditional sort of meaning, with a certain sense and reference), "illocutionary" ("which has a force in saying something," a conventional force), and "perlocutionary" utterances (which is "the achieving of certain effects by saying something"; can have a perlocutionary object or sequel; Austin, 1962, pp. 103, 108-109, 117):

Act (A) or Locution [can be true or false]

He said to me "Shoot her!" meaning by "shoot" shoot, and by "her" her.

Act (B) or Illocution [can be happy/unhappy, i.e., successful/unsuccessful]

He urged (or advised, ordered, etc.) me to shoot her.

Act (C. $a$ ) or Perlocution

He persuaded me to shoot her.

$\operatorname{Act}($ C. $b$ )

He got me to (or made me, etc.) shoot her.

Act (A) or Locution

He said to me, "You can't do that".

Act (B) or Illocution

He protested against my doing it.

Act (C. $a$ ) or Perlocution

He pulled me up, checked me.

Act (C. $b$ )

He stopped me, he brought me to my senses, etc. He annoyed me.

(Austin, 1962, pp. 101-102 and 147) 
Austin focuses on the illocutionary act for his performative utterance in its singular present indicative active tense. Loxley comments: "It is precisely a matter of invoking procedures or formulae; it requires such an aspect in order to achieve its effects and make its special impact in the world [....] to be understood as linguistic events produced or enabled by convention or rules" (Austin, 1962, p. 91; Loxley, 2006, p. 53).

From a rhetorical perspective, Chaïm Perelman and Lydia OlbrechtsTyteca present compelling reasoning, arguing that the successful efficacy of an argument intended for a specific audience intensifies the commitment of the receiver to making the intended action happen or increasing their willingness to act. In the age-old debate between philosophers seeking the absolute and rhetors involved in the action - between truth and opinion; convincing and persuading; knowledge and action for specific results; free poetic works and the art of speech for a practical, final purpose - they apply "the term persuasive to argumentation that only claims validity for a particular audience, and the term convincing to argumentation that presumes to gain the adherence of every rational being" (Perelman \& Olbrechts-Tyteca, 1969, locs. 253, 636, 662 and 997; Rueger, 2011, p. 204). Before aesthetics became a thing, however, during the early modern period, works of art were also meant to persuade the audience, just like rhetoric (Rueger, 2011, p. 204). According to Jacobo Zabarella (1533-1589), for instance, poetry and rhetoric were both branches of logic, and neither were a proper science. Alexander Rueger argues that "[b]oth rhetoric and poetry are thus directed at inducing action or moral improvement in the audience; therefore they are associated with the 'active sciences,' with moral philosophy" (Rueger, 2011, 205).

As Austin illustrates how illocutionary utterances can perform something by being uttered, beyond merely generating consequences (Loxley, 2006, p. 2), Perelman and Olbrechts-Tyteca emphasise the perlocutionary force of arguments. The two perspectives do not exclude each other, and they are not easily separated, as Austin repeatedly demonstrates (1962). We can, therefore, speak of both how an utterance is designed and supported to produce a certain effect, and how uttering it effectively makes it happen. Consider, for instance, the ethos of the teacher. The educator, through their position, becomes a spokesman for the values recognised 
by the community (or the deciding politician, at least). Different from the propagandist who must "gain the goodwill of his audience", the educator is already in a better position to gain acceptance for what they teach through "the prestige of [their] office" (Perelman \& Olbrechts-Tyteca, 1969, loc. 1133). Their pedagogical activities' perlocutionary effect depends on structure and design, but the ability to construct a truth can also be illocutionary through their institutional agency as knowledge providers, either through persuading or convincing alone, or through the one leading to the other: "You are wrong, dad, my teacher said it was so". Obviously, interesting stuff can happen when rhetoric and performativity coincide. And this separation, both when relating to the historical source and through its implementation and application today in artistic, pedagogical and sociopolitical settings can contribute to already ongoing historical and critical musicological discourse.

\section{Performativity $_{2}$ : Jacques Derrida}

At the end of his How to Do Things With Words? (1962), Austin argues that all utterances are performative in some sense. This sets the scene for utterances to be viewed as actions, introducing possibilities that did not pass undetected by later scholars (Hall, 2000, p. 184). Derrida, being one of those reworking Austin's theories, often functions as a sort of bridge between Austin and Butler within a standard narrative of the performative (Loxley, 2006, p. 2; Sommerfeldt et al., 2014, p. 6). Derrida's performativity is vastly underrepresented in the surveyed journal articles, at least beyond providing mere transition leading to Butler. A few draw on Derrida in general (Mathew, 2018; Moseley, 2015; Schuiling, 2019), but only Venn (2015) does so (at least explicitly) in terms of his concept of performativity.

Writing a sort of eulogy (or something close to it), Derrida's interest in Austin is diagnostic, and was presented as a contribution to a conference on communication (Bearn, 1995, p. 4; McKinlay, 2010, p. 132). What Derrida does is to resituate Austin's performative within the act of writing rather than speaking, in which he favours a transcendental, general theory of the mark over the narrow, case-specific one promoted by Austin (Hollywood, 2002, pp. 103-104). Perhaps what we see here, 
both in Derrida's reading of Austin and in the following, heated debate between Derrida and Searle mentioned above - which I do not pay specific attention to in this chapter for the sake of efficiency - is a sort of manifestation of the differences between what Stephen Davies compartmentalises as Anglo-American analytic philosophy (i.e., issue-focused, problem-based philosophy), and continental philosophy (describing over-arching, complete systems, placing the theme of study within its embrace) (Davies, 2010, p. 18; Loxley, 2006, p. 1). Philosopher Amia Srinivasan suggests that analytical philosophers look for the coherent and non-paradoxical in opposition to their continental philosopher colleagues (Srinivasan, 2018, p. 215). This is arguably why the performative takes such an interesting turn through Derrida as it shifts from the specific to the general. According to Amy Hollywood: "He suggests that in providing a more general theory of language (as writing), a generalizing movement eschewed by Austin, he is able to show the way in which that which seems external to the operation of the performative is also internal to it [...]" (Hollywood, 2002, p. 105; Loxley, 2006, p. 83). What Derrida identifies in Austin's writing is the interdependency of context and intentionality, which he finds troublesome since we cannot ever fully know the context of the written text (Hollywood, 2002, p. 105). Loxley, however, finds that Derrida assumes too quickly that Austin shares his aim of generating a transcendental, general theory: "an assumption that has misled a number of readers over the years with occasionally disastrous consequences [...] In fact, the thinking of the performative from Austin onwards is inflected by a sense of language as somewhat machine-like" (Loxley, 2006, pp. 86-87 and 91-92).

Following a critique of Austin's linguistic performative, Derrida presents what I call a "linear" type of performativity as it focuses on the repeatability of the ever-changing sign over time, which before him had been conceived more as a secondary effect (Loxley, 2006, p. 109). In my understanding of Derrida's performative, I identify three main themes:

1. Meaning and communication

2. Detachment from the original context

3. Iterability and citationality 
When Derrida addresses "communication", he questions whether it implies specific content, value or identifiable "meaning". No, he argues, particularly when we do not limit our focus to spoken communication, and instead look at communication through the written word. Whereas Austin's theory operates within a traditional way of thinking about communication, where some meaning is transferred from one party to another, Derrida is more concerned with the seemingly naive question of what makes communication possible. Writing, he asserts, is a powerful means of communication which by far extends the temporal boundaries of something being said. It is a representation and imitation of its content - which does not have to be some identifiable meaning of something specific - that lives on when both the author and addressee have left the communicative situation. When people read books, they deduce and comprehend different meanings from the given text, and may come to completely different conclusions about its contents. The communicative text thus seems to remove the identifiably social from language and utterances. The original context is not unimportant, but we cannot know it (Derrida, 1982, pp. 309 and 311; Hollywood, 2002, p. 105; Loxley, 2006, pp. 76-77).

From this it follows that the content and meaning of the text is detached from its original context. That is, the context is never fully determinable, fully known. If communication depends on a known intention and content, communicated from $\mathrm{A}$ to $\mathrm{B}$, writing cannot be communication in the traditional sense. It instead communicates something else that is supplementary and particular. The absence of addressee and addressor puts the text in a situation where it alone, as a representation of something, communicates with someone unknown. It still, however, communicates something (Bearn, 1995, p. 10; Derrida, 1982, pp. 310-311, 313-315; Loxley, 2006, p. 103; Wolfe, 2013, p. 253). According to Kira Hall, this instigated a small revolution in literature studies: "The buzzword in poststructuralist literary theory becomes 'iterability', the endless repetition of speech acts within a discursive history that has lost its original context" (Hall, 2000, p. 185).

When introducing the terms "iterability" and "citationality", Derrida seeks to develop this perspective further (Ruitenberg, 2007, p. 264). The 
text and the sign must then be repeatable, even when removed from the addressor and addressee. A written sign is a mark that remains, and which can be cited, even replicated, elsewhere and by others. To be legible, it must refer to something recognisable, an identifiable, repeatable code which constructs what it refers to even when removed from its original situation. Things can be cited, put between quotation marks, and function within, as well as form, new contexts. These citable codes are what makes performative utterances possible. Citations transcendentally provide the scaffolding on which communication evolves regardless of its original intent (Derrida, 1982, pp. 315-318 and 326-329; Hollywood, 2002, p. 104-107). Iteration is both imitation and change: the first stems from citation and repetition, the latter from alteration and new contexts (Loxley, 2006, pp. 78-79 and 82; Ruitenberg, 2007, p. 264). Loxley adds, "If it is essentially repeatable, it can be extracted from any set of linguistic or social circumstances and grafted into another [...]. It can, in other words, be redeployed, quoted, or cited, in principle ad infinitum" (Loxley, 2006, p. 78).

Looking at reiteration historically, then, offers cumulative perspectives on historical fragments being implemented in agential settings. When doing HIP rhetorically as an HIP, what do we exclude from that rhetorical scaffold when we utter? What is being said, and what is not? And what do we wish to achieve by introducing that utterance into a given setting? As Jonathan Culler puts it when speaking of context in the light of Derrida's criticism of Austin: "[A]ny attempt to codify context can always be grafted onto the context which escapes the previous formulation. Attempts to describe limits always make possible a displacement of those limits [...]. Its denial establishes a connection that can be exploited" (Culler, 1981, p. 25). Clearly, I am not deserting Austin's premise of intention in my perspectives here, which Derrida would oppose, but, somehow an HIP is primarily intended. One does not merely learn to play a "lost" instrument to the extent that one becomes a historically informed performer by accident. What is lost is the original intention and context, but its transformation into a new purpose and its inclusion in other communications persist, only that it is someone else's than it first was. Thus perlocutionary rhetoric and illocutionary utterances coincide once more with artistic 
designs made to convince by representation, association and analogies. Not only individually, but also as collectively cumulative. Artists use previous texts, recordings and films as a reference to inspire their HIP, which again becomes a part of someone else's foundation in the future. Genres assert and establish themselves (not necessarily by the force of the artist) through compartmentalised similarity and repeated citation. HIP does not communicate what it once did, does not perhaps even represent it, but creates some new shifting normativity, with secondary and supplementary features to be communicated. This again is reinforced through rhetorical and pedagogical activities in the name of HIP. (This, of course, extends an open invitation to ontologists concerned with work conceptions, but I will not treat that here. See e.g., Butt, 2015 for a short summary of the ontological debate in classical music.) "Paradoxically," Amy Hollywood adds, "the force of this rupture or of the break constitutive of history is what enables the fiction of a universal, disembodied, selfpresent subject" (Hollywood, 2002, pp. 106-107).

\section{Performativity $_{3}$ : Judith Butler}

Finally, I argue that Butler, focusing on gender and identity, represents a circular performativity that is political (which is also reflected in her serious and carefully balanced language, in opposition to Austin's playfulness and quirky rhetoric). This seems to be the most common and most recent interpretation of the performative today (Butler, 1990/2006, pp. 3 , 172, 185 and 203; Loxley, 2013, p. 6; McKinlay, 2010, p. 131; Sommerfeldt et al., 2014, p. 7). The literature in the above journal survey, as well as additional music-related work cited elsewhere in the present chapter, bases an understanding of Butler's performativity on her earlier 1990s work, that is, if they refer to her at all. In fact, only two of the 46 survey journal articles using the terminology (i.e., only 4\%) cite the work of Judith Butler in their lists of references at all (see Cole, 2018; Hambridge, 2015). To this, we can add a few other articles included in the present chapter (Franko, 2003), which also only refer to the 1990 os publications.

Butler's performativity operates on the border between the linguistic performative and theatricality, and when drawing on her work, one 
may draw on one or the other. The presence and, it should be noted, the importance of performance to her performativity easily tilts related discourse in favour of theatricality (Miller, 2009, p. 308; Ruitenberg, 2007, pp. 260-261; Salih, 2002, p. 59). Butler, however, makes a clear distinction between performance and performative, and does not claim gender to be mere performance (Salih, 2002, p. 56). In attempting to provide a philosophical space for both the effable and ineffable, she holds that the body is defined by language. This is, however, not to be comprehended as a reduction of the body into merely abstract language, but an acknowledgement of the fact that for there to be a language of the body, the body must be real thus providing something for the language to claim (Salih, 2002, p. 56; Srinivasan, 2018, pp. 215-216). In doing so, Wendy Kohli adds, "[s]he shakes up liberals and Marxists alike - including many feminists" (Kohli, 1999, pp. 321-322). Where Austin speaks of the singular utterance as it is being acted out, Butler follows Derrida's lead to focus on its cumulative power (Kohli, 1999, p. 321; Ruitenberg, 2007, p. 262). And, where Austin is mostly preoccupied with illocutionary utterances, Butler leans more towards the constative (Munday, 2010, pp. 284-285). From Kohli's perspective, "Butler performs Austin through Derrida through Foucault" (Kohli, 1999, p. 320). In Butler's account, the body is itself temporal and mortal, but it gains its significance and categorical belonging from the realisation of long-lasting norms, blueprints, so to speak - the key is repetition (Franko, 2003, p. 72; Jalving, 2011, p. 54; McKinlay, 2010, p. 137; Munday, pp. 284-285; Salih, 2002, p. 55). The force of efficacy that Austin and Derrida ascribe to the word (said or written) can subsequently also be acted out by the body (Hollywood, 2002, p. 99 and 110; Loxley, 2006, p. 115). As such, Butler refuses binaries and dualities. Two perspectives will be pursued here:

1. Norms and reinforcement

2. Possibility of change

The primary conditions for Butler's performative are norms and reinforcement. This perspective has its roots in her idea that "[g]ender is always doing. Gender identity is performatively constituted by the very 
expressions that are said to be its result" (Butler, 1990/2006, p. xv, 34). Hence, expectations promote actions, and actions withhold expectations, in a circular stylised fashion (Hollywood, 2002, p. 96; Loxley, 2006, pp. 117-121). To Butler, the subject is both acted on and acting (Salih, 2002, p. 55; Srinivasan, 2018, p. 218). We expect a certain categorisation, or ideal, and then live up to it as we perform the associated acts, repeatedly over time as a sort of ritual, until they become a naturalised part of our everyday conduct, which again constitutes and upholds the very same categorisation that we first expected. As such, our compliance with that ideal is not who we are, physically, but who we perform as. Separating sex from gender, i.e., our physical, biological sex contra labels such as man, woman, she-male, gay, lesbian, etc., she speaks of a real and a fantasised body, which are separate phenomena. The fantasised body is political, social and ideological, and exists in relation to culturally infused normative truths. It conforms to a historical, but not fixed, possible idea that is sustained and spread through repetition and citation. Identity is acted out according to expectations of what it should be (Butler, 1988, p. 520, 1990/2006, pp. 71, 74 and 97; Loxley, 2006, p. 134; Salih, 2002, p. 55). As such, the social and juridical laws of a society, through their normative constitutions and compositions, produce what they claim to represent (Butler, 1990/2006, p. 3). Legalisation here is important. For instance, one could be the same person, but at one point in history you are criminalised (abnormal and non-accepted), and in the next, following new legislation, you are "normal" and accepted. Similarly, in terms of mental health, you could on one occasion be outside what is, at the time, statistically normal, but the population and research develop, and suddenly you are within the bounds of normality (Perelman \& Olbrechts-Tyteca, 1969, loc. 1241). "In effect, the law produces and then conceals the notion of a 'subject before the law' in order to invoke that discursive formation as a naturalised foundational premise that subsequently legitimates that law's own regulatory hegemony."

What norms and reinforcement provide through their institutional presence is the possibility of change, or collective re-signification, to break out from the power of repetitive signs (Butler, 1988, p. 520; Hall, 2000, p. 186; Hollywood, 2002, p. 97; Loxley, 2006, p. 127; Salih, 2002, 
p. 58). Rather than merely accepting the social framework promoted by a group of people holding the power of definition, it also invites actions to undermine it. According to Butler, we should pay better attention to what has been historically excluded in order to propose alternatives that we can actively pursue (Butler, 1988, p. 520; Ruitenberg, 2007, pp. 255-256 and 267). In recasting iterability, Butler similarly targets "the political promise of the performative" (Loxley, 2006, p. 135). Not only does this align well with Foucaultian worldviews, but particularly, also enables music and musicology to be seen as practice and action. Drawing on the historical situation of African-American women and American legislation, Mary Frances Berry suggests that "in any society law reflects the will of the powerful, their will is to keep the power in their own hands" (Berry, 1991, p. 835). This resonates with Bergeron's remark mentioned earlier, that scholars negotiate their scholarship to comply with norms and codes of conduct set out by the ruling body (Bergeron, 1992, p. 5). Yet, Berry implies: "Depending on who they are, some thinking people might discourage saying such things to the powerless, who might mobilize against the powerful" (Berry, 1991, p. 835).

From a rhetorical perspective, Butler understands "constituting acts not only as constituting the identity of the actor but as constituting that identity as a compelling illusion, an object of belief" (Butler, 1988, p. 520; cf., Burke, 1992), Thus, in citing historical signs we can promote a persuasive argument for settling a norm, but at the same time we also construct a representation of a possible reality that has political, ideological and social implications through inclusion and exclusion (see, e.g., Liakos \& Bilalis, 2017; I return to this below). As such, conforming to certain norms, such as educational policies or some perceived ontology of HIP, and educating others to do the same, these structures are pretty much maintained. Those who do not comply may be excluded and dismissed as outsiders.

\section{A summary of the survey: Proceeding towards a performative musicology}

We could argue that Performativity $=$ Performance in one sense, but the former is used rather simplistically, as an alternative nomenclature for 
simply performing something, while the latter has received more elaborate theorisation and development. I have proposed that the remaining performativities focused on here be compartmentalised as follows (Table 1 below):

Table 1. Operational and Conditional Differences Between Performativities ${ }_{1-3}$

\begin{tabular}{|c|c|c|c|}
\hline Central figure & Austin & Derrida & Butler \\
\hline Type & Performativity $_{1}$ & Performativity $_{2}$ & Performativity $_{3}$ \\
\hline \multirow[t]{7}{*}{ Conditions } & \multirow{2}{*}{$\begin{array}{l}\text { We know who says it } \\
\text { and their intention. }\end{array}$} & \multirow{5}{*}{$\begin{array}{l}\text { We may not know } \\
\text { who writes it and their } \\
\text { intention. } \\
\text { We may not know their } \\
\text { authority to write it. }\end{array}$} & \multirow{4}{*}{$\begin{array}{l}\text { We know who does it. } \\
\text { We know the norm it } \\
\text { corresponds to and } \\
\text { maintains. }\end{array}$} \\
\hline & & & \\
\hline & We know their & & \\
\hline & authority to say it. & & \\
\hline & We know what it & & \multirow{3}{*}{$\begin{array}{l}\text { We have a theory of } \\
\text { how they both relate to } \\
\text { and enforce each other. }\end{array}$} \\
\hline & establishes. & \multirow{2}{*}{$\begin{array}{l}\text { We know that it } \\
\text { establishes through } \\
\text { citation. }\end{array}$} & \\
\hline & $\begin{array}{l}\text { We know the context } \\
\text { that enables it. }\end{array}$ & & \\
\hline Situation & $\begin{array}{l}\text { Singular utterances in } \\
\text { known contexts }\end{array}$ & $\begin{array}{l}\text { Citational utterances } \\
\text { detached from their } \\
\text { original contexts }\end{array}$ & $\begin{array}{l}\text { Cumulative actions } \\
\text { in mutual relation to } \\
\text { societal norms }\end{array}$ \\
\hline Focus & Speech & Writing and literature & $\begin{array}{l}\text { Embodiment and } \\
\text { culture }\end{array}$ \\
\hline Operative mode & In situ & Linear & Circular \\
\hline
\end{tabular}

The different performativities share a, sometimes ill-conceived, genealogy and operate on different levels and in separate contexts. It is not surprising that performativity can be confusing and unfocused if maintaining that the genealogy represents one prevalent performativity. Returning to the above journal article survey, some articles are even difficult to place, as their use allows several possible interpretations inherited through citation (see Freitas 2018; Moseley, 2015; Romero, 2019;) or implied meaning, which enables several possible readings, yet are not delineated sufficiently to make the intended terminological use apparent to the reader (Arendell, 2015; Butt, 2018; Flory, 2019; Kennaway, 2015; Mathew, 2018; Morais, 2015; Rindom, 2019; Robin, 2018; Romero, 2019; Saltzstein, 2017; Shelley, 2019; Spohr, 2019; Valiquet, 2019). A more schematic view of how performativity is conceived for the selected articles (see Table 2 below) can help. In doing this, I have tried to trace the inherited meaning by following the references (although, it is not always clear if the inherited meaning is intentionally continued 
by the article author). In the case of implied meaning, I have based my categorisation on my own judgement of the contextual implementation of performative/performativity. In fact, $32 \%$ of the surveyed journal articles containing the words performative/performativity (i.e., 15 out of 46) only use the word once (Arendell 2015; Bianchi, 2017; Bonds 2017; Citron, 2017; Clarke et al., 2016; Cypess, 2017; Goldmark, 2017; Korhonen-Björkman, 2019; Lie, 2019; Mathew, 2018; Rindom, 2019; Romero 2019; Saltzstein, 2019; Spohr, 2019; Weaver, 2017). Some only use the word when contained in citations of other authors (Lie, 2019; Slater, 2016; Vandagriff, 2017; Venn, 2015).

We should be reminded that the present survey of a total of 132 journal articles revealed that performativity, as a terminology, is underrepresented and falls between only two perspectives (with the one exception being Venn (2015)): a generic nomenclature somewhat synonymous to performance grounded in the musical text as an artefact (Performativity ${ }_{0}$ ); and a performance theory based version focusing on the situation at hand, preferably in relation to feminist, gender and ethnicity studies (Performativity ${ }_{3}$. This disregard of Austin's and Derrida's conceptions of the performative is perhaps natural since Butler comes from the realms of more music performance friendly performance theory (see e.g., Loxley, 2006, pp. 2, 120, 125 and 140). Austin's and Derrida's performativities, on the other hand, belong in linguistic discourse. And when Venn (2015) draws on Derrida's writings, it is in the interest of hermeneutically interpreting a composition as text. Of the 46 surveyed journal articles using the word performativity/performative, 26 focus on the stereotypical classical music repertoire including contemporary art music following a traditional format (often involving string quartets, grand pianos, opera, ballet, symphony orchestras, early music and the like, as opposed to popular music, electronic music, film, cabaret, etc.). Of those, 10 articles focus on the music of the Baroque or earlier. It is interesting to note that of the 26 classically focused cases, I would categorise $65 \%$ as performativity,, $30 \%$ as performativity, and only $4 \%$ (one single article) as performativity ${ }_{2}$. Focusing only on those dealing with the Baroque era or earlier, performativity is represented by $70 \%$ and performativity ${ }_{3}$ by $30 \%$. The first emphasises the text as an artefact, the 
latter the situation of the text. Additionally, the surveyed journal articles mentioned here are aimed mostly at canonical works and figures (cf., Bergeron, 1992).

Table 2. The Various Performativities and Their Respective, Approximated Literature Relationships Based on Their Main Theory Focus, According to the Present Survey. Underlined references appear in multiple categories. Parentheses imply that the terms performativity and/or performative are only used within quotes. An asterix suggests that performative, or performativity, as words, appear only one time in the article. A question mark suggests an inconclusive entry.

\begin{tabular}{|c|c|c|c|c|}
\hline & Performativity $_{0}$ & Performativity & Performativity ${ }_{2}$ & Performativity $_{3}$ \\
\hline $\begin{array}{l}\text { Modus } \\
\text { operandi; } \\
\text { form }\end{array}$ & $\begin{array}{l}\text { Synonymous } \\
\text { nomenclature; to } \\
\text { distinguish from } \\
\text { other modalities; a } \\
\text { noun or an adjective }\end{array}$ & In situ & Linear & Circular \\
\hline $\begin{array}{l}\text { Cited } \\
\text { literature } \\
\text { in survey }\end{array}$ & $\begin{array}{l}\text { Saltzstein, 2019*?; } \\
\text { Shelley, 2019; } \\
\text { Bonds 2017*; } \\
\text { Arendell, 2015*; } \\
\text { Morais, 2015; } \\
\text { Bianchi, 2017*; } \\
\text { Ferreira, 2016; } \\
\text { Citron, 2017*; } \\
\text { Rumph, 2015; } \\
\text { Goldmark, 2017*; } \\
\text { Clarke et al., 2016*; } \\
\text { Caldwell, 2018; } \\
\text { Williams, 2016; } \\
\text { Cypess, 2017*?; } \\
\text { (Slater, 2016*); } \\
\text { Weaver, 2017*; } \\
\text { Butt, 2018*?; } \\
\text { Llorens, 2017; } \\
\text { Korhonen-Björkman, } \\
\text { 2019; } \\
\text { Golomb 2017; } \\
\text { Schuiling, 2019; } \\
\text { Curry, 2017; } \\
\text { Zanovello, 2016 }\end{array}$ & - & (Venn, 2015*) & $\begin{array}{l}\text { Kohli, 1999; } \\
\text { Franko, 2003; } \\
\text { Freitas, 2018; } \\
\text { Hambridge, 2015; } \\
\text { Moseley 2015; } \\
\text { Flory, 2019; } \\
\text { Callahan, 2018; } \\
\text { Saltzstein, 2017; } \\
\text { Spohr, 2019*; } \\
\text { Mathew, 2018*; } \\
\text { (Lie, 2019*); } \\
\text { Robin, 2018; } \\
\text { Morrison, 2019; } \\
\text { Thurman, 2019; } \\
\text { Romero, 2019?*; } \\
\text { Rindom, 2019?*; } \\
\text { Cole, 2018; } \\
\text { Kennaway, 2015?; } \\
\text { (Vandagriff, 2017?); } \\
\text { Valiquet, 2019?; } \\
\text { Summers, 2015?; } \\
\text { Musser, 2019 }\end{array}$ \\
\hline
\end{tabular}

Clearly, a more differentiated performativity has much to offer musicology as its various versions can highlight new perspectives, otherwise implied or passed by in silence thus only to be overseen. 
When each step of its evolution is acknowledged for its own individual contribution and operationality, each version can provide individual assets that in comparison unlock complex matters. So far, I hope to have shown this potential, and how together with rhetoric and logic and unveiling mechanisms that otherwise may be taken for granted, it will have consequences for how we relate to the past-perhaps more significantly, how the past and present effectively construct and maintain each other through a different perspective than traditional hermeneutical discourse.

By applying their individual perspectives to the artefact or situation being studied and examining the cumulative knowledge arising from their individual contributions and differences, we may find new ways of embracing HIP within other fields of study. We may find ways of relating the past, present and future at the intersection between practice and artefact, text and situation, self-referentiality and external norms, etc. Therefore, a performative musicology supersedes the ontological status of one preferred definition over others, thus producing interrelated knowledge where the performative act plays the role of an operational catalyst through its inner differences rather than in spite of them. A performative musicology based on the strands and central ideas presented here, then, is nothing new per se. It is a cumulative perspective, where performativity is not taken for granted, and does not add to an already confusing umbrella phenomenon where references to Austin, Derrida and Butler are made out of habit without considering their different agendas. It is not strictly artistic research, nor traditional musicology because it lies in between. Rather than excluding or dividing, it aims at including and inviting all who find performativities to be feasible within new contexts, outside of drama and theatre studies, gender studies, feminist studies, ethnicity studies, and so on. As such I am not (naively or arrogantly) claiming to be inventing a new type of musicology, I am merely lingering on what seems to be a confused, insufficiently explored concept, through which musicology dedicated to classical music and early music in particular, seems to be lagging behind the other arts in accepting its potential. Perhaps the performative turn should still be talked about in present rather than in past tense, particularly when talking about 
the past in the present. As Foucault put it in a paper delivered in Japan in April 1978:

For a long time one has known that the role of philosophy is not to discover what is hidden, but to make visible precisely what is visible, that is to say, to make evident what is so close, so immediate, so intimately linked to us, that because of that we do not perceive it. Whereas the role of science is to reveal what we do not see, the role of philosophy is to let us see what we see. (Foucault cited in Marshall, 1999, p. 309)

\section{Rhetoric and HIP}

Of course, the issue raised by Foucault has already been vigorously pursued through centuries in various forms and guises. My shift to rhetoric, however, is not by accident. In today's Western societies (which constitute the reality of my present scholarly contribution), I think it is more apt than ever to promote and emphasise the rhetorical perspectives of our musical lives, and our historical past. This is applicable especially in what could be described as a Western "post-truth" society where our collective worldview is not necessarily guided first and foremost by truth, but by emotion and opinions - what I like to call (with a not so subtle, courteous nod to Descartes) modes of sentio ergo recta (I feel, therefore I am right) and puto ergo recta (I believe, therefore I am right). Alternative realities have now, more than ever, become vessels of political strategies to subordinate reality, as Lee McIntyre puts it, to challenge truth "as a mechanism for asserting political dominance". Post-truth, as the Oxford Dictionary defines it, denotes a phenomenon where emotion and personal belief guide public opinion, collectively rather than individually, at the cost of objective facts and those who produce them. Through social media, we have been given direct access to politicians and the public where they, or anyone, can post anything uncensored (McIntyre, 2018, pp., xii-xiv, 4, 14, 87; authors' italics removed from the original). This relates not only to politicians but to any authority. As we saw above, we can accept baroque music to be a certain way just because an authority on the subject said so, convincing by uttering. A rhetorical perspective, 
thus, serves two functions: 1 ) to identify opinion creating mechanisms both in past and present sense (and tense); and 2) to use rhetoric again to construe possibilities of efficacy where performativity is a mechanism within a rhetorical ecology.

I have already illustrated that HIP, as I conceive it, is very much a rhetorically based phenomenon. Whether it is understood to have a distinct meaning operating within set premises with an already known social construct (performativity), or through its detached temporal repeatability (performativity ${ }_{2}$ ), or as a construction and self-reassertion through performance (performativity), it is still a matter of citing fractions (singular or related) of the past, and using them in some guise to persuade in the present. Scholars Antonis Liakos and Mitsos Bilalis (2017) ask "how the past, and which past, comes back to the present with such a dynamism". One must explore "[...] the sudden reappearances of the past in the present, and the outbreak of smaller or larger disputes which dominate the public sphere, break the present and the temporal order, create unjustifiable tensions and construct particular senses of the past" (Liakos \& Bilalis, 2017, pp. 208-209). Reconstructions and various combinations of historical fragments of the past are used actively in diverse rhetorical contexts - familiar, social, educational, political, propagandistic, etc. - to provide perspectives on the present, to conceive the now and forge the way to the future. Supported by various conditioning agents - including music, lightning, crowd effects, scenery, imagery and objects - that better facilitate persuasion (Perelman \& Olbrechts-Tyteca, 1969, locs. 309 and 569), it makes an impact (if successful, of course) and lives on through transcending iterability, thus contributing to developing future discourse: "It will be an event for the history books", one might say. It lives its own life (in the Derridean sense).

The relationship between the past and present, therefore, is not preordained. Which version of the past that becomes apparent in which circumstance is unpredictable. Historical analogies are used in various rhetorical contexts "to understand new realities and metaphors", to meet and control unexpected situations, familiarising the unfamiliar through the lense of old experiences (Liakos \& Bilalis, 2017, p. 208). This makes continued discourse on what HIP is and can be particularly interesting, 
ensuring its place and relevance in the future too. As Butt similarly argues for the work ontology: "Only by recognising the contingency of the work concept, only by recognising its historical boundedness, do we have a chance of planning for its survival and revival in a rapidly changing world" (Butt, 2015, p. 7). As such, a performative musicology, like that suggested here, cannot, in its efforts to shed light on present mechanisms, perhaps escape the personal agenda of the one performing it (if, in fact, any analytical approach can). A musicology dedicated to the doing of something by uttering it also constructs a rhetorical scaffold, drawing on historical fragments to promote and perform something specific. It is active rather than passive, and recognises scholars not only as observers and analysts, but participating performers in the same phenomenon they seek to unveil. As Butt reminds us, the function of historical discourse could be conceived as activities aimed at enhancing our sense of belonging to a greater context, and learning certain lessons, "[b]ut this should not be confused with a sense of the past seeking resonances in the future" (Butt, 2015, pp. 6 and 10). The past itself does not necessarily "beg" to be reimagined or reinstated in whatever format, but it may certainly have had the future in mind (Butt, 2015, p. 6).

Acknowledging this perspective, I propose that to unmask the ecological rhetorical agency of past actions is also to construct a transferrable design that can move back and forth in the temporal domain, not to recreate the same significance and action, but to offer comparable ones to create new content. These comparable rhetorical practices can then be used to: 1) reproduce, reestablish or re-present the past in the present; or 2) they can be appropriated to signify new meaning and action detached from the original setting. This is both where Liakos' and Bilalis' Jurassic Park (see below) and performativities ${ }_{1-3}$ come into play within the pedagogical view. To make this claim, I will take a position where: 1) rhetoric arguably serves us better, by providing a transferrable, relatable and reiterative space for early music to keep unfolding, than aesthetic perspectives; 2) as historically informed performers, we appropriate historical fragments in rhetorical settings both to construct ourselves and to persuade others and, as such, reinforce normativity with controlled and censored developments; and 3) such transferable rhetorical design alongside 
various concepts of performativities can also be used to approach the future of early music performance. I will use the remaineder of this chapter to pursue this position, particularly from a pedagogical perspective.

\section{Rhetoric as pre-aesthetics}

It is perhaps a question of separating how history is written from how it should be written, and how normativity overcomes what really happened (Liakos \& Bilalis, 2017, p. 211). The reason why I suggest that rhetorical approaches serve early music performances (at least that leading up to the 1730s) better than aesthetics has to do with the fact that aesthetics is a more modern concern. When researching or, even more as laymen speaking of music, we often assume a position of speaking of aesthetics in the sense of "pleasure of the imagination" (Rueger, 2011, p. 201), and so we keep the canon intact as a framework (Bergeron, 1992), through which we regard the musical "work" to be an object, and the basis for our discourse. We speak of the "work" itself and its creator. We speak of how to perform the "work" in a historically informed manner, preferably assigning "right" and "wrong" to its execution. We gladly discuss how we perceive the work, and how our perception correlates to what the author of the work originally intended (see, e.g., Butt, 2015). To me, this is to embrace aesthetics, particularly from a romanticised worldview in which the audience buy their entry to a concert venue in order to sit obediently as subjects for the reenactment of the objectified, aural, "early modern work". But if such a focus, I think, is to provide the framework for discussing pre-aesthetic music, that is music before the 1735 recognition of the term "aesthetics," and before the je ne sais quoi, we are off on the wrong foot. We are somehow judging the book by its cover. As philosopher Alexander Rueger comments: "One has to resist the temptation to impose on the early modern debates reconstructions of problems in terms that achieved their meaning only much later" (Rueger, 2011, pp. 201-202, 213-214). From this perspective, rhetoric should be a more natural analytical approach to the early modern "artefact", especially to unlock its potentially agential and active features within a certain context. In the seventeenth century, for instance, one was concerned with how the arts could stimulate and 
manage the passions of the audience effectively. The fine arts were not distinct from the rest of traditional arts (e.g., optics, mechanics or astronomy), and as such, there was no room for dedicated aesthetic philosophical debate before the mid-eighteenth century. As Rueger points out:

This rhetorical framework is visible as the background of debates in art theory throughout the seventeenth century. [...] All parties, philosophers, artists, and art theorists, drew on the same resources for this topic, the treatises on rhetoric. [...] Only in the eighteenth century did the Baroque cabinets of curiosities, the collections of specimens of all the arts and of nature, dissolve into separate museums for the "fine arts" and scientific collections. (Rueger, 2011, pp. 202-203)

A rhetorical approach offers the possibility of not only appreciating a communicative, persuasive design, but also unveiling the means by which it was generated (Toye, 2013, loc. 227). A work of art was intended to amaze and invoke wonder, but it also had to be believable (Rueger, 2011, pp. 206-207). Some means of rhetorical design could, for instance, be used to establish rapport between two people by invoking the same sort of language, thus building beneficial social relations through positive assimilation and expressed admiration (Butt, 2015, p. 14; Rolfhamre, 2018). Rhetoric, then, was a balancing act between "the requirements of believability and the stimulation of emotions", to secure decorum (Rueger, 2011, p. 212). Thus, when analysing rhetorical design, we must ask why it was put together in a specific way and for what purpose (Toye, 2013, loc. 734). We must consider whether what the rhetorical design was invoked to realise had illocutionary or perlocutionary force (or both?), and how its separate fragments were deliberately aimed at a certain discourse. Furthermore, how do we again, today, put these fragments together in new arrangements to promote a certain HIP-guise? While arguing that the "linear relationship between the accumulation of 'positive' knowledge of the past, and our moral and political preoccupations of the present, is a big delusion", Liakos and Bilalis inform us that the historian's sense of moral responsibility to enlighten the public by telling the truth about the past is misconstrued. By identifying our present, massive history consumption that produces "mass perceptions of history 
and what feelings and passions it creates", they ask us to place this history telling phenomenon centre stage, as a social and cultural (even mimetic) practice (Liakos \& Bilalis, 2017, pp. 210-211 and 220). This perspective further emphasises the role of rhetoric in telling, reimagining and representing the distant past. This shows how we actively use the past in terms of convincing and persuading, as well as establishing and doing history (Metzger, 2010, pp. 131-132). Through the analogy of the well-known 1993 science fiction film Jurassic Park (director Stephen Spielberg), Liakos and Bilalis ask us to:

Imagine a theme park, full of history and memory creatures, made and controlled by historians, archivists and memory guardians. Suddenly these creatures acquire life, become autonomous, uncontrollable, start to fight each other, and scare the humans. Yet, the humans are not innocent victims. They recruit the past phantoms for their power games, give them roles and often borrow their voices. The past acquires life, a second hybrid life. This second life of the past contaminates its first life. It is difficult, if not impossible, for humans to imagine these creatures in their original setting, outside their role in the park. Modern imagination contaminates the past and its images [...]. (Liakos \& Bilalis, 2017, p. 209)

\section{Rhetorical ecology}

Clearly, rhetorical texts and acts are not self-sufficient, self-maintained entities. They exist within a certain context in which multiple rhetorical texts together provide space for others in an everlasting space-time continuum (evoking performativities ${ }_{2-3}$, in particular). In their pursuit of an ecological pedagogy of rhetoric, Nathaniel A. Rivers and Ryan P. Weber criticise how often, in rhetoric, atomistic models focus on isolated rhetorical acts. "Rhetorics move and evolve, and too often theories of the rhetorical situation and the classrooms they inhabit act as if rhetoric sits still." Consider, in composition textbooks, how Martin Luther King's speeches and letters, and how Rosa Parks' actions leading to the bus boycott in Montgomery in 1955-56, are all treated in isolation (Rivers \& Weber, 2011, pp. 194 and 196). (Personally, I find Peter Burke’s The Fabrication of Louis 
$X I V$ (1992) to be one interesting exception to this rule where he analyses the multifaceted rhetoric and propaganda of Louis XIV's image or brand, so to speak). Rivers and Weber's rhetorical ecology focuses not on the one document, but on the many authors, receivers, texts, institutions, artefacts and histories targeted at different audiences for different purposes to highlight "rhetorical action as emergent and enacted through a complex ecology [...]" which we can navigate for cumulative insight. "The concept of rhetorical ecology emphasizes the symbiotic nature of texts, including the way texts, events, and feelings influence or 'contaminate' one another" (Rivers \& Weber, 2011, pp. 188-190 and 193).

So, in maintaining a performative musicological perspective related to rhetoric and pedagogy, we are able to construe a multifaceted ecology in which we can identify the doing, the intent of doing, and the selfassuring iterable practices enabling and sustaining the possibility of doing. Through this ecology, we can see how HIP suddenly invites us not only to do more than re-present a musical practice so that it is not entirely forgotten, but rather to get to know our present in relation to a rhetorical concept of the past so as to do things differently in the future. For what is the pursuit of the past, the purchase of a gittern, orpharion or ancient harp if not a yearning for the different, the other? The effectiveness of the context, then, is not only interesting and important, but vital. The pedagogical perspective of this very complex phenomenon (and yet so simple in principle) is further emphasised when Rivers and Weber ask "what rhetoric is compounded by the choices we have to make as educators: what rhetoric, how rhetoric and why rhetoric?". Moreover, they add that "ecology as framework suggests modes of engagement, we find both possible in and desirable for a rhetorical paideia" (Rivers \& Weber, 2011, pp. 202, 207). We start to see a possibility of the, somewhat narrowly framed, Jurassic Park of HIP for the sake of society (which returns us to the opening section of this chapter once more). How can HIP be agential and "do" the present and future by providing both a canonic normativity, and what Rivers and Weber call a "protopublic space" where we learn how the more general public is formed and operates (Rivers \& Weber, 2011, pp. 209-210 and 212-213)? So, my opening questions (Does historical music performance make sense today, particularly in an educational 
setting? In what way can learning to play early music contribute to our society? Could historical music knowledge make us better citizens?) seem somehow less figurative and farfetched. They seem more plausible and relevant, and even possible. The configuration of an HIP "that does" is then, also ethical and pedagogical.

Clearly, we must not only ask how to do HIP but also how we do musicology. What constitutes the way in which we understand the musical world, and what genealogy informs our perspective? Without getting lost in this distant but relevant perspective, this "parecbasis", the issue of musicology can be regarded as rooted in two different world views, at least in how they are portrayed through their related discourses. In Introducing Critical Theory: A Graphical Guide, to exemplify what I aim at here, we are introduced to a sort of genetic coding of critical theory through a family tree. It starts from the Enlightenment and divides into various branches including economics, philosophy (leading to empiricism, idealism (Kant, Hegel, etc.)), science (physics, biology, human sciences, etc.), and romanticism (leading to modernism and postmodernism, etc.) (Sim \& Loon, 2012, pp. 24-25). Without repeating the full tree here, my point is that these kinds of genetic studies of thought say something about who we are and how we describe, judge and perceive the world in terms of scientific enquiry. Just as the academisation process of vocational music education (i.e., main instrument conservatory education merging with academic universities) does not automatically alter the previously tenured teaching staff's heritage, and perceived "classical music performer" mandate. It instead provokes friction, and conflicting ideas of what a university music degree is and should be, and how its economic and knowledge creating performance are to be judged (in a neo-liberalistic sense) (Angelo et al., 2019, pp. 79-80). It is a matter of formation, of upbringing and coming into being within a certain setting.

Musicology itself is a relatively young discipline, compared to other sciences, stemming from the likes of Guido Adler's 1885 Umfang, Methode und Ziel der Musikwissenschaft dividing the discipline in an encyclopaedic fashion into two main tenets: historical musicology (treating Western art music) and systematic musicology (dedicated to acoustics, psychology, sociology, aesthetics and what came to be known later as 
ethnomusicology). This Austro-German tradition of studying historical European music positioned itself at the centre of musicology, Western art music or not, for generations to come. With the following developments promoted by scholars such as Joseph Kerman (1924-2014), whose book Musicology (1985, Britain; published as Contemplating Music: Challenges to Musicology in the USA) according to some, marks the divide between old and new musicologies. He introduces a distinction between scholarship and criticism, suggesting that the former should become more like the latter, preferring the experience, value and importance of music before its objectification. Yet scholars were still reluctant to accept anything other than factual detail and interpretative schemes (Williams, 2001, pp. 1-3). Focusing on central figures (including Joseph Kerman, Theodor Adorno and Carl Dahlhaus) in European musicology, Alastair Williams identifies three main concerns: 1) "Demonstrating how knowledge is dependent on often unstated assumptions that can be analysed, contested and possibly modified"; 2) "The historical and sociological forces that construct the values of musical autonomy [...], leaving as a residue the question of how the specific actuality of music can be understood alongside the social forms it embodies"; and 3) "A shared sense of crisis in the values enshrined in classical music is also central" (p. 20). Still, the hierarchical, Marxist flavoured divide between high and low, classical and popular music (where the first was a more preferable object of study than the latter) remained. As a reaction to the American new musicologists who focused more or less solely on the classical music canon, critical musicology arose in the UK doing similar projects, but they also embraced popular music and other genres. It joined a post-modernist movement in the 1990s alongside the rise of feminist musicology, critical musicology, and gay and lesbian musicology (Scott, 2003, pp. 4-5).

Roberta Montemorra Marvin suggests that the source studies, which used to be at the very centre of musicology were pushed to the side by the developments in the 1980s, to be "viewed as a "positivistic," empirical component of a loftier process [...]" (Marvin, 2004, pp. 2-3). During this phase, source studies became passé, giving rise to a scholarly divide between the culturally infused "new musicology" and the "old" ways. Now it seems that the pendulum is resting in the centre where we see 
an increase in scholarly work drawing on the positive contributions of both:

Now, traditional and contemporary approaches have recently come into balance: source studies have been enhanced by new theoretical applications and modes of inquiry have been enhanced by new theoretical applications and modes of inquiry and newer ideologies have incorporated documentary evidence. (Marvin, 2004, p. 2; see also Fabian, 2016; Butt, 2015)

In the present context, I do not intend to distance myself from that worldview. In fact, I doubt whether I am able to do so because of my upbringing both as a musician and a scholar, and the theoretical foundation upon which the present argument rests. I also doubt whether it should be an aim at all in early music, and historical music discourse, because if we distance ourselves too much from the discipline we claim, we do not contribute to broadening its perspectives effectively enough, but become "the other" who is distant and part of something else that is not "us". That is, criticism, change and new perspectives should preferably come from within to be accepted by its own members. Outsider perspectives have more difficulty in doing so (Sutton \& Douglas, 2013, p. 414). Furthermore, in studying historical music, we accept its premises as historical music and the re-creation and fantasising of past texts, because that is why we study it. In the words of Rueger:

We seem to desire to know those things most intensely of which we can in principle not acquire much knowledge because they are too 'distant' from us and which we therefore admire most [...]. Thus the pleasure we feel about the marvellous seemed to be connected with our lack of knowledge rather than with the beginning of an actual investigation into the causes of wonder. (Rueger, 2011, p. 209)

There is not only need, therefore, to reconstruct it for the sake of merely reconstructing it, but also to see it from new perspectives aimed at broadening our co-presence within its realm. This is, of course, no novel perception, but it is a perspective worth repeating whenever there is a search for the "new", or the "other". This could perhaps be a contributing factor as to why some newer artistic disciplines, such as artistic research, seem 
to struggle at times to be fully accepted as research by traditional science communities. But this question belongs in a different context than the present one.

\section{Pedagogy, rhetorical ecology and performativities: Past, present and future}

For a deeper insight into the pedagogical aspects and potential of historical music performance then, we could turn to Alan Metzger. Focusing on one element of the massive history consumption that Liakos and Bilalis spoke of, namely the historical film, he asks: "Are historical feature films - commercial movies set entirely or mostly in previous time periods - the most powerful force shaping how people think about the past?" (Metzger, 2007, p. 67). If we connect this perspective to David Huron's (2006) ITPRA theory, proposing that our expectations of what is to come are founded on our compound, past experiences and that our central nervous system (CNS) rewards us in relation to the accuracy of our predictions of what is to come, then mass history prepares our initial meeting with HIP. As commercial products constructed to convey a particular message, these films affect how we think of the past and relate it to our present. They provide public references for communicating conceptions of the world around us in a way that do not necessarily promote historical literacy: "Filmmakers often use a historical event as a metaphor for current concerns, attitudes, and values that are easier to sell to contemporary audiences". As rhetorical complexities they evoke emotions in a memorable and persuasive way, and the millions of viewers - many of them school-age students lacking sufficient knowledge to critique the films' possibly manipulative and trivialising efficacy, undistracted by counter-narratives - establish the historical film as an important educational issue. "When students watch history movies without the support of sufficient content knowledge and nuanced understandings of history, a possible (or probable) outcome is for the filmic account to "colonize" their thinking about the past - taking up residence in the mind as a kind of literal truth" (Metzger, 2007, pp. 67-71). In a later publication Metzger evokes the term "cultural curriculum", which is to 
be found at "intersections between school, home, and the collective memory of society at large". Through this manner of perceiving our historical presence, we can become historical empaths (through the lense of the present collective historical consciousness), who "recognize and respect potentially foreign perspectives" (Metzger, 2010, pp. 128-129; 2007, p. 71).

Perhaps one of contemporary audio-visual historical-rhetorical work's most powerful features, in addition to its visual force - one can soon think of Peter Sloterdijk's connection between concepts of truth and "seeing is believing" (e.g., Sloterdijk, 2017, pp. 27 and 50) - has to do with its presence, its being experienced by us here and now, and not then by others. According to Perelman and Olbrechts-Tyteca, "Presence acts directly on our sensibility. [...] The thing that is present to the consciousness assumes thus an importance that the [rhetor] must take into consideration" (Perelman \& Olbrechts-Tyteca, 1969, loc. 2677, original italics removed). The concept of aesthetics, or art-informed learning, plays an important role in international education studies, since it presents an educational potential for transformational critique and learning (Illeris, 2012, p. 10; McGregor, 2012, p. 310). When, on the one hand, educational systems are utilised to reinforce societal norms and identity formation in new generations (Kohli, 1999, p. 321), the arts have the particular ability to encourage multiple readings thus providing more open spaces for learning (McGregor, 2012, p. 313).

Illeris focuses on three concepts: subjectivation (per Thomas Ziehe's definition), positioning and performance, in order to assert that today's young audience presents a new reality for arts education. Through Ziehe, she delineates a new psychological state in Western cultures where differences between people are more a matter of personality than of structurally determined social differences. Young people now wish to be true to themselves rather than be governed by "social factors that can be changed through political means" (Illeris, 2012, p. 15), thus taking control of, or willingly ignoring the performative ${ }_{3}$ reality offered by Butler. (Whether they succeed in doing so is a different matter). If things do not feel right, they do not wish to participate. Where the inner world is the only real world and everything else is in various degrees forced on them (the sentio ergo recta appears). Subjectivation offers a way of pinpointing young 
people's preference for allowing their own "interpretation and sensation to dominate their interaction forms in all spheres of life [...]" (Illeris, 2012, p. 15). A link between an HIP that "does" and the present subject's personal motivation not only emerges, but also reinforces the importance of acknowledging rhetorical ecologies alongside illocutionary and perlocutionary efficacies. That is, the parallel operation of performativities and Jurassic Park from society to HIP, and from HIP to society: "The question "Does this appeal to me?" overshadows the feeling of being in open contact with reality so to speak, challenging the essentialist didactic claim about unmediated sense based interaction as the basis for picture production" (Illeris, 2012, p. 15). This would perhaps explain why Rivers and Weber, in presenting their rhetorical ecological pedagogy, observe that rhetorical portfolios work best when focused on the student's own ecology (Rivers \& Weber, 2011, p. 205).

Staying with the student, we can also add several issues: a competitive school environment that benefits those who succeed and make it (Guha, 2013, p. 36; Mukherjee, 2017, p. 538); compartmentalising students based on their academic achievements into A, B and C students (Marshall, 1999, p. 314); and, following a Foucaultian line of reasoning, initialising "special" needs education for those unable to be "normative" enough (which again enforces the social norm they do not fit into in a Butlerian sense). Furthermore, there exists the possibility of our being too occupied with storing knowledge according to a norm (Guha, 2013, p. 36), which in the Norwegian school system is also annually tested through national competence tests throughout the primary school system measuring all students' compliance with the state officiated competence norm. Those who do not meet the norms get special support to enable them to meet the required standards (Utdanningsdirektoratet, 2020). So, what do we do with the prevailing concept of standard knowledge? Do we focus on including and nurturing disadvantaged social areas in our trying to meet the challenges of the global world (Guha, 2013, p. 38), or is this a responsibility reserved for the privileged? Should the responsibility of equality and inclusion, and of making oneself understood, rest with the oppressed or the oppressor (Srinivasan, n.d., p. 9)? Should we foster love and compassion (Guha, 2013, p. 40), or entrepreneurship and value creation? 
Should we impose academic excellence on all or attempt to get students to "choose" academic excellence (Ladson-Billings, 1995, p. 160)? And how do we use the curriculum both to maintain norms and/or foster change (whatever is identified to be in need of change) (Howard, 2003, p. 195; Mukherjee, 2017, p. 541)? Does the teacher possess a required intellectual and pedagogical commitment to making change (Howard, 2003, p. 199)?

As Gloria Ladson-Billings argues, it becomes a question of whether we insert culture into education or education into culture (LadsonBillings, 1995, p. 159). The perspectives presented by the scholars above relate primarily to race, gender, oppression and economic segregationparticularly issues of normativity and policies in relation to individual versus community, and one community versus another community. But their contributions have a transferrable significance that is useful also in understanding a core mechanism of HIP as a rhetorical, pedagogical, performativities contingent, and social psychological project: inclusion versus exclusion; compliance to the norm or misconduct; safekeeping canons or going rogue; creating a piece of art or a piece of history (or both). Madhumita Guha reminds us that "[e]ducation is in continuation of the past to the present and will be carried over to the future. What we receive in the present is the result of the efforts put in by our ancestors. Every period of history leaves a mark in the system of education" (Guha, 2013, p. 41). As Tyrone C. Howard reminds us (alongside the numerous publications drawing on Butler's performativity ${ }_{3}$, we must "[r]ecognize that teaching is not a neutral act" (Howard, 2003, p. 200), and as Nina S. Edsheim argues in different circumstances: "[...] if we reduce and limit the world we inhabit, we reduce and limit ourselves" (Eidsheim, 2015, loc. 325). Those having been given some sort of pedagogical mandate (teacher, concert presenter, musician, historian, etc.) must remember that the sort of normalising framework portrayed by those above and especially Butler is still very much at work, and also that those who violate the norms bring cultural capital to the community, which can widen the perspectives of mainstream norms and worldviews (Howard, 2003, p. 197-198). The ability to truly make an impact on others depends on being in a position to do so, and one also often sees a relationship between one's personal interests, external attitudes, and where one makes 
an impact (Berry, 1982, p. 288 and 299). Furthermore there is the question of whether we, in effect, make an impact on ourselves, on others or both. Mary Frances Berry reminds us of impact inconsistencies when she turns to post World War II negotiations between US officials and representatives from Japan and Germany in relation to the two countries' post-war constitutions: The US delegates insisted on guaranteeing equal rights for women in Japan and Germany, yet at the same time opposed this for American women (Berry, 1988, pp. 31-32).

In light of this recent parecbasis, the relationship between individual and community is interesting, not only in terms of achieving verified or falsified compliance with social, cultural and political norms, but also in terms of early music's (or classical music in general) future recruitment. The "What's in it for me?" does not necessarily correspond to the interest in and motivation behind historic preservation, that is, the balancing act between presentism and historicism. In my own experience, I have seen numerous films, re-enactment festival reports, and other manifestations of the historical where much effort and attention to detail was given to the visual, yet the music could be anything, without any historical connection. The historical music performance, at least based on my personal observations here, is then at risk of being the first to perish in the mass historical consciousness, at least in the traditional sense (historically themed computer games, in general, are particularly good references for such problems, where the lute can be anything and sound like anything, but I must postpone this perspective for future work).

So, what can an HIP pedagogically do for the past in the present and future? Eidsheim in particular reminds us, "Most of the live music we hear in a Western context is presented within an acoustic frame so naturalized that any other acoustic setting is understood as wrong rather than different" (Eidsheim, 2015, loc. 782). Perhaps, by merely recognising the mechanics of normativity and musical canons and reacting to the past "thinking about significance, long-term causation, and interpretation of events and meaning [..., between what happened in the past and what that means to our world today", we can identify multiplicity and diversity in historical framing in order to foster more ethically contingent debate (Metzger, 2010, p. 133). For instance: What identities does HIP 
promote and perform? How do non-typical communities relate to what HIP offers? How does HIP perform gender? The questions are manifold, and I hope that the performative musicology perspective promoted here can contribute to these issues in the future by highlighting HIP's contextual relations as an activity strongly related to and relying on the historical artefact. However the possibilities introduced by deliberate use of cumulative rhetorical fragments of historical essence, are by no means automatic, nor easily implemented. In fact, given the recent upswing in exclusive nationalistic rhetoric in Western politics and media, we may ask whether the numerous World War II films produced in recent times do in fact contribute on a mass scale to learning from history and nurturing compassion and tolerance, or if they pass us by as uncritical, entertaining narratives. Where do we identify our thresholds for tolerance (e.g., "They can do or be whatever they want, as long as it is not here with me", which is indeed an example for ethical discussion)?

Through Julia Annas' use of music performance analogies to understand the formation and development of virtue, we see how learning to act depends on an initial trust in the educator. In order for what we learn to promote virtue rather than mere habit, there must be an inherent drive in us to aspire; to understand and act deliberately before replicating what should be done; to habituate before becoming mere routine (Annas, 2011, pp. 15, 52 and 87). A rhetorical and performativities centred focus on HIP as an activity, with different degrees of efficacy in a pedagogical setting, may well provide such a space, functioning as an ongoing activity rather than a final end, or at least a state of truth we can relate to normatively. Many didactical approaches could easily be made interesting and fruitful here (e.g., Guha, 2013; Howard, 2003; Metzger 2001, 2010, and many others not discussed here, such as Lynn Fels' performative inquiry (2015) and Irit Rogoff's criticality $(2003,2006))$. However let us return to Helene Illeris (2012) as she is already included in the present text through her emphasis on art pedagogy in relation to subjectivation, in particular. To meet the subjectivising self-centredness of the young generation, she argues, one must seek to position the students in a concrete situation and in relation to other positions (which can also change within the same situation). Positioning, as a pedagogical concept, "is about getting and giving 
possibilities of experiencing the possibility to act that can challenge the sides of subjectivation that lock the learners into a limiting self-centredness". This means that, in meeting the artwork, one transcends the cognition and analysis of representation to:

work with an active construction of identity and action forms as a presentation of possible realities [..., replacing artefact analysis with] strategic experiments where the question "What is the meaning expressed by this work?" is replaced by the questions "How can I act in relation to this? Which positioning possibilities does this construct?" (Illeris, 2012, p. 16)

Exchanging passive empathy to the artwork for the exposure and creation of relations to the artwork, Illeris also emphasises that "positions are social products to be played with, without constantly wondering whether what one does or says is in harmony with "oneself". [...] One must do something, one must choose" (p. 16). While Illeris' research bases itself in visual arts education and the aesthetic experience, a shift from aesthetically contingent readings of early music to rhetoric, and performativities centred approaches may provide HIP with new sorts of agencies. This may activate a new set of functions within early music discourse, as a way to appreciate by not only reflecting on the past and seeking to understand it from our present, but also by extending the invitation to use it as a pedagogical means to relate to the past in the present. That is how we can choose to create and re-create ourselves through connections between our own subjectivity, historical empathy, operative performative and rhetorical mechanics, and some sort of consciousness of how we are subject to societal norms and expectations. Without leading to presentism where the historical artefact is made obsolete, we assert that it is the very historical artefact that, through contextualisation, makes other futures possible through active and conscious past-present relations.

\section{Concluding discussion: Performative musicology and foreseeing the future of HIP}

The first attempt to enter a different perspective, such as the one outlined here, can certainly provoke a feeling of opening Pandora's box. 
Every perspective demands additional ones that have to be postponed for future efforts, thus leaving much of the "story" untold. But what this exercise has shown is, hopefully, that different concepts of the performative, rhetoric, pedagogy and habit, collectively and cumulatively provide important elements for a reconfiguration of our understanding of what it means to be an HIP performer, what responsibility that entails, and how HIP can "do ethics”. Performative musicology thus acknowledges its creative and productive agency. Rather than representing, re-establishing and re-enacting past musical practices, it offers something else. It is not merely historical deciphering and reconstruction; it is not merely the performance of historical artefacts; it is neither performance as theatricality, classical music craftspersonship nor re-enactment in a singular sense. It is a cumulative construction aimed at establishing something through its activity. Therefore, the performativities focused perspective drawing on pedagogy and rhetoric presented here - without excluding other possible approaches to the practice, but contributing to them - offers a historically informed music performance practice highlighting it's rhetorical agency. In so doing, we regard historical music performance practice as neither an "artefact" alone, nor as only constituted by social practice, nor only existing in the theoretical, philosophical domain. What we pursue here is the cumulative relationship between the individual contributions emphasising dynamic readings from more than one perspective, rather than determining and safekeeping one preferred ontology. We look beyond the separate spaces and agencies provided by the score, sound, reception, meaning making, aestheticism, historicity, embodiment, etc., to gain a richer understanding of cause and effect in broader temporal, situational, practical and social contexts, focusing directly on agency. Such persuasive agency, naturally, will not only affect present audiences and participants, but will also set a course for future activities to unfold. This, obviously, not only allows HIP to be read as a pedagogical and rhetorical practice, but will also forge the way to its ethical agency. As Liakos and Bilalis assert: "[...] new events illuminate the past in a different way, shed light on different events or allow new interpretations of past events. The past has power and provides images and emotions that escape from the intentionality of its re-evocation" (Liakos \& Bilalis, 2017, p. 208). 
Simply put: I seek to contribute to HIP by moving beyond the traditional text-performance-reception approach, without moving into historically detached, here and now focused branches of performance studies, in order to examine what early music performance, in this case, does and how it is used to move forward.

This supports the chapter's hypothesis that the historically informed music performance, when re-situated and re-contextualised, can indeed offer to do more than provide an opportunity to re-experience or even fantasise a re-living of the past. If I am right in my compartmentalisation of these theories, particularly when considering performativities ${ }_{1-3}$, then we are at the same time presented with three different opportunities for rhetorical ecologies and decorum, pedagogy and ethical discourse, particularly in terms of virtue, paideia and phronesis, that is education for the ideal member of a state. Of course, the latter perspectives represent huge, complicated questions, deserving much more attention and thought than the present context can provide. However I will nonetheless introduce certain perspectives that I hope to pursue later in other, more fitting, publications.

Nodding to Austin's (1962) work while asking "how to do things with HIP", a theoretical utopia for this operation could possibly look something like this:

$P: \quad$ If HIP persuades the audience, and the performers theselves believe they portray a truthful representation of past musical practice, then HIP can establish itself (performativities ${ }_{1-\mathrm{x}}$ ) as a juxtaposed true representation of the past (performativity ${ }_{1}$ ).

$\Gamma_{1}(x)$ : If some $P$ is reiterated by multiple actors, a cumulative understanding of the past is established (performativities ${ }_{2,3}$ ).

$\Gamma_{2}: \quad$ Through reiterating selected fragments of our perceived, construed past we discover our present: We both see the past through our present understanding and current worldviews, and understand our present by identifying and (citationally) recognising features of the past that we translate into knowledge of the present (performativity ${ }_{2}$ ).

$\alpha(x)$ : Current politicians define a model citizen, which educational institutions should realise (performativity ${ }_{1}$ ) mimetically, but knowledge 
of the past can produce alternative, competing models. Cumulative knowledge of the past and the present enables us to judge the state model in comparison to possible alternatives. Persuasive reasoning (utilising our Jurassic Park) may lead to the conviction of which model citizen (state or alternative) is desirable and what effect it would have on society if collectively implemented.

$\beta(x)$ : The conception and implementation of $\alpha(x)$ produce moral wisdom accordingly. The acceptance of and agency effectuated through the lense of said moral wisdom (phronesis) lead to new policies, new blueprints and norms, new scaffolds to be realised through education (from the individual teacher to state white papers; paideia).

$W(x)$ : If all above are successful, we can continue the reiteration (performativity ${ }_{2}$ ) to produce a scaffold enabling us to imagine a possible future. By acknowledging, accepting and aspiring to the proposed future, we could formalise a norm that serves as a blueprint that we, in the end, realise by acting it out (performativity ${ }_{3}$ ), if enforced persuasively through the educational system.

Now, this is obviously not a realistic real-life scenario because it depends on far too many variables to be successful and harmonious. It can only serve as an in vitro assimilation of some sort of operationality. Moreover, the model above would demand an HIP that is not conceived as a normative end, but one that acts; one that calls for action; one that ultimately does something. Although an alternative worldview may be easily designed and appeal to the masses, current managerial practices within the educational system may make it hard to implement practically (see e.g., Rolfhamre, 2020). What this logic suggests, however, is that a linkage between HIP and societal impact, sustainability and imagining the future is not entirely inconceivable. But it relies on successful rhetoric and conviction throughout its entire process. Although the present context does not sufficiently provide enough foundation to satisfy this logic, it possibly provides enough incentive to give the idea further consideration in future research work. (And have we not learned from recent development that anything goes, anything is possible in our post-truth (McIntyre, 2018), sentio/puto ergo recta society, as long as you find yourself in the right time and place to make it happen (performativities in particular)?) 
Martha C. Nussbaum argues that aesthetic activity creates a safe and protected "potential space" in which we "investigate and try out some of life's possibilities [...]. Because we are in a context of safety, we are also encouraged to have a range of reactive emotions" (Nussbaum, 2001, pp. 243-244, 246). Through the additional perspectives above - primarily those of Illeris (2012), Liakos and Bilalis (2017), Rivers and Weber (2011) and Rueger (2011) - I conclude that performative musicology, as a distinct, dedicated focus, has something to offer, because it goes beyond the idea of understanding musical practice from an artefact-performance-reception view, to pronouncing its agential advocacy for change (or sometimes for resisting change). It is both a performative perspective for historical musicology, and a musicology that seeks to be performative, and as such, it is also inevitably ethically charged precisely because of its aspiring efficacy.

This is my first publication on, and the first attempt to outline, the topic of what could be identified as performative musicology. It will be interesting to see how it may develop in the future. Suffice it to say, for the moment, that there is a growing tendency to address performativities more fully in music research (see e.g., Chung, 2019; Kartomi, 2014; Madrid, 2009), in addition to the established Butlerian approaches affiliated with, for instance, identity, gender and ethnicity studies. In one sense, we seek to join forces with Chung's $\mathrm{P}_{1}$-Performativity and $\mathrm{P}_{2}$-Performativity, as well as Miller's Performativities sub 1 and sub 2 (Chung, 2019; Miller, 2009), while at the same time acknowledging the individual contributions and genealogical steps of performativity's development (e.g., Loxley, 2006; Loxley \& Robson, 2013) in close relation to pedagogy and rhetoric. I offer here a possible starting point, not a complete methodology, but rather a contributory incentive towards creating a course for future research: What will HIP do for us in the future? And what will we do for HIP? Well, we will simply have to see.

\section{Acknowledgements}

I wish to extend my sincere gratitude to Professor Elin Angelo and Research Fellow Inga Marie Nesmann-Aas for providing useful and insightful feedback for this chapter. 


\section{References}

Angelo, E., Varkøy, Ø. \& Georgii-Hemming, E. (2019). Notions of mandate, knowledge and research in Norwegian classical music performance studies. Journal for Research in Arts and Sports Education, 3(1), 78-100. https://doi.org/ 10.23865/jased.v3.1284

Annas, J. (2011). Intelligent virtue. Oxford University Press.

Arendell, T. D. (2015). Thinking spatially, speaking visually: Robert Wilson and Christopher Knowles. International Journal of Music and Performing Arts, 3(1), 16-24. http://dx.doi.org/10.1564o/ijmpa.v3n1a2

Auslander, P. (2006). The performativity of performance documentation. PAJ, 28(84), 1-10. https://doi.org/10.1162/pajj.2006.28.3.1

Austin, J. L. (1962). How to do things with words. In The William James lectures delivered at Harvard University in 1955. Oxford University Press.

Barty, L. (2004). Embracing ambiguity in the artefacts of the past: Teacher identity and pedagogy. Canadian Social Studies, 38(3), https://canadian-social-studiesjournal.educ.ualberta.ca/content/articles-2000-2010\#ARbarty_embracing_ ambiguity 163

Bearn, G. C. F. (1995). Derrida dry: Iterating iterability analytically. Diacritics, 25(3), 2-25.http://automatist.org/2016/web/Derrida_Dry_Iterating_Iterability_ Analyt.pdf

Bergeron, K. (1992). Prologue: Disciplining music. In K. Burgeron \& P. V. Bohlman (Eds.), Disciplining music: Musicology and its canons (pp. 2-8). The University of Chicago Press.

Berry, M. F. (1982). Twentieth-century black women in education. The Journal of Negro Education, 51(3), 288-30o. https://www.jstor.org/stable/2294696

Berry, M. F. (1988). How to teach controversial constitutional issues facing women. OAH Magazine of History, 3(3/4), 30-32. https://www.jstor.org/stable/25162616

Berry, M. F. (1991). Judging morality: Sexual behaviour and legal consequences in the late nineteenth-century South. The Journal of American History, 78(3), 835-856. https://www.jstor.org/stable/2078793

Bianchi, E. (2017). Scholars, friends, flagiarists: The musician as author in the seventeenth century. Journal of the American Musicological Society, 7o(1), 61-128. https://doi.org/10.1525/jams.2017.70.1.61

Bonds, M. E. (2017). Irony and incomprehensibility: Beethoven's Serioso string quartet in F minor, Opus 95, and the path to the late style. Journal of the American Musicological Society, 7o(2), 285-356. https://doi.org/10.1525/jams.2017.70.2.285

Burke, P. (1992). The fabrication of Louis XIV. Yale University Press.

Butler, J. (1988). Performativity acts and gender constitution: An essay in phenomenology and feminist theory. Theatre Journal, 4o(4), 519-531. https:// www.jstor.org/stable/3207893 
Butler, J. (1990/2006). Gender trouble. Routledge Classics. Routledge.

Butt, J. (2001). Authenticity. In Grove Music Online. https://doi.org/10.1093/gmo/ 9781561592630. article. 46587

Butt, J. (2015). What is a "musical work"? Reflections on the origins of the "work concept" in Western art music. In A. Rahmatian (Ed.), Concepts of music and copyright: How music perceives itself and how copyright perceives music (pp. 1-22). Edward Elgar Publishing Ltd. https://www.elgaronline.com/view/ edcoll/9781783478187/9781783478187.00006.xml

Butt, J. (2018). Monteverdi, the 1610 vespers and the beginnings of the modern musical work. Journal of the Royal Musical Association, 143(1), 21-50. https://doi. org/10.1080/02690403.2018.1434328

Böhnisch, S. (2010). Feedbacksløyfer i teater for svort unge tilskuere: Et bidrag til en performativ teori og analyse. [Doctoral dissertation, Aarhus University].

Caldwell, M. C. (2018). Cueing refrains in the medieval conductus. Journal of the Royal Musical Association, 143(2), 273-324. https://doi.org/10.1080/02690403. 2018.1507115

Callahan, D. M. (2018). The gay divorce of music and dance: Choreomusicality and the early works of Cage-Cunningham. Journal of the American Musicological Society, 71(2), 439-525. https://doi.org/10.1525/jams.2018.71.2.439

Chung, A. J. (2019). What is musical meaning? Theorizing music as performative utterance. Music Theory Online, 25(1), 1-40. Pdf-version of online article. https:// www.academia.edu/39258648/What_is_Musical_Meaning_Theorizing_Music_ as_Performative_Utterance

Citron, M. J. (2017). Opera-film as television: Remediation in Tony Britten's Falstaff. Journal of the American Musicological Society, 7o(2), 475-522. https://doi.org/ 10.1525/jams.2017.70.2.475

Clarke, E., Doffman, M. \& Timmers, R. (2016). Creativity, collaboration and development in Jeremy Thurlow's Ouija for Peter Sheppard Skærved. Journal of the Royal Musical Association, 141(1), 113-165. https://doi.org/10.1080/02690403. 2016.1151240

Cole, R. (2018). Mastery and masquerade in the transatlantic blues revival. Journal of the Royal Musical Association, 143(1), 173-210. https://doi.org/10.1080/026904 03.2018.1434352

Collins, J. \& Mayblin, B. (2012). Introducing Derrida: A graphic guide. Icon Books Ltd. https://www.amazon.com

Culler, J. (1981). Convention and meaning: Derrida and Austin. New Literary History, 13(1). [On Convention: I, 15-30]. https://www.jstor.org/stable/468640

Correia, J. (2020, 20 January). When is research artistic research? [PowerPoint slides]. Curry, B. (2017). Valency-actuality-meaning: A Peircean semiotic approach to music. Journal of the Royal Musical Association, 142(2), 401-443. https://doi.org/10.1080/ 02690403.2017.1361177 
Cypess, R. (2017). "It would be without error": Automated technology and the pursuit of correct performance in the French enlightenment. Journal of the Royal Musical Association, 142(1), 1-29. https://doi.org/10.1080/02690403.2017.1286115

Davies, S. (2010). Emotions expressed and aroused by music: Philosophical perspectives. In P. N. Juslin \& J. A. Sloboda (Eds.), Handbook of music and emotion: Theory, research, applications (pp. 15-43). Oxford University Press.

Derrida, J. (1982). Margins of philosophy (A. Bass, trans.). The University of Chicago Press.

Early Music Sources. (2017a, 10 January). High clefs (so called chiavetta) and transposition [film]. YouTube. https://www.youtube.com/ watch $? \mathrm{v}=\mathrm{qBmBuMsiIto} \&$ feature $=$ youtu.be

Early music Sources. (2017b, 27 July). Solmization and the Guidonian hand in the $16^{\text {th }}$ century [film]. YouTube. https://www.youtube.com/watch?v=IRDDT1uSrdo \&feature=youtu.be

Echols, Paul C. (2013, 11 February). Early-music revival (M.V. Coldwell, Rev.). In Grove Music Online. https://doi.org/10.1093/gmo/9781561592630.article.A2235052

Eidsheim, N. S. (2015). Sensing sound: Singing and listening as vibrational practice: Sign, storage, transmission. Duke University Press. https://www.amazon.com

Englund, A. (2019). A note from the guest editor. The Opera Quarterly, 35(1-2), 1-6. [Advance access publication]. https://doi.org/10.1093/oq/kbzo21

Fabian, D. (2016). A musicology of performance: Theory and method based on Bach's solos for violin. Open Book Publishers.

Fels, L. (2015). Performative inquiry: Reflection as a scholarly pedagogical act. In E. Vettraino \& W. Linds (Eds.), Playing in a house of mirrors: Applied theatre as reflective practice (pp. 151-174). Sense Publishers. https://doi.org/10.1007/978-946300-118-2_11

Ferreira, M. P. (2016). The medieval fate of the cantigas de Santa Maria: Iberian politics meets song. Journal of the American Musicological Society, 69(2), 295-353. https://doi.org/10.1525/jams.2016.69.2.295

Fischer-Lichte, E. (2008). The transformative power of performance: A new aesthetics (S.I. Jain, trans.). Routledge.

Flory, A. (2019). The ballads of Marvin Gaye. Journal of the American Musicological Society, 72(2), 313-362. https://doi.org/10.1525/jams.2019.72.2.313

Franko, M. (2003). Majestic drag: Monarchical performativity and the king. The Drama Review, 47(2), 71-87. https://www.jstor.org/stable/1147011

Freitas, R. (2018). Singing herself: Adelina Patti and the performance of femininity. Journal of the American Musicological Society, 71(2), 287-369. https://doi.org/ 10.1525/jams.2018.71.2.287

Friman, A. M. (2008). Modern performance of sacred medieval music with particular reference to women's voices [Doctoral dissertation, University of York]. 
Goldmark, D. (2017). Adapting The jazz singer from short story to screen: A musical profile. Journal of the American Musicological Society, 70(3), 767-817. https://doi. org/10.1525/jams.2017.70.3.767

Golomb, U. (2017). Doubting the resurrection? Questions and dilemmas in performances of the first Et expecto from Bach's mass in B minor. Music Performance Research, 8, 55-79. http://mpronline.net/Issues/Volume\%208\%20 [2017]/MPRo115.pdf

Graubart, M. (2000). Musical hermeneutics: The "authentic" performance of early music. Philosophy Now. https://philosophynow.org/issues/28/Musical_ Hermeneutics_The_Authentic_Performance_of_Early_Music

Green, L. (1997). Music, gender, education. Cambridge University Press.

Guha, M. (2013). Education in a Tagorean perspective. International Journal of Humanities and Social Science Invention, 2(12), 35-41. http://www.ijhssi.org/ papers/v2(12)/Version-2/Fo21202035041.pdf

Hall, K. (200o). Performativity. Journal of Linguistic Anthropology, 9(1-2), 184-187. https://www.researchgate.net/publication/264737370_Performativity

Hambridge, K. (2015). Staging singing in the theatre of war (Berlin, 1805). Journal of the American Musicological Society, 68(1), 39-97. https://doi.org/10.1525/ jams.2015.68.1.39

Haskell, H. (2001). Early music. In Grove Music Online. https://doi.org/10.1093/ gmo/9781561592630.article.46003

Hawkins, S. (Ed.). (2017). The Routledge companion to popular music and gender. Routledge.

Hollywood, A. (2002). Performativity, citationality, ritualization. History of Religions, 42(2), 93-115. https://www.jstor.org/stable/3176407

Howard, T. C. (2003). Culturally relevant pedagogy: Ingredients for critical teacher reflection. Theory Into Practice, 42(3), 195-202. https://doi.org/10.1207/ S15430421tip4203_5

Huron, D. (2006). Sweet anticipation: Music and the psychology of expectation. A Bradford Book. The MIT Press.

Illeris, H. (2012). Aesthetic learning processes for the $21^{\text {st }}$ century: Epistemology, didactics, performance. Journal of the International Society for Teacher Education, 16(1), 10-19.

Jalving, C. (2011). Verk som handling: Performativitet, kunst og metode. Museum Tusculanums Forlag.

Kania, A. (2017, 11 July). The philosophy of music. The Stanford encyclopedia of philosophy. https://plato.stanford.edu/archives/fall2017/entries/music/

Kartomi, M. (2014). Concepts, terminology and methodology in music performativity research. Musicology Australia, 36(2), 189-208. https://doi.org/ 10.1080/08145857.2014.958268 
Kattenbeldt, C. (2010). Intermediality in performance and as a mode of performativity. In S. Bay-Cheng, C. Kattenbeldt, A. Lavender \& R. Nelson (Eds.), Mapping intermediality in performance (pp. 29-37). Amsterdam University Press. https://www.jstor.org/stable/j.ctt46mwjd.7

Kennaway, G. (2015). Trills and trilling: Masks, dandyism, historical performance, and the self. Music Performance Research, 7, 47-64. http://mpronline.net/Issues/ Volume\%207\%20[2015]/MPRoo91\%20Kennaway\%20(2015).pdf

Kohli, W. (1999). Performativity and pedagogy: The making of educational subjects. Studies in Philosophy and Education, 18, 319-326. https://doi. org/10.1023/A:1005284924565

Koopman, C. (2005). Music education, performativity and aestheticization. Educational Philosophy and Theory, 37(1), 119-131. https://doi.org/10.1111/j.14695812.2005.00102.x

Korhonen-Björkman, H. (2019). Bach points and virtuosity: A performer's dialogic analysis of Betsy Jolas' Ô Bach! Music Performance Research, 9, 31-59. http:// mpronline.net/Issues/Volume\%209\%20[2019]/MPR\%200110\%20KorhonenBj\%C3\%B6rkman\%2o(31-59).pdf

Kyndrup, M. (2006). Performativitet, æstetik, udsigelse: Lille note om det performatives æstetik. Peripeti, 6, 37- 46. http://www.peripeti.dk/pdf/ peripeti_6_2006.pdf

Ladson-Billings, G. (1995). But that's just good teaching! The case for culturally relevant pedagogy. Theory Into Practice, 34(3), 159-165. https://www.researchgate. net/publication/245591801_But_That's_Just_Good_Teaching_The_Case_for_ Culturally_Relevant_Pedagogy

Liakos, A. \& Bilalis, M. (2017). The Jurassic park of historical culture. In M. Carretero, S. Berger \& M. Grever (Eds.), Palgrave handbook of research in historical culture and education (pp. 207-224). Macmillan. https://doi.org/ 10.1057/978-1-137-52908-4_11

Lie, S. B. (2019). Genre, ethnoracial alterity, and the genesis of jazz manouche. Journal of the American Musicological Society, 72(3), 665-718. https://doi.org/ 10.1525/jams.2019.72.3.665

Llorens, A. (2017). Recorded asynchronies, structural dialogues: Brahms's Adagio affettuoso, Opus 99ii, in the hands of Casals and Horszowski. Music Performance Research, 8, 1-31. http://mpronline.net/Issues/Volume\%208\%20[2017]/MPR\% 200109\%20Llorens\%201-31.pdf

Locke, K. (2015). Performativity, performance and education. Educational Philosophy and Theory, 47(3), 247-259. https://doi.org/10.108o/oo131857.2013.857287

Loxley, J. (2006). Performativity: The new critical idiom. Routledge. https://www.amazon.com 
Loxley, J. \& Robson, M. (2013). Shakespeare, Johnson, and the claims of the performative. Routledge.

Madrid, A. L. (2009). Why music and performance studies? Why now? An introduction to the special issue. [translation]. Revista Transcultural de Música, 2009(13). URL: http://www.sibetrans.com/trans/articulo/1/why-music-andperformance-studies-why-now-an-introduction-to-the-special-issue

Marshall, J. D. (1999). Performativity: Lyotard and Foucault through Searle and Austin. Studies in Philosophy and Education, 18, 309-317. https://doi.org/ 10.1023/A:1005272607727

Marvin, R. M. (2004). Introduction: Scholarly inquiry in historical musicology: Sources, methods, interpretations. In S. A. Crist \& R. M. Marvin (Eds.), Historical musicology: Sources, methods, interpretations (pp. 1-7). University of Rochester Press.

Mathew, N. (2018). Interesting Haydn: On attention's materials. Journal of the American Musicological Society, 71(3), 655-701. https://doi.org/10.1525/jams. 2018.71.3.655

McGragor, C. (2012). Art-informed pedagogy: Tools for social transformation. International Journal of Lifelong Education, 31(3), 309-324. https://doi.org/ 10.1080/02601370.2012.683612

McKinlay, A. (2010). Performativity: From J. L. Austin to Judith Butler. In P. Armstrong \& G. Lightfoot (Eds.), The leading journal in the field: Destabilizing authority in the social sciences of management (pp. 119-142). MayFly Books. http://mayflybooks.org/wp-content/uploads/2010/12/ 9781906948092TheLeadingPublicationInTheField.pdf

McIntyre, L. (2018). Post-truth. MIT Press.

Metzger, S. A. (2007). Pedagogy and the historical feature film: Toward historical literacy. Film \& History: An Interdisciplinary Journal of Film and Television Studies, 37(2), 67-75. http://doi.org/10.1353/flm.2007.0058

Metzger, S. A. (2010). Maximizing the educational power of history movies in the classroom. The Social Studies, 101(3), 127-136. https://doi.org/10.108o/ 00377990903284047

Miller, J. H. (2009). Performativity ${ }_{1} /$ Performativity $y_{2}$. In B. Fraser \& K. Turner (Eds.), Language in life, and life in language: Jacob Mey - a festschrift (pp. 307-312). Studies in Pragmatics 6. Emerald Group Publishing Ltd. https://doi.org/ 10.1163/9789004253209_039

de Morais, R. G. (2015). Listening and analysis of mixed electroacoustic music as tools for interpretation's construction. International Journal of Music and Performing Arts, 3(2), 7-18. http://ijmpa.com/journals/ijmpa/Vol_3_No_2_ December_2015/2.pdf 
Morrison, M. (2019). Race, blacksound, and the (re)making of musicological discourse. Journal of the American Musicological Society, 72(3), 781-823. https:// doi.org/10.1525/jams.2019.72.3.781

Moseley, R. (2015). Digital analogies: The keyboard as field of musical play. Journal of the American Musicological Society, 68(1), 151-227. https://doi.org/10.1525/ jams.2015.68.1.151

Mukherjee, M. (2017). Educating the heart and the mind: Conceptualizing inclusive pedagogy for sustainable development. Educational Philosophy and Theory 49(5), 531-549. https://doi.org/10.1080/00131857.2016.1185002

Munday, I. (2010). Improvisation in the disorders of desire: Performativity, passion and moral education. Ethics and Education, 5(3), 281-297. https://doi.org/10.108o/ 17449642.2010 .533469

Musser, J. (2019). Carl Czerny's mechanical reproductions. Journal of the American Musicological Society, 72(2), 363-429. https://doi.org/10.1525/jams.2019.72.2.363

Nussbaum, M. C. (2001). Upheavals of thought: The intelligence of emotions. Cambridge University Press. https://www.amazon.com

Parker, A. \& Sedgwick, E. K. (1995). Introduction: performativity and performance. In A. Parker \& E. K. Sedgwick (Eds.), Performativity and performance (pp. 1-18). Routledge.

Perelman, C. \& Olbrechts-Tyteca, L. (1969). The new rhetoric: A treatise on argumentation. University of Notre Dame Press. https://www.amazon.com

Potolsky, M. (2006). Mimesis (The new critical idiom). Taylor and Francis. https://www.amazon.com

Potter, J. (2001). Wittgenstein and Austin. In M. Wetherell, S. Taylor \& S. Yates (Eds.), Discourse theory and practice: A reader (pp. 39-46). Sage Publications. https://www.academia.edu/2601295/Wittgenstein_and_Austin

Priest, G. (2000). Logic: A very short introduction. Oxford University Press. https://www.amazon.com

Reinelt, J. (2002). The politics of discourse: Performativity meets theatricality. SubStance, 31(2/3). [Issue 98/99: Special Issue: Theatricality, 201-215]. https://www.jstor.org/stable/3685486

Rindom, D. (2019). Celluloid diva: Staging Leoncavallo's Zazà in the cinematic age. Journal of the Royal Musical Association, 144(2), 287-321. https://doi.org/10.1080/ 02690403.2019.1651515

Rivers, N. A. \& Weber, R. P. (2011). Ecological, pedagogical, public rhetoric. College Composition and Communication, 3(2), 187-218. https://www.jstor.org/ stable/23131582

Robin, W. (2018). Balance problems: Neoliberalism and new music in the American university and ensemble. Journal of the American Musicological Society, 71(3), 749-793. https://doi.org/10.1525/jams.2018.71.3.749 
Rogoff, I. (2003). From criticism to critique to criticality. https://transversal.at/ transversal/o8o6/rogoffi/en

Rogoff, I. (2006). "Smuggling" - an embodied criticality. https://xenopraxis.net/ readings/rogoff_smuggling.pdf

Rolfhamre, R. (2014). Dissecting transformation: Towards a biology of recorded lute sound. Studia Musicologica Norvegica, 40, 43-62.

Rolfhamre, R. (2018). Caprice de chaconne (1671): Symmetry and proportions in Francesco Corbetta's work for baroque guitar. Early Modern Culture Online, 4(1). https://boap.uib.no/index.php/emco/article/view/1513/1285

Rolfhamre, R. (2020). Through the eyes of an entangled teacher: When classical musical instrument performance tuition in higher education is subject to quality assurance. Action, Criticism, and Theory for Music Education, 19(1), 81-117. http:// act.maydaygroup.org/articles/Rolfhamre19_1.pdf

Romero, S. O. (2019). Ghosts in the machine and other tales around a "marvelous invention": Player pianos in Latin America in the early twentieth century. Journal of the American Musicological Society, 72(1), 1-42. https://doi.org/10.1525/ jams.2019.72.1.1

Rueger, A. (2011). Aesthetics. In D. M. Clarke \& C. Wilson (Eds.), The Oxford handbook of philosophy in early modern Europe (pp. 201-223). Oxford University Press.

Ruitenberg, C. W. (2007). Discourse, theatrical performance, agency: The analytic force of "performativity" in education. Philosophy of Education Archive, 260-268. https://www.researchgate.net/publication/274392718_Discourse_theatrical_ performance_agency_The_analytic_force_of_performativity_in_education

Rumph, S. (2015). Fauré and the effable: Theatricality, reflection, and semiosis in the melodies. Journal of the American Musicological Society, 68(3), 497-558. https:// doi.org/10.1525/jams.2015.68.3.497

Salih, S. (2007). On Judith Butler and performativity. Sexualities and Communication, 1, 55-68. http://citeseerx.ist.psu.edu/viewdoc/download? doi=10.1.1.527.8862\&rep=rep1\&type $=$ pdf

Saltzstein, J. (2017). Rape and repentance in two medieval motets. Journal of the American Musicological Society, 7o(3), 583-616. https://doi.org/10.1525/jams. 2017.70.3.583

Saltzstein, J. (2019). Songs of nature in medieval northern France: Landscape, identity, and environment. Journal of the American Musicological Society, 72(1), 115-180. https://doi.org/10.1525/jams.2019.72.1.115

Schuiling, F. (2019). Notation cultures: Towards an ethnomusicology of notation. Journal of the Royal Musical Association, 144(2), 429-458. https://doi.org/10.1080/ 02690403.2019.1651508 
Scott, D. B. (2003). From the erotic to the demonic: On critical musicology. Oxford University Press.

Shelley, B. D. (2019). Analyzing gospel. Journal of the American Musicological Society, 72(1), 181-243. https://doi.org/10.1525/jams.2019.72.1.181

Sim, S. \& van Loon, B. (2012). Introducing critical theory: A graphic guide. Icon.

Slater, M. (2016). Locating project studios and studio projects. Journal of the Royal Musical Association, 141(1), 167-202. https://doi.org/10.1080/02690403.2016.1151241

Sloterdijk, P. (2017). The aesthetic imperative: Writings on art (K. Margolis, Trans.; P. Weibel, Ed.). Polity Press. https://www.amazon.com

Small, C. (1998). Musicking: The meanings of performing and listening. Wesleyan University Press. https://www.amazon.com

Sommerfeldt, S. C., Caine, V. \& Molzahn, A. (2014). Considering performativity and methodology and phenomena. Forum: Qualitative Social Research, 15(2). http://dx.doi.org/10.17169/fqs-15.2.2108

Spohr, A. (2019). "Mohr und trompeter": Blackness and social status in early modern Germany. Journal of the American Musicological Society, 72(3), 613-663. https://doi.org/10.1525/jams.2019.72.3.613

Srinivasan, A. (2018). The ineffable and the ethical. Philosophy and Phenomenological Research, 96(1), 215-223. http://doi.org/10.1111/phpr.12484

Srinivasan, A. (n.d.). The political limits of compassion. http://users.ox.ac.uk/ corp1468/Research_files/Nussbaum\%20-\%2opolitical\%2oemotions\%2opaper_ Palgrave.pdf

Summers, T. (2015). "Sparks of meaning": Comics, music and Alan Moore. Journal of the Royal Musical Association, 140(1), 121-162. https://doi.org/10.1080/02690403. 2015.1008865

Sutton, R. \& Douglas, K. (2013). Social psychology. Palgrave Macmillan.

Thurman, K. (2019). Performing Lieder, hearing race: Debating blackness, whiteness, and German identity in interwar central Europe. Journal of the American Musicological Society, 72(3), 825-865. https://doi.org/10.1525/jams.2019.72.3.825

Toye, R. (2013). Rhetoric: A very short introduction. Oxford University Press. https:// www.amazon.com

Utdanningsdirektoratet. (2020). Nasjonale prøver. https://www.udir.no/eksamen-ogprover/prover/nasjonale-prover/

Vandagriff, R. S. (2017). Perspectives and the patron: Paul Fromm, Benjamin Boretz and perspectives of new music. Journal of the Royal Musical Association, 142(2), 327-365. https://doi.org/10.1080/02690403.2017.1361175

Valiquet, P. (2019). Remediating modernism: On the digital ends of Montreal's electroacoustic tradition. Journal of the Royal Musical Association, 144(1), 157-189. https://doi.org/10.1080/02690403.2019.1575593 
Venn, E. (2015). Thomas Adès and the spectres of Brahms. Journal of the Royal Musical Association, 140(1), 163-212. https://doi.org/10.1080/02690403.2015.1008867

Weaver, A. H. (2017). Memories spoken and unspoken: Hearing the narrative voice in dichterliebe. Journal of the Royal Musical Association, 142(1), 31-67. https://doi. org/10.1080/02690403.2015.1008867

Williams, A. (2001). Constructing musicology. Ashgate.

Williams, S. (2016). Interpretation and performance practice in realizing Stockhausen's Studie II. Journal of the Royal Musical Association, 141(2), pp. 445-481. https://doi.org/10.1080/02690403.2016.1216059

Wolfe, J. (2013). "The ordinary” in Stanley Cavell and Jacques Derrida. Minerva: An Internet Journal of Philosophy, 17, 250-268. https://pdfs.semanticscholar.org/82fb/ c66f 49046366 c67a216f15713b438od706c6.pdf

Zanovello, G. (2016). "You will take this sacred book": The musical strambotto as a learned gift. Journal of the Royal Musical Association, 141(1), 1-26. https://doi.org/ 10.1080/02690403.2016.1151230 



\title{
Contextual In-Depth Knowledge as a Liberating Force in Artistic and Pedagogical Communication of Early Modern Material
}

\author{
Inga Marie Nesmann-Aas \\ Research Fellow, University of Agder
}

\begin{abstract}
How are essential parts of early modern material communicated in our present-day context? This chapter addresses the issue of how the historical is expressed in artistic contexts, and presents examples showing that this also applies in a pedagogical context. The argument asserts that in-depth study and knowledge result in greater freedom when making informed choices in relation to the material itself, and communicating it to students and audiences. Through various historical sources, in-depth analysis of text structure, rhetoric, and early modern references, this chapter presents a possible way forward. The case used is Henry Purcell's Dido and Aeneas, with libretto by Nahum Tate. This work is part of a larger whole in the author's doctoral dissertation. For the first time, a topomorphological analysis of the opera is presented, shedding light on rhetorical structures within the work, thus adding fascinating layers of meaning to the understanding of it. Using this material in pedagogical and artistic work expands the potential for interpretation. Bridging the gap between theory and practise enables us to access both a deeper and wider foundation for our pedagogical and artistic communication of early modern material.
\end{abstract}

Keywords: early modern, topomorphology, artistic and pedagogical communication, artistic integrity

Citation: Nesmann-Aas, I. M. (2022). Contextual in-depth knowledge as a liberating force in artistic and pedagogical communication of early modern material. In R. Rolfhamre \& E. Angelo (Eds.), Views on early music as representation: Invitations, congruity, performance (MusPed:Research No. 4, Ch. 3 , pp. 97-118). Cappelen Damm Akademisk. https://doi.org/10.23865/noasp.157.ch3

Licens: CC BY-NC-ND 4.0 


\section{Introduction}

How do we experience the historical? Some would even say: Is it at all possible to encounter and learn about historical art and performance? This chapter addresses the issue of how we express the historical in artistic and pedagogical contexts. Starting with the question of the historical, employing in-depth analysis and central examples, I wish to lead the way towards a well-informed, embodied approach to artistic freedom and ways of learning.

Understanding historical material is always a complex issue. Philosophical questions regarding the possibility of ever approaching any material outside our own context, reality and time in history, cannot be entirely rejected without contemplation. However, such a point of view opposes the premise of historical musicology. Approaching the material completely out of its original context is not an alternative if we wish to relate to the historical part of this field of study. Traditionally, this has been based on a search for "authenticity" in historically informed performance, HIP. ${ }^{1}$ However, authenticity is a problematic term and fallacy in itself, since the possibility of a truthful, authentic experience of the historical can never exist without also belonging to our present-day context and experience. Therefore, the fields of historical musicology and early modern ${ }^{2}$ performance need to move beyond this, towards a "post-historically-informed" era (Friman, 2008). ${ }^{3}$ Working within the fields of historical musicology and early modern music and text, history and context themselves become important angles of approach. In my experience as a performer and teacher, this also enriches my understanding, imagination and potential in terms of interpretation and immersing myself in

1 Historically Informed Performance, HIP, is a term originating with the movement that started with Christopher Hogwood, founder of Early Music Consort (1967) and later the Academy of Ancient Music. The movement, spanning over five decades, focuses on a quest for authenticity in the performance of Early Music (Rile, 2014).

2 The term early modern is a general term often used in historical and literary contexts, but it is also applicable to historical music. It generally covers the period spanning from the 15 th to the 18th century, making it a useful term in covering periods from the late Medieval, Renaissance, Baroque and Classical eras.

Term first found in the PhD dissertation of Anna Maria Friman, in which she defines the performance practice of Trio Mediæval as a part of a "post-historically-informed" era (Friman, 2008, p. 125). 
the musical and textual artistic experience. My doctoral dissertation is entitled "Reconfiguring Dido: A Practical and Theoretical Investigation of the Changing Musical and Literary Representations of Dido, Queen of Carthage as the Basis for Character Interpretation in Henry Purcell's Opera Dido and Aeneas". This opera is a central work of its era, and I have been interested in it musically, and in terms of its content and literary references, for a long time. It is also a well-suited point of departure as an example of my approach and combined methodology. The focus of this chapter is in line with my dissertation project and an essential part of the premise of my studies, combining literary analysis, historicalmusicological approaches and modern performance practise with a multisensorial, spatial and embodied approach to performance integrity and artistic communication. The overall aim is to illustrate through examples how combining these approaches lays the groundwork for well-informed choices supporting an embodied understanding, resulting in artistic freedom and better communication. This is relevant for performers, students and teachers, as well as researchers within related fields, encouraging a wider perspective and more integrated views on these topics.

This chapter will elucidate the process of in-depth study of sources and analysis of the material, and some of its contexts as a knowledge base for artistic integrity. ${ }^{4}$ This, in turn, is also highly applicable to the pedagogical process of teaching historical material, and communicating it in a meaningful manner through an open-minded dialogue with students. Limited by the scope of this chapter and the nature of my approach, there is little room for a deeper focus on more specific pedagogical discourse. My goal here is to show how this approach is also highly relevant and applicable in a music pedagogical context, and I will thus refer to this when relevant throughout the text.

The research process will be demonstrated through a topomorphological analysis 5 of the overall structure of the opera Dido and Aeneas

\footnotetext{
4 The term artistic integrity refers to the competence, experience and understanding that a performer personifies, and this is strengthened through well-founded choices, enabling the performer to "stand one's ground" in explaining one's artistic choices in terms of performance and interpretation. I see this as a liberating force providing both humility, confidence and artistic freedom resulting in a better communication.

Term explained in the context of analysis later in this article.
} 
from around 1689, composed by Henry Purcell with a libretto by Nahum Tate. The same analytical approach will delve deeper into the aria "Dido's Lament". Further, I will combine this with analyses of structures and key signatures, to name a few examples. In accordance with current knowledge from historical research on the work's time of origin, I will explain some possible interconnections, interpretations and inspiration for an embodied artistic approach to the material. Methodologically, I have worked for some time with this material from a literary perspective, drawing on the competence gained from my Master's in English literature. I have also utilised a similar approach in both my Master theses, in English and music. This has now been further developed and widened methodologically in my $\mathrm{PhD}$ work, based on detailed reading, personal experience in singing, working with the material creatively, and a combination of all these methods. This can have clear implications for performers and pedagogues. Thus, the discussion in this chapter will explore some pathways towards finding new, meaningful ways of studying and approaching the artistic and pedagogical experience of the opera Dido and Aeneas.

\section{Past and present: A meaningful dialogue?}

As an artist approaching historical material wishing to immerse oneself and perform the music, there can be many choices in relation to material, context and primary sources. However, the foundational knowledge for making good choices is not always present, and because it is time consuming and may seem dreary and less important, it is often the case that performers wish to be told what to do and given the material they are to work with. Choices are often not made consciously, or rather made by others, such as coaches, conductors, or based on a performance tradition already established as mainstream and acceptable. Support for the fact that such ideas are prevalent in the world of classical music and should be challenged is found, among others, in Austbø (2018) and Friman (2008).

I argue that there is a lot to be gained from doing the work oneself as a performer. Through my case study of Dido and Aeneas I will present the main aspects of the process of studying primary and secondary 
sources, adding contextual historical knowledge, and combining this with an artistic sensibility, so as to build a solid foundation of knowledge for one's artistic choices. The essence of my argument is based on the premise that the integrity and ethics of informed choices lead to more complex and interesting artistic communication. The artist will also be prepared to stand one's ground and defend the artistic interpretation if challenged, and such integrity and independence of artistry is needed in the field of classical music in general and, more specifically, in early modern music. In the essay "On Quality in Musical Performances” [My translation, Norwegian title: “Om kvalitet i musikalske fremføringer”], Håkon Austbø discusses the challenge of traditional approaches to performance in classical music competitions. The measurable and objective criteria of accurate interpretation of the notated music with impeccable technique, following tradition and style, being in line with the composer's intent and displaying knowledge of the work's structure, are all favoured over a personal and unique interpretation (Austbø, 2018). He goes on to claim that there is often a price to be paid for being unique and presenting a personal interpretation. He sees this as a problem, as the survival and renewal of classical music depends on development and not just conservation. Leaning on tradition and objective criteria does little to promote a genuine and living artistic practise. As Nina Sun Eidsheim points out in her article "Sensing Voice":

What is familiar to those who study Western music is that which can be written down. Common methods of musical representation and analysis evidence Western culture's preoccupation with what notation can capture and preserve. [...] Consequently, the abstractly yet fixedly notated overshadows the concrete, ever-shifting experience of music. (Eidsheim, 2011, p. 134)

The point that the objective, notated and measurable dominate the musical experience, and that this fact must be challenged, might seem counter-intuitive to my case for studying material in detail. My argument is precisely that following tradition does not lead to renewal, however renewal will not stand its ground against high status and widespread tradition unless it is well founded. This foundation is built both through meaningful dialogue with the historical past and in embodied interaction 
with the material in our present-day context. In her article, Eidsheim displays these two perspectives as opposing each other:

In vocal studies, this orientation plays out as a privileging of dramatic, structural and semiotic content (libretto, score), and sociohistorical context over the distinct quality, or timbre, of each individual voice in each performance of each work. Generally, Western music studies favor the idealized and abstract at the expense of the sensible, unrepeatable experience. (Eidsheim, 2011, p. 134)

I do not agree that there must necessarily be an opposition between the two. As previously stated, to renew the field one must have the integrity and ethos to be in dialogue with the past, while at the same time be aware, not to say, proud, of one's artistic uniqueness and interpretation. I fully endorse the multisensory approach favoured by Eidsheim, but in addition, I also see an inspiring potential in the unpredictable and unknown landscape in the intersection between the historical past, the performative present, and future artistic potential. To me, perspectives of content and context of historical material, and multisensorial, interpretative and unique performative artistic expression activate each other and result in greater artistic power and communication.

\section{Historical sources: Do they matter?}

In relation to Dido and Aeneas, when choosing a source for the musical and textual material, there are many factors to consider. It is not usual for performers to seek out all possible editions, prints and original sources of the score. At best, one seeks to find a critical score where the editor has done a thorough job. But there is often more than one version out there. How do you choose? And on what basis do you choose? The job of reviewing all available scores, and the research and researchers behind the work is a daunting task. Choosing the seemingly most acknowledged one, the more widespread one, or the one that sounds more definite (not leaving too many demanding choices) is tempting. In my work with various scores of Dido and Aeneas, it is clear that a score named "Norton Critical Scores", "an authoritative score", sounds well researched and 
definite. The status of the publisher and editor is clear. However, I have delved into discussions of the research on this opera, and find that there is some debate among acknowledged scholars. Curtis Price (Purcell, 1986), Ellen Harris (Purcell, 1987), William H. Cummings (Purcell, 1995) and Margaret Laurie (Purcell, 1974) are all renowned, and to choose between editions edited by any one of them requires an in-depth understanding of their points of view on controversial issues, in terms of historical research on the opera, and the various manuscripts and original sources in existence.

The whole issue of finding the most "authentic" original version builds on the premise that there is one definite, original and authoritative version out there, defined sometime in the 1680 s by Henry Purcell and Nahum Tate, and that the ultimate goal for any work with this opera and performance thereof, should do the "work" justice. This classical romantic idea of the "work" (Goehr, 2007) and performance is increasingly challenged in today's world of classical music and opera, but the traditional approach is deeply embedded in tradition and culture and is still a given, although it is sometimes somewhat expanded.

A discussion of historical evidence shows that there are many good reasons for challenging the classical tradition in terms of work interpretation. There is an intimate and very interesting connection between acquiring knowledge embedded in the material itself, and the social, political and cultural context from which it came into being. The freedom of understanding and integrating the material on many levels can lead to meaningful artistic interpretation for performer and audience.

Tanja Orning, at the time of her postdoc at the Norwegian Academy of Music, states that "styles of the past are in themselves emptied of meaning" (Orning, 2018, p. 2, my translation). ${ }^{6}$ I strongly disagree with this statement.

6 Original Norwegian full quote: "Musikksosiologen Theodor Adorno beskrev materiale som noe som er i stadig dialog med historien og den sosiale konteksten. Samfunnet reflekteres implisitt i materialet fordi det filtreres gjennom komponistens erfaringer, og på denne måten vil materialet alltid ha en historisk dimensjon. I dette perspektivet er tidligere tiders stiler isolert sett tømt for mening. Et senromantisk tonedikt eller en sonate i neoklassisk stil skrevet i dag, kan være ypperlig utført stilistisk, men hvilken estetisk verdi det har for oss, er et annet spørsmål. Slike stiløvelser vil i ytterste konsekvens forbli kun stiløvelser fordi de ikke bringer inn en dialog med samtiden" (Orning, 2018, p. 2). 
She explains that this is because styles of the past are not in dialogue with society today. In my opinion, her approach focuses on the "work" as a composition on a piece of paper, not the experience of music as it is performed. The performer is an artist communicating with the past in working with and performing the music. The audience is a part of this multisensorial experience of music performance, both parts being at once in the present and in dialogue with the past. I find this to be true of music of various styles from different times throughout history. Thus, this is a premise of my reason for engaging in a dialogue with historical material.

It is clear that the field of historical musicology focuses in large part on facts and details. Being able to document original manuscripts, first performances, performers, conductors, conventions of performance, playing technique, and so on, is important in that it sheds light on the context of the material we have today. However, this discussion can become immensely detailed, and building arguments to support a claim, theory or idea based on the knowledge we possess today can become a neverending debate. This seems like discussion for its own sake. In my opinion, it is important to connect theoretical discussion to performance practise. But this is not a common practise everywhere. The gap between the field of musicology and performers is well established through, for example, Anna Maria Friman's dissertation “Modern Performance of Sacred Medieval Music with Particular Reference to Women's Voices" (2008), in which the research shows that there is not much communication between musicologists and performers in the field of early music. In an interview with musicologist Susan Boynton, Boynton makes the point that musicologists have the freedom to speculate without having to make definite decisions. This liberty is in contrast to performers, who have to decide when they perform (Friman, 2008, pp. 113-114). Although approaching the material, as well as purpose, for musicologists and performers are naturally different, I truly believe that understanding each other's perspective, and learning from each other's practise, can result in more meaningful research and more well-informed and creative artistic practise. There are already examples of successful collaboration between scholars and performers, however, I wish to make this more mainstream and embedded in music education and performance practice. 
"The knowledge the performers bring to their performances creates freedom and enhances their feelings of non-confinement, and that freedom opens up the creative process through which music can happen in an unrestrictive way" (Friman, 2008, p. 131). This quote is powerful in that is encompasses the ontological premise for my overall argument. Friman boldly states that knowledge leads to freedom, non-confinement and creativity for the performers. And she bases this on empirical data from her $\mathrm{PhD}$ research on her own performance, and from interviews with internationally renowned performers of medieval music, as well as established musicologists within the field. What this knowledge encompasses is different for each performer, but as I will show, a lot of knowledge is freeing rather than restricting, in terms of a creative and free performance.

The idea of historically informed performance, HIP, has since the start been almost obsessed with notions of authenticity: the premise of an authoritative original source in order to find the ideal performance with regard to how the original composer and listener might have defined it. As this goal is impossible no matter how you approach it, the premise is false and results in a restricted view, a museum-like approach, not at all in line with artistic creativity. However, historical context reveals an enormous amount of information about how the composers, writers, performers and audiences viewed the work and how they approached it. This knowledge supplies us with new ideas, possible interpretations and approaches, where there is not a definite right or wrong, but where the goal is for the work to be performed and experienced in a meaningful artistic manner for all involved. In this context, it is also highly relevant to include parameters such as modern or period instruments, baroque or modern pitch, use of vibrato and ornamentation, to name some relevant elements. An extensive investigation into such choices is important, but not the focus of this chapter. However, I find it necessary to mention this, and further discussions will be included in my $\mathrm{PhD}$ dissertation.

In both Harris (2018) and Price (1984), to name a couple of authoritative sources, there is a detailed account and discussion of surviving sources of librettos and scores of Dido and Aeneas. "The state of the surviving sources of Dido and Aeneas is the most deplorable of any of Purcell's 
major stage works" (Price, 1984, p. 239). The only source from 1689 (?) is Tate's printed libretto including the prologue. However, the earliest surviving score is the Tenbury score MS1266 dating from 1750, lacking both the prologue and the chorus at the end of Act II. Without going into a detailed discussion of the variations and discrepancies between various surviving sources, it is clear that choices have to be made if the opera is to be performed. What sources to trust and what to do with missing sections are all important to consider. The debate among musicologists has been going on for decades, and we are left with several possible solutions, most of them argued by some to be the most historically correct. But again, the premise of seeking out an authoritative "authentic" version is perhaps not the most historically informed way of approaching the issue at hand, anyway.

Some of the missing sections in the preserved manuscripts have been "filled in" through different means at different times and contexts. In part three of her book, Harris (2018) writes about the performance history of the opera. Many alterations, variations, extensions and other changes and additions have been performed throughout history. They are products of their time, and in hindsight, many are considered to be "unhistorical", far from the original and out of genre and style. Discussions on issues like these go deep into music philosophy and concepts of "authenticity". I do not wish to be considered a purist, as my point of view is that interpretation and recontextualisation of a work will always be the only way to perform it, as it is impossible to truthfully recreate the past. However, the issue of how far away from the "work" we can go before it becomes a new work, is an interesting philosophical issue, with somewhat fuzzy logic. As Eidsheim states in relation to the recognition of various genres of music:

Musical genres are generally recognized within a few seconds, based on timbre: If the formal parameters of a genre are fulfilled but the timbral aspects are not, the status and intactness of the work in a particular instantiation - that is, the extent to which the work remains itself -are called into question. (Eidsheim, 2015, loc. 2883-2885)

Purcell's Dido and Aeneas as a musical genre and musical work is recognised, among other parameters, by its timbre. If, for example, the 
melody and text remain intact, but the instrumentation, style, vocal technique, etc. are altered, does the work remain itself? There are several interesting and, in my opinion, beautiful new, modern versions of, for example, “Dido's Lament”. The melody is mainly the same, but the timbral aspects are altered. In my view, this represents something new in the sense that the extent to which the work remains itself is called into question. This means that it is, to a greater extent, something new based on historical material, rather than actually being historical music. And the difference is crucial when working within the field of early modern music, as the historical is the premise, even though we recontextualise it and make it meaningful as an artistic expression and communication in our own time.

\section{A historical case for appropriation and recontextualisation}

As far back as 1700, opera Dido and Aeneas was included as an allegorical play-within-the-play in Gildon's adaptation of Shakespeare's Measure for Measure. This version was based on both Shakespeare's original and Davenant's reworking of the play from 1662. Rewriting famous plays was a common practise in seventeenth-century England, some reworkings being more popular than others. The opera was divided into four sections and placed between acts as a commentary on the plot and an allegory for the characters, being displayed for them onstage, so the opera became a part of the play, not just a musical interlude. This reveals the opera in a new light, adding layers of interpretation. As Price puts it:

7 I would love to give several examples of this with analysis and comparisons, but it would be a step aside with regards to the focus and frame of this article, so it must be left for later publications. However, here are some links to examples on YouTube in terms of timbral and visual alterations and new interpretations:

Jeff Buckley: https://www.youtube.com/watch?v=sA5UAbliOWY

Annie Lennox and London City Voices: https://www.youtube.com/watch?v=f3DFaIovZxc

Allison Moyet: https://www.youtube.com/watch?v=8EIrvGro3n8

Director Andrew Ondrejcak with trans and queer lip-sync: https://www.youtube.com/watch? $\mathrm{v}=8$ EIrvGro3n 8 
Purists may view the joining of the opera and play as a misguided conflation that saps the lifeblood of each, but I think the union provides a valuable, if indirect, insight into how the composer's near contemporaries may have interpreted the troublesome ambiguities surrounding Aeneas. (Price, 1984, p. 238)

Drawing on this argument, seeing the near contemporaries' treatment and interpretation of the material should also inspire us to be bolder in our recontextualisation. If they found it natural to adapt, edit and employ plays, operas, songs and poems in new contexts in order to become meaningful new artistic performances, why shouldn't we?

Another good example following a similar train of thought, is the issue of the missing dances. In various libretto and score sources, up to eleven dances are mentioned. However, in the oldest and most complete score in existence, there are only four dances specified in the musical score (Harris, 2018). However, Harris argues through historical references on performance conventions of the time, that several dances can be "hidden" in the score, for example through repetition of a choral movement or improvised, conjoined with the preceding music. And references in the libretto of two dances for guitar were almost certainly improvised. That is the reason for them not being notated in the score. They are both based on a repeating bass pattern, a chaconne and a ground, and such guitar pieces were common knowledge in terms of improvisation at the time (Harris, 2018, pp. 76-81). This attitude towards improvisation should remind us that improvisation was a natural and embedded practise and thus a part of the composition. What we can learn from this, is that we should adopt a similar attitude in recreating and performing this work. It is a collaborative practise and is created through the performance. At the same time, I would like to mention that in order to maintain the timbre of the opera, the nature of improvisation should be musically and stylistically in line with the notated score.

\section{Music and rhetoric}

Moving on to musical and textual analysis, it is clear that an in-depth study and knowledge of the musical and textual material reveal the intimate interconnection between music and text. It will suffice here to 
present some central examples. To begin with, the relationship between key signatures, characters and plot is an intricate one, on many levels.

From the beginning of the sixteenth century musicians tried to rekindle the Classical ties between rhetoric and music, and several late Renaissance theorists wrote at length about the different emotional qualities of the modes. In Purcell's time these ideas were taken up again, perhaps most passionately by Johann Mattheson of Hamburg. In Das neu-eröffnete Orchestre (1713), he attempts to broaden the doctrine of the affects to include tonality. [...] Purcell did not leave us with such a catalogue. But he did use certain keys in the theatre music with remarkable consistency. (Price, 1984, p. 22)

This foundation in classical rhetoric in relation to music is also central to my argument regarding textual analysis and topomorphology, to which I will return later on. But related to the music in Dido and Aeneas, there are manifold representations of these consistent uses of key signatures in line with Purcell's compositional style. Some of these typical collocations are also common among his predecessors and contemporaries, according to Price (1984, p. 23). The most obvious example is "Dido's Lament" in G minor, and Price states that this key signature had a traditional association with death for at least two generations of English theatre composers. Another important feature is that Dido as a character is always in tune with the established tonality of the scene, whereas Aeneas rarely is. This expresses his intrusion into her established life, and hints musically that he has not come to stay; he does not fit in. In addition, Price establishes the idea that a tonality, seemingly at variance with the usual scheme, can presage an otherwise unexpected horrific event (Price, 1984, p. 23). For more examples, see Figure 1 below.

An important premise in working with historical texts is that the texts are understandable and possible to interpret. As Roy Eriksen and Peter Young emphasise in Approaches to the Text (2014), historical texts communicate across time. "That there should be a division between these [historical texts from different times in history] causing communication break-down and preventing knowledge transfer is ahistorical and a fabrication of the biased mind" (Eriksen \& Young, 2014, p. 10). At the same time, it takes great effort to truly interact with historical texts, 
and the manner of studying them is also a historical and traditional practise.

Careful and philological study and explication de texte are indispensable tools when tackling texts that are no longer immediately open to be processed and digested by many scholars or the general reader. Patient and meticulous examination of the texts and the conventions and contexts that shaped them is to a large extent the fruit of the rigorous methods developed by Early Modern Humanists in their studies of the extant exemplars of the ancient world, texts both spiritual and secular. (Eriksen \& Young, 2014, p. 10)

Combining these perspectives, namely meticulous studying and believing in the possibility of communication and knowledge transfer between texts of the past and our own time, the premise is established for a meaningful dialogue across history. This can result in new and creative perspectives based on old ones, and further, in meaningful artistic interpretation and communication. One such detailed and rigorous method of study is topomorphological analysis.

The method entails studying the design and distribution of topoi (that is "places" and "themes") within the structure (morphê) of a text - hence topomorphology. In other words, in the analysis of written compositions topomorphology considers the spatial relationships and the shape of segments within a text as an aid to interpretation [...]. (Eriksen, 2001, p. xiv)

Through topomorphology, layers of meaning embedded by the author in the textual structures can be revealed. It is based on classical rhetoric, and it is evident that this manner of structure was pervasive in early modern writing. I have also found evidence of such structures in Tate's libretto for Dido and Aeneas. As such analysis of the textual material has not been previously applied, this is also one of my new contributions to historical-musicological research on this material. My interest in such analysis is not only for its own sake, although the knowledge revealed is fascinating in itself. The goal is always to apply it in a performance context in our own time. 
In Figure 1, below, the macro level of the topomorphological structure of the opera is illustrated. Due to the limitations of the present text, some central examples must suffice. A detailed and more extensive analysis will be material for my upcoming $\mathrm{PhD}$ dissertation. A central element is the continuous repetition of the word "fate" in the libretto, appearing at central points throughout the plot. Fate, or destiny, is in many ways the essence of the opera, but most of all, the essence of the character Dido. It is the very last word of her emotional aria at the end of the opera. Being aware of such structures and the importance of rhetorical and topomorphological devices in early modern times, reveals layers of meaning that can add to our interpretation today. We are not governed by these structures, as I see it. On the contrary, they are an aid in finding new interpretations through a dialogue with the past. Adding layers of knowledge and understanding is empowering, in that all the choices we unconsciously make in studying and performing are brought to the fore. As a performer, then, it is now natural to make conscious choices based on a combination of extensive knowledge and artistic sensibility. And I argue that this results in a performance with integrity and artistry, communicating with the audience. And, in extension, it is an important foundation for teaching and guiding students in manoeuvring such historical material, be it in theoretical or practical studies.

In many ways structured as a classical Aristotelian tragedy, the action and development progress with a clear structure, reflected in both libretto and music. Another centrally placed and repeated word is "flame". In Act I it represents Dido's love and desire, in Acts II and III it refers to Carthage going up in flames as the witches plot the destruction of Queen Dido and her kingdom. At the end of Act III it refers to Dido's death. Layers of meaning in central words like these are rhetorical devices intentionally embedded to support structure and affect us on a subliminal level, as well as being explicitly apparent. They also function as foreshadowing on a subtle level, as multiple meanings of the same word portend upcoming events. More examples are illustrated here in Figure 1. All related incidents and topics are colour coordinated, so that the connections will be as clear as possible. 


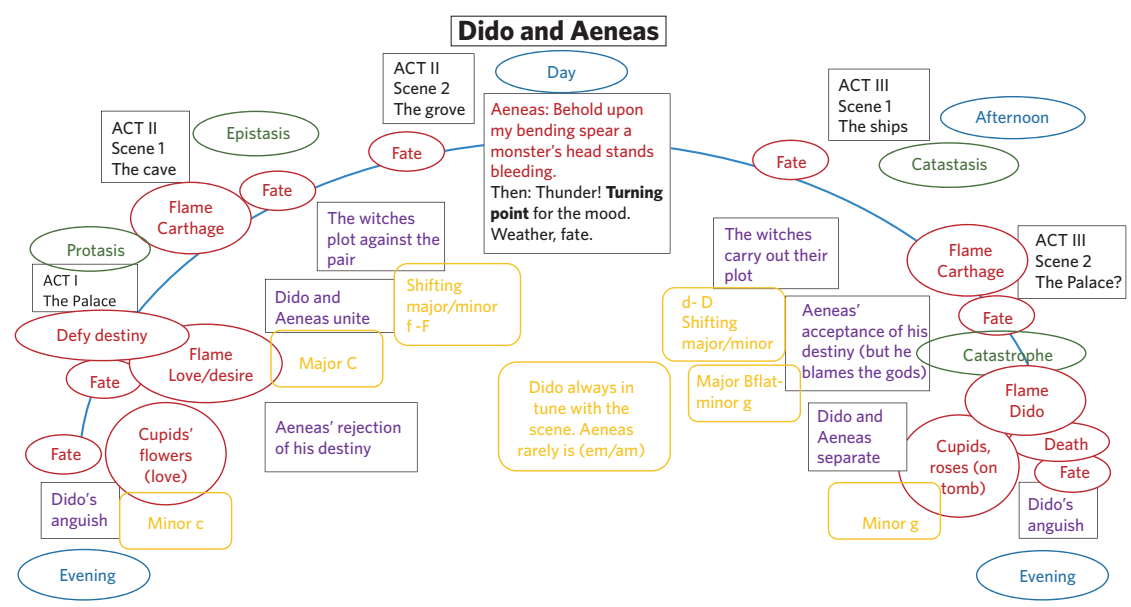

Figure 1. Dido and Aeneas: Illustrated Topomorphological Macrostructure (my own illustration)

As mentioned, structures are found on macro, meso and micro levels in the libretto and music. I will present a more detailed approach through a similar analysis of "Dido's Lament", her final aria when she dies at the end of the opera:

Thy hand, Belinda, darkness shades me,

On thy Bosom let me rest,

More I wou'd but Death invades me.

Death is now a Welcom[sic] Guest,

When I am laid in Earth [may] my wrongs Create

No trouble in thy Breast

Remember me, but ah! Forget my Fate.

The colour coding is not symbolic, but purely a practical matter to represent different effects. The colours illustrate important structures that are purposefully distributed in the poetic lines, in order to create a structure that can influence from an explicit to a subliminal level. The purple words refer to Dido herself, the subject of the text. With all these repetitions and references to herself in this short text, it is evident that she is the focal point throughout the text. Green refers to the synonyms breast and bosom and occurs in a circular mirrored pattern. The red words are all the repetitions of death, beginning with death as an invasion, moving towards acceptance. 
This is ordered in a chiastic centripetal structure, a symmetric, circular pattern. The brown words are synonyms for errors, problems and their consequences. The grey words are centripetal, meaning that they are in the very middle, and deal with Dido being at peace with her fate. The blue words are clear antitheses, opposites. All these rhetorical devices are well-known structures, emphasising the message and strengthening the emotional nerve of the aria. The last word, fate, is marked in yellow. Fate is a central word throughout the plot and distributed evenly and at central points in the libretto, as shown in Figure 1. It is very fitting that this is Dido's very last word. An illustration of these same points is found in Figure 2.

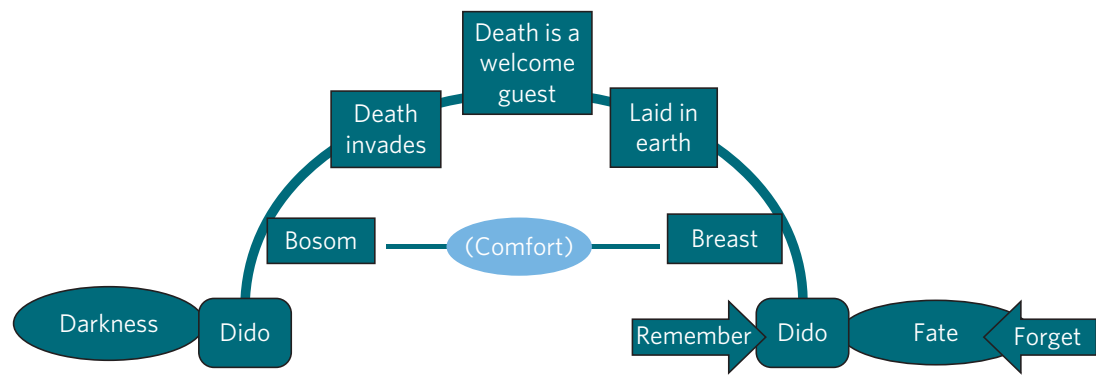

Figure 2. Dido's Lament: Illustrated Topomorhological Structure (my own illustration)

An analysis such as this provides the singer with a very detailed structure of the poetic message in the text. I note that these textual focal points are in line with the musical phrasing and accompaniment. "Dido's Lament" in $\mathrm{G}$ minor is structured around a ground bass pattern, and in addition it is one of very few vocal pieces with independent string accompaniment. The ground bass pattern is made up of a descending tetrachord but has distinctive features.

First, it is five bars in length, in itself antithetical to regular phrasing, but even more important to its profile is the chromatic descent through the upper fourth of the scale and the cadence by leap to the lower octave (in $\mathrm{G}$ minor). These two distinct parts of the ground, the chromatic descent and cadence [...] divide it equally into two balanced halves. (Harris, 2018, p. 133)

As Harris explains, the combination of a regular structure contrasted by irregular features results in a more intricate musical structure. It builds 
a tension which supports the content of the words. The aria also has a lack of full tonic resolution in the sung melody and accompanied harmony, which is withheld until the end. "The chromatic transformation only occurs in the instrumental postlude where, as Dido expires, the full-octave chromatic G minor scale finally is given, not in the bass, but in the treble [...]. This is certainly one of the most sublime moments in the opera" (Harris, 2018, p. 137). She goes on to explain: "One senses a meaning in these structures that rises above technique. [...] And as Dido completes her requests, the vocal line coincides with the fate motive for the first time -Dido and her fate finally touch, and she dies" (Harris, 2018, p. 138). She concludes: "Purcell yokes the disparate elements of his craft (often miraculously) to a single purpose - the composition of music that rises above simple accompaniment of the text to become the active embodiment of the drama" (Harris, 2018, p. 139). Clearly, the music itself embodies the drama. Such an analysis of the enactment of music and text reveals crucial information when interpreting material and character. And as the music is an embodiment of the drama, the performer's individual interpretation based on this knowledge can become a present embodiment of the character and the opera in a present-day performance. ${ }^{8}$ Combined, all this knowledge supplies the performers with competence and an understanding of the interconnections of textual and musical messages, that add to the understanding and interpretation of the scene and the character. This aids in placing emphasis on certain words and musical phrases, supporting the emotional and embodied communication in the performance.

\section{Mind and body}

Another important contextual point is the question of Dido's death. How does she die? In the classical sources from Greek and Roman

8 The nature of this article is to supply examples of analysis and encourage the use of this in an individual artistic interpretation. There is no room for detailed explanations and suggestions for how a singer might make use of this in an interpretation in terms of musical score analysis with emphasis and use of phrasing, emphasis, articulation, diction, vibrato, gestures and so on. Such level of detail is material for my upcoming PhD dissertation. 
mythology, such as Homer and Ovid, she commits suicide, stabbing herself with a dagger. However, there are no references to this either in the libretto or the score. Dido dies from grief in Purcell and Tate's version. To us, this might seem a bit odd. However, when investigating historical sources for theories of acting, the idea that the body reacted physically to emotions to such an extent that one could die from grief, was a generally accepted belief of the time. Moreover, today it is medically recognised as broken heart syndrome and can even lead to a heart attack and death. ${ }^{9}$ Ideas of the direct connections between thought, emotion and body are well explained in historical sources (Roach, 1993). I find it particularly interesting that these early modern ideas, oftentimes rejected as superstition and outdated concepts of the body, to some extent can be rediscovered, understood and supported through modern cognitive research and philosophy of the embodied mind (Lakoff \& Johnson, 1999, 2008). In my PhD research, I go further into detail in these matters.

My point in this detail on Dido dying from grief, is that such knowledge unquestionably adds new perspectives to the interpretation of the character Dido. Relating emotionally to literally dying from grief differs fundamentally from being desperate and killing oneself. Awareness of this demands new decisions regarding interpretation and performance. Conscious thoughts and reflections on Dido's psychosomatic state will, in various ways, affect the interpretation and performance of the aria. The multisensorial approach as described by Eidsheim (2015), and the ontological premise of the embodied mind as discussed by Lakoff and Johnson (1999) fit together perfectly. My view is that performers must awaken to the fact that music performance involves all senses and the whole body for both performers and audiences. It is not simply a case of auditive practice. Our experience of reality comes through the senses, so an awareness of a multisensorial approach is crucial in relating to the historical material and the practice of music as experience. We can then make it come alive for both performers and audiences today.

9 https://www.mayoclinic.org/diseases-conditions/broken-heart-syndrome/symptoms-causes/ syc-20354617 
These premises are ideal as a foundation for working with the historical in a pedagogical context, be it music history, studying an instrument, or working with performance training with students. As a teacher, the goal is to enable the students to become independent and apply their knowledge and competence in a meaningful manner. Supplying them with a broad foundation to be able to reflect upon issues relating to the connection between past and present, can supply them with a tool they can apply again and again. ${ }^{10}$ Reminding students of the importance of integrity and reflecting upon the complexity of the issues presented in this chapter, gives them the ability to become involved with the given material on a more tactile, multisensorial and experiential level, hopefully aiding them towards a deeper and more meaningful understanding that will come alive in practise.

\section{Enacting the past through contemporary unrestricted recontextualisation}

Throughout this chapter I have argued that through studying historical and contextual information, it is possible to reveal various relevant and interesting perspectives on the material being studied, in this case Purcell and Tate's opera Dido and Aeneas. I have given some examples of different approaches, revealing issues of importance in terms of providing a more complex basis for interpretation. As a performer internalising and processing this information, it alters my perspectives and my interpretation, shaping my idea of the character Dido. More knowledge leads to more conscious choices being made throughout the process, emboldening integrity and artistry. In turn, this will also be part of a unique artistic interpretation and performance, resulting in a more complex message in artistic communication. ${ }^{11}$ Building on historical ideas of communication

10 I would like to bring in further examples on what this might offer practitioners, students, or educators with a description of a practical approach and how this has been used in practise. However, that reaches beyond the scope of this chapter, and must be left for later publications.

11 Given the nature of the essay, I have chosen to explain this in more general examples. Going into details on how this can be realised in my own artistic process, or in others', is not possible within this text's limitations. I therefore make the conscious choice to leave this for my $\mathrm{PhD}$ dissertation. 
on all levels from the subliminal to the explicit, the premise that knowledge transfer across history is possible and meaningful is central. These ideas are also in line with contemporary concepts of embodied and multisensorial viewpoints (Eidsheim, 2015; Lakoff \& Johnson, 1999) regarding singing and human communication. As such, this approach has the potential to inspire a free and creative recontextualisation that will become more than a mere historically informed performance. The initiative behind the argument presented here originates from my longterm ambition to contribute to change and renewal in the field of early modern performance in order to better synthesise theory with performance. Therefore, I encourage both the historical-musicological field and performers to bridge the gap and become familiar with present-day discourse on these related topics in research and performance traditions. This explains the need for my detailed analysis and dealings with historical matters, as well as emphasising its relevance for performers, and the practical and artistic value of the approach. Bridging the gap between historical musicology and contemporary concepts of performance and interpretation of early modern repertoires, this approach can create a meaningful interaction between theory and artistic practise. The performance, then, becomes, as Friman puts it beautifully, "an act of simultaneous preservation and re-creation" (Friman, 2008, p. 132).

\section{References}

Austbø, H. (2018). Om kvalitet i musikalske fremføringer. In Ø. Prytz (Ed.), Når kunsten tar form. Norsk Kulturråd. https://www.kulturradet.no/kvalitet/vis/-/ essay-kkk

Eidsheim, N. S. (2011). Sensing voice. The Senses and Society, 6(2), 133-155. https:// doi.org/10.2752/174589311X12961584845729

Eidsheim, N. S. (2015). Sensing sound: Singing and listening as vibrational practice. Duke University Press.

Eriksen, R. T. (2001). The building in the text: Alberti to Shakespeare and Milton. Pennsylvania State University Press.

Eriksen, R. T. \& Young, P. (2014). Approaches to the text: From pre-gospel to postbaroque (Vol. 9). Fabrizio Serra.

Friman, A. M. (2008). Modern performance of sacred medieval music with particular reference to women's voices. [ $\mathrm{PhD}$ in performance, Doctoral dissertation, 
University of York]. ETHOS. https://ethos.bl.uk/OrderDetails.do?uin=uk. bl.ethos. 520043

Goehr, L. (2007). The imaginary museum of musical works: An essay in the philosophy of music (Rev. ed.). Oxford University Press.

Harris, E. T. (2018). Henry Purcell's Dido and Aeneas (2nd ed.). Oxford University Press.

Lakoff, G. \& Johnson, M. (1999). Philosophy in the flesh: The embodied mind and its challenge to Western thought. Basic Books.

Lakoff, G. \& Johnson, M. (2008). Metaphors we live by. Chicago University Press. https://www.amazon.com

Orning, T. (2018). Eksperimentell praksis-eksperimentell vurdering? In Ø. Prytz (Ed.), Når kunsten tar form. Norsk kulturråd.

Price, C. A. (1984). Henry Purcell and the London stage. Cambridge University Press.

Purcell, H. (1974). Dido and Aeneas. Novello Publishing Limited.

Purcell, H. (1986). Dido and Aeneas: An opera. Norton \& Company, Inc.

Purcell, H. (1987). Dido and Aeneas: Opera. Oxford University Press.

Purcell, H. (1995). Dido and Aeneas. Dover Publications, Inc.

Rile, K. (2014). Christopher Hogwood: Founder of the 'historically informed performance' movement dies. https://daily.jstor.org/christopher-hogwoodfounder-of-the-historically-informed-performance-movement-dies/

Roach, J. R. (1993). The player's passion: Studies in the science of acting. University of Michigan Press. 


\title{
CHAPTER 4
}

\section{Hearing Early Modern Music Through the Contemporary}

\author{
Daniel Henry Øvrebø \\ Research Fellow, University of Agder*
}

\begin{abstract}
This chapter focuses on how contemporary music practice interacts with early modern ${ }^{1}$ aesthetics. Two projects, in which Georg Philip Telemann's solo fantasias are interspersed with contemporary techniques and repertoire, serve as case studies. Firstly, the flutist Felix Renggli commissioned new pieces from 11 contemporary Swiss composers, to be inserted in between Telemann's 12 Fantasias for Solo Flute. Secondly, violinist Aisha Orazbayeva performed a set of Telemann's Solo Fantasias for Violin using extended techniques pioneered by Salvatore Sciarrino in his 6 caprices. In this text I use these two different approaches as case studies for how early modern music, exemplified by Telemann, can be communicated to a modern audience without relying upon the concept of historically informed performance, but instead communicates through the operation of semiotics in performance.
\end{abstract}

Keywords: Telemann, fantasias, performance, early modern, contemporary, semiotics

\section{Introduction}

The past two decades have produced an increasing number of different contexts in which performers build on both early modern and high modernist aesthetics. This text makes a comparative analysis of two specific artistic projects and discusses their similarities and differences regarding

\footnotetext{
* Affiliation at the time of writing; Øvrebø's current position is Research Advisor, Oslo Metropolitan University.

1 Although the music of Georg Philip Telemann is perhaps more widely understood and referenced as a part of the Baroque period, I am for the sake of this anthology using the term early modern even though it is a wider period and its boundaries are subject to debate.
}

Citation: Øvrebø, D. H. (2022). Hearing early modern music through the contemporary. In R. Rolfhamre \& E. Angelo (Eds.), Views on early music as representation: Invitations, congruity, performance (MusPed:Research No. 4, Ch. 4, pp. 119-137). Cappelen Damm Akademisk. https://doi.org/10.23865/ noasp.157.ch4

Licens: CC BY-NC-ND 4.0 
the relationship between old and new, and how they shape a modern audience's perspective on the early modern. The first one is Renggli's Fantasia Telemania, in which he commissioned eleven Swiss contemporary composers to let Telemann's 12 Fantasias for Flute Without Bass serve as the inspiration for a short solo piece. The second one is Orazbayeva's merging of Telemann's 12 Fantasias for Violin Without Bass with "techniques [...] used in works by composers including Luigi Nono, Salvatore Sciarrino and Helmut Lachenmann" (Orazbayeva, 2016). In this text I want to look at how two different approaches to contextualising Telemann's solo instrumental music can communicate to a modern audience, operationalised in two steps.

First, I seek to explain what subject positions each of these two approaches establishes. My method here is guided much by Eric Clarke's work on listening and subject position in music as written in Ways of Listening (2005), which I will develop within a post-structuralist framework. This means looking at "the way in which characteristics of the musical material shape the general character of a listener's response or engagement" (Clarke, 2005, pp. 91-92), as opposed to simply discussing any subjective responses more or less detached from the material. Clarke uses the term subject position to address the listening experience of certain tracks on recordings, while I investigate the artistic projects in their entirety, but focus on the related recordings. My use of the term "musical materials" thus refers not primarily to the compositional features of Telemann's fantasias, nor is it limited to questions of any performance practice that can be considered "authentic". Rather, as stated in the preface to this anthology, I am looking for ways of re-contextualising the musical work and will do so using a semiotic approach as a baseline. This procedure can be described in three steps. On the outset, I assess the semiotics of the recorded performances, asking how certain features of the musical material are signified by the performers. Following from this, I use Clarke's terminology to investigate which perceptual effects these signs produce. Finally, I examine which subject positions these perceptual effects create.

My general approach to discussing early modern performance in light of high modernist aesthetics is furthermore inspired by Mieke Bal's project in which she investigates the relationship between early modern visual aesthetics and selected contemporary artists. In Quoting Caravaggio she 
argues that "wilfully anachronistic" quoting of the early modern is a form of critical engagement with past aesthetic ideals that "makes the conditions and implications of the merging of the [past and present] more visible" (Bal, 1999, p. 5). Her argument is not only that early modern aesthetics inform contemporary aesthetics, but also that contemporary quotations of the early modern change the way we perceive the early modern. In this text I shed light on how the two case studies engage with Telemann's solo fantasias in a manner that is similar to what Bal describes. I argue that the two projects are not only relevant and interesting because they provide creative examples of how early modern and high modernist music can fuse together, but also that they performatively change the way we listen to early modern music. My use of "performative" here is not related simply to describing music as an art form of which performance is an integral component. The term "performative" is problematic in its own right. Morten Kyndrup argued even in 2006 that the term has become somewhat overcharged with definitions and usages, and that it is "not clear which status it has, and thus which shifts and object fields it actually pertains to. In other words: How is the term distinctive? What can and will it do, and what can't, and won't it do?"2 (Kyndrup, 2006, p. 38, my translation). Robin Rolfhamre discusses, in chapter 2 of this anthology, several approaches to how the term "performativity" can be meaningful in a musicological context. By asking which subject position the two above mentioned artistic projects establish, I subscribe to a use of performativity based on "iterability" and "citationality". Jacques Derrida argues in the essay "Signature Event Context" for an understanding of the term "iterability" as a double gesture that simultaneously means repetition (from the modern etymology of iter meaning "once again") and alteration (based on the term's original etymology from Sanskrit itara meaning “other”) (Derrida, 1982, p. 315). This provides a way to understand the two artistic projects in this text as "performative", in the sense that they both repeat early modern aesthetics while changing them at the same time.

2 “... ikke helt klart hvilken status og dermed bevægelsesinteresse og genstandsomrade, det i grunden har. Eller anderledes formuleret: på hvilken måde er begrebet distinktivt? Hvad kan det og vil det, og hvad kan det og vil det ikke?" 
In this text, I import this sense of doing when discussing the semiotics of early modern music on the one hand, and contemporary expressions on the other. By way of subject positions, I ask what early modern and contemporary aesthetics do to one another as artistic artefacts, and by doing so I expand ever so slightly Mieke Bal's concept of quoting. I perceive this to be a fruitful interplay with early modern music, taking into consideration how much creativity is needed to fill the gaps of missing knowledge on early modern performance practice, as for instance argued by Daniel Leech-Wilkinson in The Modern Invention of Medieval Music (2002). Leech-Wilkinson speaks of an "interaction of past materials with present imaginations" as a "legitimate way of using historical materials", and this sentiment is deeply characteristic of the following sections in this text.

The explicit references to Clarke's subject positions, as well as Bal and Derrida, involve adopting a post-structuralist approach to studying semiotics. Clarke places less emphasis on the authority of the composer and focuses on the interpretant, which in this text includes both the performer and the listener. As such, we can speak of a composer-function much in the same way that Michel Foucault outlines the characteristics of an author-function in his essay What Is an Author? (1969/200o). In the essay, which in itself is a response to Roland Barthes' essay The Death of the Author (1967/1977), Foucault argues that the author is an entity constructed by the discursive structure in which a given work circulates. This is a notion in line with what Clarke suggests, and what I base this text upon.

My second aim for this text is to outline tentative prospects for the kind of comparative analysis that my semiotic approach affords. This anthology, as a whole, addresses a number of questions related to reconfiguring early modern performance. What happens when the early modern work is presented in various contexts and situations? Before starting the discussion on work-concept and subject positions, I will briefly outline the distinct characteristics of the two projects. In the end, I will discuss some pedagogical implications of the different perspectives on performance indicated by these projects. These implications encompass two fields. First, I wish to outline a methodical approach to lyttefaget [the listening module] in Norwegian upper secondary education. Second, 
I believe the issues discussed in this text can inform the development of higher-level music performance in Norway.

\section{A semiotic approach to Telemann's fantasias}

The title for Telemann's solo pieces is worth a brief reflection because it will allow us to establish some preliminary concepts of how his music can communicate to an audience of today, based on a semiotic approach. Günter Haußwald ${ }^{3}$ characterises the form of the fantasias as an "interchange of manifold inspirations" (Telemann \& Haußwald, 1955b), as well as a "mosaiclike gaiety of the colours" (Telemann \& Haußwald, 1955a). He also adds that "delight in playing, freedom in the form, in the time and in the key structure emphasise the improvisatory character of the works" (Telemann \& Haußwald, 1955a). The fantasias were not meant to be complex compositions, but represent rather short bursts of creativity in Telemann's output. Here, freedom of form and time refers to the variation of sections in each individual fantasia, while key structure refers to Telemann's choice of selecting an individual key signature for each of them. See the comparison in Table 1 below. The first Fantasia in B Flat Major (track 2) is in two movements, with a largo followed by an allegro, which has a grave inserted in the middle of it, while the third in F minor (track 6) consists of an adagio followed by a presto, and finishes with a vivace prefaced by a short grave. These are just two examples of the highly varied form these fantasias take. Furthermore, we should consider the rather different approach to aesthetics that was common in the early modern period. Alexander Rueger argues extensively for art in the early modern period to be understood in terms of rhetoric, in the sense that the final purpose is one of persuasion (and not as what Hegel called "free poetic works of art") (Rueger, 2011). Here Hegel's term refers to the separation of rhetoric and aesthetics into distinct categories, in which the former equates rhetoric with speech for a practical final purpose, while aesthetics concerns artworks devoid of a distinct purpose. This establishes an interesting ground upon which to examine how

3 German musicologist and editor of Bärenreiter's collected edition of Telemann's scores. 
modern musicians perform the rhetorical devices of the early modern by looking at a play of semiotics.

By extending Mieke Bal's conception of quoting, we can then ask: How do the artistic projects of Renggli and Orazbayeva clarify the conditions and implications of a merging of Telemann's "interchange of manifold inspiration" and "freedom in form and time" with performance in modern times? In Quoting Caravaggio, Bal specifies through Jacques Derrida's concept of "supplementation" (Derrida, 1967/2016) her idea of quotation as a

valid ground for an interpretation that accounts for a different sense of 'understanding.' This interpretation neither contradicts historical evidence that it may accept but does not make central, nor projects present concerns upon it. It does not construct a fictitious intention or unconscious psychic makeup, nor is it a totally relativistic subjectivism in which anything goes but which is rigorously contemporary in its effect. (Bal, 1999, p. 13)

The reference to Derrida places Bal in an inherently deconstructionist framework, in which issues of representation are problematised. Her argument is distinctly philosophical, but refers to specific case studies in which certain visual, aesthetic features in the works of modern artists change how we as modern audiences perceive the notion of art history as chronological. I will attempt to specify the consequences of importing this line of thought into matters of music performance, and specify how the case studies in this text employ a play of semiotics in their performances, which I argue resembles Derrida's "play of representation" in which the "point of origin becomes ungraspable" (Derrida, 1967/2016, p. 39).

\section{The semiotics of juxtaposition}

Let us start from the outside and look at how the physical compact disc recording participates in a play of semiotics. What might at first glance appear as a random curiosity - inserting modern compositions into a cycle of early modern works - is in fact a delicate curation. ${ }^{4}$ In 2000

4 Holliger's Passacanaille is an exception to this. It was originally composed in 1995 and is the $12^{\text {th }}$ and final movement of Sonata (in)solit(air)e, which is both a mixture of and plays with early modern elements. The preface to the published score reveals a premiere performance in 1996. 
Renggli recorded an album entitled Fantasia Telemania, in which he juxtaposes Telemann's 12 Fantasias for Solo Flute with 11 commissioned solo pieces by different composers. The double CD was published on the label Musique Suisses, which advertises itself as "The CD-label for Swiss classical music, new popular music and jazz." ${ }^{5}$ The tracklist, which covers two discs, is as follows:

Table 1. Track Listing Fantasia Telemania

\begin{tabular}{|c|c|c|c|}
\hline Track & Composer & Title & Instrumentarium \\
\hline 1 & $\begin{array}{l}\text { Georg Philipp Telemann } \\
(1681-1767)\end{array}$ & Fantasia No.1 in A Major & Traverso \\
\hline 2 & Bettina Skrzypczak (1962-) & Mouvement (1999) & Flute \\
\hline 3 & Georg Philipp Telemann & Fantasia No.2 in A Minor & Traverso \\
\hline 4 & Xavier Dayer (1972-) & $\begin{array}{l}\text { To the sea (homage a Cy } \\
\text { Twombly) }\end{array}$ & Alto flute \\
\hline 5 & Georg Philipp Telemann & Fantasia No.3 in B Minor & Traverso \\
\hline 6 & Mathias Steinauer (1959-) & $\begin{array}{l}\text { Phantasos (Pavarotti's Traum), } \\
\text { Op. } 16\end{array}$ & $\begin{array}{l}\text { Flute with attached } \\
\text { glissando stand }\end{array}$ \\
\hline 7 & Georg Philipp Telemann & Fantasia No.4 in B-Flat Major & Traverso \\
\hline 8 & Robert Suter (1919-) & $\begin{array}{l}\text { Notturno Appassionato in G } \\
\text { Major }\end{array}$ & Alto flute \\
\hline 9 & Georg Philipp Telemann & Fantasia No.5 in C Major & Traverso \\
\hline 10 & Roland Moser (1892-1960) & Intermezzo & Piccolo, traverso \\
\hline 11 & Georg Philipp Telemann & Fantasia No.6 in D Minor & Traverso \\
\hline 12 & Heinz Holliger (1939-) & $\begin{array}{l}\text { Sonate (in)solit(air)e: XII. } \\
\text { Passacanaille (1999) }\end{array}$ & Flute \\
\hline 13 & Georg Philipp Telemann & Fantasia No.7 in D Major & Traverso \\
\hline 14 & $\begin{array}{l}\text { Jacques Wildberger } \\
(1922-2006)\end{array}$ & Fantasia sul Re in C (1999) & Contrabass flute \\
\hline 15 & Georg Philipp Telemann & Fantasia No.8 in E Minor & Traverso \\
\hline 16 & Nadir Vassena (1970-) & $\begin{array}{l}\text { Come perduto nel mare un } \\
\text { bambino (1999) }\end{array}$ & Flute \\
\hline 17 & Georg Philipp Telemann & Fantasia No.9 in E Major & Traverso \\
\hline 18 & Christoph Neidhöfer (1967) & Interlude & Bass flute \\
\hline 19 & Georg Philipp Telemann & Fantasia No.10 in F-Sharp Minor & Traverso \\
\hline 20 & $\begin{array}{l}\text { Hans Ulrich Lehmann } \\
\text { (1937-2013) }\end{array}$ & Tele-Man(n)ia & Bass flute \\
\hline 21 & Georg Philipp Telemann & Fantasia No.11 in G Major & Traverso \\
\hline 22 & Bernhard A. Batschelet & Intrata & Flute \\
\hline 23 & Georg Philipp Telemann & Fantasia No.12 in G Minor & Traverso \\
\hline
\end{tabular}

Thus, while not an authentic contribution to Renggli's commission, it nevertheless fits into the general idea of the project, that of quoting the early modern (Holliger, 1995).

5 „Das CD-Label für Schweizer Klassik, neue Volksmusik und Jazz“ (Startseite, 2019). 
Detecting the traces of Telemann in them is not the main point of this text. My interest goes the other way - how the juxtapositions shape the way we hear Telemann. The Telemann fantasias are performed on a traverso, while the juxtaposed compositions utilize a wide range of flutes. The ordering makes it clear that Telemann's fantasias provide the frame through which one is supposed to hear the subsequent pieces - it starts and ends with Telemann. Indeed, the review in the Swiss newspaper Tages-Anzeiger, although it discourages listening to it in one sitting, endorses this interpretation:

Whoever listens to this Double-CD bit by bit, will discover countless jewels, as well as an exciting idea: Basel flutist Felix Renggli has combined Georg Philipp Telemann's 12 Fantaisies for flute without bass with solo works by contemporary Swiss composers. After every Telemann-Fantaisie follows the modern answer, which more or less directly relates to the Baroque model. [...] Telemann's cycle was a pedagogic project as well, one that extends its activity/range into the present [...]. (Fantasia Telemania, 2001) ${ }^{6}$

The first part of this quote is also included in the online catalogue of Musique Suisses, further reinforcing the notion that Telemann provides the key to understanding the modern pieces. This is also reflected in the commission itself: "[...] thus in his project 'Telemania', he has asked 11 composers to interpolate Georg Philipp Telemann's '12 Fantasias for flute without bass' in a free manner." 7 In the CD booklet, a more precise description of the commission is to be found:

6 „Wer sich diese Doppel-CD häppchenweise zu Gemüte führt, wird etliche Preziosen entdecken - und eine spannende Idee: Der Basler Flötist Felix Renggli hat Georg Philipp Telemanns ,12 Fantaisies à Travers sans Basse‘ mit Solowerken von zeitgenössischen Schweizer Komponisten kombiniert. Auf jede Telemann-Fantasie folgt also die moderne Antwort, die in mehr oder weniger direktem Bezug zum barocken Vorbild steht. [...] Telemanns Zyklus war einst auch ein didaktisch gedachtes Projekt, das nun seine Wirksamkeit gleichsam in die Gegenwart hinein verlängert $[\ldots]$. “

7 „[...] so in seinem Projekt ,Telemania; für das er elf Komponisten gebeten hat, Georg Philipp Telemanns, 12 Fantaisies á Travers sans Basse` auf freie Art zu interpolieren [...]“ (Kunkel, 2004). 
[...] the piece they were to write had to be for flute solo. However, it could be for any instrument from the flute family. The work should either refer to one of Telemann's fantasies in particular, or to the fantasy form in general as this musical form is understood today. As far as the length of the work was concerned, it was not to be longer than the average duration of one of Telemann's own fantasies. (Renggli, 2001)

It is well worth pointing out here how the recording itself participates in a play of representation with an "ungraspable point of origin." We do not know if Renggli rehearsed and recorded the compositions in the same order as they appear. It is also possible that each track was recorded in several takes. The point of origin - a complete performance of the tracks in the order in which they appear - is therefore ungraspable, in as much as the recording attempts to represent it by affording uninterrupted listening.

Furthermore, the subtitle of Kunkel's review - "the Pan principle" (das Prinzip Pan) - provides an interesting reading of Renggli's project. Aside from establishing the mythological origin of the panpipe, thus inspiring a long-sustained association with flute playing, "pan" also has a secondary meaning in the sense of the Greek prefix "all/every" (think of pandemic meaning all + people, or pantheism meaning all/ everything + God), and indicates the idea of something all-encompassing. Indeed, in Roman culture Pan was attributed the property of universality. Certainly, Renggli's ability to perform and record at length early modern music and contemporary compositions featuring several different flutes, is a testament to a musical homo universalis, seemingly able to study and perform whatever comes his way. Extending this thought, we can say that the creative ethos seems to remain to a greater extent with the composers, while Renggli's artistic ethos remains one of sheer ability to execute. It could be argued that Renggli's artistic ethos is expanded by perceiving it as a collaborative creative project, for instance as represented in the volume Distributed Creativity, which discusses a number of approaches to how contemporary music practice benefits from looking at it as collaborative efforts rather than singular acts of interpretation (Clarke \& Doffman, 2017). 


\section{Telemann, Sciarrino, and the semiotics of entanglement}

I was fortunate to witness an interesting performance in November 2017 under the label Tanja Orning inviterer [Tanja Orning Invites]. ${ }^{8}$ It took place in nyMusikk's tiny headquarters in Oslo and featured, among other things, a solo set by violinist Orazbayeva. Occupying the main position in her set was a selection of the Sei Capricci for Solo Violin by Salvatore Sciarrino, featuring, as readers familiar with his music can imagine, a wide array of extended performance techniques. Then something transcendental, even for me as a contemporary music afficionado, took place: One of Telemann's 12 Fantasias for Solo Violin suddenly appeared, in a fragile manner, filtered and distorted through the soundscape established by Sciarrino's Capricci. Orazbayeva elaborated on this during the discussion that followed, and explained how she got the idea of merging the texture of Sciarrino's Capricci with the formal structure of Telemann's Fantasias.

Her CD Telemann Fantasias was published in 2016 and features six of the fantasias, prefaced by three minutes of a quiet urban soundscape. According to her own notes, the performances "range from personal and stylistic interpretations to versions marked by the distortion and fragmentation of the material through the use of contemporary violin technique" (Orazbayeva, 2016). For the sake of this text, I am more concerned with the latter range of performance style, and I will focus on the perceptual effects afforded specifically by Sciarrino's techniques.

Table 2. Track Listing Telemann Fantasias

\begin{tabular}{ll}
\hline Track & Title \\
\hline 1 & [untitled] \\
2 & Fantasia for Solo Violin I in B-Flat Major: Largo, Allegro - Grave - Allegro \\
3 & Fantasia for Solo Violin X in D Major: Presto, Largo, Allegro \\
4 & Fantasia for Solo Violin II in G Major: Largo, Allegro, Allegro \\
5 & Fantasia for Solo Violin IX in B Minor: Siciliana, Vivace, Allegro \\
6 & Fantasia for Solo Violin III in F Minor: Adagio, Presto, Grave - Vivace \\
7 & Fantasia for Solo Violin VI in E Minor: Grave, Presto, Siciliana, Allegro \\
\hline
\end{tabular}

8 Tanja Orning inviterer was a regular event occurring as a part of nyMusikk's seasonal program, in which she invites performers of contemporary music both to play and talk about their practice. nyMusikk is Norway's centre for contemporary music, and the Norwegian section of the International Society for Contemporary Music (ISCM). 
The first fantasia on Orazbayeva's album, No.1 in B-Flat Major, begins with the recognisable tune somewhat distorted by the use of a performance technique from one of Sciarrino's Capricci. The bow is flipped upside down so that the wooden back is in contact with the strings, rather than the rosin coated horsehairs. The result is a thin fragile sound, in which several overtones can be heard. A similar sound is found in the fifth track on the album, Fantasia No.9 in B-Minor. Here she plays with the bow on the wrong side of the bridge, creating a sound that varies between clear and veiled, panning back and forth almost as if it was added digitally after recording.

Compared with Renggli's semiotics of juxtaposition, the distorted and fragmented way of performing the two fantasias mentioned here represents a more entangled approach. The overall structure of Telemann's "interchange of manifold inspiration" is intact but portrays a different dimension here than in the case of Renggli. Aside from her "personal and stylistic interpretations", the distortion shifts the creative ethos from Telemann as a composer to Orazbayeva herself as a performer.

\section{Intermezzo}

These two projects, then, have one feature in common: They supplement early modern music, meaning that they both duplicate it and change it at the same time, a characteristic that Derrida specified as iteration. The crucial difference, however, is the manner in which this Derridean iteration is undertaken. They diverge in terms of how they treat the "origin": the musical work. Although they both keep the formal structure of the Telemann fantasias intact, Renggli nurtures the historical gap between the early modern and the contemporary by performing the fantasias on a traverso, as opposed to the modern concert flute. For him, it is the constant leap between the past and present that is most essential, and constitutes the main play of semiotics. Nevertheless, he seems apt at treating Telemann's fantasias as separate compositions, and the novel feature relies heavily on the contemporary compositions. This also becomes evident when considering the project as a whole. In terms of performer agency, his artistic ambitions seem to rest upon his ability to execute the works 
by themselves, and let the listener take from that what he or she wishes. Indeed, the notion of Renggli as a musical homo universalis, and thus the central figure, seems to be evident in the album design as well. The cover simply features his name and picture, with no mention of Telemann or the other composers, or indeed any of the compositions.

Orazbayeva, on the other hand, alters the sound of certain fantasias themselves in a more radical fashion. Her distortions have little to do with historical representation. Rather, she engages in the dynamic between the early modern and the contemporary more actively. Her aim, in contrast to Renggli's juxtaposition, is then to present old and new in a state of entanglement. How should we then proceed if we want to specify which subject positions these two approaches demonstrate? In developing his ecological approach to listening and perceiving, Clarke depends on describing the musical material in terms of perceptual effects. Let us then see which perceptual effects Renggli and Orazbayeva provide.

\section{Subject positions: Perceptual effects}

Starting with Orazbayeva's first track, we return to the technique of letting the wood from the bow touch the strings to produce a fragile sound. Combined with the introductory noise from the start of the album, the perceptual effect can be likened to that of hearing Telemann's music through the static noise of an FM radio, not quite tuned to the correct frequency. The short noise track conveys a strong urban sense embodying a certain ambiguity. In one way it is quite far removed from the environment in which performances of classical music in general take place. On the other hand, however, it can represent the very same urban soundscape that concert attendees might hear right before entering a concert hall.

Furthermore, the perceptual effect of the two fantasias performed with different distortion techniques - the No.1 in B-Flat Major with the bow played upside down and the No.9 in B Major with the bow played on the other side of the bridge closer to the fine-tuning pegs - is one of stylistic entanglement. Early modern and modernism cease to exist as individual stable elements: the performance practice is radically detached from established notions of early modern (or indeed any Baroque, Classical 
or Romantic) performance practices, and the compositions are based on ideals alien to modernist notions of predictable structures.

Next, I will begin my outline of perceptual effects in Renggli's project by drawing attention to one interesting detail in the very midpoint of the album (the second and third final tracks on the first disc), Rudolf Moser's Intermezzo, which precedes Telemann's Fantasia No.6 in D Minor, begins with the piccolo flute but ends on a traverso. The final phrase, when heard without moving on to the next track, seems to end in an abrupt quasi-unfinished manner. The harmonic landscape is primarily atonal, but some of the leaps from the low register to the high register imitate Telemann's manner of indicating counterpoint for a monodic instrument. In many of his fantasias, Telemann uses wide leaps to simulate the effect of two melodic lines. When listening to the transition from Moser's Intermezzo to Telemann's Fantasia in D Minor, we nevertheless hear a harmonic preparation. The final note of Intermezzo is a $\mathrm{G}$, which in a D minor tonality is the subdominant. In functional harmonics, the subdominant leads to the dominant, which again leads to the tonic, and this is precisely what happens. The first interval in the D minor fantasia is a leap from a sustained tenuto A down to D. Including the $G$ from the end of Intermezzo, we thus have a perfect cadence that connects the two pieces together: G (subdominant) - A (dominant) - D (tonic).

The perceptual effect here - the bridging between the two pieces by way of reading the functional harmonics - is most likely lost on listeners unfamiliar with these kinds of technical terms. The accompanying booklet for the recording describes Moser's Intermezzo as a "concrete interpolation", indicating that this perceptual effect is supposed to be noticed. It is not impossible to hear, but the effect is difficult to notice unless the listener pays very close attention. By extension, listeners unfamiliar with Telemann's fantasias are even more likely to miss out on this perceptual effect.

Another similar example of this kind of convoluted quoting of Telemann is found in Jacques Wildberger's Fantasia sul Re in C. The title carries multiple references. The Italian sul means "on (the)", while re has a double meaning. In the solfeggio system, according to which ear training is based on singing syllables connected to each note in the 
diatonic scale, "re" always refers to the note D. However, Renggli's last name begins with "re", so the title can also be interpreted as a note of dedication. Furthermore, "in C" is in itself a double meaning. On the one hand, it is a common designation that signifies in which key a given work is composed. As such, a listener should expect a tonality based on $\mathrm{C}$ as the root note. However, the sustained low note drone that opens and closes Wildberger's Fantasia is D, not C. This confusion is resolved when considering the sounding tone that concludes the preceding track, Telemann's Fantasia No.7 in D Major. I say the sounding tone here, because it is performed on a traverso, which is tuned to $415 \mathrm{~Hz}$ as opposed to the standard $440 \mathrm{~Hz}$ or $442 \mathrm{~Hz}$. So although Renggli grips and plays the $\mathrm{D}$ that Telemann composed for the traverso, it sounds in modern tuning roughly equivalent to a $\mathrm{C}$.

\section{Summary of analysis}

At the outset of this text I asked, using Bal's terminology, how these two projects clarify the conditions and implications of a merging of Telemann's "interchange of manifold inspiration" and "freedom in form and time" with performance in modern times. Through the analysis, two distinct subject positions emerge related to two different quotation strategies, as shown most clearly in the table below:

Table 3. Comparative Analysis

\begin{tabular}{|c|c|c|}
\hline Performer & Felix Renggli & Aisha Orazbayeva \\
\hline Instrument & Flute & Violin \\
\hline Strategy & Juxtaposition of compositions & Entanglement through texture \\
\hline Work-concept & $\begin{array}{l}\text { Autonomous. Telemann's } \\
\text { compositions played "as is" and } \\
\text { relatively faithful to the score. }\end{array}$ & $\begin{array}{l}\text { Heteronomous. Work-concept } \\
\text { subject to experimentation with } \\
\text { certain performance techniques } \\
\text { not required by the score. }\end{array}$ \\
\hline Creative ethos & Composers & Performer \\
\hline Perceptual effects & $\begin{array}{l}\text { Functional harmonic bridging } \\
\text { Play of meaning in titles }\end{array}$ & $\begin{array}{l}\text { Timbral distortion through } \\
\text { different bowing techniques }\end{array}$ \\
\hline Subject position & $\begin{array}{l}\text { Perceptual effects are lost on } \\
\text { listeners who do not possess insight } \\
\text { into harmonic structuring, and } \\
\text { require broad contextualisation. }\end{array}$ & $\begin{array}{l}\text { Perceptual effects are easier to } \\
\text { access since they require less } \\
\text { contextualisation on behalf of } \\
\text { the listener }\end{array}$ \\
\hline
\end{tabular}


Renggli's approach is based on a juxtaposition of compositions, a strategy in which each composition is performed more or less "as is". It therefore seems to demand substantial insight into the harmonic structuring of the compositions in order to grasp the perceptual effects mentioned earlier. Thus, issues of creativity in interpretation are not problematised. As a result, we can say that the "ethos" of creativity is placed with the composer. Renggli provides access to Telemann's “interchange of manifold inspiration" and "freedom in form and time" not through his specific interpretations, but through the specific mirroring of the commissioned compositions. In contrast, we have a quotation method based on entanglement of textures.

By extension, we could say that Orazbayeva not only quotes Telemann, but also Sciarrino by performing Telemann using a specific technique that Sciarrino developed in his own compositions. Nevertheless, this double quoting is an iteration that uses an entanglement of texture to simultaneously repeat and alter Telemann's fantasias. If we were to identify the semiology of Telemann's solo compositions as a sense of "manifold inspirations" and "delight in playing", as well as "freedom in form and time", Orazbayeva's project is perhaps better suited to communicate these ideas to a modern audience. In comparison, Renggli's approach is considerably more reliant upon familiarity with the material, as well as a making an analytical effort to gain access to these ideas.

We can therefore determine the two subject positions represented by Renggli and Orazbayeva by how they facilitate access to freedom in form and time for the listener. In Renggli's case, semiotic elements, such as functional harmonics and playing with the meaning of titles, require a rather broad historical contextualisation with regard to the listener in order to communicate. Listeners who do not share this network of references are likely to miss out on these particular signs, and might dismiss the "freedom in form and time" of the old and new compositions as an interesting gimmick in favour of Renggli's sheer ability to rehearse and perform such a vast variety of different styles and techniques. In Orazbayeva's case, the semiotic play of employing anachronistic performance techniques does not require the same historical contextualisation in the listener. "Freedom in form and time" therefore acquires a more 
personal meaning that is both more available and more likely to communicate with the listener.

\section{Didactical prospects I: Ways of listening}

Returning to the introduction, the question was how this kind of comparative analysis could involve implications for the didactical course on music listening in Norwegian upper secondary school education. The course, according to Utdanningsdirektoratet [The Norwegian Directorate for Education and Training], is supposed to "contribute to enhancing the pupils' cultural anchoring, musical identity and mutual respect through an insight into a wide selection of genres, cultures and forms of music" (Utdanningsdirektoratet, 2020, my translation). More specifically, the course's second core module, musical understanding, "is about working with characteristics of music in different genres" (Utdanningsdirektoratet, 2020, my translation). A listening strategy based on, among other things, a juxtaposition of different styles has been tried out with higher level students of musicology at the University of Oslo through the course Listening to the Twentieth Century and Beyond, which emanated from the research project 20/21 - Musical Trajectories Today (Dirdal, 2014). Dirdal's article in Ballade.no, referred to one particular approach. Here, the students listened to one modern composition, György Ligeti's Atmospheres, followed by one from the late nineteenth century, the prelude to Richard Wagner's Lohengrin, and were asked why these two compositions fit together. Course leader and Associate Professor in musicology at the University of Oslo, Peter Edwards, remarked that the main point is how essential timbre is: The logic of harmony is not able to provide a stable reference point between the two works, but associations through timbre is. Extending this thought, we can say that the timbre in Ligeti's Atmospheres provides a different access to the music of Wagner. As such we can say that Atmospheres quotes the orchestration of Wagner in a way that communicates it to a modern audience, much in the same way that Renggli's juxtaposition allows a different access to Telemann's music, an access that is based on listening rather than reading the scores. 
How can this comparative approach to different styles and genres benefit music listening in Norwegian upper secondary school education? The core module states that the students should work with characteristics of musical genres, but does not specify precisely how. In my work with music performance students on the upper secondary level, the approach to music listening appears to be a complementary way of studying scores. The compositions that the students listen to are analysed based on what the students read in the score, rather than what they actually hear. While this is a useful approach when teaching the historical circumstances during which certain compositions were written, I want to expand this methodology. Renggli's juxtapositions and the listening course at the University of Oslo have one thing in common: They both focus on how certain compositions sound a specific way to us today, instead of focusing on how they were composed at a given historical point, during given historical circumstances. For students in upper secondary school, comparative studies of compositions based exclusively on listening to specific timbres common to them can be a fruitful complement to studying scores, when the aim is to develop an "insight into a wide selection of genres, cultures and forms of music” (Utdanningsdirektoratet, 2020).

\section{Didactical prospects II: Ways of playing}

In terms of music performance education, I argue that the performance style of Orazbayeva can serve as a stimulating alternative to students who wish to expand from a rigid approach to engagement with early modern music. I say “alternative” here, because I do not suggest a dismissal of, for instance, early modern performance style in general, or specific approaches to studying early modern music performance, as it might have been performed in its own time. It is important to consider how the creative ethos of classical musicians is now receiving increasingly more scholarly attention. In Norway, the Artistic Research Programme was established in 1995, and was in 2018 granted the ability to award doctoral degrees based on both artistic and scientific inquiry. The formalist tendencies of higher education in classical music are further criticised for perpetuating dogmatic notions of what constitutes a good performance 
(Austbø, 2018). The creative ethos displayed by Orazbayeva's approach to performing early modern music represents an interesting and highly relevant break with "apparent objective criteria" (Austbø, 2018, p. 16) for assessing quality in musical performance.

The essential point here is to challenge the idea of autonomous musical works, and we are currently educating musicians to remain less free to interpret them. It seems odd, taking into account how an approach such as that of Orazbayeva might more easily communicate to a modern audience, who are arguably less exposed to classical music in general, and therefore might not possess a network of semiotic references, as required by Renggli's approach. Since classical music performance is gradually less understood through the traditional separate terms of composer, work and performer, we need to incorporate this awareness into the way we educate our musicians, in order to sustain the communication of classical music to a new audience.

\section{References}

Austbø, H. (2018). Om kvalitet i musikalske fremføringer. In Ø. Prytz (Ed.), Når kunsten tar form: Essay om kvalitet (pp. 16-21). Fagbokforlaget.

Bal, M. (1999). Quoting Caravaggio: Contemporary art, preposterous history. University of Chicago Press.

Barthes, R. (1967/1977). The death of the author (S. Heath, Trans.). In Image, music, text. Fontana Press.

Clarke, E. F. (2005). Ways of listening: An ecological approach to the perception of musical meaning. Oxford University Press.

Clarke, E. F. \& Doffman, M. (2017). Distributed creativity: Collaboration and improvisation in contemporary music (Vol. 2). Oxford University Press.

Derrida, J. (1967/2016). Of grammatology (G. C. Spivak, Trans.). Johns Hopkins University Press.

Derrida, J. (1982). Signature event context (A. Bass, Trans.). In A. Bass (Ed.), Margins of philosophy (pp. 309-330). Chicago University Press.

Dirdal, L. C. (2014, October 28). Lytting er et arbeid. Ballade.no. Retrieved from https://www.ballade.no/kunstmusikk/lytting-er-et-arbeid/

Fantasia Telemania. (2001, April 4). Review. Tages-Anzeiger, 67.

Foucault, M. (1969/200o). What is an author? In D. W. Lodge \& N. Wood (Eds.), Modern criticism and theory: A reader. Longman. 
Holliger, H. (1995). Sonata (in)solit(air)e. Schott.

Kunkel, M. (2004, June 15). Das prinzip Pan. Basler Zeitung, 11.

Kyndrup, M. (2006). Performativitet, æstetik, udsigelse: Lille note om det performatives æstetik. Peripeti(6), 37-46.

Leech-Wilkinson, D. (2002). The modern invention of medieval music: Scholarship, ideology, performance. Cambridge University Press.

Orazbayeva, A. (2016). Telemann Fantasias [CD]. PRAH Recordings.

Renggli, F. (2001). Fantasia Telemania [CD]. Migros-Genossenschafts-Bund.

Rueger, A. (2011). Aesthetics. In D. M. Clarke \& C. Wilson (Eds.), The Oxford handbook of philosophy in early modern Europe (pp. 201-223). Oxford University Press.

Startseite. (2019). Retrieved from https://www.musiques-suisses.ch/en/startseite.html Telemann, G. P. \& Haußwald, G. (1955a). Zwölf Fantasien für Querflöte ohne Bass : TWV 40:2-13. Bärenreiter.

Telemann, G. P. \& Haußwald, G. (1955b). Zwölf Fantasien für Violine ohne Bass, TWV 40:14-40:25. In Urtext der Telemann-Ausgabe. Bärenreiter.

Utdanningsdirektoratet. (2020). Loreplan i lytting. (MDDo3-02). https://www.udir. no/lk2o/mddo3-02 



\section{Rolf Lislevand in Conversation with Randi Margrethe Eidsaa and Daniel Henry Øvrebø}

Daniel Henry Øvrebø

Research Fellow, University of Agder*

Randi Margrethe Eidsaa

Professor of Music Education, University of Agder

Rolf Lislevand

Professor, University of Agder and Staatliche Hochschule für Musik Trossingen

On 26 October 2020, we were so fortunate as to participate in a digital conversation with renowned early music performer and educator Rolf Lislevand. Our conversation addressed topics related to early music: research, performance, pedagogy and education. The interview was conducted by Daniel Henry Øvrebø and Randi Margrethe Eidsaa. Daniel Henry Øvrebø works with contemporary music and did his $\mathrm{PhD}$ in communication and musical experience of postwar modernist works for solo flute. His own chapter in this anthology relates to how contemporary musicians "quote", and otherwise refer to Baroque music, exemplified by

* Affiliation at the time of writing; Øvrebø's current position is Research Advisor, Oslo Metropolitan University.

Citation: Øvrebø, D. H., Eidsaa, R. M. \& Lislevand, R. (2022). Rolf Lislevand in conversation with Randi Margrethe Eidsaa and Daniel Henry Øvrebø. In R. Rolfhamre \& E. Angelo (Eds.), Views on early music as representation: Invitations, congruity, performance (MusPed:Research No. 4, Ch. 5, pp. 139-148). Cappelen Damm Akademisk. https://doi.org/10.23865/noasp.157.ch5

Licens: CC BY-NC-ND 4.0 
flautist Felix Renggli and violinist Aisha Orazbayeva. They both explore the expressive potential of Georg Philip Telemann through various contemporary approaches. Randi Margrethe Eidsaa is a professor of music didactics. In 2015 she completed her doctoral study on creative concert productions for professional musicians and children. Eidsaa teaches musicology, music pedagogy, concert production and composition. Her other contribution in this anthology is an analysis of an interdisciplinary artistic production based on repertoires from the Renaissance and the Baroque eras.

The following text is a transcription of the conversation, done by both Daniel and Randi, and with minor editing for the sake of readability.

Rolf Lislevand [RL]: I am a performer, and have been working for 30 years as an early music instrument teacher. I started with a professorate in Germany and, simultaneously, in a tradition different from that of the mid twentieth century, became involved with the early modern repertoire, regarding very specific assumptions. My background is not primarily classical music, but belongs in a jazz/rock context, which has perhaps led me to question certain premises of doing classical music based on notions of "authenticity". I find it important to combine faithfulness to original sources with a creative and individual artistic credo, leading to the problem of [the] information gap in how "we do things".

RME: So when you reflect upon your own practice, you also include audiences and students in your approach? It's not just "tradition" anymore, it's "tradition and you".

RL: Definitely. We need to remind ourselves that the purpose of all forms of performance art is to communicate. The explanatory model of thought is such: You find yourself in a situation in which you know how a given composition was meant to be performed, and you possess the means to realise this performance today. We know which instruments were used, how they sounded, how they were played, at which tempi and so on. However should a modern audience be able to experience this as it was intended to be experienced in, for instance, the seventeenth century? An important choice is placed upon the performers. Should they decide 
to still, after all, realise it in the manner that we, with a great degree of certainty, can say it was in fact realised in the seventeenth century, or should they do something else, so that the experience of the audience today can approach the experience that the seventeenth century audience may have had? There is always the possibility of finding oneself in a situation in which we have very strong evidence demonstrating how it was specifically done, but modern audiences do not, by virtue of being humans in given historical contexts, necessarily possess the same sensibility in many areas. Audiences change over time, and I think that what is important here is that we may have to change certain important musical-instrumental factors, so that the genuine content, be it aesthetic, spiritual or ethical, is actually revealed. Consequently the communicative situation dominates above all else.

DHØ: Can you say a bit more about this historical development that you indicated?

RL: There are two points in the history of music in which people were interested in placing themselves within a different standpoint as performers, so to speak. First it happened in the interwar period in Germany. They started to pick up a lot of earlier music in their repertoire and perform it on the instruments for which it was originally written. Then, for historical reasons, this practice vanished, but was resumed during the 6os, parallel to many other forms of radicalisations. In a way, early music was part of the radical attack on everything that was perceived to be conservative in one way or another. So we can think of early music performers as critiquing the classical tradition as it had come to be, because they perceived it as degenerate and far removed from its origin. So, early music performers became, in a way, 68ers or a "hippie" generation phenomenon, and they eventually produced some leading figures, who were also tremendous artists and great musicians, leading them to attain a much higher degree of credibility when performing what eventually would be called historically informed performance.

RME: Is it possible to ask where this came from? Are we talking about Southern Europe or the Scandinavian countries? Are there specific places or specific environments/milieus that this emanated from? Or is it a general change that you are referring to from the 6os? 
RL: We are talking first and foremost about the countries that maintain a tradition going back to the period itself. Another phenomenon that was perhaps not so related to the "rebellious" attitude, was the fact that it was also used to highlight questions of national identity. One reason for all the attention it got was related to how it facilitated the promotion of a stronger national identity through a unique, historical national culture. So, in countries such as France, Spain - not so much in Italy because they never seem to identify as one country - and England, this became a topic and a means to focus on the country's own national history. So, France in the 1600 s and 170os, Spain even in the 1500s, and England, not least through Elizabethan music, as well as movements later in the Baroque with the development of English opera. So once again there was a connection to political development, and it was supported by a range of institutions that benefited from a sense of national identity fortified through culture. I can also add regarding this a small anecdote that is perhaps not shared so much, at least not in Germany. As I said, this revival started first in Germany in the interwar period. They started with what they called "Hausmusik" - Germans visited each other and played quintets for gamba and recorders and lute, music that they found in libraries. Eventually, this became more closely associated with propaganda for German national socialism. The Nazi Germans were very much concerned with exploiting historical German culture in their propaganda material, so they used artefacts from the German late romantic and medieval periods. In many ways, German early music acquired equal status with Richard Wagner as propaganda material. Consequentially, when the war ended, it became very difficult to reintroduce this music, due to its heavy associations with Nazi German propaganda.

DНØ: Regarding this development of performing early modern music: Is it possible to identify any current international trends? What does the big picture look like?

$\mathrm{RL}$ : What is interesting is that during the seventeenth and eighteenth centuries there were tremendous differences in terms of individual national styles and how they perceived music. There were lots of polemics, and our access to written sources shows in particular, tremendous polemics between French and Italian styles for instance. Now, in a 
strange way, this is something I find to be the case even today. I mean, the timelines go way back, and our present modes of communication are very close and intimate, but still - one could speculate whether it's due to the mentality of the people or the national identity. I see this very clearly, because I maintain a very close relationship to and living and working in Germany, France and Italy. It is almost parodically how, for instance, France struggles when performing high quality German and Italian music. And whenever they do, one can hear loud and clear that it is performed by French musicians. The same is also the case for Italians and Germans. In any case, it relates to very specific musical issues - if you listen to Italian musicians performing French baroque music, then you can know in advance that there are issues of tempo and articulation, and the general force of expression will be performed in a different way because the musicians are Italian.

DHØ: Yeah, I noticed things like this when I spent a year at the Hochschule für Musik in Würzburg, Germany. Even when it comes to repertoire from the mid-to-late twentieth century, they were more preoccupied with German composers - Heinz Holliger, Hans Werner Henze and so on - rather than French composers, such as Betsy Jolas, whose music I was studying at the time.

RME: How do you clarify your own position between research and performance?

RL: There is an emerging trend towards combining these two roles, in terms of what is considered research activity and what is considered artistic activity. In a way, I think it sometimes seems wrong to think that these two can be united. In the early music department, in particular, there remains for me a distinction between these two. I've never seen anyone who has successfully managed to break down that separation. Musicology seems to me still to be predicated on a very old idea of what science is, an idea that goes all the way back to Newton. The notion of verifiability or accountability grants a work of research the status of "scientific". There are aspects of music and the arts that are not concerned with this. The most important thing for me is how research and performance meet in this, as I mentioned earlier, "empty space" and how this serves as inspiration. Of course, it is essential to be able to describe and 
systematise what has happened throughout the history of music. But as a performer, I know that research only gets me so far regarding accuracy and knowledge of a certain practice. This is a bit special because research on a particular type of music that has not survived due to aural traditions is preoccupied with everything that is written down. We need to bear in mind that the reasons for describing things related to music and the arts are completely different today than what they were in the seventeenth century. In that period, when you wrote something down, it was for different reasons than it is for us today. We tend to forget that in that period, the most important element of handing down artistic impulses was that it happened directly: orally, not written. It also happened within the same regional and cultural space. A consequence of this was then a lack of motivation to write such impulses down.

Furthermore, the selection of [the] information available was then entirely conditioned around that. There is something I've often thought about: What we have of documentation from the Renaissance and Baroque originated shortly after the invention of book printing. Gutenberg's invention was in many ways the social media of the time, because it facilitated what was (at the time) speedy duplication of cultures. If we consider what has happened in our time, during the last two decades, with social media and the ability to communicate, extremely quickly, very private and personal things - it makes me think that, let's say for instance, in 200 years some researchers may want to figure out what happened in our time based on data material from Silicon Valley consisting of text messages. It could end up being completely detached from what the reality was, entirely contingent on the medium of communication. It seems that this was also the case at that time in the Renaissance. They were so entertained by the idea that one could write a preface to a score and it would be published, that they didn't think through whether what they wrote was essential or meaningful or important. Now, in terms of source criticism, it's important to question precisely how much authority should be given to these descriptions, even though they could be very well written and could aptly describe a given musical phenomenon. But the question remains whether the selection of texts remains representative. If it isn't, we are left with a radically different image of that period and the stylistic phenomena in question. 
DHØ: Yes, this is an exciting way of thinking because as a musician and a researcher, I think it is possible to combine this distinction appropriately so that it also serves the work of art itself, and not merely a scientific work that stands on its academic legs.

RE: I am thinking of a concept in music pedagogy that is now often referred to when discussing music curricula in schools: the relational turn. According to this perspective, each music activity situation is concerned with relational factors. You mentioned the topic of communication, and my question is whether the demand for communication is being taken a little too far. We are so fascinated by communication that maybe this could mean that we may forget the value of the music itself.

RL: Despite what I have already said, I belong with those who believe that the value of the work is judged to be higher, and is also more respected when you have developed deeper knowledge about it. Consequently, you may use or re-create the context that was relevant when the musical work was created. Finally, this is what we are doing. We believe that if one can re-create the conditions that were relevant at the time the piece of music was created, then this will be the best approach. Although I started from another perspective by saying that one could suffer a break in communication with the audience and then face a dilemma, I think it is fascinating to have academic and solid information when musicians start the process of re-creating a work, even for audiences today.

RME: When working with improvisation, is the state of feeling "free" the point of departure, or is it the knowledge of the work you have become acquainted with? Which is the best starting point for improvisation?

RL: Improvisation is precisely what turns the whole concept of historical authenticity into a practice of construction. In fact, it must be thrown away since it is no longer valid. Because the moment you improvise, this is a kind of spontaneous composition. And the moment you compose something new in an old-style framework, it is no longer an authentic continuation of that style. In a way, you should think that if you improvise, then you have to play the concert that was the day after the last concert was played at the time, and which never took place. It would be a kind of concept, as well.

DHØ: I sense a similar parallel between the role of an academic and the role of a performer. There is a kind of ethical responsibility in this. Perhaps 
in the last twenty or thirty years, at least in social research, this understanding of the researcher's role has gained greater relevance. The researcher is not just a neutral observer who works with a phenomenon from a distance, but he or she takes part in something that can always unfold in various ways. There is a crucial ethical responsibility in the decisions the researcher makes. And this is a bit like what you are talking about; the way we play and make choices when we either choose to improvise or relate to a kind of authentic ideal.

RME: Would you say that there are some unique things in the pedagogical practices that we work with, where you see changes? You have been working as a performer for many years. Are there some things you feel are essential in higher music education? As an experienced musician, what would you think characterises present-day performing music education?

RL: This is an important and, also a difficult question. Perhaps one thing I experience is that in many of the institutions I have been in contact with and worked for, there has been a strong desire to be creative and trendsetting. In a way, institutions aim to be historically upfront, and at the forefront of what happens in music cultural life in society in general. I am not sure if this is possible, nor if such goals should be the main task of a higher music education institution. I think of the fact that in Norway, people tend to call higher music education institutions music conservatories, we preserve something, ${ }^{1}$ in the sense of storing objects. Perhaps we sometimes store things without necessarily asking if we have chosen the most important elements.

And this has been one of the hallmarks of music institutions: When a phenomenon, a musical style, or a musical practice becomes old enough and clearly defined, it enters the conservatory or a college in order to be passed on further. However, there are many institutions that seem to want it the other way around: The institutions themselves create new styles and practices. I do not know, in fact, how far it is possible to sustain this development.

I experience that what we communicate to our students is a mixture of methods for and knowledge of how to progress in certain areas. 
And then, of course, we need to work with original material. Students ask for information and they seek knowledge about music. But, for the students, the most important experiences in their lives often occur after their education is completed. On the other hand, these experiences probably wouldn't have happened without having completed their degrees in higher music education.

RME: So, one needs to consider the balance between what to take care of and what we present among recent cultural trends. You do not always need to mirror a cultural "frontline".

RL: No, exactly. And there are a lot of differences in Europe in terms of how strong a country's national history is. What is unique in Norway is that in our music education we work mostly with music that does not have a particular Norwegian national history, since it is not our national music. And there are some continents that have the same situation, such as South and North America and many Asian countries, where European art and music occupy such firm positions. But still, European music is not part of the history of these countries. From my perspective, there may be a minor reference problem to understanding something based on one's own culture. However, it can also be an advantage, because one does not have the burden of the whole European tradition and culture on your shoulders when pursuing a free-thinking and creative artistic career, which I find very good as well.

In my experience from Scandinavian music education, we tend towards a very liberal relationship to what we are used to, especially compared to Germany. Here in Norway, we approach a lot of things without necessarily relating them to a bigger historical or cultural context. This is something I have always experienced. I maintain a deep respect for Norwegian musicians, in particular in the tradition of contemporary and improvised music. This is a unique Scandinavian phenomenon which began with Jan Garbarek: a type of Scandinavian music that's not exactly jazz, but more impressionistic improvised music. This tradition is an innovation based on the background we have in Norway, liberated in particular from American improvised music, but also from other European styles in general. It manages to create something that is connected to the Norwegian way of life, our feelings for nature and 
space, which can be considered distinctly Norwegian compared to Central European music.

DHØ: Perhaps a final question. In terms of teaching practices, when you talk about how to make choices where you do not have sufficient knowledge to know precisely how to perform strictly, in a credible way, in accordance with the source material: How does that dialectic work in specific teaching situations?

RL: As a teacher or supervisor in higher music performance education you may focus on current historical knowledge, and then emphasise that there are multiple approaches towards interpreting this historical information, before quickly adding that this is not everything there is. As part of the work process, you need to relate to the material in a way that you feel is important. We have the principle of freedom under responsibility: It is essential to know what one is doing differently, and perhaps even doing contradictory to the rules, thereby calling things what they are. It is very much a matter of acquiring as much as possible of the source material you know, then trying to understand it alongside source criticism: Is this a representative selection of information according to the topic in question, for whom was it written, why was it written, and can it be understood in any other way? Furthermore, when you have completed this process, you cannot get very much further when trying to view it from different perspectives. The remaining lack of knowledge then becomes a space for creative artistic freedom. What always applies to artistic activity is personal taste and universality, which means whether one's choices are recognised as valuable in a community. This is a standard criterion for all kinds of artistic activity. This is what applies, and there are no principles and no "Baroque police" that can override my decisions. This is the essential component, and we may then use this lack of information as a source of creativity. 


\title{
CHAPTER 6
}

\section{Early Music in an Interdisciplinary Artistic Production: The Project Pluvinel's Academy}

\author{
Randi Margrethe Eidsaa \\ Professor of Music Education, University of Agder
}

\begin{abstract}
This chapter explores the previously completed interdisciplinary performance project Pluvinel's Academy by investigating the production process, aesthetic dimensions and educational relevance. Early music repertoires and historical narratives are the core elements of the performance concept, which is inspired by the American musicologist Kate van Orden's book Music, Discipline, and Arms in Early Modern France (van Orden, 2005), and the article "Komponisten som smisket med Solkongen" by Rolfhamre (2017). Pluvinel's Academy was a pilot project which presented a combination of artistic expressions and equestrian sport, developed in an educational environment and presented in a riding hall. The participant group included fifteen music performance students, professional guest performers and a group of riders and their horses. The various aspects of the project will be presented and discussed in relation to artistic research perspectives and the early music objectives presented in this anthology, primarily related to pedagogy. The chapter highlights creating new works of art, the Pluvinel's Academy performance, and suggests that early music is valuable as material in an interdisciplinary performance concept in pedagogical settings.
\end{abstract}

Keywords: early music, artistic research, interdisciplinarity, collaboration

\section{Prelude}

Music was not just a pastime that was solely about beautifully realising a work of art. Music was also about taking part in social life to develop contact with others. Moreover, even more important, music was a tool for creating emotions and relationships. (Rolfhamre, 2017)

Citation: Eidsaa, R. M. (2022). Early music in an interdisciplinary artistic production: The project Pluvinel's academy. In R. Rolfhamre \& E. Angelo (Eds.), Views on early music as representation: Invitations, congruity, performance (MusPed:Research No. 4, Ch. 6, pp. 149-175). Cappelen Damm Akademisk. https://doi.org/10.23865/noasp.157.ch6

Licens: CC BY-NC-ND 4.0 
The above vignette provides a glimpse into music philosophy in the early 1600 , which through the exploration of the completed artistic project Pluvinel's Academy, expanded my knowledge of early music performance. My interest in early music and Renaissance culture was sparked in 2010 during an encounter with Trollspeilet, a group of riders who promote medieval equestrian tournament presentations at cultural events in Norway. Some years later, I met the riders again at the Monteriggioni Medieval Festival in Siena, Italy.

At the festival, I experienced how visitors of all ages enjoyed participating in music, dance, pantomimes and other activities in a Renaissance environment. ${ }^{1}$ Inspired by the medieval equestrian show presented by Trollspeilet at the Italian festival, I searched through historical sources to create a "history play" for riders and dancers. During the production process, I discovered The Maneige Royal a book written by the French riding master and military commander Antoine de Pluvinel, as well as historians' descriptions of his work and the institution he established in Paris in 1594, Academie d'Equitation, referred to as Pluvinel's Academy.

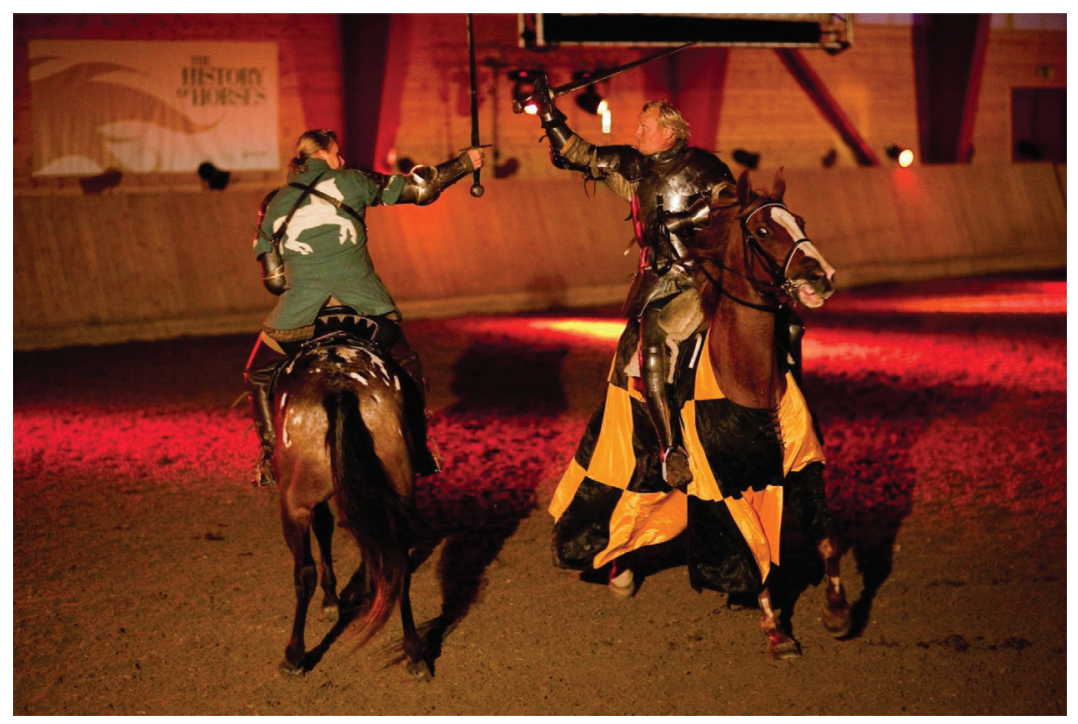

Figure 1. Medieval Riders From Trollspeilet in the Performance "The History of Horses" in Kristiansand, Norway

Photographer: Roger Svalsrød. Used with permission of the photographer.

1 https://www.youtube.com/watch?v=IJeymUTheFQ 
American professor, Kate van Orden, has done an in-depth study of French culture and the educational philosophy which characterised the Pluvinel's Academy project. This chapter presents how research on early modern France (van Orden, 2005) and early music (Rolfhamre, 2017, 2019) generated aesthetic outcomes that were studied in retrospect through artistic research (Borgdorff, 2011; Correia et al., 2018; Holgersen 2019; Leavy, 2018).

\section{Introduction}

Pluvinel's Academy was designed as a practice project for fifteen Bachelor of music performance students at the University of Agder in Kristiansand, Norway. This chapter revisits the work process, including two artistic performances, in 2016 and 2017. To re-examine a completed project, I have adapted methodological tools related to artistic research or "arts-based research" to "gain new insights, to show multiple meanings, discover interdisciplinary connections and to produce research which may have an impact in an educational context" (Leavy, 2018, p. 9). Pedagogy was the driving force behind the creation of the Pluvinel's Academy practice project. However, the re-examination of the 2016 and 2017 performances also aims to reflect academic, pedagogical and artistic research perspectives.

In the introductory chapter, the editors state that early music performance in this anthology happens through pedagogy. They refer to the broad capabilities early music performances appear to have: the ability to present, enact, re-enact, live and re-live, concretise and fantasise a historical past. This chapter is one of the explicitly pedagogical contributions to the anthology, and early music is portrayed not only as "an instrument to be used within an educational setting ..., but also as something primarily pedagogical in its formation and re-formation" (Rolfhamre \& Angelo, 2022, p. 12). Consequently, it highlights how early music repertoires have been combined with historical narratives and equestrian sport in a performance concept. The research questions are

- In what ways were early music repertoires and early music aesthetics used in concretising a historical past in artistic practice in a pedagogical setting?

- What was the knowledge production in the Pluvinel's Academy project? 


\section{Context}

The educational context that made it possible to develop the Pluvinel's Academy project was the 5 -credit course, musical communication, in the Bachelor program in music performance at the University of Agder. ${ }^{2}$ The Bachelor program was a three-year pilot project from 2015 to 2018 that highlighted creative approaches to music performance and aimed at preparing students for their future careers as musicians. The performance idea was based on my general interest in exploring musical repertoires in educational environments, especially genres defined as classical music or art music.

Artistic practices are always positioned and embedded, and "artistic actions acquire their meaning in interchange with relevant environments" (Borgdorff, 2011, p. 56). In this case, the point of departure is a pragmatic one since practice projects were mandatory in the musical communication course, in order to help develop students' skills relating to collaborative activities with non-musicians outside campus environments. Thus, the Pluvinel's Academy project was developed for the purpose of education in an academic and pedagogical setting. However, an additional environment, in which the artistic expressions referred to in this chapter gain their meaning, namely the equestrian centre, was the venue for the final presentations. Since I am involved in equestrian sports as an after-school activity for children and young people in the local community, a collaboration between the university and a local riding school was possible. Small-scale shows and presentations were inclusive components in the riders' preparation for competitions in show jumping and dressage. Consequently, the Pluvinel's Academy project was at the intersection between art practices and sports activity. This chapter sheds light on how the project became an encounter between participants from the disciplines of music performing, and equestrian sports dressage.

2 https://www.uia.no/en/studieplaner/topic/MUK173-1 


\section{Methodology}

This chapter refers to revisiting a completed project, a research process inspired by Holgersen (2019). The explorative process differs from conducting a research procedure parallel to activities in an ongoing project. In this case, to revisit Pluvinel's Academy means to study project intentions, the students' project reports, performance photos and videoclips, and to reflect on my process when transforming ideas into various artistic expressions, and merge them into an aesthetic performance concept. Thus, the chapter reflects how artistic research may unite aesthetic and academic approaches in "broadening and deepening our knowledge and understanding of the discipline or disciplines in question" (Borgdorff, 2011, p. 54).

\section{Ethical issues and critical reflections}

The revisited artistic project is part of a bachelor course module highlighting creative approaches to music performing and collaborative concepts. In this case, the revisit implies looking back on a past artistic project. The project was also part of a Bachelor programme that had already been explored (Eidsaa \& Schau, 2021). This programme was a three-year pilot project, Bachelor in music performance, funded by the University of Agder from 2015 to 2018. The programme focused on contextual thinking, student-centred artistic concepts and cross-aesthetic perspectives on performance. After explorative investigations involving students and teachers, the programme was revised in June 2018 (Eidsaa \& Schau, 2021).

Revisiting the Pluvinel's Academy project investigates a practice in which I was personally involved, which may generate challenges connected to questions about the researcher's insider or outsider roles and perspectives (Balsnes, 2009). However, since the Bachelor programme was already defined as a pilot project, the students were informed that the curriculum, the methodological approaches and their responses to the project's design by the module teachers would be objects for exploration and critical reflection, and an arena for data collection. Thus, as participants in a newly developed educational programme, they knew that their 
perspectives in discussions and reflection reports would be used to shed light on, correct, and adjust the new bachelor programme curriculum. ${ }^{3}$

Warren (2014), who discusses music and ethical responsibility, argues that since music is an activity of relationships, ethical issues will arise in situations where individuals meet to be involved in music or other artistic practices (Warren, 2014, p. 24). During the Pluvinel's Academy work process, few controversial issues seemed to emerge. However, the students were concerned that the number of hours spent on the performance workshop resulted in fewer hours of solo instrumental rehearsing. ${ }^{4}$ An additional ethical concern was related to designing collaborative projects with outside campus groups. Collaboration between university students and partnership institutions or freelance performers, should always be beneficial to both parties. An artistic project may appear as an intrusion in the partnership group's daily life if not carefully prepared. In his article “The Infectious Outsider: Towards a Pedagogy for Artist Educators", Owen (2005) reflects on collaborative partnerships where individuals from different cultural backgrounds "meet and interact in particular points of space and time" (Owen, 2005, p. 9). The Pluvinel's Academy project was intended to be a meeting place enabling interaction, and for this reason it was essential to conduct the project with respect for all participants, thus defining each group's role and responsibility so that the project became clear and transparent (Hallam, 2011). As guests, the music students and we as teachers and instructors, needed to follow the routines of the equestrian centre to avoid our project being reduced to an intrusion in daily activities.

\section{Artistic research}

This revisiting of the Pluvinel's Academy project through artistic research perspectives aims to unveil an artistic practice like a complex web, where multiple elements and circumstances constitute each other (Beech et al.,

3 As responsible for the Pluvinel's Academy project, I was in dialogue with the students about using their reports, performance videos and photos when evaluating the project in the course module musical communication (MUK173).

4 The music performer students and their perspectives on main instrument modules are discussed in the article "Higher Music Performance Education in a Changing World. Towards a New Curriculum? A Report from a Pilot Project” (Eidsaa \& Schau, 2021). 
2015, p. 18). In this case, the elements referred to are "materials", such as music, narratives, collaboration and equestrian sports presentations, and "actions" of the various participant groups. Data collection includes observation notes, sound recordings, video recordings, students' reports and photos.

Even though this exploration was done in retrospect, the research process for Pluvinel's Academy could be defined to have started when the idea was born. Correia et al. (2018) assert that artistic research takes place when the artist starts "establishing new relationships with materials and with degraded environments promoted by myths, allowing for the emergence of new ones" (Correia et al., 2018, p. 14). Borgdorff (2011) describes every process of creating art as research, claiming that:

Every artist does research as she works, as she tries to find the right material, the right subject, as she looks for information and techniques to use in her studio or atelier, or when she encounters something, changes something or begins anew in the course of her work. (Borgdorff, 2010, p. 44)

Thus, revisiting Pluvinel's Academy is an exploration of early music performance in a pedagogical setting, the use of historical documentary sources in artistic presentations, the relationship between the music students, outside campus participants and professional performers. Furthermore, it is about merging aesthetic expressions and equestrian sports in artistic presentations, and the relationship between the human participants and the horses. In this study, the creative process formed the pathway through which new insights, understanding and products came into being (Borgdorff, 2010, p. 44).

Østern (2017) defines artistic research as "a meaning-seeking process where the researcher uses a wide range of formal language as well as various modalities". The exploration of the completed Pluvinel's Academy project uses traditional verbal texts and other written formats such as vignettes, manuscript excerpts and quotations from students' reflection reports, and assessment papers. Performance photos and video clips exemplify various components of the project and are essential modalities for documentation. 
This retrospective study of Pluvinel's Academy was an investigation of how early music can be adapted into artistic concepts and be used pedagogically. The study includes analysis of artistic activities and objects, and of the pilot project's Bachelor programme in music performance, 2015 to 2018. This chapter also mirrors how traditional academic research, clarified through written arguments, sheds light on practical-artistic work (Correia, 2018, p. 14 f.). In the concluding section of the chapter, there is a reflection on early music as a core element in artistic productions in educational settings.

\section{Project presentation}

Pluvinel's Academy was a multifaceted practice-based project, and the themes explored in this chapter have been limited to interdisciplinarity, music repertoires, concert dramaturgy and collaboration.

\section{Interdisciplinarity}

Pluvinel's Academy was an interdisciplinary project using multimedia communication tools such as live music performance, recorded music, costumes and stage lightning, horses and narratives. The apparent interdisciplinarity aspects are the aesthetic expressions that appeared when components from the arts and sports disciplines were transformed into practical actions and put together on a stage. However, the interdisciplinary dimension exceeds the tangible result, since the project is deeply rooted in history and philosophy. Consequently, Pluvinel's Academy could be understood as a project that reflects a transdisciplinary pedagogy, a theme-based interdisciplinary approach (Bolstad, 2020, p. 4) ${ }^{6}$ Finley (2018) refers to multi-methods arts-based research when two or more art forms are used in a multimedia presentation. She uses the American musical Hamilton as an example:

5 https://www.uia.no/en/research/kunstfag/remp

6 Bolstad (2020) presents a four-level model of interdisciplinarity, ranging from intradisciplinarity, multidisciplinarity, interdisciplinarity to transdisciplinarity. 
In the instance of Hamilton, multimodal arts have been used to analyse information and to enhance the qualitative methods of biographical research - art is not only used as an analytical tool for understanding existing information but also generates new and exciting ways of thinking about data/information. (Finley, 2018, p. 478)

The Pluvinel's Academy project was a small-scale concept compared to the elaborate Broadway production of Hamilton, but it reflects some of the same ideas, such as: using aesthetic expressions as spaces for different voices; and re-telling ways of thinking closely connected to politics in a defined historical place and time (Finley, 2018, p. 478). I have included two examples which show how multimodal perspectives became artistic expressions.

Example 1: Transdisciplinarity. Van Orden (2005) states that the sixteenth century saw a revolution in public schooling in France, and one of the most famous places was Pluvinel's Academy in Paris. Antoine de Pluvinel was the school manager, and the core curriculum was related to cavalry disciplines. Despite this, the military institution's educational thinking was rooted in Greek philosophy programs that juxtaposed military activity with other disciplines, such as music. Van Orden explains:

The grouping of music with sport and arms may seem unusual given the disciplinary boundaries that placed music in the scholastic quadrivium of mathematical sciences. However, the formulation came from the Greeks and enjoyed significant currency in the sixteenth century. In both the Laws and the Republic, Plato treated gymnastics and music side by side, maintaining that the best training in gymnastics would resemble music training. Like other physical activities proper to a nobleman, music developed adroitness and agility. (van Orden, 2005, pp. 38-39)

The reason for bringing in music as a subject side by side with military exercises was that music created the soul's well-being, just as physical exercises were well-being for the body. By teaching the young men activities, such as music, dance, painting and literature, they would learn to behave meaningfully in social situations, since noblemen lacked 
competence in socialising in non-violent environments. Van Orden refers to their "need for training in politeness, civil conversation and even skills in social dance so that they could become gentilhommes" (van Orden, 2005, p. 42).

Example 2: Historical sources as performance content. In equestrian sports environments, Antoine de Pluvinel is a well-known historical person because he was one of the first authors to promote humane training methods of war horses. He was associated with "good horsemanship". The term "horsemanship" usually refers to the art of riding, handling and training horses (Encyclopædia Britannica). Pluvinel was the teacher of King Louis XIII and the author of books on equestrian training. His book Le Maneige Royal (1626) became famous for treating the horse with humane training methods and not as an unwilling slave. Pluvinel focused on the rider's friendly and kind approach to enhance the horse's natural movements, which he tries to regulate and make more pronounced through training without any loss of the animal's natural charm. ${ }^{7}$ Famous quotations from his book were selected for the performance narrative, among them the following text:

I go further and claim that it is unnecessary to beat the horse at the beginning, the middle, or the end (if one can help it), as it is much more necessary to train him by gentleness (if there are the means) than by harshness since a horse who works with pleasure moves much more gracefully than a horse who is dominated by force.

If possible, one must be sparing with punishment and lavish with caresses, as I have already said, and I will repeat it in order to make the horse obey and go out of pleasure rather than discomfort. (Pluvinel, 1626, pp. $29 \& 47)^{8}$

7 https://www.dressageandsporthorse.com/dressage-history

8 http://imh.org/exhibits/online/legacy-of-the-horse/xenophon 


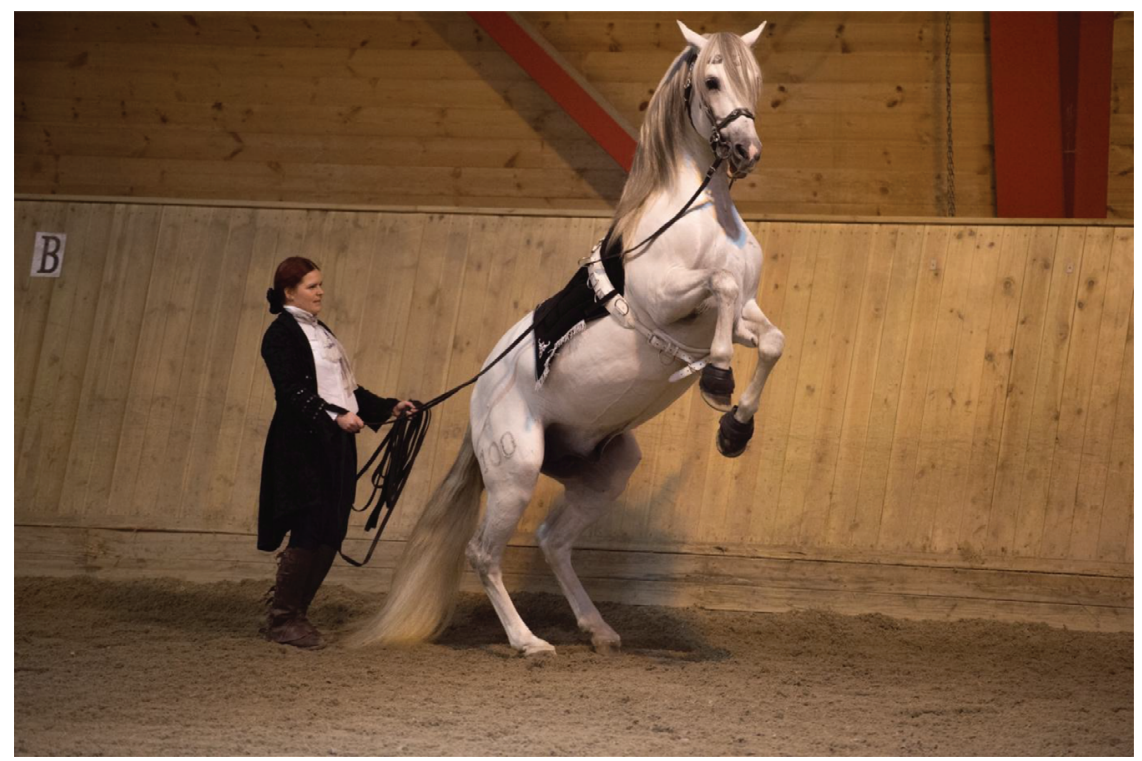

Figure 2. The Professional Rider Rozemarijn Keuning and her Horse Gesto Ram in a Re-Presentation of Pluvinel's Training Principles During the Pluvinel's Academy Performance in 2016 Photographer: Anders Martinsen. Used with permission of the photographer.

The inclusion of horses in stage productions demands carefully exposing the horses to stage lighting, sound volumes, musical instruments, note stands and the ensemble's movements.

In an equestrian venue, these are intrusive objects and disruptive actions. Consequently, the equipages' function as aesthetic elements in the Pluvinel's Academy performances was balanced against animal welfare concerns and ethical principles. These issues will be commented on in the chapter summary.

Example 3: Costumes. In artistic presentations, costumes may create moods that contrast with everyday life, and spark the ensemble's motivation to act and communicate. The music students considered costumes to be valuable, as one student commented: "When we started the project, I must say that I was very motivated. Much of the reason was the costumes which we borrowed from Rosegården" (Student 1, project report, 3 November 2017). Even if the costumes were not historically correct, the outfits were professionally designed and complemented 
the overall visual concept. The director of the costume department addressed students during a workshop and challenged them to reflect on their stage identity:

Why do we bring in costumes at a concert? Is it to take up your time or to make you look funny? Not at all. There are two questions all performers should think about when entering a stage: Firstly, how will I present my identity? What does my costume reflect? Secondly, am I a member of a group, or will I be presented as a soloist? Musicians tend to think that they are invisible and that the audience is only watching their instrument. However, the audience is watching the performer. They ask who that person on the stage is and their story. (Interview, 25 February 2018)

The costume director's rationale for using costumes in the presentation was to enhance the students' awareness of how colours, shapes and textiles become aesthetic expressions, which facilitate both the performers' and the audience's entrance into imaginary settings and historical pasts.

\section{The music}

The repertoire for Pluvinel's Academy included Renaissance and Baroque compositions, which were supplied by film music compositions. The music was performed live or prerecorded for the students' duplication on stage. Besides, published orchestral works were adapted for the equestrian parts, and played through the venue's sound equipment.

The 2016 repertoire included "Come Again" by J. Dowland (1563-1626), the French folksong "L'aio dè Rotso" re-arranged by J. Canteloupe for the work Chants d'Auverne composed in 1923-1930, "Lascia ch'io pianga" by G. F. Händel (1685-1759) and "Sweeter Than Roses" by H. Purcell (16591695).The songs were accompanied by a baroque guitar, violin or keyboard and interwoven between narratives presented by the singer, who also appeared as conferencier, exemplified in Pluvinels Akademi Fransk folkevise. ${ }^{9}$ In this performance, a Master student's recorded music was an

9 https://www.youtube.com/watch?v=scFTvPt22fc 
essential component. The repertoire was based on his Bachelor exam concert and included "Toccata Arpeggiate" (Kapsberger, 1580-1651), "Folias Gallegas” (de Murcia, 1673-1739), “Zaraband Espanola” (Sanz, 1640-1710), "Etude 3 Opus 6o" (Carcassi, 1792-1853), and "Lagrima" (Tarrega, 18521909). The pieces were recorded by four students who played the guitar, harmonium, violin and percussion instruments, and accompanied various equestrian presentations, such as shown in Pluvinel Toccata Espanola (del 2) Gesto. ${ }^{10}$

The 2017 performance included well-known pieces such as "Ave Maria”, "Badinerie”, "Air on the G String” by J.S. Bach (1685-1750), and "Let Us Wander" by H. Purcell (1659-1695). One of the students created a brief drama sequence accompanied by a live keyboard version of "Hedwig's Theme" by John Williams (b. 1932) from Harry Potter (2001) to activate the youngest children. When the ensemble gathered on stage for the "café scene", they duplicated the recorded songs "Dame Tartine" and "En Passant par La Lorraine" (Pluvinel Forestilling 2). ${ }^{11}$ The lutenist played "Chaconne" by de Visée (1650-1725) and "Vittoria, Mio Core" by Carissimi (1605-1674) in a duet with a specialist in early vocal music. An excerpt from the movie Le Roi Danse (2000) accompanied a dance sequence. $^{12}$

Recorded music by J.S. Bach, J.B. Lully (1632-1687) and the French film music composer Alexandre Desplat (b. 1961) was used during carriage driving, pas de deux dressage and quadrilles. The riders prepared their parts in accordance with the music's dynamics, tempi, timbre and moods. Thus, the music repertoire functioned as connective lines between the music students and the riders as they shared a "momentary space for interaction" (O’ Neill, 2011 p. 183).

\footnotetext{
10 https://www.youtube.com/watch?v=bgLrzi2X2sk

11 https://www.youtube.com/watch?v=LbwiwAeYITo The example includes a pre-recorded excerpt played by the lute player who took part in the performance.

12 The movie portraits King Louis XIV and the aristocrat's companion, the composer Jean-Baptiste Lully. Themes related to music, society and politics may easily be delineated from Le roi danse.
} 


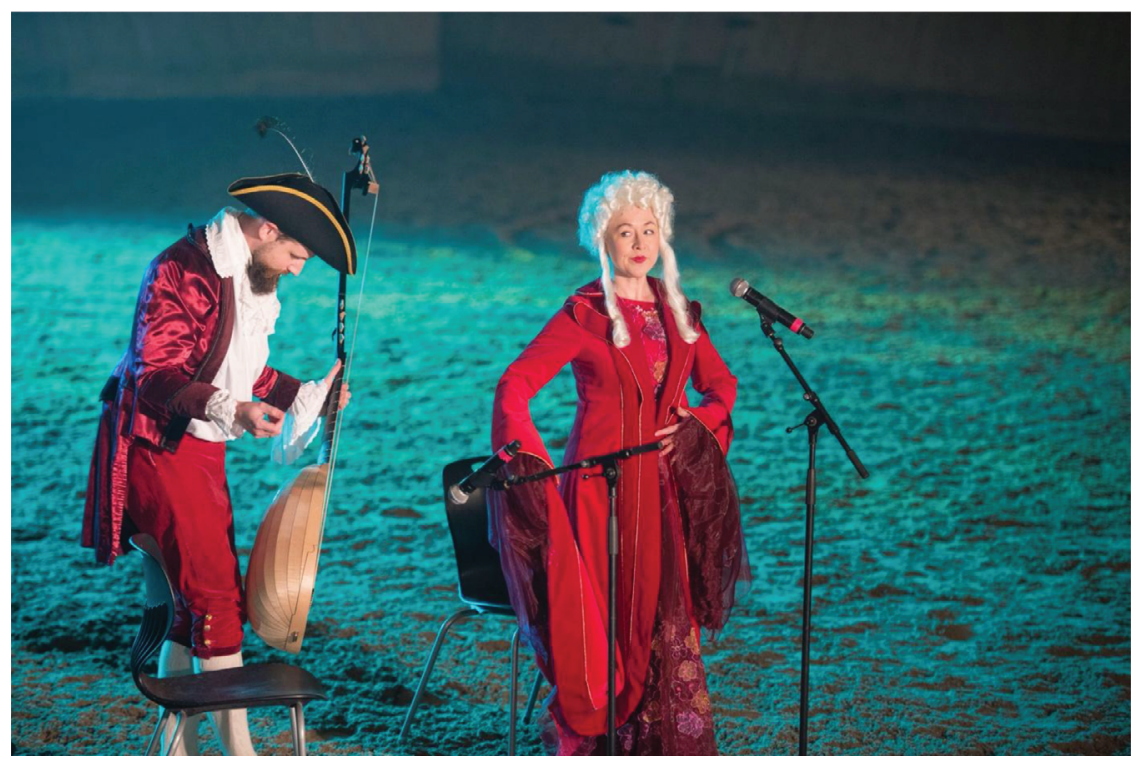

Figure 3. The Lutenist and the Singer Present Early Music in the Pluvinel's Academy Performance in 2017

Photographer: Anders Martinsen. Used with permission of the photographer.

\section{Concert dramaturgy}

In this chapter, the term "concert dramaturgy" is used to describe the content of the artistic performance, including the musical repertoire, lyrics and narratives, the movements on stage, the aesthetic moods and additional art forms. The term comes from Greek and is defined as "the principle of dramatic composition" (Chambers $20^{\text {th }}$ Century Dictionary, n.d.). Sønning (in press) explains dramaturgy as the theory of "how to structure, compose any performance or play, with all communicative codes and tools considered consciously, from start to end". In the Pluvinel's Academy performance, solemnity, jollity, anxiety, elegance and overconfidence were acted out as "communicative codes and tools" to mirror a spectre of emotions and atmospheres (Sønning, in press).

The performance manuscript. The Pluvinel's Academy manuscript narrative was based on fictional, dramaturgical and pedagogical considerations. Selected items from van Orden's research (van Orden, 2005) and extracts of the most famous quotations from Antoine de Pluvinel's 
book Le Maneige Royal, published in 1625, were combined to create the plot and the verbal sequences of the Pluvinel's Academy performance. Since family audiences were the primary target group for the presentations, ideas from the Harry Potter chronicles were added to the historical sources.

The various components were merged into monologues, dialogues, quotations and storytelling. When exploring the writing process in retrospect, the development of the complete stage manuscript could be understood as a "fictionalising process", described by Leavy (2018) as "a marriage between the real and the imaginary". Leavy explains the process as taking "identifiable items from social reality, importing them into a fictional world" (Leavy, 2018, p. 195). In this case, the elements that reflected history were names of places and events, and references to early modern French education philosophy. The historical elements were "translated" into a fictional world that was created to communicate with the participants and the audience. The writing of texts demanded being conscious of themes and motifs, language style and tone, and characterisation, which is "the creation of those who people the story" (Leavy, 1998, p. 198). In the 2016 performance, Pluvinel's voice was "peopled" by the professional singer. In the 2017 performance, the narrative reflected correspondence, through letters, between an academy student and his mother.

Example 1: The lute playing. The Pluvinel's Academy performance parts were structured in sections with school schedule headlines such as: Riding, Marching and Gymnastics, Fencing, Political Discussions, Literature, Dance and The Playing of the Lute. The example below reflects how van Orden's historical research was interwoven with imaginative elements: ${ }^{13}$

\footnotetext{
13 van Orden (2005) explains that the young aristocratic students at Pluvinel's Academy hurried between the lectures. The illustration Figure 2.1. "Abraham Bosse, Cavalier playing the Lute" in Music, Disciplines and Arms in Early Modern France shows a lute player with his riding boots and spurs on. According to van Orden, the music teachers seemed to have been lutenists. To play the lute was counted as a skill among gentlemen, she says that "many fathers believed their sons had learned nothing if they did not take it up" (van Orden, 2005, p. 45).
} 
Every morning there is a riding lesson, and after this follows training in the use of a weapon and then fencing. Moreover, every student must play the lute. The lute teacher arrives every Wednesday at noon. We need to rush from the fencing lessons to the music room without having time to change clothes! (Excerpt from Narrative 1, Pluvinel's Academy performance, 2017)

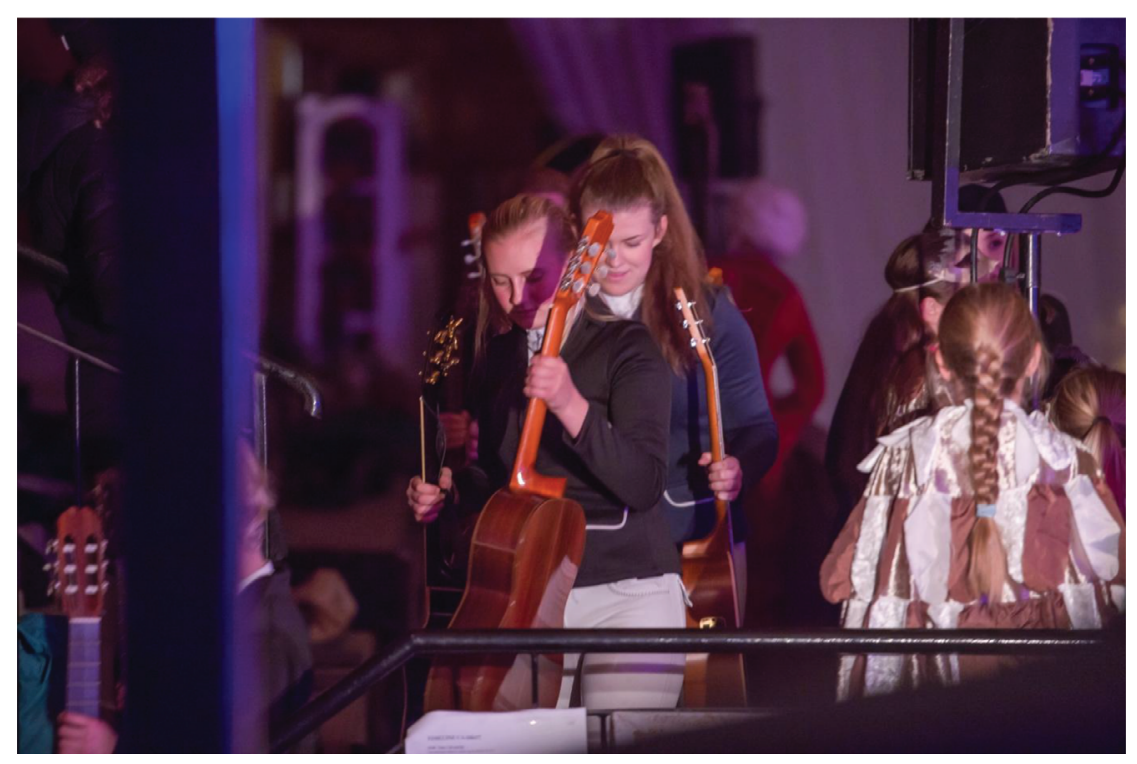

Figure 4. Riders Carrying the Music Students' Guitars During the Pluvinel's Academy 2017 Performance

Photographer: Anders Martinsen. Used with permission of the photographer.

As a dramaturgical tool, a group of students arrived at this stage in the performance, followed by riders on foot, carrying guitars. Parallel to their entrance, a professional lute player entered the stage and performed two early music compositions. The music students acted as pupils in a lute lesson and practised the composition "Arie di Firenze per la C", inspired by Ensemble Kapsberger and Rolf Lislevand (Alfabeto, 2001). The students' acting as a group of indifferent spectators and lute players, the use of guitars as aesthetic objects, and the professional musician solemnly rapturous as the "lute teacher", reflected a satirical mood that seemed to communicate effectively with the audience, who were mainly individuals with little knowledge of early music. 
Example 2: Performance elements. Based on former research, ensembles' search for musical repertoire, narratives, and artistic concepts to use in creative performance concepts is time-consuming and demands extensive scaffolding (Eidsaa, 2015, 2018). Decision-making processes in groups are complex, and the participants need the freedom to experiment and take risks (Fautley \& Savage, 2007, p. 64 f.).

For this reason, the instructors and professionals pre-selected the artistic content and discussed each component with the ensemble. Consequently, ensemble tasks were focused on developing the participants' aesthetic, music-technical and interpretative skills and enhancing audience communication, mentored by the professionals. One of the students commented:

It was smart that the teacher gave us a fixed repertoire at an early stage of the project. Consequently, it was easier for the students to understand their tasks from the beginning of the project. A professional choir director was hired for the rehearsal of the songs. Her instruction worked nicely. However, it was challenging for students in their 20s to sing French folk songs from the seventeenth century, but the choir director played an essential role in the success. (Student 8, project report, 20 November 2017)

It was not only the music that was fixed. The student ensemble worked with a manuscript from the very start of the project, since verbal texts were essential and functioned as a dramaturgical frame throughout the performance.

The verbal content demanded the presentation of various moods, among them the notion of humour. The professional singer in the 2016 performance coloured Pluvinel's quotation with an exaggerated FrenchBritish intonation. ${ }^{14}$ The actor developed this humoristic element further during the 2017 performance. He adopted nonsense language into the students' parodic imitation of military commands and noblemen's conversations in the new social groups in Paris salons during the early 1600 s (van Orden, 2005, p. 101). The actor's theatrical experience

\footnotetext{
14 The pronunciation joke was received as "funny" as shown in the video Pluvinel Introduksjon. https://www.youtube.com/watch?v=MXMBglGMvGA
} 
influenced the music students and enhanced their confidence on stage. One commented, "I never thought that me and my fellow student would have taken the risk to create a nonsense language dialogue on the spot, during a performance" (Informal talk, student 9, 20 November 2017).

Another student mentioned that despite being illiterate in French, he became confident on stage since he knew that in this case, to have the correct intonation was less important than communicating the phonetic sound of the language. The student commented: "To sing in French was complicated. However, due to the concept, I could use nonsense words when I forgot how to pronounce French correctly" (Student 5, project report, 20 November 2017).

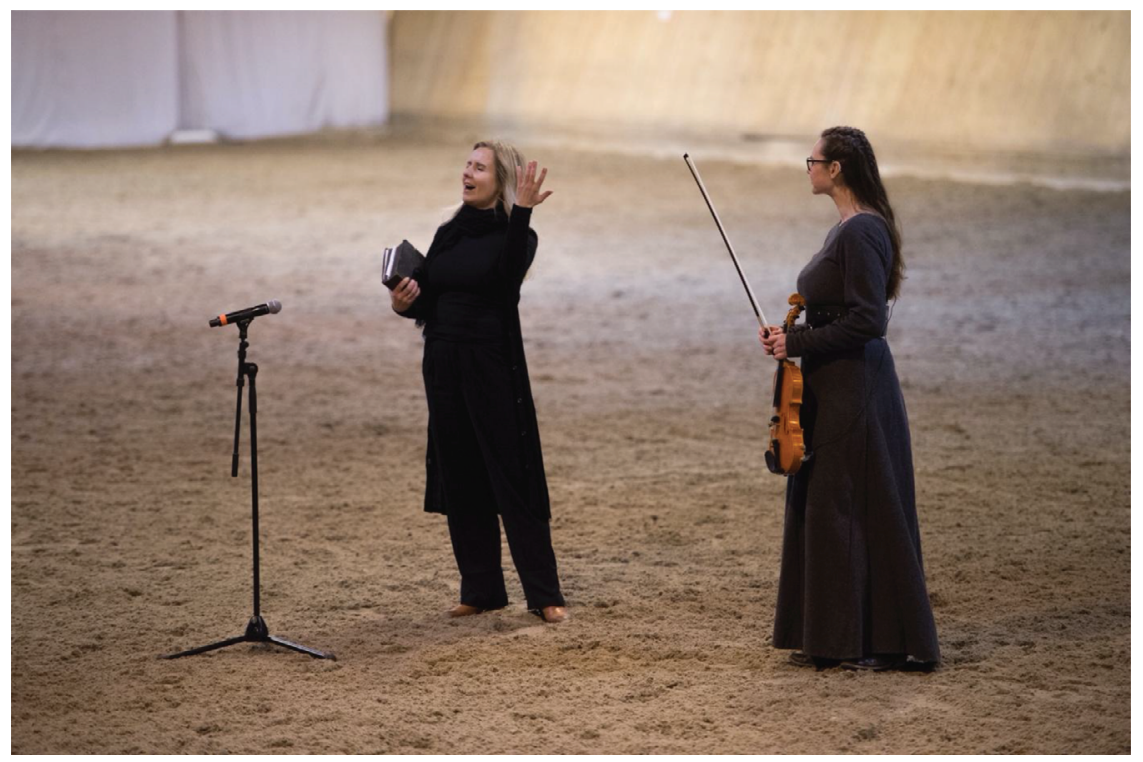

Figure 5. Professional Singer and a Master Student During the Pluvinel's Academy Performance in 2016 Their confidence bolstered the students' communication with the audience.

Photographer: Anders Martinsen. Used with permission of the photographer.

\section{Collaboration}

The new relationships developed during the Pluvinel's Academy performance project included the professional performers and the students' ensemble, the students and the equestrian team, the ensembles and the audience, and the horses and the people. The discussion below focuses on 
collaboration between the music students and the professional performers, and the relationship between horses and participants.

Scaffolding. Two professional guest performers were well prepared and shared an open, attentive and inclusive approach towards the students, me as a project leader, and the upcoming presentations. Their professional attitude provided adequate support and kept the students' performance anxiety at a minimum. One student commented on the issue, as shown below:

When we first started with Pluvinel's Academy, I was a little sceptical about how it would all go. How could we convey something so distant to our daily life? Only one of us had been in the military, which was different to the military at the end of the 16th century. With the assistance of the actor, we understood that we needed to act out our performance roles in a severe and concentrated mood. (Student 2, project report, 20 November 2017)

Based on former research experience with collaborative artistic projects, Vygotsky's notion of "the zone of proximal development" is frequently seen in action in successful educational partnership projects (Eidsaa, 2018). Professional performers' expertise is vital for the music students' construction of meaning in obligatory curriculum projects (Eidsaa, in press). This is mirrored in the student's comment below:

The collaboration with the actor was fantastic. Everyone in the group liked him very much and quickly noticed his skills in acting. At the same time, he was serious and wanted to help to create something unique. (Student 3, project report, 20 November 2017)

The reflection above shows that when participants on different levels of ability collaborate in inclusive environments, those involved may achieve a higher level as a group, and as individual participants (Fautley \& Savage, 2007, p. 61). One of the students explained:

The actor assisted us in the dramaturgical part; he told us where to move, how to use our voices, and how we should relate to the various performance elements. In particular, it was of great help that he joined us on stage, doing his own thing together with us. (Student 8, project report, 20 November 2017) 
The music students performed both popular and classical music in formal concerts and informal settings. They were less experienced in collaborations with non-musicians, performing in alternative venues and communicating with family audiences. Consequently, the music students needed to rethink their performing ideas and adjust their presentations in relation to the various dramaturgical sections. The professionals assisted the students in finding connections between performance moods and their aesthetic interpretations, and how changing physical positions and movements on stage could be used to enhance communication with the audience. In collaboration with the project leader, the students also solved challenges connected to venue acoustics, technical equipment and the recording and digitalisation of selected compositions to create high-quality sound files for the playback files used on stage. The inclusion of professionals in educational, artistic performances is usually a driving force in collaborative work. Close encounters between children, students, amateur adults and highly competent individuals motivate participants on all levels.

The presence of the horses. Horses have been used in military parades, official ceremonies and artistic performances since ancient times. The inclusion of horses in artistic events can be discussed from various perspectives, such as a historical point of view, a relational perspective, artistic perspectives, and a practice-based approach. In the Pluvinel's Academy performances, the interaction between horses and humans appeared from the introduction throughout the various scenes to the performance's conclusion. Firstly, the historical dimension was evident since the performance refers to historical places and people connected to equestrian military education. One student commented that the equestrian inclusion created a feeling of authenticity, as illustrated below:

It was cool that we got to collaborate with the participants from the riding hall. The fact that the riders were involved with us provided a more credible and fun tool for the presentation. (Student 4, project report, 20 November 2017).

Secondly, relational elements were observed through the close encounters between the equipages and the students in sequences of dance, marching parades and acting. The riding sequences demanded trust between 
horses and riders, and the riders' competence in controlling the situation. Some of the students were frightened to be in the arena when the horses were around. However, after having observed the riders controlling their horses, they gradually became confident. Thus, they adjusted to "the demands of the venue" (Boyce-Tillman, 2018, p. 113). Horses on an advanced level of dressage were presented in both performances, but the movements that originated in early modern France were performed only during the 2016 performance. ${ }^{15}$ The equipage presented some of the movements van Orden describes, among them the elevated postures derived from natural movements, such as rearing, kicking and pivoting on the haunches, which were useful in battles (van Orden, 2005, p. 235-284). Such elevated postures demand close communication between the rider and the horse, characterised by mutual trust and confidence. The photo below shows the professional rider in elevated posture, one of the most advanced movements a rider may ask the horse to do.

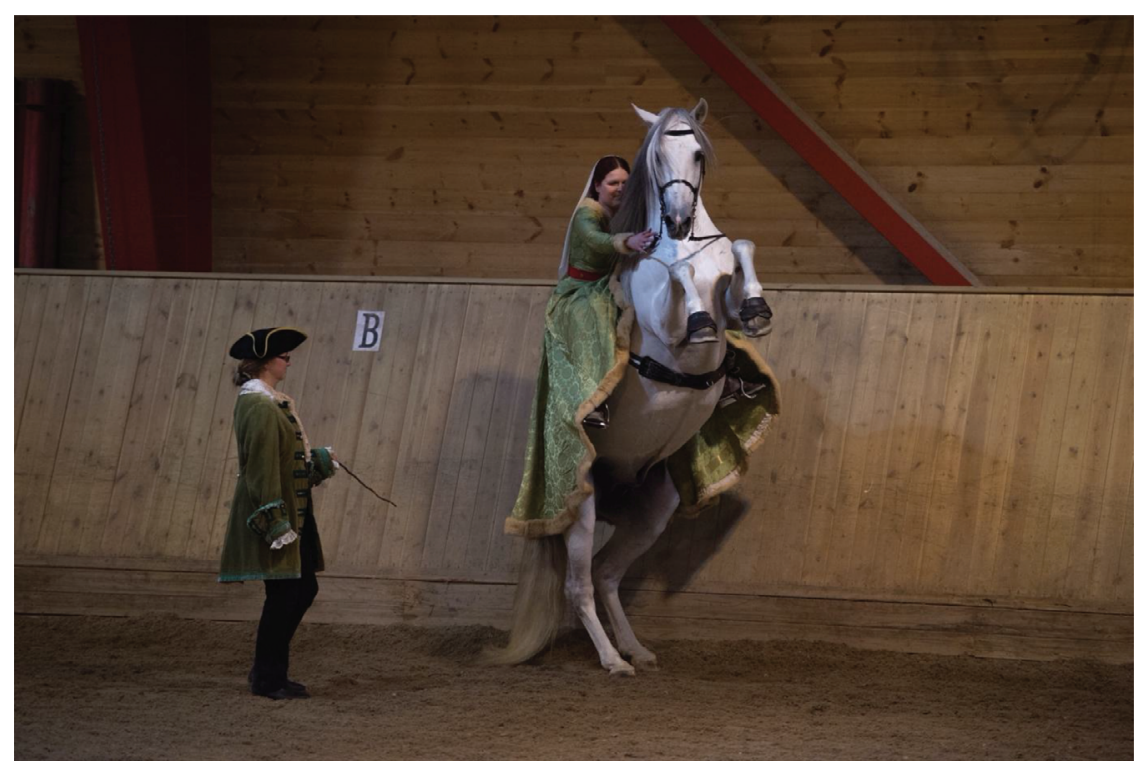

Figure 6. Professional Rider Rozemarijn Keuning and the Stallion Gesto Ram at the Pluvinel Performance in 2016

Photographer: Anders Martinsen. Used with permission of the photographer.

15 Baroque riding, also referred to as academic riding is a genre of dressage riding based on certain historical principles. http://www.akademiskridkonst.se/om_akademisk_ridkonst/ridkonsten/ 
Close interaction between horse and rider was also observed when the young participants presented elementary exercises of walk, trot and canter in the arena in lines, pairs and circles. Thus, the riders adopted the roles of young military students at Pluvinel's Academy in Paris during the early 1600 , re-enacting a historical past accompanied by early music, narratives and acting. A practice-based approach is the fourth dimension in this discussion of the presence of horses in stage productions and was already commented on in the section mentioning animal welfare. The presence of horses demanded restrictions to sound volume, stage lighting, participants' movements and audience's reactions.

The music students' physical actions along with voices and instruments could be compared to the riders' interaction with their horses. From an audience perspective, the horses' size, colours, and movements, together with the students' appearance with their musical instruments and costumes, could be experienced as aesthetic impressions, like a "gesamtkunstwerk".

To conclude this section on the presence of the horses, I will briefly mention the new international interdisciplinary research field of anthrozoology, which has emerged in academia during the past decade. Anthrozoology is defined as "a modern discipline that focuses on the interaction between animals and humans" ${ }^{16}$ Research from the anthrozoologist's perspective highlights both animal welfare issues and animal-assisted therapy (AAT). However, if the Pluvinel's Academy project had been explored from an anthrozoological point of view, it would have been created differently from the very start.

\section{Summary}

This chapter presented an artistic research approach to the completed practice-based project Pluvinel's Academy. The result of exploring the

16 Anthrozoology research is an established research discipline at the University of Agder. https://www.uia.no/en/research/helse-og-idrettsvitenskap/interaction-between-animals-andhumans-anthrozoology 
Pluvinel's Academy project, therefore, could be described by referring to Borgdorff (2011), who explains the intent of artistic research as "uncovering new facts or relationships or shedding new light on existing facts or relationships" (Borgdorff, 2011, p. 54). Firstly, Pluvinel's Academy is an artwork in itself. The artistic research process referred to in this chapter focuses on a completed project and a new product. First of all, its originality pertains to the fact that it did not exist before (Borgdorff, 2011). Secondly, the research process revealed details of aesthetic expressions and actions, as well as connections, which were developed through dramaturgical reflection, rehearsals and performances. Thus, the research process reflects personal artistic development, and may contribute to enhancing practices within interdisciplinary artistic productions in educational contexts. Thirdly, the knowledge outcome includes facts about early music and the late Renaissance and Baroque eras (van Orden, 2005; Rolfhamre, 2017). As a fourth perspective, the analysis resulted in a deeper understanding of multidisciplinary approaches to artistic practice projects, showing the interrelation of music performing, sports presentations, history and music philosophy.

The development of technological knowledge during practice seems crucial. The sound recordings were essential as dramaturgical tools, such as when the students duplicated their recordings on stage. The videos and the photos were used as research objects in this retrospective exploration.

Borgdorff (2011) also refers to an "acquaintance" as a form of knowledge, which is characterized by "familiarity and receptiveness to persons, conditions or situations" (Borgdorff, 2011, p. 55). Even though Pluvinel's Academy was completed without participating researchers, the revisit revealed relationships or acquaintances which could have been explored further, such as the relationship between the ensemble and the horses. As commented on in the section "The Presence of Horses", the university ensemble became acquainted with the horses during rehearsals and gained knowledge about the equestrian environment's regulations. To enhance the students' understanding of conditions, situations and venues is an essential issue in artistic practice projects in general (Boyce-Tillman, 2018, p. 113). 


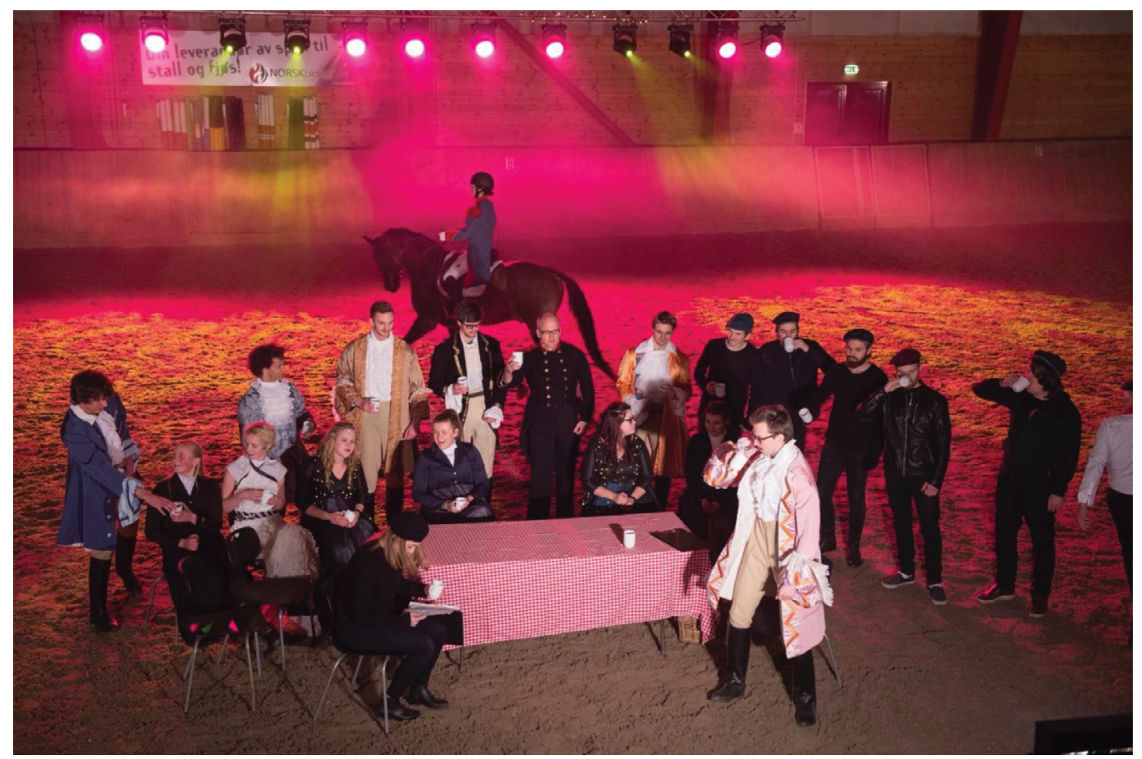

Figure 7. The Ensemble and a Dressage Equipage During the Café Scene in Pluvinel's Academy, 2017 Performance

Photographer: Anders Martinsen. Used with permission of the photographer.

This study of Pluvinel's Academy shows that early music is a relevant and inspirational point of departure for in-depth work with interdisciplinary stage concepts in educational contexts. One reason is the close connection between music, politics and society. Another reason is that the aesthetical performance principles of early music contrast with a high-level musical-technical approach, which is usually connected to classical music concerts and performances. This is commented on by Rolfhamre (2017):

Today, it is not evident that we think practically and socially about music from the past. However, by taking a closer look at early music, we may discover more about how this music can impact our lives. The early modern music concept is about using music to communicate with the people around us. We should avoid elevating early music to something supernatural, solemn and unattainable. (Rolfhamre, 2017)

Revisiting the Pluvinel's Academy project suggests that early music repertoires are valuable in creative, collaborative and interdisciplinary contexts. One reason may be that compositions from the 1500 s and early $1600 \mathrm{~s}$ 
often are well-structured, melodious and balanced. The music seems to communicate nicely to a wide range of audiences, even to listeners who are not familiar with "classical" music. Moreover, even if the music of all genres demands an uncountable number of rehearsal hours to attain an advanced or expert level, it is possible to find early music pieces that may be achievable for relatively inexperienced ensembles, or in situations with limited time for in-depth studies and rehearsals.

\section{Concluding remarks}

The old music was not merely a pastime. It was a social gathering that developed the individual's self-understanding and social relationships between the performers and the audience. (Rolfhamre, 2017)

The vignette above illustrates that early music is connected to philosophy, society and relationships. Such a connection is expected in various art forms. Nevertheless, based on van Orden (2005) and Rolfhamre (2017), early music seems to have had a clear social, political and relational function. Even if the Pluvinel's Academy artistic idea was based on historical events, the project was not intended to be documentarily correct. That would have been a naive approach to the past, a perspective that I discussed in depth earlier (Eidsaa, 2020). However, by shedding light on history through aesthetic expression, all involved in such a practice may catch a glimpse of art and music, philosophy, history, politics and education in a bygone time. This knowledge can broaden our understanding of how art and education have always been crucial to society.

\section{References}

Balsnes, A. (2009). Koret belcanto: En gullgruve av empiri i min hule hånd? In Johnsen, Halvorsen \& Repstad (Eds.), A forske blant sine egne. Universitet og region: Norhet og uavhengighet. Høyskoleforlaget.

Beech, N., Broad, S., Cunliffe, A., Duffy, C. \& Gilmore, C. (2015). Development of organisation theory and organizing music. In N. Beech \& C. Gilmore (Eds.), Organising music: Theory, practice, performance (pp. 1-24). Cambridge University Press. 
Bolstad, B. (2020). Tverrfaglig tilnærming: Hva og hvorfor? FIKS Forskning, innovasjon og kompetanseutvikling i skolen, UiO https://www.uv.uio.no/forskning/satsinger/fiks

Borgdorff, H. (2011). The production of knowledge in artistic research. In M. Biggs \& H. Karlsson (Eds.), The Routledge companion to research in the arts (pp. 44-63). Routledge.

Correia, J., Dalagna, G., Benetti, A. \& Monteiro, F. (2018). When is research artistic research? In Cahiers of artistic research 1. UA Editora. Universidade de Aveiro. https://ria.ua.pt/bitstream/10773/24282/3/Cahier1When\%2ois\%2oresearch\%20 artistic\%2oresearch_.pdf

Chambers $2 \mathrm{O}^{\text {th }}$ Century Dictionary. (n.d.). https://www.definitions.net/definition/ dramaturgy

The place for compassionate and thinking riders: Dressage history Xenophon to Antoine de Pluvinel. Dressage and Sport Horse Magazine. https://www. dressageandsporthorse.com/dressage-history-xenophone

Eidsaa, R. M. (2020). Art-based inquiry as method in creating artistic performances based on historical narratives. In T. Smith \& K. S. Hendricks (Eds.), Narratives and reflections in music education: Listening to voices seldom heard (pp. 207-225). Springer.

Eidsaa, R. M. (2015). Hvem skaper musikken? En studie av musikalsk skapende partnerskapsprosjekter i skolen ut fra et estetisk og didaktisk perspektiv. Danish School of Education. Institut for Uddannelse og Pædagogik, Aarhus Universitet.

Eidsaa, R. M. \& Schau, J. E. (2021). Higher music performance education in a changing world. Towards a new curriculum? A report from a pilot project. In M. Rykowsky (Ed.), Music e-ducation in XXI-st century. New challenges and perspectives (pp. 195-208). Akademia Muzyczna im. I. J. Paderewskiego w Poznaniu.

Epona ryttersenter Pluvinel akademi Fransk folkevise. https://www.youtube.com/ watch?v=scFTvPt22fc

Finley, S. (2018). Multimethod arts-based research. In P. Leavy (Ed.), Handbook of arts-based research (pp. 477-490). The Guildford Press.

Grande Écuries Chantilly. (n.d.). https://domainedechantilly.com

Holgersen, S. E. (2019). Arts based research on participation in music education. European Journal of Philosophy in Arts Education, 1(4), 27-53.

Källgren, F. (n.d.). Akademisk ridekonst. Informasjonsside om akademisk ridkonst. http://www.akademiskridkonst.se/om_akademisk_ridkonst/ridkonsten/

Leavy, P. (2018). Fiction-based research. In P. Leavy (Ed.), Handbook of arts-based research (pp. 190-203). The Guildford Press.

Leavy, P. (2018). Introduction to arts-based research. In P. Leavy (Ed.), Handbook of arts-based research (pp. 3-21). The Guildford Press. 
O’Neill, S. (2011). Learning in and through music performance: Understanding cultural diversity via inquiry and dialogue. In M. Barrett (Ed.), A cultural psychology of music education (pp. 179-200). Oxford University Press.

Owen, N. (2005). The infectious outsider: Towards a pedagogy for artist educators in theatre and education: Creating new roles for the 21st century. In N. Govas \& N. Choleva (Eds.), Athens: Hellenic theatre / drama \& education network. [Also presented at ESRC Creativity Seminar, University of Strathclyde, Glasgow, 2005.]

Pluvinel forestilling 2 https://www.youtube.com/watch?v=LbwiwAeYITo

Pluvinel Toccata Espanola (del 2) Gesto https://www.youtube.com/ watch?v=bgLrzi2X 2 sk

Rolfhamre, R. (2017, September 25). Komponisten som smisket med Solkongen. Foedrelandsvennen. https://www.fvn.no/mening/i/6Lazr/komponisten-somsmisket-med-solkongen

Rolfhamre, R. \& Angelo, E. (2022). Introduction: Making history through music performance and education. In R. Rolfhamre \& E. Angelo (Eds.), Views on early music as representation - invitations, congruity, performance (MusPed:Research Vol. 4, Ch. 1, p. 12). Cappelen Damm Akademisk. https://doi.org/10.23865/ noasp.157.ch1

Sønning, A. (in press). Concert production and creative entrepreneurship. About concert dramaturgy and project development for cultural programs across genres, artistic expressions and cultural borders.

Spanische Hofreitschule. (n.d.). Welcome to the Spanish riding school [website]. https://www.srs.at/en/

The Cadre Noir of Saumur. (n.d.). Official site of the French National Riding School and the Cadre noir of Saumur [website]. https://www.ifce.fr/en/cadre-noir

University of Agder. (n.d.). Music performance: Western classical music. Musical Communication MUK 173 [online university course description]. University of Agder. https://www.uia.no/en/studieplaner/topic/MUK173-1

University of Agder. (n.d.). REMP: Reconfiguring early modern music [website]. Faculty of Fine Arts, University of Agder. https://www.uia.no/en/research/ kunstfag/remp-reconfiguring-early-modern-performance

van Orden, K. (2005). Music, discipline, and arms in early modern France. The University of Chicago Press.

Warren, J. R. (2014). Music and ethical responsibility. Cambridge University Press.

Østern, T. P. (2017). Å forske med kunsten som metodologisk praksis med aestesis som mandat. Journal for Research in Arts and Sport Education, 1 [Special issue: $\AA$ forske med kunsten, 7-27]. 



\title{
Re-Enacting Beat Art: An Aesthetic and Pedagogical Approach to Re-Living History
}

\author{
Frida Forsgren \\ Associate Professor, University of Agder
}

\begin{abstract}
The chapter presents the pedagogical strategies in a 10-credit course dedicated to the teaching of American Beat culture at the Faculty of Humanities and Pedagogy at the University of Agder. The course combines artistic work with an academic curriculum. It does not pretend to be an art course, but it uses an artistic way of thinking and working to enrich and expand the academic and the historical. It does history through art and is inspired by the hands-on learning-by-doing pedagogy of John Dewey. The text proposes that this method may be applicable to early modern studies as a pedagogical method for presenting, enacting, re-enacting, living, re-living and fantasising a historical past.
\end{abstract}

Keywords: learning-by-doing, Beat culture, pedagogical strategies, teaching history

\section{Preface}

A driving force behind this volume relates to the implications inherent in protecting our European cultural heritage in a broader sense than what is to be expected from a strict, insider scholarly practice. Although being neither a dedicated music nor pedagogy scholar, I was invited into this project to contribute from a very different perspective, to provide a fresh pair of eyes to scrutinise an alien (to me) established practice of which I have little prior knowledge. I hold a $\mathrm{PhD}$ in Renaissance art history, but in recent years, my work has been dedicated to much later art practices,

Citation: Forsgren, F. (2022). Re-enacting Beat art: An aesthetic and pedagogical approach to re-living history. In R. Rolfhamre \& E. Angelo (Eds.), Views on early music as representation: Invitations, congruity, performance (MusPed:Research No. 4, Ch. 7, pp. 177-197). Cappelen Damm Akademisk. https://doi.org/10.23865/noasp.157.ch7

Licens: CC BY-NC-ND 4.0 
particularly Modernism and Beat art. It is from this latter realm that I will approach the subject of interacting with earlier arts pedagogy. Although my contribution centres on visual arts rather than music, I will discuss how the model, in its broadest sense, can be transferrable to music studies. I wish to stress that I do not belong to the field of arts education. I teach art as a historical, theoretical and aesthetic subject within the humanities. I am an art historian, stressing the historian. This text is not a part of a practice-led research project, rather it describes and presents the pedagogical strategies in the Beat culture course that I have taught since 2008, with my colleague Michael J. Prince. My research interest in this chapter lies not in audience reception, performativity, nor museum pedagogy, but rather in how ideas, theories and history may function as learning strategies and assets.

\section{Introduction}

The Beat Art Collection at the University of Agder and the Kristiansand Cathedral School Gimle (KKG) in Kristiansand is a major collection of visual art from the Beat and Funk period in California between 1955 and 1965. The collection consists of approximately 850 works of art in a vast range of artistic styles: Funk sculpture, American abstract painting, California figurative art and sketches, plus a collection of African, South Pacific, Norwegian and European modernist painting. The collection was donated to the two institutions in 1971 and 1978 by the medical doctor Reidar Wennesland from Kristiansand, who lived his adult life in San Francisco (Hennum, 2007). The Beat art collection is an active part of the two institutions' public spaces, and functions as a "living art gallery". Moreover, the Wennesland/Beat collection is actively used in both marketing and teaching at the two institutions. The KKG organises a "Beat week" for the pupils each year, and the University of Agder has a 10-credit course in Beat culture organised within the Bachelor programme in English at the Faculty of Humanities and Pedagogy. This chapter presents the Beat culture course at the University of Agder, and explores the pedagogical strategies designed to communicate Beat culture. It proposes that this is a pedagogical practice that can be transferred to much 
earlier artistic eras as well, such as early modern visual art and music. The pedagogical methods in the course differ substantially from the other 10-credit courses at the Faculty of Humanities and Pedagogy in that it is more experimental and practical. The course has a more "hands-on" approach to the subject matter and sees Beat culture as an active field that the students may engage in as a living field of practice. The chapter presents two main research questions: (1) What strategies are used in the course to create a place for learning, acting, mediating, and communicating a historically remote cultural practice? (2) How may this method be applicable to the early modern field as a pedagogical method to present, enact, re-enact, live, re-live, and fantasise a historical past?

\section{What is Beat culture? The Beats and the squares: The challenges of teaching and studying Beat}

The post World War II era in the United States was marked by artistic censorship and a conformist culture dominated by militarism, consumerism and racism. The Beat generation in New York, and later in San Francisco, gradually became a strong countercultural underground movement that challenged this mainstream culture (Albright, 1985; Lipton, 1959; Philips, 1995; Smith, 2009; Solnit, 1990). The Beats protested against an increasingly materialistic and conformist society, and gave a voice to the oppressed and outcast: to the communists, the gays, the drug addicts, and others who did not fit into "square" society. The Beat generation was not primarily a political activist movement, but was rather concerned with living a free life without being oppressed by the norms and values of mainstream society. The interesting thing about many of the Beat artists was that they consciously chose to live their lives anonymously, in artist collectives, hidden from the eyes of the media and society, where they could live in peace. They were not especially concerned with making money or becoming successful, but with having control over their own lives and over their own time and creativity. But this freedom also had a high price, many used alcohol and drugs in their search for freedom, and in their uncompromising artistic work, and many became heavily 
addicted. Many Beats eventually failed to take care of their children, and a large majority died young and beaten down.

One of the challenges as a researcher and student of Beat art is the lack of sources and information about the artists and their works. The works were often not made to last forever, but were rather the result of spontaneous creative processes, and what has survived to the present day is often completely random. Art history as an academic discipline is traditionally a field that concentrates on the well-known periods and isms, and the well-known school-forming artists and works, and the Beat artists do not conform to these parametres. Most of the artists represented in the Wennesland Collection had few, if any, exhibitions while they lived. They received little attention in the press, or from art critics of their time, and the vast majority had no desire for a public life. It is believed that as few as $10 \%$ of Beat artists actually exhibited their work (Monroe, 1998). ${ }^{1}$ When Jay DeFeo (1929-1989) was offered a permanent gallery in New York after her participation in Dorothy Miller's exhibition Sixteen Americans in 1958, she flatly declined. She was totally uninterested in linking her artistic production to commercial activity. Instead, she remained in San Francisco and worked underground in the artist collective at 2322 Fillmore Street on her monumental work The Rose (Levy, 2003; Miller, 2012). Most artists in this milieu did not achieve the kinds of opportunities that DeFeo was offered, but this does not seem to have been an expressed wish. The environment was organized in a collective spirit and had a spontaneous, improvised agenda. Galleries were mostly artist-run with random opening hours, and were often meeting places for painters, sculptors, poets and musicians, the most famous being The Six, The Dilexi and The Place in San Francisco (Lyrical Vision, 1990; The Beat Generation Galleries and Beyond, 1996). Their works and the environment reflected the unstable, fragile spirit of the times: the Holocaust, the world war, and the atomic bomb threat lay like dark shadows over life and made them feel unsure whether tomorrow was safe, or if it would come at all.

"Probably fewer than 10 percent, perhaps 150 or so in the entire country, exhibited in galleries at all" (Monroe, 1998). 
The artists, musicians and poets in this environment range from well-documented and historically established names, such as the visual artists Jay DeFeo, George Herms, the poets Jack Kerouac, William S. Burroughs and Allen Ginsberg, to completely or partially undiscovered and unknown artists. In the Wennesland Collection we find artists such as Michael McCracken, Arthur Monroe, Dimitri Grachis, Jack Carrigg, Dean Fleming, Keith Sanzenbach, Joan Savo, Michael Dachmund and Dick Kiggins, all relatively undocumented in art historical contexts (Forsgren, 2013). Thanks to Reidar Wennesland, who was a friend, doctor and patron of several of the Beat artists, we have preserved a large number of their works, but in very many cases we paradoxically know very little about the artists behind the works. The works stand as strong images of a time and represent themselves, rather than a name or a talent. This is in stark contrast to the role of the artist and works of art in contemporary society, where capital often defines aesthetics, and where the name of the artist often helps to hype and sell a work. Beat artists chose a more anonymous life, less concerned with public attention or sales, but with a focus on the creative process. This differs from the cultural and societal context that the early modern artist operated in. His or her work would have been made on commission for a patron, for a particular religious, didactic or societal function. And the work would have been displayed or performed within a defined context or situation (Ames-Lewis, 2000).

When teaching the multifaceted and complex field of Beat culture to students, Michael J. Prince and I have chosen a set of diverse pedagogical strategies that combine historical-aesthetic elements, along with the development of practical artistic and literary skills. This "kit" of pedagogical strategies is presented below.

\section{Presentation of the pedagogical strategies in "TFL 111 Beat Culture"}

The curriculum: The Beat culture course presents a reading list with core texts by and about the Beat generation. The students read seminal texts, such as Jack Kerouac's On the Road, Allan Ginsberg's poem Howl, 
William S. Burroughs Junky, as well as poems by writers such as Lawrence Ferlinghetti, Diane di Prima and Gary Snyder. In the art classes they read Erica Doss' American Art of the Twentieth Century, and complementary texts that contextualise the concept of Beat art (Albright, 1985; Doss, 2002). Focus is placed on visual art terms like American abstract expressionism, funk, neo-dada, Beat culture and California figuration. The literary and art historical lectures/seminars are based on powerpoint lectures and constitute approximately $70 \%$ of the course. One session is dedicated to jazz, and one session presents the aesthetic collaborations in the Black Mountain College milieu. The remaining part of the course consists of creative writing sessions, art tours and an art workshop, which introduces the students to a more hands-on and practical art experience. The Wennesland Collection is shared by the Kristiansand Cathedral School Gimle and the University of Agder, and the students are introduced to both collections during the first weeks of the semester. We take two separate art tours in which the central artists and art works are presented during a visual tour. At both institutions the art works are displayed in common areas like corridors and auditoriums. It is a living and busy school context, which provides a less formal atmosphere than the institutional and traditional white cube. Students are invited to take part in the description and analysis of the works presented, based on the art historical method of iconography. The students generally participate more actively in class during these art tours, clearly energised by the possibility of experiencing the paintings "live" rather than on a digital screen in the classroom. When they write their mid-term art essay, they are encouraged to choose a work from the Wennesland Collection, which allows them to close read the object in a similar manner as that presented during these art tours.

Seminal parts of the course are the art workshop and the creative writing session. Each year the work and methods of a contemporary artist are presented to the student groups. The idea behind the workshop is that the students meet a professional artist, and have the chance to make art themselves. The workshops may focus on diverse topics discussed in class, such as collage, funk objects, aleatory music, performance, painting, or drawing. In the autumn of 2020 the students met artist Erlend Helling-Larsen, 
who conducted a course in automatic art/drawing. ${ }^{2}$ American abstract expressionism and Beat art has a close affinity with the dada and surrealist methods of automatic drawing. This method can be described as "expressing the subconscious" based on the theories of Sigmund Freud. In art, automatism refers to creating art without conscious thought, accessing material from the unconscious mind as part of the creative process (Fløgstad, 1980, p. 107). In class, the students are confronted with images of surrealist-inspired automatic art works, and in this specific workshop, they were presented with the challenge of experimenting with automatic art as an artistic technique. Erlend Helling-Larsen presented the students with two exercises to introduce them to the medium of drawing. The first exercise focused on what drawing essentially is: making signs on a piece of paper. "Drawing is first and foremost something you do, an action that leaves traces," according to Erlend Helling-Larsen. With a ruler the students were encouraged to make a straight line somewhere on the white paper. Then they were asked to follow this straight line with a freehand drawing to observe what happened to the lines. They discovered that the lines eventually became increasingly undulous and wavy, creating individual patterns echoing the process that the hand/body had undergone. They had not "made a drawing" consciously, but the drawing had in a way made itself while they were moving their hands. The next exercise was to draw several doodles on individual sheets of paper, not to think, but just to make the doodles spontaneously. They were then asked to take the doodle they liked best and describe in words what they liked about this exact form. The exercise was a way of articulating the aesthetic qualities observed on the paper. They were then asked to make a copy of the doodle shape on a new sheet of paper. It was a difficult exercise to copy the first shape, it lost its original "flow" and it became "stiff" and "impersonal". Through these two exercises the students had a chance to focus on some of the central aesthetic features of automatic art and Beat culture. Firstly, making art might not be such a serious enterprise, fundamentally it is about daring to leave physical traces on a sheet of paper.

2 Erlend Helling-Larsen has kindly approved being a research participant and has signed a letter of consent. 
The important thing is to "make the object" as Bruce Conner said (Conner, 1974). Secondly, they observed how a doodle made spontaneously had more flow and energy, than if the shape was made intentionally and copied. Flow, improvisation, and "in-the-momentness" are important aesthetic features in both Beat literature and visual art.

Also, in the creative writing session, which was conducted during autumn 2020, the students were given exercises that involved automatic and spontaneous challenges (Appendix 2). In freewriting session one, they were asked to use the requirements/method in Jack Kerouac's Essentials of Spontaneous Prose which meant writing for 30 minutes consecutively. In freewriting session two, they were asked to produce one complete A-4 sheet of writing of their own prose. Next they were asked to cut this piece of paper into four pieces, and subsequently put the pieces of paper next to each other paying close attention to groups of words that made interesting sense. The last step in the exercise was to collect no less than 5 phrases or sentences that resulted from the cut-up experiment. Creative writing teacher Michael J. Prince's main objective for these exercises was to encourage the students to play with language in space. Like the art workshop, these exercises too, drew attention to central features of Beat culture aesthetics: the spontaneous prose method as a way to produce free-flowing texts from the subconscious, and the cut-up technique as a way to experiment with aleatory text production like writer William S. Burroughs and composer John Cage did (Belgrad, 1998).

Also, the final exam of the Beat culture course includes a practical and creative segment. The final examination may be either an artistic or a theoretical project, but both options include a performative aspect that mimics a Beat style venue. The Beat galleries were famous for being places that combined art, music, literature and live performance - they were places to exhibit, perform and to hang-out and experiment with friends and peers. The final examination is inspired by Beat galleries such as The Six, The Dilexi and The Place that had such profiles. We call it Beat Nite and it takes place in the evening either at the student pub Østsia or a similar downtown venue. During the examination the students present and exhibit their artworks (painting, musical compositions, sculpture, 
performance, films, poetry, etc.) in the provided space, and they present either their work process or a theoretical paper in a 10-minute presentation. All students attend, examinators are present, and friends and family are welcome.

The art tours, the art workshop, the creative writing session and Beat Nite are examples of different pedagogical strategies that widen students' learning experiences and extend and challenge traditionally expected learning outcomes. Why have we chosen these pedagogical strategies? Can they provide the students with better supplementary tools than traditional learning outcomes?

\section{Method: A deeper embedded learning}

The Beat culture course is designed to convey a historical, artistic and literary subject through pedagogy. In the expected learning outcomes of the course, we see that they clearly illuminate the historical definition of "Beat" culture and its artistic expressions as their main elements (Appendix 1). ${ }^{3}$ However when we envisaged the course, we also wanted it to lead to more extended learning outcomes, what we might call a "deeper" embedded meaning. We wished that the course would be not only a place to gain content knowledge, but also a place to learn how to live. This is of course more difficult to measure than the formal learning outcomes in the university catalogue, but this vision was an important motivation behind the choices of course strategies. These methods and strategies were informed and inspired by the pedagogy of "learning-by-doing", as it was taught at Black Mountain College. Black Mountain College had no intention of training professional artists or teaching individual selfexpression, but saw art education as a pedagogical method (Miller, 2018, p. 53).

Upon successful completion of the course the students will develop an understanding of the artistic expressions related to Beat culture, be able to account for the expression "Beat", the changes it has been through and the aesthetic parameters that have influenced these changes. They will be able to discuss and analyse artistic expression in terms of these aesthetic models. 
The Beat culture course has strong elements in common with this artist-based pedagogy: We do not aim to train artists, rather we use art and poetry as pedagogical methods. Black Mountain College in North Carolina (1933-1957) was an interdisciplinary liberal arts college founded by John Andrew Rice that was profoundly inspired by the pedagogy of John Dewey. During its years of existence, it gathered the leading artists and intellectuals of the time: Josef and Anni Albers, John Cage, Robert Creeley, Merce Cunningham, Willem and Elaine de Kooning, Robert Duncan, Buckminster Fuller, Walter Gropius, Lou Harrison, Franz Kline, Jacob Lawrence, Charles Olson, Jack Tworkov, and Robert Motherwell. Guest lecturers were Albert Einstein, Clement Greenberg, Richard Lippold, and William Carlos Williams. John Dewey, Albert Einstein, Walter Gropius, and Carl Jung constituted the advisory board. At the school the students were introduced to a vast range of subjects, such as painting, photography, architecture, dance, music, sculpture, weaving, poetry, gardening, as well as biology, chemistry, physics, psychology mathematics, economics, English, French German, Latin, Greek, government, history, and philosophy. The students lived on campus and ate all meals together with their teachers. The school had a holistic approach to learning, and did not believe in the supremacy of one subject over another (Erickson, 2015; Katz, 2002; Miller, 2018). Process and collaboration were paramount, and the centrality of the arts was a defining feature in the curriculum, as Ruth Erickson has stressed: "What distinguished Black Mountain from other schools was the vital role that the arts played in the college's democratic aims." (Erickson, 2015, p. 80) In addition to this, the school believed in an education that not only spoke to the cognitive side of the human being, but to the body and to the senses. Artist Josef Albers, who was the first principal of the school, expressed in his "Address for the Black Mountain College Meeting at New York", how this not was a school for traditional schooling: "If education would aim more at being something instead of at getting something, then our schools would be, maybe, less intellectualistic, but less unjust to the intellectual types; I mean, for instance, the visual type, the manual type, which are just as important as intellectuals" (J. Albers, n.d.). Anni Albers, who taught weaving at the school, saw the creation of art as an important way of thinking and solving problems, also more generally: 
Art work deals with the problem of a piece of art, but more, it teaches the process of all creating, the shaping out of the shapelessness. We learn from it that no picture exists before it is done, no form before it is shaped. The conception of a work gives only its temper, not its consistency. Things take shape in material and in the process of working it, and no imagination is great enough to know before the works are done what they will be like. (A. Albers, n.d.)

What Albers describes here is physical and hands-on problem solving, which emerges as you work with a material and with your body. "The arts foster, as it were, a phenomenology of learning," as Miller describes it poignantly (Miller, 2018, p. 57). The overall objective behind the Black Mountain school was to educate students that would become good, democratic citizens (Miller, 2018, p. 55). Most teachers at the school were expatriates from a Europe devastated by war and conflict, and a central question among faculty and students alike was how education might "heal" society. John Dewey was a key figure in this humane pedagogy and in Art as Experience he stresses that one should use liberal education as a means to create good, humane and democratic societies: "The present function of the liberal arts college, in my belief, is to use the resources put at our disposal alike by humane literature, by science, by subjects that have a vocational bearing, so as to secure ability, to appraise the needs and issues of the world in which we live" (Trepanier, 2017, p. 14). These features - the non-cognitive, the phenomenological and democratic ideals - were elements that inspired and governed the ideas behind the Beat culture course.

A second inspiration governing the strategies in the Beat culture course was the affordances of the subject matter and the historical period itself. Aesthetic features of physicality, intersubjectivity and art as plastic dialogue are central to Beat culture. Beat culture has a distinct multimodal and experimental nature: painters wrote, poets painted, and musicians accompanied words and images. Paintings were exhibited in venues where poems were performed to jazz. Daniel Belgrad has discussed how spontaneity, improvisation and physicality were central components in Beat aesthetics, stressing the bodily and material qualities of the creative process (Belgrad, 1999). ${ }^{4}$ He has shown how the drip paintings of Jackson

4 See particularly chapters 4,7 and 9 where he discusses art works as plastic dialogues and spontaneous subjectivity. 
Pollock, the bebop solos of Charlie Parker, and the prose of Jack Kerouac are all inspired by the same creative bodily impulse. There are striking affinities between the Beat writers' free, confessional literary style and the painters' raw improvisations on canvas, as the body of work connected to the Beat movement show (Forsgren, 2008). The Beat culture course draws inspiration from this multimodal way of working by combining art and literature with the academic curriculum.

The question now arises whether this method may be applicable to the early modern as a pedagogical method and strategy to present, enact, re-enact, live, re-live and fantasise a historical past?

\section{"To do history through art"}

The pedagogical method designed for the Beat culture course combines artistic work with an academic curriculum. It does not pretend to be an art course, but it uses an artistic way of thinking and working to enrich and expand the academic and historical. It does history through art. In this respect, it is different from a majority of the courses at the Faculty of Humanities, which are based on the academic curriculum and traditional classroom lectures. At the Faculty of Arts however, the situation is reversed: A majority of the courses are designed to train art teachers, and the students are generally exposed to fewer academic lectures and less theory. The disciplines of art history and history have a minor place in the curriculum, art-based practice is at the centre. In the Beat culture course cultural history is the core subject. The course is designed to provide the students with tools to interpret a historical period by studying historical sources. We read literary and secondary texts, mainly from the 1950 s and 196os, to enable the students to understand what Beat meant in its historical time, not primarily what is means to us today, but what it meant then, and why it meant what it did. The students are taught to develop historical thinking, which means learning to apply theoretical tools to analyse how historical knowledge is constructed. These tools are defined by Lévesque as: being able to account for continuity and change and progress and decline; to be able to scrutinise historical evidence; and finally, to have what is called historical empathy. Historical empathy is 
best described as an ability to contextualise things past and present, and to understand what that means, in other words to appreciate how historical societies and historical people differed from present day societies and people (Lévesque, 2008). Another central concept we wish our students to develop is historical consciousness, which entails an ability to historicise past and present societies and cultures, by explaining continuity and change through the use of history (Rüsen, 2006, p. 72). ${ }^{5} \mathrm{We}$ firmly believe that students need historical thinking and historical consciousness as tools to develop critical thinking. In contemporary society there is a tendency to treat history and historical subjects as something we command and something we control, instead of trying to understand why and how historical societies and historical people differed from present day societies and people. The present climate of historical revisionism and cancel culture, i.e., the withdrawal of support for things and people who are considered objectionable, is a striking example of an increasing lack of historical consciousness. Within the field of art history cancel culture manifests itself, for instance, in the removal of monuments of historical figures considered racist, sexist, or problematic by today's standards. In Norway several thousand people have signed petitions to remove statues of Winston Churchill (racist) and Ludvig Holberg (involved in slave trade), and internationally several similar monuments have been torn down in the wake of the \#BlackLivesMatter movement. There is also an increasing tendency for university students to question a curriculum that consists of problematic figures like Allen Ginsberg, William S. Burroughs or Salvador Dalì, defining them as pedophile or misogynist. Developing a historical consciousness and historical empathy may ensure that students can learn to see problematic figures as products of their historical time, instead of products of our time. It is our wish that an in-depth

5 Jörn Rüsen defines four characteristics of historical consciousness: The most basic kind of historical consciousness is the "traditional" one: history is full of repetition and all members of society are supposed to uphold what tradition dictates. The next kind is the "exemplary" one, and here history is still static, but also generates normative rules about how a person should lead her life (historia magistra vitae). The third kind is called a "critical" historical consciousness and a person possessing this uses history as a way of criticising contemporary society and culture. The final, and most advanced, type of historical consciousness is the "genetic" one, which conveys an ability to historicise past and present societies and cultures by explaining continuity and change through the use of history (Rüsen, 2006, p. 72). 
history course such as the Beat culture course, which studies authors like Ginsberg and Burroughs in their historical time, may help develop such historical consciousness and critical thinking.

When we designed the Beat culture course, we hoped that the combination of academic curriculum with artistic practice might create a stimulating exchange between the intellect and the body. In addition, we also had the ambitious goal of helping develop students' democratic citizenship. We hoped that the study of postwar cultural and societal topics such as the Holocaust, McCarthyism, racism, anti-semitism, misogynism, and outsider-art might help students reflect on the values of a well-functioning, democratic society. In the same way that the Black Mountain College founders used their knowledge of art, history, philosophy and science as powerful learning tools during and after the rise of Nazism, we believe that the dissemination of Black Mountain College values ensures their importance for today's students. It is of course difficult to measure whether our pedagogical strategies work or not. There may be negative consequences of "doing history" in this way. And we might even risk a "flattening" of historical knowledge. My main concern in this respect is not the academic curriculum per se, but rather the art and literature workshops. The course has very few hours and resources at its disposal, and the students have little chance of acquiring the amount of serious practice needed to develop an artistic skill. We may thus risk the possibility that art as a professional craft is understood as a less serious undertaking. I have also observed a tendency that students may tend to oversimplify Beat culture and Beat artists as a standardised pack of dopeheads wearing berets, instead of grasping the deeper philosophical and societal concerns of the period. This is the risk when history is acted out, it can easily become a cliché. In order to learn more about such possible negative consequences of our method of "teaching history", we would have to conduct a thorough qualitative study involving students, but that is beyond the scope of this chapter.

Let us at last consider whether this way of teaching history and doing art are methods that could be transferred successfully to the early modern period. In the Faculty of Arts at the University of Agder one might, for instance, make use of the early modern painting collection at Gimle Gård 
to create a visual counterpart to the music performed. The collection consists of paintings in Renaissance, mannerist and Baroque styles displayed in a renaissance style manor from the late eighteenth century. A pedagogical strategy might be to study similarities within art, architecture and music in the early modern period "in situ". A second strategy could be to close read early modern literature as a way of accessing historical and philosophical thinking of the time. And a third strategy might be to look at the educational strategies and functions of music in the early modern period. ${ }^{6}$

\section{Concluding remarks: How may this relate to early music practice?}

The Beat culture course at the University of Agder utilises pedagogical strategies that are a combination of theory and practice, emphasising literary and artistic theory and history to increase student's historical consciousness. Inspired by the pedagogy of the Black Mountain school and John Dewey's Art as Experience, we wish to prepare students to become good, democratic citizens. We wish for the learning outcomes to have a "deeper meaning" beyond merely knowing what Beat is. And though not aiming to train artists, we wish to teach students by using art as a pedagogical method.

As this method has interdisciplinarity at its core, there should not be any difficulty in providing a place for music performance - here, early music performance in particular - within its practice. However, a few words may be called for as to how to facilitate this from a performer's perspective. First, we must acknowledge that historical music performance is by nature both multidisciplinary and practical. Without the doing we have no sound, and without multidisciplinary approaches we do not have enough sources to provide us with any idea of where even to begin. There are, however, some pedagogical practices here that differ from the traditional "classical music performer" education that has been

6 Excursions to the Gimle Gard manor were included as a pedagogical strategy in the early modern studies course EN-210, formerly taught at the Faculty of Humanities and Education, University of Agder. 
the institutional norm for centuries. First, when we work to reproduce and reestablish historical music in a hermeneutical manner, preferably as close as possible to "the composer's intention", we saw from the above Helling-Larsen exercise that such attempts may become stiff and impersonal. Moreover, that by focusing not only on constructing the historically informed performance, but also on deconstructing it, we may reveal new perspectives on the music through its fragments. Not only would this support the performers in expanding their musical vocabulary in unforeseen, intriguing ways, but it may also highlight music composition as a practice both for the author and the mediating artist. Finally, and perhaps the most important contribution, is to present the student work, not in a music centred venue where the music being performed and the quality of its performance is the sole focus, but in situations where multiple artistic expressions coincide within a social situation emphasising being together rather than displaying the student. This means emphasising the development of historical empathy before correct executions.

Of course, music performance education implies different opportunities to various sorts of learners. A higher education student would for instance have an extensive toolbox for musical performance, but many rules governing how they are used. A much younger municipal culture school pupil, on the other hand, may be less aware of the "industry standard" in early music performance, so to say, and would thus be much freer and experimental in their approach, but may at the same time have acquired fewer technical skills to express their creative efforts. Likewise, a general upper-secondary school pupil may not play an instrument or sing comfortably at all, and may only have become acquainted with early modern music and art works as anecdotal artefacts in a history class or through popular culture films, games, and the like. What unites them all, however, is whether the learning mode aims at a correct understanding of the artwork as an artefact, or if they are to become familiarised more with aesthetic-ethical processes and practices leading up to the artwork. It is here, by promoting historical empathy, social practice, and criticism by doing and exploring, that I wish to contribute my teaching experiences to all levels of music education. The practical implementation would, as mentioned, differ depending on the learning situation, but the essence 
and purpose of the practice outlined above could form a unifying thread through all levels of education, ensuring that we can not only refer to and talk about art intellectually, but also acquire a better sense of our being part of history and of history being part of us. In this sense, this method would also highlight the implications of protecting our European cultural heritage as an ongoing community activity, rather than simply not forgetting the great works of the past. For a further reflection on the applicability to practice, I refer to Robin Rolhamre's chapter in this volume.

The reasoning presented in this chapter has hopefully shown a way to combine theory and practice, and may be a fruitful pedagogical model in other historical periods as well, such as the early modern. Especially in the present climate of cancel culture, an in-depth, historically rooted culture course is pertinent at any university, in order to understand why and how historical societies and historical people differed from present day societies and people.

\section{References}

Albers, A. (n.d.). Handweaving today: Textile work at Black Mountain College. The Josef and Anni Foundation. https://albersfoundation.org/teaching/anni-albers/texts/ Albers, J. (n.d.). Address for the Black Mountain College meeting, June 12, 1940. The Josef and Anni Albers Foundation. https://albersfoundation.org/teaching/josefalbers/lectures/\#tab3

Albright, T. (1985). Art in the San Francisco bay area: 1946 to 1980. University of California Press.

Ames-Lewis, F. (2000). The intellectual life of the early renaissance artist. Yale University Press.

Belgrad, D. (1998). The culture of spontaneity: Improvisation and the arts in postwar America. University of Chicago Press.

Burroughs, W. S. (2002). Junky. Penguin.

Dewey, J. (1934). Art as experience. Later works, 1935-53. (Vol. 10). Southern Illinois University Press.

Dewey, J. (2008). Å gjøre en erfaring: fra Art as experience (1934). Universitetsforlaget.

Doss, E. (2002). Twentieth-century American art. Oxford University Press.

Erickson, R. (2015). A progressive education. In H. Molesworth et al. (Eds.), Leap before you look: Black Mountain College, 1933-1957 (pp. 76-86). Yale University Press. 
Fløgstad, K., Gundersen, G., Hegglund, K. \& Lie, S. (1980). Surrealisme: En antologi. Gyldendal.

Forsgren, F. (2008). Beatkunst i Norge. Press.

Forsgren, F. (2013). Beat lives. Portal.

Ginsberg, A. (2002). Howl and other poems. City Lights Books.

Harris, M. E. (1987). The arts at Black Mountain College. MIT Press.

Hennum, G. (1998). På sporet av beat-bohemene. H. Aschehoug og Co.

Kamstra, J. (1975). The Frisco kid. Harper and Row.

Katz, V. Brody, M. M., \& Museo Nacional Centro de Arte Reina Sofía. (2003). Black Mountain College: Experiment in art. MIT Press.

Kerouac, J. (1991). On the road. Penguin Books.

Lévesque, S. (2008). Thinking historically: Educating students for the twenty-first century. University of Toronto Press.

Levy, L. \& Green, J. (2003). Jay DeFeo and the rose. University of California Press.

Lipton, L. (1959). Holy barbarians. Julian Messner, Inc.

Lyrical vision: The 6 Gallery 1954-1957. (1990). Natsoulas Novelozo Gallery, Jan. - Feb. 1990. John Natsoulas Press.

Miller, D. (2012). Jay DeFeo: A retrospective. Whitney Museum of American Art.

Miller, J. (2018). The arts and the liberal arts at Black Mountain College. The Journal of Aesthetic Education, 52(4), 49-68.

Monroe, A. (1998). The decade of bebop, beatniks and painting. https://web.archive. org/web/20180226061312/http://www.somarts.org:8o/beat/beat_text2.html

Natsoulas, J. (Ed.). (1996). The beat generation galleries and beyond. John Natsoulas Press.

Oral history interview with Bruce Conner. (1974, August 12). Archives of American Art, Smithsonian Institution.

Phillips, L. (1995). Beat culture and the new America: 1950-1965. Whitney Museum of American Art.

Rüsen, J. (2006). Historical consciousness: Narrative, structure, moral function, and ontogenetic development. In P. Seixas (Ed.), Theorizing historical consciousness (pp. 63-85). University of Toronto Press.

Smith, R. C. (2009). The modern moves west: Californian artists and democratic culture in the twentieth century. University of Pennsylvania Press.

Solnit, R. (1990). Secret exhibition: Six California artists of the cold era. City Lights Books.

Stephen, F. (2005). Semina culture: Wallace Berman and his circle. Santa Monica Museum of Art.

Trepanier, L. (2017). Why the humanities matter today: In defense of liberal education. Lexington Books. 


\section{Appendix 1: Presentation of the Case-study: The 10-credit Course in Beat Culture at the University}

The description below describes the course content, learning outcomes, teaching methods, examination requirements, assessment methods and criteria of Beat Culture TFL 111 as they are presented by the University of Agder:

Course contents:

Beat Culture is an introduction to a radical, experimental tradition in art and literature in post WW2 America. These forms of artistic expression will be studied in an aesthetic-cultural framework that takes into account the contemporary social conditions as well as its historical roots in European, American, and non-Western culture. We will emphasize ideas that are similar or run parallel in radical and avant-garde literature and art.

Learning outcomes:

Upon successful completion of the course the students will

- develop an understanding of the artistic expressions related to Beat culture

- be able to account for the expression "Beat", the changes it has been through and the aesthetical parameters that have influenced these changes

- discuss and analyze artistic expression in terms of these aesthetic models

Teaching methods:

The course includes literature and art. Instruction is in the form of lectures, seminars, workshops and excursions. The instruction combines theoretical understanding with hands-on practice, however literary or artistic abilities are not a prerequisite for taking this course. $80 \%$ compulsory attendance at seminars, workshops and excursions. The workload is estimated to 270 hours. 
Examination requirements:

Students must have attended obligatory seminar groups and passed the mid-term essay assignments.

Assessment methods and criteria:

Final assessment comprises a portfolio of two assignments, one in the discipline Literature and one in the discipline Art, and a final examination. The final examination may be either an artistic or a theoretical project. The two parts each count $50 \%$ of the final grade. Both parts must be assessed as a Pass. Graded assessment.

Language is optional, English or Norwegian may be used. 


\section{Appendix 2: Presentation of the Two Spontaneous Writing Challenges Beat Culture Autumn 2020}

Free-writing one: "The Weekend Challenge Spontaneous Writing"

1. Refresh your memory on Kerouac's techniques

2. Set aside 30 minutes (use a timer) and write as much as you can.

3. Still on the timer, peruse the product and correct according to Kerouac'scriteria.

4. Select up to two A-4 pages and submit them to the "Oppgave mappe" "Weekend Challenge" by Sunday night.

Free-writing two "The Weekend Challenge Spontaneous Writing \#2 - Cut ups The second weekend challenge is to produce exactly one complete A-4 sheet of paper, one side of the page only, space and a half, of your own prose.

This can be anything, including a page from an assignment you have handed in for another course, a totally random free-writing, another attempt at following Kerouac's method of spontaneous prose. Anything. Make sure it is PRINTED OUT, a complete A-4 sheet, $1 \& 1 / 2$ space.

You may work alone or in groups, but everyone submits some cut-up results. Next, cut this piece of paper with scissors in four pieces: cut lengthways, and then across so you have 4 pieces.

Then, put the pieces next to each other, and move them up and down, paying close attention to groups of words that sort of make interesting sense. If you need to generate more combinations, let the pieces overlap, invert them, anything: you are playing with language in space!

If you are working with someone, combine their pieces with yours; mix and match!

In a text document or on another sheet of paper, collect no less than 5 phrases or sentences (per person) that resulted from your cut-up experiment! (Group work is submitted in each member's folder; please be sure to include all the names!) 



\title{
CHAPTER 8
}

\section{Rhetorically Performative Early Music: YouTube Videos as Statements}

\author{
Robin Rolfhamre
}

Professor of Music Education, University of Agder

\section{Daniel H. Øvrebø}

\section{Research Fellow, University of Agder}

\begin{abstract}
Increasing history consumption in today's society creates, in different social formations, a common expectation of what historical music is, can and should be. In this chapter, we draw on music education and Baradian agential realism perspectives to offer what we perceive as a promising procedure for studying early music performance from a less anthropocentric stand. We ask: How does early music performance intra-act with YouTube as medium, and how does this intra-action enable informal learning? We first address the significance and prevailing interpretation of rhetoric in this context, and what a move from a single-case rhetoric to an ecological one offers. Subsequently, we introduce agential realism as an approach to studying early music performance, particularly through the lense of Barad (2007). Here, we offer a discursive practice that can contribute to future studies, which we follow up with an exemplary case study. The case is later discussed and analysed, and in conclusion we draw attention to the online media's role both in sustaining historical culture for new generations, and in cumulatively reinventing itself as a pedagogical process both within and outside educational settings.
\end{abstract}

Keywords: early music performance, YouTube, agential realism, rhetoric, musical communication

\footnotetext{
* Affiliation at the time of writing; Øvrebø's current position is Research Advisor, Oslo Metropolitan University.
}

Citation: Rolfhamre, R. \& Øvrebø, D. H. (2022). Rhetorically performative early music: YouTube videos as statements. In R. Rolfhamre \& E. Angelo (Eds.), Views on early music as representation: Invitations, congruity, performance (MusPed:Research No. 4, Ch. 8, pp. 199-221). Cappelen Damm Akademisk. https://doi.org/10.23865/noasp.157.ch8

Licens: CC BY-NC-ND 4.0 


\section{Introduction}

Jenna (a fictional character in this example scenario) has to study. The theme for the day is literature from the Rennaissance era. Sitting down at her desk, she is soon distracted, and suddenly finds herself wandering off, looking for videos online, searching for more entertaining input than her current textbook offers. She browses through Netflix, and watches a couple of episodes of a Renaissance period drama. She finds the music intriguing, something she has not heard the likes of before. On an impulse, she enters YouTube and searches for Renaissance music, only to find a plethora of music performance videos of every kind, all parading under the label "Renaissance". After a while, she returns to her textbook again with the audiovisual examples still in mind, and reads on about the period's literature. Here, something truly important happens in terms of pedagogy and historical perception. In a non-moderated fashion, through her online excursion, she has familiarised herself, perceivingly learned something, or acquired a greater understanding of what the "Rennaissance" means. That is, she has been the subject of informal learning without guidance, with the effect of creating an uncensored sense of a historical past.

Increasing history consumption in today's society creates, in different social formations, a common expectation of what historical music is, can and should be (Liakos \& Bilalis, 2017, p. 5). Period dramas, costume TV series, docudramas, fantasy games, and romanticised medieval historical event portraits all contribute to what we expect, for instance, the medieval, Renaissance or Baroque to be. This affects not only mass perceptions of history, but also present and future generations of aspiring historians and musicians. The question is, from what perspective do we approach and make sense of historical evidence, and how do we ultimately "connect the dots", so to speak, and convey our take on history to others. These matters have become even more pressing today, particularly during the current on-going COVID-19 pandemic. There is, now, increased pressure on educators to create online educational content for classes, a problem easily solved through online resources. Moreover, early music performers, like many others, have, to a much greater extent than before, started to inhabit digital performance space, compensating for cancelled 
live concerts. Therefore, more and more content related to music performance has become available to basically anyone with internet access.

Contrasting conceptions merge - for instance, the emotive emphasis of much present-day entertainment media with the distanced and more objective restoration of past practices and truisms - to become something at once alien and mystical (the alluring otherness of old lost arts), as well as something reassuringly familiar, conforming to what we expect. This is indeed a deeply interesting phenomenon offering many different approaches (e.g., historical culturalism, digital humanities, cultural heritage, psychoanalysis, historiography, materialism, and so on). We will here address the issue from the perspective of music education and Baradian new materialism, offering what we perceive as a promising, and often very different from canonical approaches, procedure for studying early music performance from a less anthropocentric stand.

A music educational setting, here, means an informal, every day, intra-active situation where learning is acquired mostly through a sum of impressions and conclusions, stemming from material exposure (in this case, YouTube videos). Rather than choosing to focus on a formal educational setting where a teacher utilises selected music performance videos - as curiosities - to pinpoint an otherwise carefully designed narrative, we are more interested in the cumulative, non-choreographed knowledge discovered through the individual perceiver's own browsing. That is, how the exposure of more or less random, un-censored YouTube videos shapes their concept of a given cultural heritage, and how this happens. In this sense, the preservation of a cultural heritage, and its development through new generations of audiences, is more a matter of collective responsibility, based on cause and effect relationships rather than the decisions of one specialist at an acclaimed institution.

The aim of this chapter, therefore, is to offer a starting point into this complex matter, within the field of European early music heritage and performance studies, highlighting an understanding of what early music is and was, from the perspective of an active material process, rather than a passive acceptance of historical truths and their representations. In an earlier chapter of this volume, Rolfhamre presents his idea of what the historically informed performance, as a phenomenon and practice, does 
performatively, rhetorically and pedagogically in terms of present early music discourse. While his view is dedicated to meta-perspectives on musicology and performance practices, we are here concerned with digital audiovisual representations of performances as case studies shedding light on early music as a current practice, rather than a more or less skilfully executed representation and re-establishing of something long gone. Although it would be natural to digress into the historically informed performance movement here, this is covered in chapters 2 and 5 of this volume. To avoid unnecessary repetition, we advise the reader to see those chapters should they want to read more. What should be pinpointed here, however, is how technological advances, both in the past and present, go hand in hand with artistic expression and rhetorical constructs. From the impressive gardens of Versailles with their fountains, to printed propaganda (posters, artworks, sculptures, coins, etc.), to the sound of musical instruments, to theatres built to enable (even force) the audience to focus on stage activities, to gramophones, to television, to VR, the available technologies have always been used to promote the intended content and effects, thus making an impression (understood from a rhetorical perspective). Audiovisual media, including YouTube videos, are, of course, no exception here. There is an ever-growing body of literature dedicated to film music, music on small screens, televisions, and computers. Steadily developing into a vibrant scholarly tradition that by far exceeds the limitations of the present chapter, education and the media has more recently crystalised into a discipline. Studies show that YouTube, for instance, has become a platform enabling users to connect, inspire and learn from each other, particularly through the tutorial format (Lange, 2019; Whitaker et al., 2014). Pires et al. (2019) identifies five pronounced ways of engaging with YouTube among youths: 1) radiophonic, as if listening to radio; 2) televisual, as if engaging with a user-controlled television; 3) social, seeking interactions with others beyond mere solitary online presence; 4) productive, as in distributing their media to others; and 5) educational, for the purpose of learning something. Some studies focus on YouTube based learning and teaching, in which the pedagogical agenda is created more or less explicitly through the perspectives of the content creators (e.g., Marone \& Rodriguez, 2019; Waldron, 2013; Whitaker et al, 2014). 
Others look more specifically at incorporating YouTube videos into more formalised learning scenarios and what effects this causes (e.g., Cayari, 2018; DeWitt et al., 2013; Jones \& Cuthrel, 2011).

Many of the studies we encountered emphasise planned, active participation in social networks for learning and exchange. This also seems to be the case for studies aimed more specifically at music performance videos and education. While studies show that music performance videos can be incorporated into more formal educational settings (e.g., Cayari, 2018; Marone \& Rodriguez, 2019), the authors of music performance videos, at least from an educational perspective, generally seem more concerned with showcasing their own skills and/or inspiring others, normally without expressing an intended educational purpose (e.g., Whitaker et al., 2014).

More work seems to be necessary, however, on incidental learning and music-specific cultural sustainability in relation to YouTube music performance videos, which were originally conceived and presented as aesthetic presentations with no expressed educational purpose or agenda. Moreover, the music performance videos of period music, such as early music, served to represent and preserve selected interpretations of a cultural legacy. Lange (2019) distinguishes between YouTube based informal learning, and incidental learning, which differ in that the first is planned and conscious, while the latter is an unplanned result of doing something else. In the fictional case of Jenna, above, we could say that her unplanned excursion into period music performance videos - which introduced her to Renaissance music - while initially performing other learning activities, constitutes a case of incidental learning, in terms of her forming an idea of what constitutes the "Renaissance". She also participates in more than one of Pires et al.'s (2019) five categories while doing so, from the recreational entertainment of the period drama to the move to YouTube, thus learning more about a topic by consuming in a radiophonic or televisual manner. Maybe she even commented and interacted with others, and gained some kind of knowledge from doing so, a perspective studied by scholars including Lee et al. (2017) and Dubovi and Tabak (2020).

In this chapter, following a Baradian new materialist position, we ask: How do we intra-act with early music performance represented through 
online videos in ways that convey different subject positions? The incentive has its roots in the online media's ever-growing importance in distributing and communicating musical performances globally, reaching new audiences who may otherwise have had little or no access to the general early music community. In this view, early music is very much a present, social activity drawing on something once lost, and offering something exotic, as well as pursuing the historical through representation and appropriation. It is how we convey our European cultural heritage today, and how we protect it as a rich tradition beyond the written word. Therefore, in the present chapter, we are not particularly interested in what should or would be considered accurate representations of early music through original sources. What we are interested in, however, is its rhetorical function as a medium today, favouring presentism over historicism. Analyses comparing historical sources to what is performed are therefore entirely omitted in the following case studies. Our contribution to early music performance studies is to offer a perspective on its mediating, rhetorical function through online media, by providing an alternative analytical method utilising rhetorical and new materialist ideas. Our goal is for Medieval early music performances to be more readily included in educational ethical discourse, showing how cognition and encounters through their inherent rhetorical persuasive function - blend effectively with filmed music performances to create sensation and calls for action, as well as a sense of meaning. This will help to highlight both the communicative potential for early music represented through performances on YouTube, as well as the responsibility of early music performers who use online media channels to extend the scope of their performances. In addition, we aim to provide input to future discourse on incidental learning in the contexts of cultural heritage, music performance and communication of and through music.

Early music performance studies, as well as pedagogy and rhetoric, are very much anthropocentric matters. Recent work acknowledges the material world and its influence on the human subject to a greater degree than what was common earlier. In Judith Butler's influential work on gender (e.g., 1990/2006), discussion centres on people as interacting with the material and socio-political world. These perspectives have also entered 
early modern music through the path paved by feminist and gender studies (e.g., McClary, 1991/2002; Scott, 2003, to name only two). But these materialist approaches still place humans on higher ground. Barad's (2007) agential realism and intra-action offers a levelling of the hierarchical relationship between humans and the material world, with the first being positioned, not as a focal point interacting with the external material world, but as one piece of a whole operating on the same playing field as the external material world, where all exert influence on all (hence, intra-acting rather than inter-acting). As Liakos and Bilalis comment in a very different context than Barad:

To understand historical culture, historians need to abdicate from their role as the rulers (and judges) of the history production process. They need to become objects of their research and to embark on a collective journey regarding the role of history in society and their role as historians, without implying a duality between academic history and lay historical culture. (Liakos \& Bilalis, 2017, p. 7)

This decentralisation of the human subject as truth provider offers interesting pathways into the study of early music presentation and historical cultural heritage. It can offer a complement to historicist approaches, thus redefining the performer and inspiring new self-perception and artistic possibilities. This will be especially relevant in a future post-COVID-19 society, where online streaming, digital cultural heritage immersion, and mass cultural consumption will most likely operate very differently from just last year (this is written during the pandemic).

For the rest of this chapter, we first address the significance and prevailing idea of rhetoric in this context, and what a move from a single-case rhetoric to an ecological one offers. Subsequently, we introduce a new-materialist approach to studying early music performance, particularly through the lense of Barad (2007). Here, we offer a discursive practice that can contribute to future studies, which we follow up with an exemplary case study. The case is later discussed and analysed according to agential realism ideals and, in conclusion, we draw attention to the online media's role both in sustaining historical culture for new generations, and in cumulatively reinventing itself as a pedagogical process both within and outside educational settings. 


\section{Setting up a rhetorical ecology}

Pre-aesthetic, early modern cultural production was predominantly governed by rhetoric (Rueger, 2011). It was carefully and holistically designed to persuade the receiver using multiple areas of expertise, all working towards the same end - to create rapport (Eriksen, 2001; Rolfhamre, 2018a; Rueger, 2011). With social, and socialising effects in mind (Rolfhamre, 2018a, 2014), it sought to constitute itself within the realms of rhetorical ecologies (cf. Rivers \& Weber, 2011) based on iterative formations (cf. Derrida, 1982), in which selected imagery, analogies and designs - or historical fragments in general - were meant to position the subject forcefully, maintaining its image and brand (to use modern terminology) or simply promoting a specific cause (Burke, 1994; Liakos \& Bilalis, 2017).

Early music performance being rhetorically performative is, then, no novelty. This is why rhetoric and phenomenal reception together offer a particularly interesting analytical perspective in the sense of the online early music performance video as a mediator of early music - that is, an early music-ness, or what we perceive as a convincing early music performance. This perspective is especially important in terms of the historically informed performance (HIP), not only as a field of interest and artistic creativity, but also as a cultural heritage safekeeping-phenomenon. Moreover, the open online format offered by social media platforms, such as YouTube, enables the mediation of this cultural heritage from the initiated HIP "natives" to the uninitiated on a global scale. Indeed to the latter the non-refereed early music performance video, as is, may fully represent what constitutes early music, no matter who its creator was. Such multiplicities of early music signifiers offered by social media platforms, thus, iterably and cumulatively create the popular concept of cultural historicism often presented as "cultural heritage", which it performatively (in both a Derridean and Butlerian sense) helps maintain and develop further.

One obvious issue that arises from this chapter's use of rhetoric in new materialist analysis is the very different emphasis on the human subject, which begs the question of how they can combine well. The question, however, is perhaps not how a rhetoric can or should, in fact, be 
fully anthropocentric, but how it fits within a more levelled hierarchical intra-action, which is less of a conundrum. It is merely something intra-acting with other things. Moreover, it may be argued that rhetoric being about persuasion, or inducing someone to do, feel or believe something, for instance - can function both in conscious and unconscious, deliberate and undeliberate instances. Imagine a cathedral church organ, for instance, with all of its rhetorical devices (material, ornaments, size, tone-quality, amplitude, etc.) as a symbol of rank, wealth and power. Or, consider a microscope or spectral analysis machine, designed to show persuasively one, delimited aspect of reality. With a wink and a nod to both Barad and Derrida, once they leave their creator (being bought by someone else, somewhere else), these items still act out their significance iterably in relation to other designs without (perhaps) there being a known addressor or addressee. In Rivers and Weber's (2011) rhetorical ecology the possibility for such considerations appears. The rhetoric among materials may or may not have been construed by different individuals in different times, contexts and with varying intent (some may be for something while others against). Yet at the same time, the theory of argumentation, Perelman and Olbrechts-Tyteca inform us, has discursive technique as its object (1969, loc. 227). This is also where rhetoric may indeed meet new materialist theory.

Online media, particularly social media, are very much about discourse techniques and how to captivate the site visitor to keep them from leaving your website, or, even better, become loyal returning visitors. Rhetoric can, here, be placed within the individual text's persuasiveness, but it can also be located in relation to other sites. Particularly, it may build its strongest discourse by relating to what it is not (e.g., "This website seems much more well-designed and trustworthy than that home-made, basic HTML-coded mess of a reader experience”). Hence, a creation's rhetorical effect, or efficacy, exists in relation to other texts, which precede and succeed it, and creates new meaning as it moves through history and geography (following the principles of a Derridean (1982) iteration-type of performativity, cf. chapter 2 of this volume). This makes rhetorical intra-action, as Barad (2007) asserts, very much an ethical matter. Indeed, while drawing on the analogy of 
the famous film series starting with Jurassic Park (Spielberg, 1993) to illustrate how detached, historical fragments are used to construct realities and arguments, Liakos and Bilalis point out:

... In Jurassic Park, the deadly confrontation of human and beast is associated with the park as a leisure activity and commercial venture. In contemporary historical culture, history wars and the marketing of activities related to history and the display of the past go hand in hand. (Liakos \& Bilalis, 2017, pp. 6-7)

Take for instance how current lute performance practice uses a rhetoric of being historically correct based on unhistorical practices, and changes its artistic expression and execution according to the social formations it seeks to conform to - very much like rhetoric (Rolfhamre, 2018b). Nonetheless, if a lutenist's performance activity does not correspond to the expectations of the audience, they may lose their market and their ability to be professionally active. Hence, being a professional musician is also - whether we like it or not - a venture, if it should ever excel the status of personal leisure and pastime. In online media such as YouTube, we meet the rhetoric of the professional and the amateur, as well as the expert and the autodidact novice, and they are interchangeably exposed to us as we browse through the archives.

\section{Agential realism as an approach to representations of rhetorically performative early music as YouTube content}

Picking up the notion of early music performance as a rhetorically performative phenomenon, it is worth discussing exactly what an agential realism approach to doing research on early music can achieve. "The primary value of agential realism," as Rosiek (2018, p. 638) asserts in a stimulating text on agency and ethics in arts based research, "is that it offers a way to acknowledge the way inquiries can reveal real things about the world, without treating these revelations as totalizing accounts of what is possible". In arguing the affordance of agential realism for arts based research in general, he stresses that it provides a 
more robust framework for discussions on ethics and agency, because art is ontologically generative. More precisely, research on artistic practice benefits from agential realism because it is "about generating new modes of being in the world" (p. 644). These modes of being are the subject of this text. Our case study investigates a specific intra-action in which early music as a phenomenon, digital media platforms, a rhetorical ecology and research meet.

Early music performance studies, with a long tradition of debating the relationship between authenticity and representation, seems therefore to benefit from an analytical perspective having as its point of departure how both research and practice are ontologically generative processes. Since we want to study its mediating, rhetorical function through online media, we are, to remain with Rosiek, not interested in treating these performances as "totalising accounts" of what is possible in early music.

Before presenting our case study, we need to consider how early music fits into the theoretical and methodological vocabulary intrinsic to Barad's agential realism. Adopting this approach means studying early music performance as a social material-discursive phenomenon, rather than treating disciplines such as historical musicology, systematic musicology and organology as separate entities. The modes of being mentioned above become the starting point of the inquiry. Agential realism necessitates the notion that identities are considered to be undecided prior to being measured. Intra-action is the moment in which the different possibilities of being are decided. In our case study, a series of becomings take place: our own researcher and musician selves (see next paragraph); the performers in the video; the sound qualities of their instruments; the works performed; the rhetorical devices employed by the musicians; YouTube as a mediator of rhetoric in general. All of these are considered to be agents within the early music phenomenon, and our specific intra-action (our case study) lets us investigate how these becomings happen.

For Barad (2007), ethics (the responsibility researchers have when designing their experiments), ontology (the existential belief that guides the inquiry), and epistemology (the characteristics of the knowledge 
produced by the inquiry) are not entirely separate entities. They are entangled units that influence each other, and thus she condenses them into the concept of ethico-onto-epistemology.

\section{The case study}

When specifying what kind of case study we wanted to do, we found it very useful to discuss our approach through Postholm's (2010) differentiation of case studies, based on their utility value. Postholm's work belongs within a phenomenological approach to case studies. She distinguishes between case studies that simply present information in an area with little previous research (descriptive), case studies that afford a richer theorising of a given field (interpretive), and case studies that can clarify where previously there existed few conclusive studies (evaluative). In addition, Postholm, in reference to Stake's (1995) The Art of Case Study Research, specifies a distinction between case studies that seek to exemplify a given practice within one field (internal), and case studies that seek to illustrate a case across different fields (instrumental). As such, our case study is interpretive, because we seek to theorise how early modern rhetoric communicates in different performances, as presented on YouTube. Furthermore, the case study is distinctly instrumental, in as much as we work across different fields when combining perspectives from rhetoric, music performance and digital media.

The main idea behind the case study was to select representative YouTube videos containing early music performances of various kinds. From the perspective of the online video as mediator, conveyor and representation of a certain early music-ness, we sought to document early music and its intra-action with the medium, in order to understand how early music-ness manifests itself to us through online media, at a phenomenal level, and how it does so. When selecting the YouTube video cases for the study, we chose to prioritise a younger, emerging generation of performers of both sexes and of varying nationalities (e.g., Sweden, Spain, and France). They represent different settings and filming techniques, and an overview of the content and characteristics can be presented in a table: 
Table 1. Overview of the Videos Used for the Case Study

\begin{tabular}{|c|c|c|c|c|}
\hline Reference & $\begin{array}{l}\text { Work } \\
\text { performed }\end{array}$ & Composer(s) & Performers & General characteristics \\
\hline $\begin{array}{l}\text { Nordberg } \\
(2020)\end{array}$ & A Fancy & John Dowland & Jonas Nordberg & $\begin{array}{l}\text { Video with different cuts } \\
\text { of Nordberg performing } \\
\text { by himself. }\end{array}$ \\
\hline $\begin{array}{l}\text { Kvarnström } \\
\text { (2013) }\end{array}$ & N/A & $\mathrm{N} / \mathrm{A}$ & $\begin{array}{l}\text { Jonas Nordberg } \\
\text { Kenneth } \\
\text { Kvarnström }\end{array}$ & $\begin{array}{l}\text { Continuous crosscutting } \\
\text { of solo guitar performance } \\
\text { and dance movements. }\end{array}$ \\
\hline Zapico (2014) & $\begin{array}{l}\text { Capona and } \\
\text { Ciaccona }\end{array}$ & $\begin{array}{l}\text { Giovanni } \\
\text { Girolamo } \\
\text { Kapsberger }\end{array}$ & $\begin{array}{l}\text { Daniel \& Pablo } \\
\text { Zapico }\end{array}$ & $\begin{array}{l}\text { Concert recording using } \\
\text { multiple cameras from } \\
\text { different angles. }\end{array}$ \\
\hline Imbs (2019) & $\begin{array}{l}\text { Corrente } \\
\text { Prima }\end{array}$ & $\begin{array}{l}\text { Giovanni } \\
\text { Girolamo } \\
\text { Kapsberger }\end{array}$ & Albane Imbs & $\begin{array}{l}\text { Informal "at home" } \\
\text { recording session. }\end{array}$ \\
\hline $\begin{array}{l}\text { Les Kapsber'girls } \\
\text { (2018) }\end{array}$ & N/A & $\mathrm{N} / \mathrm{A}$ & $\begin{array}{l}\text { Les Kapsber'girls } \\
\text { (ensemble) }\end{array}$ & $\begin{array}{l}\text { Two clips from a recording } \\
\text { studio. }\end{array}$ \\
\hline $\begin{array}{l}\text { La Cité de la } \\
\text { Voix (2018) }\end{array}$ & N/A & $\mathrm{N} / \mathrm{A}$ & Les Kapsber'girls & $\begin{array}{l}\text { Music with a voiceover } \\
\text { featuring different cuts of } \\
\text { both performers as well as } \\
\text { their surroundings. }\end{array}$ \\
\hline $\begin{array}{l}\text { Palisander } \\
\text { (2015) }\end{array}$ & $\begin{array}{l}\text { Concerto II: } \\
\text { Allegro and } \\
\text { adagio }\end{array}$ & $\begin{array}{l}\text { Johann } \\
\text { Christian } \\
\text { Schickhardt }\end{array}$ & $\begin{array}{l}\text { Palisander } \\
\text { (ensemble) }\end{array}$ & $\begin{array}{l}\text { Concert recording using } \\
\text { one stationary camera. }\end{array}$ \\
\hline Bernstein (2018) & Tarantella & $\mathrm{N} / \mathrm{A}$ & Palisander & $\begin{array}{l}\text { Informal "at home" } \\
\text { recording presented } \\
\text { as a meme, with } \\
\text { the four recorder } \\
\text { players performing } \\
\text { choreographed dance } \\
\text { movements while playing. }\end{array}$ \\
\hline
\end{tabular}

See the reference section at the end for links to each video.

The videos were watched simultaneously by both authors through a Zoom meeting, after which the authors had a brief discussion and exchange of notes taken during the videos. The table above reflects the order in which the videos were watched. Rolfhamre was responsible for selecting the videos, which had not previously been seen by $\emptyset$ vrebø. Øvrebø, on the other hand, was responsible for deciding on three keywords to frame the discussion, of which Rolfhamre had no prior knowledge. As such, both authors had familiar and unfamiliar elements presented to them during the session.

Øvrebø designated these keywords in Norwegian as ledeord (ca. guide words), taking inspiration from Knut Ove Eliassen's approach to 
extracting from the text itself a method for analysing literature, rather than relying upon any pre-existing models of theory and analysis (Eliassen \& Stene-Johansen, 2007). As an example, the keyword "repetition" provides the starting point for analysing a passage from Jorge Luis Borge's Pierre Menard, Autor del Quijote [Pierre Menard, author of Quijote], a meta-fictional essay in which Borge invents an author called Pierre Menard who is attempting to re-write, word for word, Miguel de Cervantes classic novel Don Quijote. Borge's text is discussed in light of authors, other texts, and literary concepts that all relate in different ways to repetition, such as ars combinatoria (the idea that all prose is ultimately based on a limited number of possible combinations of letters), and Aragon's surrealist "method" of "seeing the familiar as if it was strange and the strange as if it was familiar" to name only a few examples (Eliassen \& Stene-Johansen, 2007, pp. 274-275). In this way, "repetition" becomes not so much a keyword in the sense of my English translation, but a concept that guides the analysis both by establishing new relations and by conducting (in the electromagnetic sense that for instance metal conducts, and thus leads, electricity) (pp. 10-11).

The first keyword was inspired by the circumstances surrounding the COVID-19 pandemic that had to a great extent shaped social interaction in most part of society, forcing the use of digital solutions to meetings that would have otherwise taken place in person. As such, the first keyword was the "format" itself, and how watching YouTube videos is different from a concert setting. The intention was both to address the selection of clips made by Rolfhamre, and also to exchange thoughts and ideas around the whole format. The question itself might seem overwhelmingly "naive". The difference of experiencing a performance on YouTube versus live in concert is characterised by so many variables that a general comparison might seem utterly pointless.

The second guiding keyword pertained to the "content" itself, and addressed what we were noticing in the videos, in the music, in the performers, in the venues. This could be seen as an extension of the first keyword, since we now examine the relationship between what is performed and how our access to the performance shapes our experience of it. 
The third keyword was in part inspired by the increased scholarly attention to "quality" in the arts, in particular as reflected in the Norwegian Arts Council's research project that sought to investigate how we perceive relationships among the arts (be it specific artefacts or artistic practices) and questions of quality. For us, this turned our attention to what we liked in the clips. Or, to be more specific, to borrow a phrase from Eric Clarke (2005, p. 92) related to subject-position in music listening, what materials in the clips "shape the general character of our response or engagement" towards interested, rather than indifferent or repelled. Through the first two keywords, we discussed both the content of the videos, as well as the format in which they were presented. The authors had different opinions on this, which can be attributed to their different backgrounds. It is not the intention here to make a case for how quality can be objectively measured or otherwise ascertained across performances of early modern music. Rather, we want to highlight how our discussion reflects any qualitative differences in the videos.

\section{Findings: Three modes of rhetoric}

Through discussing the relationship between content and form - that is, early music performance and how it is represented through a selection of videos available on YouTube - the authors were able to distinguish three different modes of rhetoric. Before presenting the three modes, the analysis will be explained, focusing on the keywords mentioned in the previous section.

Regarding the first keyword "format", one topic that recurred in the authors' discussion after watching the videos, was how in some videos the camerawork itself shaped the viewer's perception to a considerably higher degree than in the others. The first clip for instance (Nordberg, 2020) features a wide array of angles and focus areas. Close up shots that show the performer's head from the chin upwards are contrasted with low angle cuts in which we see his fretting hand on the fretboard in focus, while his head is in the cut but out of focus. The effect is somewhat similar to that of a rack focus employed in cinematic storytelling, in which the focus shifts to an object already in view, in order to draw attention to 
something the viewer most likely would have missed. Øvrebø referred to this by comparing it with "popular music videos of the kind pioneered by MTV", because it directed one's attention to certain figures in the music that they would not have otherwise noticed. Rolfhamre addressed it more directly when he likened it to strategies of social media and suggested that it was about "keeping the viewer's attention" by telling "a supplementary visual narrative". The camera here, the material link between early modern music as performed by Jonas Nordberg, becomes in this video not so much a passive mediator, but a communication tool, an instrument on par with what Jonas is holding in his hands. It focuses the viewer's attention and thereby enforces more detailed listening that arguably benefits the music. The authors agreed that this was not the case in all the videos. In comparison, the live performance recording of the Schickhardt concerto (Palisander, 2015) had no particular focus as the camera was mounted, but also no opportunity for the viewer to move their focus around since the camera was placed quite far from the stage.

This matter of using the camera as an extended tool for letting visual communication enhance the overarching artistic communication brings the analysis to another point. On YouTube in general, and perhaps for music and arts in particular, users need to balance between two axes: videos as entertainment and videos as more "serious" artistic communication. The videos used in this case study can surely be said to demonstrate the whole range of this spectrum. The previously mentioned Schickhardt concerto (Palisander, 2015) has decidedly less value as entertainment and more ethos as a documentation of a live concert. No attempt is made to communicate the music other than to viewers who are perhaps already interested in either the ensemble or the composer. The same can also be said for the Zapico brothers (Zapico, 2014). On the other end of the spectrum, we have Nordberg's Dowland clip (2020). The visual narrative tells a story on a par with the musical narrative and enhances communication. The viewer is brought closer to the instrument and the performer, in a way that favours the performance itself above what is being performed.

Extending the discussion of how the camera is or is not used, it is worth remaining with Palisander (2015) simply because of how the static camera fixes the viewers' attention as if they were ordinary concert members, 
rather than individuals sitting at home and watching a screen. Indeed, this very pretense seems to engender some deeper distinction between some of the videos. In Palisander (2015) the performers are positioned on stage and resort to a kind of communication based on letting the musical composition - the two movements from Johann Christian Schickhardt's Concerto II - communicate on its own. Its formal elements are placed firmly in the foreground, with the ensemble assuming the role of passive mediator. This is not to de-valuate the effort that the musicians in the ensemble have made. We are here merely less interested in each individual performance in and of themselves in favour of the dynamic relationship between YouTube as a media platform and early modern music as a practice of rhetoric.

In discussing the second keyword "content" further, the authors agreed that the dual axis mentioned above can be extended into three modes of rhetorical communication. The Schickhardt video already mentioned (Palisander, 2015), as well as the Zapico brothers (Zapico, 2014), Vous avez dit Brunettes? with Les Kapsber'girls (2018), and Imbs' (2019) solo performance typify the first mode: rhetoric based on documentation, either of a live recording or of a recording session. With a mounted camera placed either at a distance or up close, the videos serve as a documentation of an artwork and its performance that took place somewhere else. In the second mode of rhetoric the video becomes the work of art itself. In Nordberg's (2020) case, as discussed above, the video with its elaborate camerawork becomes the artistic artifact rather than a medium of presenting. The second video featuring the ensemble Les Kapsber'girls (La cité de la voix, 2018) also belongs in this mode. It features extensive and sometimes rapid crosscutting between a wide array of different shots. In particular, the series of head shots of the two singers performing facial gestures that imitate the lyrical content of the music is an example of the same type of camerawork found in Nordberg (2020), which sets it quite apart from experiencing a live performance. The third mode of rhetoric is based on humour, in which the communicative act is not so much premised on the music or the performance but lets the work of art serve as entertainment with a humorous purpose extrinsic to the music. The final Palisander video (Bernstein, 2018) is an example of this, as well 
as the video with Jonas Nordberg together with Kenneth Kvarnström (2013). In the Palisander video, the music displays a high degree of virtuosity, including choreographed movements reminiscent of a military tattoo performance. The video itself has a headline indicating its use as an online meme: "When it's 1594 and you're out with your squad." The humorous anachronism in using Renaissance recorder music in reference to contemporary nightlife culture is quite far removed from any original rhetorical devices in the music.

One way for the authors to approach the third keyword "quality" was to look at whether the video format guided their attention towards general characteristics of the compositions themselves or to specific details in the performances. In the Schickhardt concerto (Palisander, 2015), more attention was given to the harmonic structure and melodic lines, rather than how the structure and melody was executed by the performers. A figure executed on the recorder was perceived primarily as a figure intrinsic to the narrative development of the composition, with nuances related to phrasing, tone and technique retreating into the background. On the other side of this perceptual shift were the videos of the ensemble Les Kapsber'girls, in which the focus was directed to the qualities of the performers: variations in timbre, vocal pronunciation, and emphasis on certain syllables - all results of artistic decisions made by the performers rather than the composers. In the case of the video titled La Cité de la Voix, this element was also supported by the camerawork, as mentioned in the previous paragraph.

\section{Concluding discussion}

In the previous analytical section, the authors identified three modes of rhetoric based on their readings and discussions of the relationship between content and form. In other words, YouTube as a medium affords three different modes through which early music performance is represented.

YouTube and similar media platforms present a low-threshold opportunity to publish your music however you choose without being restricted to the physical space of a concert venue. You can publish singlecamera-on-tripod documentation, directed multicamera productions, 
animations, 360-videos, VR videos or simply a blank screen. Moreover, you can choose to highlight or downsize the effect of the visual and aural exoticness of, for example, old instruments. It will all depend on how you stage your performance. Indubitably, what you choose to do will have an impact on the setting in which it is being perceived.

From a formalised educational perspective, for example, many teachers turn to videos to teach history because of their emotional accounts and personification of historical events, which may seem more engaging and relatable than textbooks and Powerpoint presentations. Moreover, as many students are more accustomed to and comfortable with learning about the past through film, rather than written publications (Metzger, 2007 , pp. 67, 73), it may be a readily chosen pedagogic strategy in many circumstances. But, as Metzger points out, it takes effort from the participants to avoid passive consumption (p. 73). This is an even more important matter to consider in informal and/or incidental circumstances, in which there is no moderated pedagogical strategy present. An example is when people browse YouTube to learn something new or to be entertained in both expected and unexpected ways.

As the above study indicates, our reactions to the selected early modern performance videos support how cognition and encounter blend effectively with the music performance to create not only some sort of meaning but also a sensation, and a call for action inviting the viewer to engage with the material and become affected differently. Furthermore, the authors were able to identify some meaningful ways in which we could perceive of the viewings as intra-actions, and how this shaped the viewer's "modes of being". Our attention shifted between qualities of the compositions versus the performance, depending on how the setup and camerawork focused our gaze. Indeed, this very matter of our gaze and how it is (or is not) directed through the different videos became a recurring topic of our reactions, as documented in our discussion. It was difficult to address questions of content and quality in the clips without taking the format and its techniques of focusing viewer attention into consideration.

Subsequently, the study supports the idea of medial early music performances being more readily included in educational ethical discourse. 
In this way we would not only designate the perceived performance as a cultural event or artefact, but include it in the community, and certain knowledge processes where we focus more on what becomes than what was. This would also point out the importance of including visual media strategies as an integral part of the musician's or content creator's performance intention, rather than merely considering it to be a practical way to "get the music out there". From this perspective then, music performance videos as decentralised artefacts may be more apt to create a critical historical discussion, than merely exemplifying a superior curricular narrative.

What this case study also shows is that, even though music performances are often addressed from the perspective of aesthetics, early music performance has inherited and still maintains much of its past rhetorical, multi-faceted persuasive function (Burke, 1994; Eriksen, 2001; Rolfhamre, 2018a; Rueger, 2011). From a materialist perspective, like the one presented here, we see that not only is the music performance itself, the sound, important to how we conceive early music, but so also is the performance setting, the musical instruments, the embodiment of the performer and the artistic direction. The materialistic aspects of the practice share an equally strong responsibility for the becomings of the essence and credibility of a historical re-enactment, as the music being performed. In addition, the topic of marginalisation must also be raised. Historical instruments and costumes, film cameras and sound recording equipment, etc., are often quite expensive, never mind the accumulated knowledge needed to utilise them according to a certain norm. Doing early music performance, at least from this perspective, is a privilege for those with the financial means and access. Our European early music heritage is often, in our experience as active musicians, focused on court, ecclesial and bourgeois culture which does not necessarily represent mainstream society. It is therefore worth questioning what we are preserving and for whom are we preserving it, and if it therefore is simply a matter of preserving the practices of past privileged social groups to be enjoyed by current privileged communities. This is why online representation of these sorts of music performances are so interesting, because, as long as you have access to a computer with an internet connection, you 
can participate in this cultural heritage formation as intra-acting agents, experiencing and forming the public cultural conception of early music to be inherited by future generations. This shifts the power structure of defining what our cultural heritage is, not according to the experts alone, but also according to the common person. Early music performance videos receive their impulse from their creators, but in the realm of cultural heritage, they also live a life of their own, shaping our understanding of who we were, have become, and what future becomings we can imagine.

\section{References}

Barad, K. (2007). Meeting the universe halfway: Quantum physics and the entanglement of matter and meaning. Duke University Press.

Bernstein, R. (2018, November 15). When it's 1594 and you're out with your squad! Palisander recorder group on classic FM [video]. https://youtu.be/j1ed9gqXp3 E

Burke, P. (1994). The fabrication of Louis XIV. Yale University Press.

Butler, J. (1990/2006). Gender trouble. Routledge Classics. Routledge.

Cayari, C. (2018). Connecting music education and virtual performance practices from YouTube. Music Education Research, 20(3), 360-376. https://doi.org/10.1080/ 14613808.2017 .1383374

Clarke, E. F. (2005). Ways of listening: An ecological approach to the perception of musical meaning. Oxford University Press.

Derrida, J. (1982). Margins of philosophy (A. Bass, Trans.). The University of Chicago Press.

DeWitt, D., Alias, N., Siraj, S., Yaakub, M. Y., Ayob, J. \& Ishak, R. (2013). The potential of YouTube for teaching and learning in the performing arts. Procedia - Social and Behavioral Sciences, 103, 1118-1126. https://doi.org/10.1016/j. sbspro.2013.10.439

Dubovi, I. \& Tabak, I. (2020). An empirical analysis of knowledge co-construction in YouTube comments. Computers \& Education, 156. https://doi.org/10.1016/j. compedu.2020.103939

Eliassen, K. O. \& Stene-Johansen, K. (2007). Ledeord. Cappelen Akademisk.

Eriksen, R. (2001). The building in the text: Alberti to Shakespeare and Milton. Pennsylvania State University Press.

Imbs, A. (2019). Hiéronymus Kapsberger - corrente prima [video]. https://youtu.be/ aBxMFE5Sg3g

Jones, T. \& Cuthrell, K. (2011). YouTube: Educational potentials and pitfalls. Computers In the Schools, 28, 75-85. https://doi.org/10.1080/07380569 
Kvarnstrom, K. (2013, April 14). Sofa(r) trailer [video]. https://youtu.be/GSX9XIeOgFo

La Cité de la Voix. (2018, September 12). Les Kapsber'girls | La cité de la voix [video]. https://youtu.be/9QpYX-StnyY

Lange, P. (2019). Informal learning on YouTube. In R. Hobbs \& P. Mihailidis (Eds.), The international encyclopedia of media literacy (pp. 1-11). John Wiley \& Sons. https://doi.org/10.1002/9781118978238.iemloo9o

Lee, C. S., Osop, H., Goh, D. H.-L. \& Kelni, G. (2017). Online Information Review, 41(5), 611-625. https://doi.org/10.1108/OIR-09-2016-0274

Les Kapsber'girls. (2018, 15 March). Les Kapsber'girls: Vous avez dit brunettes? [Did you say brunettes?] [video]. https://youtu.be/-ey5tbMr5ec

Liakos, A. \& Bilalis, M. (2017). The Jurassic park of historical culture. In M. Carretero, S. Berger \& M. Grever (Eds.), Palgrave handbook of research in historical culture and education (pp. 207-224). Macmillan. https://www.academia. edu/41464434/THE_JURASSIC_PARK_OF_HISTORICAL_CULTURE

Marone, V. \& Rodriguez, R. C. (2019). "What's so awesome with YouTube?": Learning music with social media celebrities. Online Journal of Communication and Media Technologies, 9(4). https://doi.org/10.29333/ojcmt/5955

McClary, S. (1991/2002). Feminine endings (with a new introduction). University of Minnesota Press.

Metzger, S. A. (2007). Pedagogy and the historical feature film: Toward historical literacy. Film \& History: An Interdisciplinary Journal of Film and Television Studies, 37(2), 67-75. https://muse.jhu.edu/article/223506

Nordberg, J. (2020, March 27). Jonas Nordberg (lute): John Dowland - a fancy (P5) [video]. https://youtu.be/zUQy7S6XiPE

Palisander. (2015, August 31). Concerto II for four recorders in D minor: Allegro \& adagio - Johann Christian Schickhardt [video]. https://youtu.be/ouZ-P-O6EDU

Perelman, C. \& Olbrechts-Tyteca, L. (1969). The new rhetoric: A treatise on argumentation. University of Notre Dame Press. https://www.amazon.com

Pires, F., Masanet, M.-J. \& Scolari, C. (2019). What are teens doing with YouTube? Practices, uses and metaphores of the most popular audiovisual platform. Information, Communication \& Society. https://doi.org/10.10.80/136911 8X.2019.1672766

Postholm, M. B. (2010). Kvalitativ metode: En innføring med fokus på fenomenologi, etnografi og kasusstudier (2nd ed.). Universitetsforlaget.

Rivers, N. A. \& Weber, R. P. (2011). Ecological, pedagogical, public rhetoric. College Composition and Communication, 3(2), 187-218. https://www.jstor.org/ stable/23131582?seq=1\#metadata_info_tab_contents

Rolfhamre, R. (2018a). "Caprice de chaconne" (1671): Symmetry and proportions in Francesco Corbetta’s work for Baroque guitar. Early Modern Culture Online, 4(1). https://boap.uib.no/index.php/emco/article/view/1513 
Rolfhamre, R. (2018b). Informed play: Approaching a concept and biology of tone production on early modern lute instruments. Cappelen Damm Akademisk/ NOASP. https://press.nordicopenaccess.no/index.php/noasp/catalog/book/38

Rosiek, J. L. (2018). Art, agency and ethics in research: How the new materialisms will require and transform arts-based research. In P. Leavy (Ed.), Handbook of arts-based research. The Guildford Press.

Rueger, A. (2011). Aesthetics. In D. M. Clarke \& C. Wilson (Eds.), The Oxford handbook of philosophy in early modern Europe (pp. 201-223). Oxford University Press.

Scott, D. B. (2003). From the erotic to the demonic: On critical musicology. Oxford University Press.

Spielberg, S. (Director). (1993). Jurassic Park [Film]. Universal Pictures.

Waldron, J. (2013). User-generated content, YouTube and participatory culture on the web: Music learning and teaching in two contrasting online communities. Music Education Research, 15(3), 257-274. https://doi.org/10.108o/14613808.2013.772131

Whitaker, J. A., Orman, E. K. \& Yarbrough, C. (2014). Characteristics of "music education" videos posted on YouTube. Applications of Research in Music Education, 33(1), 49-56. https://doi.org/10.1177/8755123314540662

Zapico, D. (2014, 9 February). Daniel Zapico \& Pablo Zapico - Gio.G. Kapsberger: Capona \& ciaconna [Vídeo 3/10][HD] [video]. https://youtu.be/ByMzi6DA-ys 



\title{
CHAPTER 9
}

\section{From Researcher/Performer to Artistic Researcher: Looking Back at the Past in Search of New Possibilities}

\author{
Jorge Salgado Correia
}

Associate Professor, University of Aveiro, INET-MD, Portugal

\begin{abstract}
Musicians involved in historically informed performance are pulled in different directions, driven by two different motivations, and when one of them is taken to the extreme, the other runs the risk of being, if not overtaken, at least overshadowed. One is the motivation to observe and analyse the past, i.e., to contribute to historical knowledge; the other is the motivation to conceive a pertinent artistic intervention, i.e., to contribute to an artistic domain. Reinforced and reassured by an analysis of the chapters in this book, I argue that this contribution to an artistic domain is an essential component of artistic research, supported by documentation that clarifies the pertinence of artistic interventions, promotes more empathetic connections and deeper intimate fruition, and results in mythopoetic reconfigurations. Only a discourse in the narrative mode can possibly play this roll, because it does not exclude embodied meanings and processes of subjective self-disclosure (re-enactments). This discursive mode will enable a reflection on the pertinence of the (inter)subjective concerns that motivated the creation, the pertinence of the creative processes, and/or the aesthetic, ethical, and ecological pertinence of the artistic intervention. Thus, going beyond an understanding of musical practice as simple "artefact-performance-reception" and embracing a sense of possibility, a specific territory opens for HIP performers. It consists of an embodied intersubjective amalgam of beliefs, convictions and mythopoetic configurations, where they, as artistic researchers, can intervene creating new realities and provoking changes and reconfigurations - rhetorically, pedagogically, and above all artistically.
\end{abstract}

Keywords: historically informed performance, artistic research, epistemological fracture, modes of knowledge, mythopoetic configurations

Citation: Correia, J. S. (2022). From researcher/performer to artistic researcher: Looking back at the past in search of new possibilities. In R. Rolfhamre \& E. Angelo (Eds.), Views on early music as representation: Invitations, congruity, performance (MusPed:Research No. 4, Ch. 9, pp. 223-257). Cappelen Damm Akademisk. https://doi.org/10.23865/noasp.157.ch9

Licens: CC BY-NC-ND 4.0 


\section{Introduction}

Historically informed performance (HIP) and artistic research have both developed at the crossroads where artistic interventions somehow articulate through research - research is here understood in the broadest sense as seeking something, i.e., seeking knowledge. Artistic researchers seek knowledge that is inextricably embedded or embodied in aesthetic interventions. They (should) seek material thinking, which Carter (2004) defines as a singular type of artistic knowledge that articulates declarative and procedural knowledge in the materiality of artistic production. Artistic researchers are artists who engage in research to become better at what they do:

The object of artistic research is art. As artists, we engage in research to become better at what we are doing, for the development of knowledge and methods. We introduce new ideas in order to rethink art, become leaders, increase audience engagement, investigate new presentation formats, tackle political and societal issues, or to develop sustainable practices. We do it for the relevance of art in an ever more complex and diverse society. (Lilja, 2021, p. 28)

Is the object of HIP also art? To answer this question properly, one needs to be aware of two divergent paths that have coexisted in the HIP movement practically since its inception (Kartomi, 2014): the path of early music scholars - who have focused on publishing written outputs (articles, books and editions) to foster their academic careers; and the path of early music performers - who have focused on performing and recording to foster their artistic engagement.

The former tend to be committed to a score-based ontology, cultivating a logocentric epistemological orientation, and diverting their attention from relational and socio-emotional aspects of the here-and-now of the performance ritual. On this divergence between scholars and performers Charles Rosen has rightfully written that "musicology is for musicians what ornithology is for the birds" (Rosen, 1994, p. 72). Thus, for scholars, the object of HIP tends to focus not so much on art as an object of study, but much more on the production of historical-musicological knowledge ontologically based on the idea that musical structures determine the meaning of music. That these epistemological premises - closely linked to an ideology preaching the autonomy of abstract musical structures - have 
dominated the research of HIP scholars for most of its history is reiterated by Doğantan-Dack:

In the majority of twentieth-century musicological discourses the score has been read and interpreted as representing abstract musical structures. Audiorecorded data - by suggesting the severance of the causal ties between the performance context, the performer, and the recorded performance - can also prompt researchers to understand the sounds of a performance in similar terms, i.e., as abstract musical structures. (Doğantan-Dack, 2014, p. 9)

Performers intervene in the artistic world of early music, and therefore have artistic purposes. Their object is art, however, what they do is not artistic research per se. Although all relevant and innovative art could not have been developed without some kind of (re)search, ${ }^{1}$ this "search" does not qualify as artistic research. What is missing is a process of deep reflection embedded in some kind of documentation designed to be shared, discussed, critically evaluated, and finally validated by peers to be archived in an academic repository. As it is proposed in this chapter, this process of profound reflection would have the function of clarifying the pertinence of artistic intervention as a production of knowledge, undertaking a critical and experimental reflection not only on the specific production methods and processes used, that is, on the "poietic" strategies, but also on the writing process of a discourse in narrative mode, which articulates symbolic and embodied meanings, that is, on the "poetic" strategies. These poietic-poetic modes of doing are constructed as a sensibleepistemic device disclosing a system of dispositions and interactions within an aesthetic, ethical and political ecology, and are indivisible from the subjectivity of those who produce them. Hopefully this will become clearer later in this chapter, however, to get to that point, it seems crucial to revisit the question that was implicit but left unanswered: Why are performer-scholars not artistic researchers by default? Although performer-scholars have to deliver both research and art, an epistemological divide seems to persist. In the following sections, I seek to identify and

1 In the opening lecture of the $2020 \mathrm{PhD}$ programme in music at Aveiro University, Bruno Tackels referred to this interesting distinction between 'search' and 'research', the latter having the extra connotation of being thoughtful, reflective, methodological, in a word, academic. 
discuss the reasons why this epistemological divide has been and remains resilient.

\section{Submission and denial}

Since performance entered the discourse on music from 1950 onwards (Assis, 2015), and consolidated itself as a domain of study throughout the 1970s (Carlson, 2010), one has witnessed a proliferation of approaches and perspectives, which, although admittedly different among themselves, seem to have one thing in common: the notion that performance is a complex term that includes a multidimensional phenomenon in which the body has a privileged status (Dalagna, Carvalho \& Welch, 2021). This complexity, besides having opened the door for artists to express their views in a debate questioning the dichotomy of body and mind, justified the emergence of interdisciplinary or multidisciplinary approaches to the study of performance. In the particular case of music performance research, however, these approaches have been subordinated to the epistemological and methodological assumptions of so-called "theorists" of music or related fields. This subordination does not recognise "the discrepancy between scientific theory and phenomenal experience" (DoğantanDack, 2014, p. 18). Together with Mine Doğantan-Dack, I endorse:

[...] the spirit of the plea John Sloboda made in the context of research on music and emotions: that our efforts to simplify and deconstruct phenomena, which are the driving principles of scientific endeavour, "need to be constantly held up against the richness of everyday [...] musical experience to ensure that it is the full experience we are attempting to explain, and not some conveniently simplified portion of it”. (Doğantan-Dack, 2014, pp. 4-5)

Although musical performance (i.e., practical, hands-on music) has undergone a process of inclusion in universities very similar to that of the other performing arts, the same has not occurred when it comes to a confrontation with research. Unlike theatre or dance, performance studies in music emerged in the research world as a subdiscipline within a pre-existing field of knowledge, which already had a long and prolific academic tradition - the field of musicology. 
The subdiscipline of performance studies in music emerged in the 1990s, when philosophers of music like David Elliot (1995) and Christopher Small (1998), and musicologists like Lydia Goehr (1992), Richard Taruskin (1995) and Nicholas Cook (1998) took a critical stance towards the dominant practices of music research as being exclusively centred on texts and scores, which some argued, contributed to the idealisation of musical works. It became imperative to look beyond the score, to observe and analyse performative practices. For instance, Small radically proposed that "music is performance" (Small 1998, p. 218). In the same vein, Cook questioned the prescriptive power of musical scores by considering them to be scripts rather than texts, thus highlighting the role of performance in determining musical meaning:

The text-based orientation of traditional musicology and theory makes it difficult to think about music as performative art. Music can be understood as both process and product, but it is the relationship between the two that defines "performance" in the Western "art" tradition. (Cook, 2001, p. 1)

According to these recommendations and warnings, which were made about twenty years ago, research in performance has been changing its focus from scores to recordings, and from these to live performances, but always placing itself (with its verbal, propositional and paradigmatic discourse) as a mediator between the artistic interventions and our understanding. In order to see how this mediation acts and what its implications are, consider the following: Artists contextualise music in order to find a general orientation, define a semantic field or certain musical gestures as a starting point for creating their interpretation of each work; also they develop a personal amalgam of cultural references (more or less informed) and technical resources that have the function of simultaneously conditioning and stimulating their imagination in the search for clues to make sounds expressive, to imprint action on sounds (Correia, 2003). The systematisation of this knowledge, when it happens, is usually carried out in response to pedagogical or academic challenges (for example, when writing a paper or delivering a paper at a conference, or even when carrying out doctoral research). This means that it is a response to the need to argue verbally in favour of a given interpretation. 
This effort to systematise or theoretically elaborate on an interpretation ends up diverting the attention, focus and investment of the "performers" from their specific function and initial goal - which is to give an account of the full experience of accepting the risk of responsibly defending their interpretations by performing before an audience, in person (Steiner, 1989), and contributing relevantly to the artistic domain in which they have chosen to intervene. Talking (or writing) about a performance is very different from experiencing it. They are two specific activities that are not only divergent, but can develop separately, or even exist, in extremis, almost independently:

It is conceivable that a violinist, say, might offer an acceptable reading of a piece, one he was implicitly endorsing, without appearing to have, as judged by other indications - e.g. what he said about the music's emotional import, or the reasons he gave for certain performing decisions, or his response to performances of the piece by others - what we would be justified in calling even an intuitive grasp of the piece's structure or expression; it seems possible that there should be "idiot joueurs", so to speak, or performers who just happen to "get it right" by luck, at least some of the time. (Levinson,1993, p. 48)

Many aspects of artistic products can be articulated or even measured, but these approaches alone are too reductive to account for socio-emotional phenomena, aesthetic qualities, creative processes or the relevance of an intervention in the respective artistic domain. Such approaches thus utterly miss this point. It was at this juncture that music performance studies established itself as a subdiscipline of musicology. Under the purview and authority of musicology, music performance studies, in the environment of universities, were confined to following the same epistemological assumptions, and resorting to similar methodological procedures. Subscribing to a quasi-archaeological attitude (i.e., trying to understand the historical processes that underpinned practices and works), this new subdiscipline found no alternative to the study of archived objects - scores, recordings - or to the objectification of live performances, understanding them predominantly from observation, analysis and/or systematic description.

The notion of musical performance as a form of artistic expression, despite being acknowledged by musicians, seems to be something else 
when it is thought of as an object of research. An example of this can be seen in the Cambridge Handbook of Expertise and Expert Performance (Ericsson et al., 2006), where art and music are covered by two different chapters. Although many explanations for this distinction might be offered, it is indicative of an academic discourse, in which expressions such as "music and performing arts", "the arts and music" or even "musicians and artists" clearly demarcate the two.

This inclusion and consolidation of music performance studies into the academic universe ended up being peaceful, applauded even by many practical musicians, but it also resulted in their withdrawal from the general process of autonomisation of performance studies that was taking place simultaneously, especially through the work of Richard Schechner, who, of all the professionals and academics emerging during the 1960s, played the most visible and consistent role in the formation of the paradigm of performance studies (Carlson, 2010). Based on Schechner's work, scholars interested in performance studies ended up defining what would be three crucial components: embodiment, presence and transgression. McKenzie (2005) argued for the pre-eminence of embodiment, because that draws attention not only to the performances of non-traditional theatre, but also to the quest for a rejection of the study of predominantly text-based drama. Instead of focusing on play scripts, it turned its attention to the training of actors' bodies, rehearsal processes, staging and site specificity (Mckenzie, 2005). Closely related to the emphasis on embodiment was the valorisation of presence (Fischer-Lichte, 2004). Gradually, both performers and so-called "performance theorists" began to devalue the representation of pre-existing texts, focusing on the spontaneity and vivacity of the performance and the co-presence of performers and audience (Mckenzie, 2005). In theatre, this entailed a shift in importance from the playwright to the director, and finally to the actor. Embodiment and presence, when combined with an emphasis on performance efficiency, motivated another point of interest: transgression, which was clearly informed by contemporary social upheavals, such as civil rights protests, anti-war demonstrations, or women's liberation marches (Mckenzie, 2005). The work initiated by Richard Schechner and developed by other authors, such as Victor Turner and Dwight Conquergood, eventually 
stimulated the development of specific academic programmes. Several American universities, including New York University and Northwestern University, developed graduate programmes specifically designated as performance studies. Performance in the field of music thus bypassed the debate on performance studies in general, and although it already assumed a critical view in relation to traditional musicology, it still depended on its authority.

Parallel to this process of the consolidation of performance studies in music, and performance studies in other arts, a political and educational transformation occurred in Europe, known as the Bologna Process, that directly affected the understanding of performance in the debate on knowledge production in the arts, music included. Supported by the ideas that teaching should be research-based, and that education should be more competitive and market-oriented, the Bologna Process led many higher arts schools to adapt their curricula so as to integrate postgraduate training, including on the doctoral level.

The political decision to impose research on art schools within higher polytechnic education did not necessarily take place in consultation with the universities, which thus ended up seeing their monopoly on the definition of research questioned. The Bologna Process, quite unintentionally, may eventually contribute to the end of the hegemony of natural sciences in the field of research. What we are witnessing today, at least in the regions and countries where arts higher education institutions, willingly or unwillingly, participate in the Bologna Process, is the beginning of a fierce battle for the definition of research. It is not so much a question of recognising that art can produce knowledge, but of how this knowledge can be recognised and validated within the academy. Those best qualified to answer this question will obviously not be researchers from other areas, but rather artists committed to research, no matter how much disparity there may eventually exist among themselves. Mainly due to the Bologna Process, many practical artists and musicians were now able to invest their time in doctoral training, aiming not only for career advancement, but also artistic improvement (Correia \& Dalagna, 2020; Crispin, 2015). Eager to capitalise on their artistic knowledge they began to explore practice-centred epistemological models, and thus the 
conditions were created for the emergence of a new domain in knowledge production: artistic research (Assis, 2018).

Despite evolving discourse on artistic research, the obligation to base higher education, including the arts, on research was initially understood by many as an obligation for academies to engage in scientific research. Given the hegemony of the natural sciences, some will have genuinely misunderstood and others deliberately misunderstood, but the stubborn rhetorical identification of "research" with "scientific research" led to difficulties accepting any other form of research within the academy. Consequently, artistic research did not gain widespread recognition, and this scepticism provoked a counter reaction that motivated some authors to "prove" the legitimacy of arts research on the basis of the robustness of its methodological framework (Stevánce \& Lacasse, 2018). While these views have contributed somewhat to the popularity of artistic research, it is often not the specific knowledge produced in this field that has been validated. It is crucial to have a clear understanding of whether it is the outcomes of artistic research that are being validated or the robustness of its methodological procedures. Linked to this insistence on the robustness of methodology (methodolatry) is the need to maintain the institutionalised disciplinary separation - for instance: "artistic research in music" or "artistic research in painting" - hindering the consolidation of a specific territory for artistic research (Stevánce \& Lacasse, 2018). These ideological and reductionist assumptions contribute to excluding creative phenomena or "invention" from academic research (Carter, 2004). One of the most representative occurrences of this state of affairs is the widespread disorientation in relation to what the role of discourse should be in the supporting documentation within an artistic investigation.

Artists often believe that they can only describe what they do if they leave out invention. Based on such a belief, auto-ethnographies have started to be advocated as a means of guaranteeing a conceptual and discursive knowledge associated with artistic practice. This strategy, although widely mentioned in artistic research manuals [...], fails in its purpose because it keeps artistic production out of the validation process. Researchers defend their discursive arguments, but not the pertinence of the artistic output or even its articulation with those 
arguments. Auto-ethnographies deviate the focus from the artistic production itself, bringing to light details related to the life of the artists, their beliefs and their cultural values. It is a type of discourse and approach that elucidates and describes the cultural identity of those involved and, eventually, the context of the process, but it does not help us to engage more intimately with the artistic production nor does it clarify its relevance. (Correia \& Dalagna, 2019, pp. 17-18)

These methodological and epistemic démarches end up obscuring and diverting researchers' attention from the meaning of the full experience. Too often artist researchers fall into the temptation to rationalise the formal elements of their practice instead of reflecting on their social effects, that is, on their re-configuring power: "Rather than account for the work as a structure for reinventing human relations, they explain the ideas behind the work" (Carter, 2004, p. 10). The difficulty for artistic researchers seems to lie mainly in keeping in mind that there are alternative discursive modes equally capable of gaining academic recognition with regard to their potential for contributing to knowledge production. While the differences between paradigmatic (generates abstract/conceptual meanings) and narrative (generates empathic/embodied meanings) verbal modes of communication are widely recognised, their consequences are not.

\section{Communication and interaction}

Problems arise when trying to give an account of the artistic and embodied domains using the declarative or paradigmatic discursive mode exclusively, that is, when trying to translate "symbols" into (verbal) "signs". ${ }^{2}$ It is not, as John Butt has suggested, a question of choosing between the two opposing poles of social constructivism on the one hand, and analytic philosophy and music analysis on the other hand:

2 Signs are here understood as markers that have a very specific and precise meaning, preferably leaving out any ambiguity. Symbols, on the other hand, appeal to complex and deeper meaning structures that are rooted in the cognitive unconscious and are thus open to individual/subjective interpretation processes. 
If some tend to assume that musical works are objects that are basically nonhuman and thus stable in character (those on the side of analytical philosophy and music analysis), others have surely gone too far in the direction of social constructivism and assumed that pieces of music exist only by virtue of the attitudes of a particular society - that there is nothing essentially "there" beyond the cultural norms at hand. (Butt, 2015, p. 4)

Both approaches seem to be caught in the same trap. In both, researchers are operating through signs within verbal propositional language in declarative, discursive, paradigmatic modes, excluding the embodied and symbolic dimensions of meaning, which are crucial for an account of the full experience they are trying to explain. Even when they openly and theoretically admit the existence and importance embodied meanings play in aesthetic experiences, they continue to design their research projects based on a markedly ideological understanding that "music making is conceived in terms of the score-mediated relationship between the performing agent and the sounding music" (Doğantan-Dack, 2014, p. 9). That is, musical or artistic communication is understood as a process of passing on to everyone the same meaning structures or even the same contents, as if merely delivering a message. This is, after all, what is expected from good communication. But aesthetic experiences require interaction rather than communication, especially if the latter is understood in the very narrow sense of conveying a message from sender to receiver. Artists operate with symbols not because they want to appear vague and mysterious, but rather to empathically involve their recipients. I contend that it is a sine qua non condition for artists to involve their recipients to the point of making them actively re-enact the symbols through metaphorical projections from their stock of bodily affections, that is, from their bodily archive where the singularities of their subjectivities are articulated with complex intersubjective and symbolically charged processes.

Creativity is possible, in part, because imagination gives us image schematic structures and metaphoric and metonymic patterns by which we can extend and elaborate those schemata. One image schema [...] can structure many different physical movements and perceptual interactions, including ones never 
experienced before. And when it is metaphorically elaborated, it can structure many nonphysical, abstract domains. Metaphorical projection is one fundamental means by which we project structure, make new connections, and remould our experience. (Johnson, 1987, p. 169)

My point is that musical interpretation, musical meaning, musical expression or musical intention gain in creativity, originality and genuineness if one becomes aware of one's own inner theatre of symbols, which connect understanding and feeling at a deeper level than the conscious mind. Some excellent performers (or listeners) could assume that, when they are playing or rehearsing, no inner theatre of symbols or figures occurs. They just enjoy sound relations. They claim that their experience is purely musical and musical intention needs no symbols or images to be effective. But what Jacques Derrida wrote about philosophical concepts could just as legitimately apply here to musical gestures:

The primitive meaning, the original figure, always sensitive and material ("all the words of human language were originally stamped with a material figure and all represented in their novelty some sensitive image [...] fatal materialism of the vocabulary [...]") is not exactly a metaphor. It is a kind of transparent figure, equivalent to a specific meaning. It becomes a metaphor when philosophical discourse puts it into circulation. The first meaning and the first displacement are then simultaneously forgotten. We no longer notice the metaphor and take it for the proper meaning. A double erasure. Philosophy would be this process of metaphorization that carries itself away. By constitution, philosophical culture will always have been crude. (Derrida 1973, p. 23)

Clearly to Derrida the expression of an abstract idea could be nothing else but an allegory: The philosophers, who believe to have left the world of appearances, are constrained to live forever within the allegory. He called this process white mythology: metaphysics erased the fabulous scene that gave rise to it, but this scene remained nevertheless, though invisible, active and insinuating, as if inscribed in white ink. Transposing the same idea, there would also be a white mythology hidden in every musical gesture for those interpreters who believe that they work exclusively with sounds.

In fact, the existence of such a white mythology in music is supported by solid arguments in its favour. The musicologist Goehr (1992) and the 
anthropologist Lévi-Strauss (1979) point out that the sixteenth and seventeenth centuries represent a critical historical moment where discursive thought became more rationalised and music - because of its subservience to religious/mythological texts - ended up absorbing the two typical mythological thought functions: ritual and narrative. During this process music also gained its autonomy. It is worth recalling that music was still in Mozart's time just one of several elements (even if a very effective and important one), which comprised the complex structure of social and religious rituals. Only around 1800, as Goehr (1992) has argued, did the concept of a "musical work" emerge, exercising its regulative power over all music-related social practices. By that time, music had inherited from mythological thought the symbolic heaviness or the mythological function that empowered it to become an independent activity, and an independent ritual in itself. Also, in Lévi-Strauss's (1979) view, music was particularly affected by these changes, it became not only more rationalised, but it absorbed important functions, which were inherent to mythical thought, as well:

It was also at that time that the great musical styles of the seventeenth and mainly the ones of the eighteenth and nineteenth centuries were born. It was as if the music changed completely its traditional form to be able to perform the function - both an intellectual and an emotional function - which the mythological thought had just abandoned at that epoch. (Lévi-Strauss, 1979, pp. 68-69)

These were crucial changes, which transformed music into what it is today. The whole transformation process was not a linear one, though. Small explains how musicians worked out these changes:

In the seventeenth century [...] musical gestures were abstracted from physical movement so that the listeners no longer moved their bodies [no dance movement responses] but sat and watched and listened, and [...] the musical gestures represented not an emotional state itself nor a temperament but the type of physical gesture, both bodily and vocal, with which the emotional state or the temperament was associated. The musical gesture represented metaphorically the physical gesture that the audience recognised as belonging to that state. It thus had to be constructed at one removed, and the masters of that first brilliant 
explosion of the new art form worked through conscious striving, exchange of ideas, polemics and a good deal of trial and error, to perfect the representation. (Small, 1998, p. 148)

In addition, John Shepherd, from the research domain of music sociology, points out that a new role had been given to music during that epoch, compensating somehow for the reductive features of rational discourse:

Post-Renaissance educated men became so aware of the potential for separating the meaning of a word from its referent, and so seduced by the intellectual power this represented in terms of manipulating and controlling the world, that they had difficulty seeing beyond the immediate implications of their own cleverness. In acting as an antidote to this tendency, the very fact of music as a social medium in sound reminds us, not so much of what has been lost, but of that of which we have ceased to be publicly enough aware. (Shepherd, 1991, p. 6)

Considering these contributions, it seems reasonable to explore a hypothesis that brings symbolic or mythical thought into a relationship with musical meaning. Meaning became a central issue in music interpretation: to interpret is to make meaning. Recognising the existence of this white mythology, that is, of this universe of symbols (personal and subjective but also inter-subjective because they are common to an entire community) helps us to understand the meaning of music better, to assume more freedom of interpretation, and to make learning music a significant step in cultural and aesthetic education. As previously stated, symbols and gestures must be re-enacted and re-enactment implies embodied meanings. However, this implication of corporeal individual action does not prevent most of these meanings from being shared by us all, that is, from being largely intersubjective as Milan Kundera has explained:

If our planet has seen some eight billion people, it is difficult to suppose that every individual has had his or her own repertory of gestures. Arithmetically, it is simply impossible. Without the slightest doubt, there are far fewer gestures in the world than there are individuals. That finding leads us to a shocking conclusion: a gesture is more individual than an individual. We could put it in the form of an aphorism: many people, few gestures. [...] A gesture cannot be regarded as the expression of an individual, as his creation (because no 
individual is capable of creating a fully original gesture, belonging to nobody else), nor can it even be regarded as that person's instrument; on the contrary, it is gestures that use us as their instruments, as their bearers and incarnations. (Kundera, 1991, p. 6)

"Gestures" are different from "concepts" because they do preserve the two distinctive dimensions of the narrative mode of thought - tacit and symbolic - because they have to be re-enacted to be perceived. This re-enactment is nurtured by the singularities of each individual, by each bodily-based stock of affections and knowledge, is triggered by empathy, and is a crucial part of the construction of meaning that reflects the recipients' involvement. It is in this profound sense that, when referring to aesthetic experiences, one should speak more accurately of "interaction" than of "communication". Symbols, articulated within a gestural narrative discourse, have the capacity to promote this empathetic involvement in meaning creation, leading eventually to deep mythopoetic reconfigurations. Without this empathetic re-enactment, without this interaction, without this involvement in meaning creation there is no reason to consider a particular experience an aesthetic experience. Deleuze's criticism to the work of abstract art stems from these same reasons, pointing out the fact that it is directed only at the brain, missing sensation, or direct action on the nervous system (Deleuze, 1981). Many other authors, such as the philosopher José Gil or the literary theorist and semiotician Roland Barthes, share the same view:

Dance is in the full domain of meaning, making its gestures immediately felt, without passing through language [...] but a danced gesture does not only transmit an explicit meaning (even if "of transition"). It also conveys an unconscious meaning. (Gil, 2001, pp. 113-115)

[...] listening [to a sonata] goes much further than the ear: it goes in the body, in the muscles, through the strokes of its rhythm, and as in the viscera, through the voluptuousness of its melody. It would seem that each time, the passage was written for only one person, for whom it is played. (Barthes, 1982, p. 260)

It seems, thus, that there is an alternative to the opposing approaches referred to above by John Butt - the social constructivism approach and 
the analytic philosophy and music analysis approach - both of which seem, after all, to be more similar than different. Suspending their differences and endorsing what they have in common, we must first realise that in these two approaches art is understood as ontologically grounded in objects or performances, and not in the way in which they are perceived. I propose an approach that places aesthetic experiences on the level of perception, an approach incompatible with the two previously mentioned. Those approaches resort to an explanation mediated by paradigmatic verbal discourse and cannot avoid abstraction, i.e., the consequent reductionist operations that tend to eliminate unconscious bodily dimensions and all the individual and subjective involvement of the recipients in the construction of meaning.

The alternative mode of discourse that I propose operates through creating narratives, combining gestures and embodied meanings, which all blend to produce implicit knowledge in the narrative mode. An example of how this implicit knowledge works, how it is generated and shared, is our knowledge of ourselves and how we make ourselves known to others. Damasio (1999) explained how the sense of self emerges in the form of a narrative; it is a story that we tell ourselves. This lifelong story that we tell ourselves builds our "subjectivities", which means that we know ourselves through narrative mode. In the same way, through telling stories to our friends and experiencing things and situations together, we make ourselves known to them. We have no other way of making ourselves known to our friends or clarifying to them the meaning of what we do, what we feel or what we think. Our friends know us through the narrative mode. This could not be easily achieved in any other way, and certainly not through the paradigmatic mode. We relate to art in a similar way: We experience artistic interventions and we have access to narratives, which somehow contribute to the clarification of their meaning. There is an important difference to point out between friendship and what Rui Penha calls "artship"s (2019). In reality, it is a difference in the level of depth, because in friendship we get to know the life stories, singularities and

"Art is the name of a relationship - perhaps we should call it an artship - that we can establish with a given object: the artwork. This object is special because it was intentionally made for us to take it as a materialisation of an action of a fellow human being, giving us the opportunity to 
idiosyncrasies of our friends, and in artship we get to know the specific contexts, values and singularities of specific communities with which we are more or less familiar. This means that we have shared socio-emotional experiences within these communities, which make us aware of and sensitive to their imaginaries, values, beliefs, convictions, in short, to their mythopoetic universes or configurations.

Artistic interventions, whether they are objects (sculptures, paintings) or performances (music, dance, theatre), are signifying systems combining and articulating gestures and symbols. Aesthetic appreciation is based on subjective personal meaning constructions and on empathy. The power of artistic communication thrives in this interaction between performers and public, which is arguably even more inescapable in performative arts because of their temporal unfolding. Meaning in performative arts seems to happen in what Deleuze \& Guattari have termed a "meeting perception," where both performer and recipient react spontaneously to the expressive materials and to the ritualised atmosphere, influencing each other's experiences in a collective and creative meaning production process, which takes place in the moment: "The perception of a musical phrase draws less on a sort of reminiscence memory, rather on an extension or contraction of a sort of meeting perception" (Deleuze \& Guattari, 1980, p. 364).

This interaction between performers and public - triggered by an empathic relationship - produces multiple meaning constructions (all construct their own specific, subjective and individual meanings), but this should not be understood as being poor communication. On the contrary, Small argued that the gestural-symbolic communication processes, in spite of being open to multiple meanings on other levels, have an overt relation to our patterns of bodily experience:

There can therefore be no such thing as completely objective knowledge, knowledge of the external world exactly as it is, since everything we can possibly know about it is mediated by the way in which we, the knowers, work on the information about it that we receive and convert it into usable knowledge. (Small, 1998, p. 55)

form a theory of mind - i.e., to conjure in us a perspective - that helps to explain such action" (Penha, 2019, p. 10). 
Thus, verbal descriptions and conceptual definitions of the external world, which are carried out in other forms of communication that I designate here as paradigmatic discourses, lack objectivity because of their production process. They are based on abstraction, which means that they diminish all the personal and subjective dimensions of meaning that are crucial to artistic (empathic) interaction.

This interaction has a direct influence on us, like no other mode of knowing seems to have: "Probably the nearest we human beings can come to 'objective' knowledge lies in meanings that are connected to those bodily experiences that are shared by us all” (Small, 1998, p. 55). Bateson (1972) explains that this language of gesture is mainly about "relationships", essentially "how the perceiving creature relates to the outside entity that is being perceived, and vice-versa" (Small, 1998, p. 56). Bodily posture, movement, facial expression, and vocal intonation, writes Small, provide "a wide repertory of gestures and responses by means of which information about relationships is given and received" (Small, 1998, p. 57). Although this interaction is clearer in performative arts, a similar process takes place when experiencing artistic objects (sculptures, paintings). The richness, the peculiarity and, I would say, the authenticity of the artistic experience lies in the fact that the artistic intervention (the sender's act) has to be re-enacted by the receptor, who can only understand it "on the basis of internal, self-generated cues" (Donald, 1991, p. 173). These re-enactments imply inevitably not only neural and, eventually, muscular activity, but also emotional responses, since "emotional states are tied to muscular states and to associated memories of similar contexts" (Cox, 2001, p. 204). Personal meanings are thus essential in the construction of our significant aesthetic experiences, which develop according to a logic of association dictated by our bodily structures of experience. In other words, gestural-symbolic meanings, in artistic communication (interaction), are revealed at the level of their embodiment. This deep involvement is crucial because it is where subjectivity meets intersubjectivity, where aesthetic responses include irreducible features that depend on the biographical background and individual characteristics of the recipients, but also on the cultural history of particular communities and societies (Higgins, 1997). Based on numerous anecdotal reports of listeners' 
personal engagement with music, Higgins presented four implications of musical idiosyncrasy, which are reproduced here because they are equally relevant to my argument:

First, some of those best educated to appreciate scores "objectively" have the most idiosyncratic perspectives. Practicing musicians would seem to be among the very individuals one would expect to be the most expert at "intellectually processing the score". In fact, however, these musicians are perhaps least likely to be simply attending to "tonally moving forms" when they hear a familiar work. Second, the idiosyncrasies involved in these cases are musically motivated and musically conditioned. [...] These idiosyncrasies emerge from intimate familiarity with and attention to music by individuals who are well acquainted with the stylistic context of the music they are hearing. Third, what is salient to listeners varies with their individual musical (and generally artistic) backgrounds. Said emphasises the "ideal purity of the individual experience", although he conscientiously acknowledges "its public setting, even when music is most inward, most private" [...] Finally, musicians and other knowledgeable listeners form something like personal relationships with particular works of music. [...] Music is interpreted in terms of its relationship to locations, categories, associations, reflections, and evaluations relevant to the listeners. (Higgins, 1997, pp. 95-96)

It seems, thus, that artistic interventions operate on this threshold where subjectivity is intertwined with intersubjectivity: all recipients have a common ground - they have access to the same performance and they have similar cultural references and backgrounds - but all also have their specific, particular, individual and subjective stock of experiences and emotional impressions. This intersubjective common ground is a huge amalgam of fictions and beliefs, together with convictions and reasonings, some more thoughtful than others, some at the edge of the unconscious, and some deeply rooted and operating in the unconscious. This level implies a specific type of representation (different from verbal, propositional and conceptual language) that Lehrer (2012) called "exemplarisation". An "exemplar" represents a class of experiences of which it is itself a member. A conscious experience of a colour can serve as an exemplar that exhibits what the colour is like. This exemplar is like a psychophysiological mark that can define a conceptual mark, 
in which this exemplar is also part of the content. The exemplar allows us to represent a class of objects that are part of the conceptual mark. Exemplarisation is not abstraction, i.e., one can only recognise blue colour if it fits their exemplar, and not from verbal explanations given by others. Exemplarisation is, thus, a process that "yields a representation of content in terms of an experienced particular that stands for other particulars. Exemplarization involves generalization of a particular" (Lehrer, 2012, p. 1). It is worth noting, however, that this generalisation is not reductive. In that intimate realm where subjectivity emerges from intersubjectivity lies a network of exemplars; it is precisely on this level that artistic interventions reach us. It is at this level that art reconfigures our old mythopoetic configurations, transforming experience by creating content. Knowledge produced by artistic interventions, thus, is not based on abstractions or intellectual propositions, but rather on a network of exemplars. Indeed, exemplars are the source and foundation though which concepts are formulated, and they allow us to expand awareness of ourselves, of the world and of ourselves in the world.

Thus, the knowledge produced by artistic interventions is a kind of knowledge that does not depend on contemplative, calculational, logical-analytical or interpretative methods. In a recent book edited by Huber et al. (2021), the term "knowing" is alternatively proposed for this kind of knowledge: "Knowing in performing refers to action in the performing arts as a specific form of the generation of knowledge" (Huber et al., 2021, p. 18). The same text further clarifies that

[the suffix 'ing' in knowing] points to a genuinely physical, sensual and practical accomplishment and thus to the fluid, process-like status of knowing: 'Knowing is literally something which we do', says John Dewey (1916, p. 331). [...] it presupposes practical learning by doing in which knowing and mastery develop in parallel and completely overlap. [...] This knowing is actually multidimensional. It comprises primarily an embodied knowing, a sensuous-situational knowing as well as an experience-bound knowing of the work process. (Huber et al., 2021, pp. 18-19)

Despite this broad consensus in recognising that art produces knowledge, it perpetuates a conservative view of knowledge that tries to 
translate the artistic and embodied domains into the declarative and discursive modes:

Art runs the risk of being held hostage by those universities where artistic quality is subjugated by pedagogical or scientific standards. In many countries there is still resistance and opposition to artistic research on artistic bases and art is forced into areas that demand methods, theories and training developed for science. (Lilja, 2021, p. 28)

In the recent history of the academy, a hybrid modality has gradually been instituted to give artists a place in academic production, which we can call a research-creation epistemology. In this modality, research, dictated by traditional methodological procedures of a given science, and artistic creation are juxtaposed. The research may have the juxtaposed artistic creation as its object, or it may have provided its materials, procedures or strategies, but in the end it is a contribution to the expansion of knowledge in areas such as musicology, anthropology, history, psychology, sociology, medicine or other disciplines, rather than in art:

The object of artistic research is art. As artists we engage in research to become better at what we are doing, for the development of knowledge and methods. We introduce new ideas in order to rethink art, become leaders, increase audience engagement, investigate new presentation formats, tackle political and societal issues, or to develop sustainable practices. We do it for the relevance of art in an ever more complex and diverse society. (Lilja, 2021, p. 28)

Phenomenological accounts of performance processes - regardless of how they are documented or by which means (including diaries, audio recordings, video recordings, etc.) - have different objectives and goals. They are not meant to replace the temporal experiences of these processes, of the experience of actually performing or actively listening. However, artistic creation on its own is not artistic research either, since in order to obtain formal recognition, additional documentation for critical dialogue with peers/colleagues must be produced and shared, usually in written form whatever the medium used, satisfying the established conditions for producing knowledge in an academic system. Subjectivity 
must be accounted for in the documentation in order for artistic research to achieve the targeted goal of art.

However, mere description will not be enough to share subjective impressions and vivid experiences adequately. Subjectivity is fundamental in our artistic experiences, both as creators and as recipients, in that its involvement in meaning-making processes is crucial. We must mobilise our individual (and subjective) stock of body-based knowledge and affections to create meaning. It is my belief and choice that without the involvement of this bodily base, implying unconscious cognitive dimensions in meaning-making processes, experiences do not reach the aesthetic realm. However, within reflexive phenomenological and auto-ethnographic accounts, subjectivity seems to be understood as a conscious personal account of the phenomenon not emerging from processes of bodily based meaning constructions (embodied meanings). Rather, they result from logocentric descriptions that establish a distance by eliminating the singularities of each subjective construction, which, again, are essential to the meaningfulness of aesthetic experiences.

Self-reflexivity has become both a common mode of thought within artistic research (and even one that has been valorised by the enshrining of the reflective commentary as a component of specific artistic research $\mathrm{PhDs}$ ). This elevation of subjectivity is a phenomenon that has, with some justification, attracted a certain amount of criticism. (Crispin, 2019, p. 46)

In my view, it is not so much about valorising subjectivity as worthy of inclusion in research, but about being aware of one's epistemological choices as a researcher. If researchers seek to explore different modes of self-reflexivity, but within the established epistemological frameworks in which auto-ethnography, for example, is understood as an autobiographical genre linking the personal to the cultural, social and political (as a means of reflecting on one's creative work in a culturally insightful rather than artistic way), then they do not escape a logocentric discourse based on the distance and abstraction imposed by observation and analysis.

Nevertheless, if artist-researchers seek to explore different modes of self-reflexivity, in which they explore ways of sharing their subjective impressions in order to clarify their artistic interventions (adding 
connections and insights to help recipients comprehend and appreciate them more thoroughly), then they will be responsible for developing a discourse in the narrative mode. They will follow an emotional logic where feeling and thinking are linked, and where empathy is the means of communicative interaction.

\section{The epistemological fracture}

The difficulty in distinguishing these two modes of knowing is directly related to a fundamental epistemological divide between the analytical/ scientific or paradigmatic mode of knowledge and the narrative mode of knowledge: In the paradigmatic mode, researchers focus on what can be similarly understood by the receivers (thanks to abstraction), on what is objectively measurable, seeking replication and consistency of results in experiments and analysis; In the narrative mode researchers accentuate the singularities and the immeasurable aesthetic qualities of a given artistic intervention. Friedrich Nietzsche (1872) pointed out the possibility of thinking of the individual, the corporeal, the instinctive, without

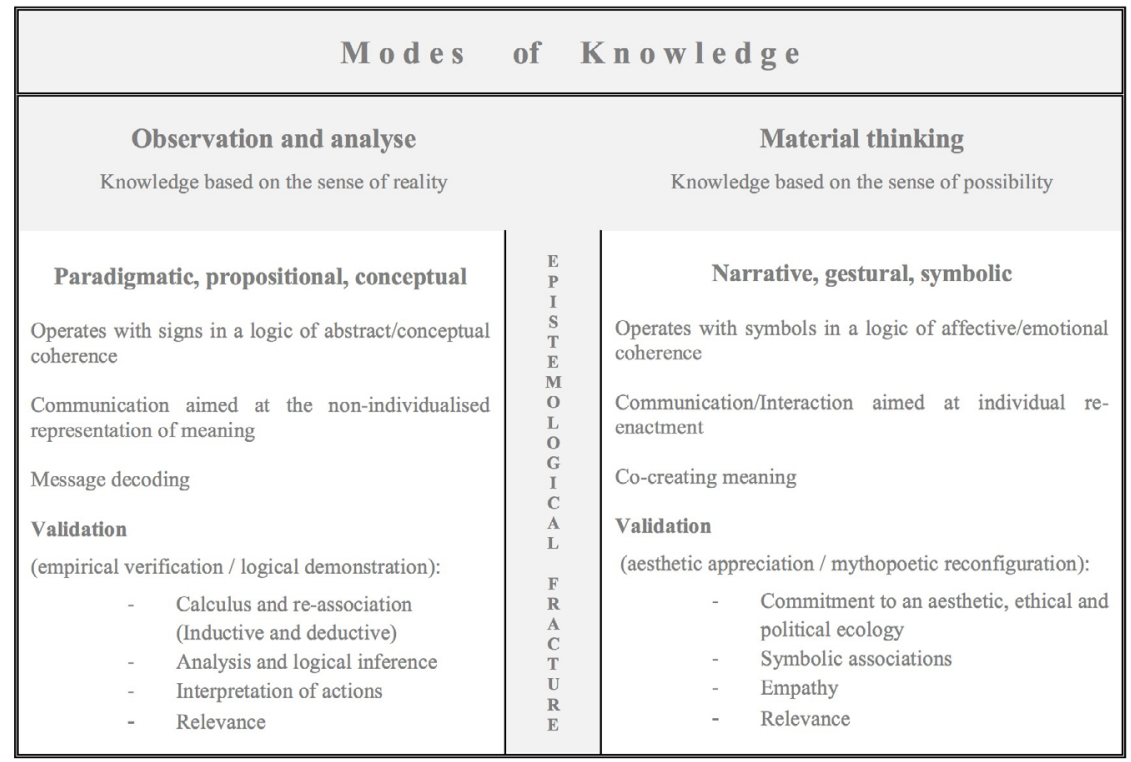

Figure 1. Modes of Knowledge and the Epistemological Fracture 
renouncing the sharing of thought and knowledge. Far from sustaining an abstract thought, which imposes generalisation and impersonality, the embodied or embedded subjectivity of an artistic intervention proposes the universality of the absolutely singular. There are thus two modes of knowledge on either side of the epistemological fracture.

There is broad agreement on the distinction between these two modes of knowledge, but if artistic researchers continue to understand research exclusively as description, they will always fall into the temptation of explaining artistic interventions by resorting to paradigmatic discourse.

There is a fundamental distinction at work here: research describes the world; composition adds something to the world. Research, at least of the scientific kind to which musical composition is generally assimilated, aims to produce generalizable results; the significance of a piece of music lies, on the contrary, in its particularity. (Croft, 2015, p. 8)

In his polemic article "Composition Is not Research", John Croft exposed the crucial issue: The general tendency of academia is to understand research as description rather than creation. Hence there exists a desperate and obsessive insistence to account for artistic creation by resorting to a paradigmatic discourse. Paradigmatic discourse is not suited to giving a verbal account of both sides of the epistemological divide. Only the narrative mode of discourse is able to articulate with the poetics of artistic creations, to explore their connections and associations, and to create an open system of dispositions and interactions, in other words, a poetic, aesthetic and political ecology. Narrative discourse is not limited to a structural analysis of regularities and elements in common, nor does it necessarily imply a historical perspective, nor aim at some articulated and homogeneous coherence. The relational operations of narrative discourse may include discontinuity, variations, contradictions, migrations, nomadisms (Deleuze \& Guattari, 1980), and many other modalities of relation that may even be paradoxical.

This narrative account, that is, the documentation that integrates artistic research, offers a kind of clarification that would foster the recipients' involvement, both emotional and symbolic, with the artistic interventions, valorising their aesthetic experiences. Any clarification of an 
artistic research project should at least explain whether what was convincingly challenging and relevant at the onset of the proposal had, at the end of the project, an equally convincing and relevant artistic response. In this way, the clarification of an artistic intervention would adequately respond to the academic demand for knowledge sharing, but again, this is only possible through discourse in the narrative mode, which communicates (i.e., interacts), shares and convinces, not through the rigor of conceptual and abstract constructions, but through empathy. The narrative mode of discourse follows an emotional logic where feeling and thinking are not separated.

\section{When HIP reaches across the epistemological divide}

As is well documented, the early music movement has developed under the aegis of authenticity since the 1950s (Fabian, 2001). Authenticity is a legacy of scientific history, now outdated, which led to musical works being objectified, and performers being charged with making them live again as they once did. Progressively, scientific history was replaced by a new vision that understands history as critical analysis and interpretation of data, but retains the old belief in objectivity (Burke, 2008). Concurrently, the early music movement has been moving away from seeking authenticity, and has paved the way for the much more open notion of historically informed performance, and later, for an even more uncompromising notion of historically inspired performance (Haynes, 2007). In a more or less uncompromising way, the HIP movement, in addition, has not failed to coincide with the aforementioned shift in the notion of history by maintaining its allegiance to objectivity - in the sense that it continues to rely on the study of historical sources and artefacts.

[...] if we distance ourselves too much from the discipline we claim, we do not contribute to broadening its perspectives effectively enough, but become the "other" who is distant and part of something else that is not "us". (Rolfhamre, 2022, p. 55) 
However, critical analysis and interpretation of data, required by the new view of history, are somehow absorbed into HIP, which is therefore no longer about the mere performance of historical artefacts. The dimension of performance - the performance turn - adds co-presence, corporeal involvement, and socio-emotional context to musicological knowledge. Thus musical objects are freed from the imaginary museum, where they were imprisoned, to become artistic (cultural-socio-political) interventions.

$[\ldots]$ it is the very historical artefact that, through contextualisation, makes other futures possible through active and conscious past-present relations. (Rolfhamre, 2022, p. 63)

This "invention" of other futures through contextualisation produces knowledge that is based on a sense of possibility, i.e., a form of practice whose analytical framework is not limited to the study of what already exists, but acts by bringing something new to the world. Rolfhamre proposes "a shift from aesthetically contingent readings of early music to rhetoric, and performativities centred approaches [that] may provide HIP with new sorts of agencies" (Rolfhamre, 2022, p. 62), and reinforces the ethical dimension of these practices by regarding HIP as a pedagogical activity:

[...] not only reflecting on the past and seeking to understand it from our present, but also by extending the invitation to use it as a pedagogical means to relate to the past in the present. That is how we can choose to create and re-create ourselves through connections between our own subjectivity, historical empathy, operative performative and rhetorical mechanics, and some sort of consciousness of how we are subject to societal norms and expectations. (Rolfhamre, 2022, pp. 62-63)

Understood in this way, HIP would act on both sides of the epistemological fracture: a musicological investigation into the musical artefact and its context, in a paradigmatic approach based on observation and analysis, on the one hand; and the creation of a rhetorical and pedagogical narrative based on the exploration of subjectivity and empathy, on the other. It becomes a narrative committed to an aesthetic, ethical and 
political ecology, provoking mythopoetic reconfigurations. HIP would produce knowledge in a hybrid manner in both a paradigmatic mode observation and analysis aiming for an unambiguous representation of meaning in a logic of abstract/conceptual coherence - and a narrative mode - creation, aiming to interact in order to provoke individual reenactment in a logic of affective/emotional coherence. Each research project will define in which direction the dial points, indicating the relevance of the knowledge produced in each mode, and in what proportion of each mode the project should be evaluated or appraised. An essentially musicological project, with a residual or merely illustrative artistic production, would be at one extreme, and a project of artistic research, in which the musicological contextualisation does not bring new knowledge, but only serves as inspiration for artistic creation, would be at the other. A myriad of possibilities lies between these two extremes, articulating research on both sides of the epistemological fracture. I thought that it would be interesting to exemplify how the dial oscillates between the two aforementioned extremes or if there are rather two dials as in the case of hybrid research projects, by epistemologically situating the research work reported in each of the remaining chapters of this book.

Randi Eidsaa's project, in chapter 6, is a good example of musicological contextualisation not really bringing new knowledge: "Even if the Pluvinel's Academy artistic idea was based on historical events, the project was not intended to be documentarily correct" (Eidsaa, 2022, p. 28). At the heart of the project is an artistic intervention, so it is about creating something that did not exist before, it is about creation. However, without experiencing the performance one cannot interact with it and empathetically co-create meaning and knowledge. Such an experience would be further deepened and clarified by documentation that includes the narrative mode: "[The] project uses traditional verbal texts and other written formats such as vignettes, manuscript excerpts and quotations from students' reflection reports, and assessment papers. Performance photos and video clips exemplify various components of the project and are essential modalities for documentation" (Eidsaa, 2022, p. 8).

In chapter 4, Daniel Henry $\emptyset_{v}$ rebø places the emphasis on perception, specifically how contemporary music - whether by juxtaposition or by 
incorporating techniques of more recent aesthetics - can change the perception of Baroque music for a modern audience. As in Randi Eidsaa's chapter, it is about a pedagogical approach in which artistic experiences, exploring a sense of possibility are reported, but in Øvrebø’s examples the historical context is not explored at all. It is reported "how early modern music, exemplified by Telemann, can be communicated to a modern audience without relying upon the concept of historically informed performance, but instead communicates through the operation of semiotics in performance" (Øvrebø, 2022, p. 1), what can be called the fantasias' genuine aesthetic content. In both cases, it is about artistic education operating on the narrative side of the epistemological divide where, in a logic of affective/emotional coherence, knowledge is shared primarily through empathy.

Inga Marie Nesmann-Aas (2022) concurs with Rolfhamre (2022) in the belief that for musicologists and performers, "understanding each other's perspective, and learning from each other's practice, can result in more meaningful research and more well-informed and creative artistic practice" (Nesmann-Aas, 2022, p. 8). The more information about the historical context - "about how the composers, writers, performers and audiences viewed the work and how they approached it" (Nesmann-Aas, 2022, p. 8) - the freer the performers are to develop new ideas and creative interpretations. Nevertheless, "the historical is the premise, even though we recontextualise it and make it meaningful as an artistic expression and communication in our own time" (Nesmann-Aas, 2022, p. 10). Based on classical rhetoric, topomorphology is also applied to reveal layers of meaning embedded in the textual structures. Thus, in the research reported by Nesmann-Aas there are historical and musicological findings, which result from empirical verification (observation and analysis), and constitute a contribution (new knowledge) to these disciplines. In this case, the dial is on the paradigmatic side of the epistemological fracture.

As such analysis of the textual material has not been previously applied, this is also one of my new contributions to the historical-musicological research on this material. My interest in such analysis is not only for its own sake, although the knowledge revealed is fascinating in itself. The goal is always to apply it in a performance context in our own time. (Nesmann-Aas, 2022, p. 14) 
But obtaining these paradigmatic results is, in essence, only a means to the main goal, which is to apply them in the creative work of developing a performance. However, this creative work implies a leap to the other side of the epistemological divide by operating with symbols in a logic of affective/emotional coherence: "As a performer, then, it is now natural to make conscious choices based on a combination of extensive knowledge and artistic sensibility" (Nesmann-Aas, 2022, p. 14).

Assuming that both research findings are relevant in their respective domains, it might be useful to discuss whether the relevance of the findings on one side of the epistemological divide intensifies the relevance of the findings on the other side. Setting aside the pedagogical relevance they both arguably have - "As a teacher, the goal is to enable the students to become independent and apply their knowledge and competence in a meaningful manner" (Nesmann-Aas, 2022, p. 19). It is not the value of the historical sources that guarantees the relevance of the artistic intervention. Nesmann-Aas wrote that "As such, this approach has the potential to inspire a free and creative recontextualisation that will become more than a mere historically informed performance" (Nesmann-Aas, 2022, p. 20). When it comes to the relevance of artistic intervention per se (i.e., outside the pedagogical context), it does not matter whether the sources that will inform and/or inspire free and creative recontextualisation are well-documented historical facts or not. It is reasonable to imagine irrelevant artistic research that was rigorously informed historically; as much as it is reasonable to imagine relevant artistic research that was inspired by non-validated historical information, by other contexts, or even by invented facts and fictional contexts. Considering that it is the respective artistic production at the centre of an artistic research project, Taruskin's (1988) notion that performance will always be intrinsically a matter of persuasion seems very pertinent here:

It is true that some performance styles that have arisen in the last quarter century under the banner of historical verisimilitude have proven extremely persuasive, influential, and (with the passage of time) authoritative - at least within the world of performance. [...] Whatever the case a scholarly prosecutor might choose to bring against them, they will remain as persuasive and authoritative as ever, until a more persuasive style, as is inevitable, comes along to supersede 
them. What makes for persuasion, I want to emphasise - and hence, what makes for authority and authenticity, in a sense I would approve - has to do both with the persuaders and with the persuaded. (Taruskin, 1988, pp. 141-142)

The ultimate determinant of the relevance of an artistic research project is its potential to interact empathetically with the audience, and to reconfigure their old mythopoetic configurations. This is how knowledge is produced and shared on the narrative side of the epistemological divide, and it is on this very side that Frida Forsgren, author of chapter 7, develops an art-based pedagogy as she describes her pedagogical strategies in a course devoted to teaching American Beat culture at Agder University. Instead of studying historical and contextual information first, in order to subsequently consider a range of more conscious choices throughout the process of creating a performance, as Nesmann-Aas proposes in chapter 3 , Forsgren, committed to the "hands-on", "learning-by-doing" pedagogy of John Dewey, claims to "do history through art". In her course, students learn through vivid artistic experiences how to present, enact, re-enact, live, re-live and fantasise a historical past. It is about doing, about creating artistic projects in order to develop historical empathy and critical thinking. It is not about distant, abstract, paradigmatic knowledge - knowing what Beat is - but about seeking a deeper meaning, in which feeling and thought are inextricably linked.

Despite the different levels of excellence and familiarity with early music performance at different stages of students' education, Forsgren suggests that there will always be a choice between a (paradigmatic) "learning mode that aims at a correct understanding of the work of art as an artefact [or another (narrative) mode of learning in which it is intended that] they become familiarised more with aesthetic-ethical processes and practices leading up to the artwork" (Forsgren, 2022, p. 16).

\section{Concluding considerations}

Understanding HIP within the framework of academic research has profound epistemological implications, since performance carries with it an irreducible knowledge that does not separate objectivity from subjectivity in a dichotomous way, and develops through intertwined reflection 
and action - the poietic and poetic of artistic creation. The substance of knowledge is found in what is done in creation itself, in its material products and in its various forms of writing, and not in the theoretical reflection that eventually may also accompany such processes. I emphasised that creative performances are activities that explore the sense of possibility, reconfiguring our old-established mythopoetic configurations.

It was mentioned at the beginning of this chapter how long it took to incorporate new activities like creation into music teaching and performance, mainly due to the disciplinary subjugation that was forced on performance research. During this transformation period, some of the general myths uniting Western European classical music have been fading away. In his book Music as Creative Practice, Cook (2018) summarised these myths into a series of binaries, giving an account of how research interests have fluctuated: "The focus was on the individual rather than the group, the producer rather than the receiver, composition rather than performance, text rather than context, mind rather than body, men rather than women, and the exceptional rather than the everyday" (Cook 2018, p. 6).

Nonetheless, there are still two logocentric assumptions that persists with much resilience in academic circles, despite other forms of knowledge being widely recognised and accepted, namely tacit knowledge (Collins, 2010) and embodied knowledge (Lakoff \& Johnson, 1999). And yet mythical knowledge, too, has always regulated and continues to regulate our lives individually and socially, including in determining our options in the development of scientific and philosophical knowledge. I refer to the "logocentric" myth, which asserts that only the paradigmatic (propositional, conceptual) mode is suitable for archiving and transferring knowledge, regardless of the field of research. As practical and effective as it has proven to be, the paradigmatic mode imposes abstraction, "which makes it useless, to explore such a peculiar, specific mode of communication [interaction] that is characterized by being direct, non-mediated by a linguistic system, and grounded on empathy" (Correia \& Dalagna, 2020, p. 6).

I have argued that relevant artistic interventions affect us on the level of our deepest mythopoetic configurations (precisely because of their 
specific mode of communication being interactive, direct, unmediated, empathic), which are founded on an intersubjective network of exemplars (Lehrer, 2012), where feeling and thinking are intertwined in an inextricable amalgam. These exemplars, like gestures, are not universal, but may be generalisable within a community and can only be reached and reconfigured through subjective re-enactments. Thus, it is through this peculiar interaction - implicating re-enactments and embodied meanings - that artistic interventions pave the way to mythopoetic reconfigurations. Subsequently, only a discourse that resists abstraction, and retains similar gestural and symbolic dimensions, may add to artistic experience by both exploring creators' subjective impressions of their creations, and clarifying the aesthetic, ethical and ecological pertinence of artistic interventions. In other words, there is a territory, constituted by an embodied intersubjective amalgam of beliefs, convictions and mythopoetic configurations, in which artistic research fulfils all the conditions for exploring new possibilities, creating new realities and intervening to provoke changes and reconfigurations. The social sciences can describe and analyse this territory, but the distance imposed by their logocentric abstraction is always reductive, because it excludes embodied meanings and subjective creative re-enactments. To observe and analyse in order to produce taxonomies and conceptual structures is to focus on the past, remaining on the paradigmatic side of the epistemological fracture. The authors brought together in this book explore the past but are pedagogically and rhetorically committed to the future. They create new possibilities, and are thus artistic researchers, crossing over to the other side of the epistemological divide. They look back at the past in search of new possibilities.

\section{References}

Assis, P. (2015). Experimental affinities in music. Leuven University Press.

Assis, P. (2018). Logic of experimentation: Rethinking music performance through artistic research. Leuven University Press.

Barthes, R. (1982). L'obvie et l'obtus. Editions du Seuil.

Bateson, G. (1972). Steps on the ecology of mind: Collected essays in anthropology, psychiatry, evolution and epistemology. Chandler Publishing Co. 
Burke, P. (2008). What is cultural history? Polity Press.

Butt, J. (2015). What is a 'musical work'? Reflections on the origins of the 'work concept' in Western art music. In A. Rahmatian (Ed.), Concepts of music and copyright: How music perceives itself and how copyright perceives music (pp. 1-22). Edward Elgar Publishing Ltd. https://www.elgaronline.com/view/ edcoll/9781783478187/9781783478187.00006.xml

Carlson, M. (2010). Performance: Uma introdução crítica. Editora Universidade Federal de Minas Gerais.

Carter, P. (2004). Material thinking: The theory and practice of creative research. Melbourne University Press.

Cook, N. (1998). Analysing musical multimedia. Oxford University Press.

Cook, N. (2001). Between process and product: Music as/and performance. Music Theory Online, 7(2), 1-15.

Cook, N. (2018). Music as creative practice. Oxford University Press.

Correia, J. (2003). Investigating musical performance as embodied socio-emotional meaning construction: Finding an effective methodology for interpretation [Doctoral dissertation, University of Sheffield].

Correia, J. \& Dalagna, G. (2019). Cahiers of artistic research 2: Premises for artistic research. Editora da Universidade de Aveiro.

Correia, J. \& Dalagna, G. (2020). Cahiers of artistic research 3: A model for artistic research. Editora da Universidade de Aveiro.

Cox, A. (2001). The mimetic hypothesis and embodied musical meaning. Musicae Scientiae, (Vol. V), 195-212.

Crispin, D. (2015). Artistic research and music scholarship: Musings and models from a continental European perspective. In M. Doğantan-Dack (Ed.), Artistic practice as research in music: Theory, criticism, practice (pp. 53-72). Ashgate Publishing.

Crispin, D. (2019). The deterritorialization and reterritorialization of artistic research. Online Journal for Artistic Research, 3(2), 45-59.

Croft, J. (2015). Composition is not research. TEMPO, 69(272), 6-11.

Dalagna, G., Carvalho, S. \& Welch, G. (2021). Desired artistic outcomes in music performance. Routledge.

Damasio, A. (1999). The feeling of what happens: Body and emotion in the making of consciousness. Harcourt Brace.

Deleuze, G. (1981). Francis Bacon: Logique de la sensation. Editions de la différence.

Deleuze, G. \& Guatari, F. (1980). Mille plateaux: Capitalisme et schizophrénie. Les Editions de Minuit.

Derrida, J. (1973). La mythologie blanche: La métaphore dans le texte philosophique. Poétique: Revue de Théorie et d'Analyse Littéraires. Éditions du Seuil, Paris, Deuxième année, Avril, Numéro 2, 1-52. 
Dogantan-Dack, M. (2014). Philosophical reflections on expressive music performance. In D. Fabian, R. Timmers \& E. Schubert (Eds.), Expressiveness in music performance empirical approaches across styles and cultures (pp. $3-21$ ). Oxford University Press.

Donald, M. (1991). Origins of the modern mind: Three stages in the evolution of culture and cognition. Harvard University Press.

Eidsaa, R. M. (2022). Early music in an Interdisciplinary artistic production: The project Pluvinel's Academy. In R. Rolfhamre \& E. Angelo (Eds.), Views on early music as representation: Invitations, congruity, performance (MusPed:Research Vol. 4, pp. 149-176). Cappelen Damm Akademisk. https://doi.org.

Elliott, D. (1995). Music matters: A new philosophy of music education. Oxford University Press.

Ericsson, K., Charness, N., Feltovich, P. \& Hoffman, R. (2006). The Cambridge handbook of expertise and expert performance. Cambridge University Press.

Fabian, D. (2001). The meaning of authenticity and the early music Movement: A historical review. International Review of the Aesthetics and Sociology of Music, $32(2), 153-167$.

Fischer-Lichte, E. (2011). Estética de lo performativo. Abada Editores.

Forsgren, F. (2022). Re-enacting Beat art: An aesthetic and pedagogical approach to re-live history. In R. Rolfhamre \& E. Angelo (Eds.). Views on early music as representation: Invitations, congruity, performance (MusPed:Research Vol. 4, pp. 177-198). Cappelen Damm Akademisk. https://doi.org.

Goehr, L. (1992). The imaginary museum of musical works. Oxford University Press. Gil, J. (Ed.). (2001). Movimento total: Corpo e dança. Relógio d'água.

Haynes, B. (2007). The end of early music: A period performer's history of music for the twenty-first century. Oxford University Press.

Higgins, K. (1997). Musical idiosyncrasy and perspectival listening. In J. Robinson (Ed.), Music and meaning (pp. 83-102). Cornell University Press.

Huber, D., Kaufmann, T., Kretz, J., Schröder, G. \& Zembylas, T. (2021). Knowing in performing: Artistic research in music and the performing arts. Columbia University Press.

Johnson, M. (1987). The body in the mind: The bodily basis of meaning, imagination and reason. University of Chicago Press.

Levinson, J. (1993). Performative vs. critical interpretation in music. In J. Krausz (Ed.), The interpretation of music: Philosophical essays (pp. 33-6o). Oxford University Press.

Lévi-Strauss, C. (1978). Myth and meaning. University Toronto Press.

Lilja, E. (2021). The pot calling the kettle black: An essay on the state of artistic research. In A. Huber, D. Ingrisch, T. Kaufmann, J. Kretz, G. Schröder \& 
T. Zembylas (Eds.), Knowing in performing: Artistic research in music and the performing arts (pp. 27-34). Columbia University Press.

Kartomi, M. (2014). Concepts, terminology and methodology in music performativity research. Musicology Australia, 36(2), 189-208. https://doi.org/10. 1080/08145857.2014.958268

Kundera, M. (1991). Immortality. HarperCollins.

Lehrer, K. (2012). Art, self and knowledge. Oxford University Press.

Lakoff, G. \& Johnson, M. (1999). Philosophy in the flesh: The embodied mind and its challenge to western thought. Basic Books.

Mckenzie, J. (2005). Performance studies. https://www.brown.edu/Departments/ Joukowsky_Institute/courses/architecturebodyperformance/files/257077.htm

Nesmann-Aas, I. M. (2022). Contextual in-depth knowledge as a liberating force in artistic communication of early modern material. In R. Rolfhamre \& E. Angelo (Eds.), Views on early music as representation: Invitations, congruity, performance (MusPed:Research Vol. 4, pp. 97-118). Cappelen Damm Akademisk. https://doi.org.

Nietzsche, F. (1967). The birth of tragedy out of the spirit of music (Walter Kaufmann, Trans.). Vintage.

$\emptyset v r e b ø$, D. H. (2022). Hearing early modern music through the contemporary. In R. Rolfhamre \& E. Angelo (Eds.), Views on early music as representation: Invitations, congruity, performance (MusPed:Research No. 4, pp. 119-137). Cappelen Damm Akademisk. https://doi.org/10.23865/noasp.157

Penha, R. (2019). On the reality clarified by art. Online Journal for Artistic Research, $3(2), 3-44$.

Rolfhamre, R. (2022). Performative musicology and HIP as rhetoric and pedagogy for the past in present and future. In R. Rolfhamre \& E. Angelo (Eds.), Views on early music as representation: Invitations, congruity, performance (MusPed:Research No. 4, pp. 21-95). Cappelen Damm Akademisk. https://doi.org/10.23865/noasp.157

Rosen, C. (1994). The frontiers of meaning: Three informal lectures on music. Harper Collins Canada Ltd.

Shepherd, J. (1991). Music as social text. Polity Press and Basil Blackwell Inc.

Small, C. (1998). Musicking: The meanings of performing and listening. Wesleyan University Press, University Press of New England.

Steiner, G. (1989). Real presences. University Chicago Press.

Stevance, S. \& Lacase, S. (2018). Research-creation in music and the arts: Towards a collaborative interdiscipline. Routledge Publishing.

Taruskin, R. (1995). Text \& act: Essays on music and performance. Oxford University Press.

Taruskin, R. (1988). The pastness of the present. In N. Kenyon (Ed), Authenticity and early music: A symposium. Oxford University Press. 



\section{About the Authors}

Elin Angelo (PhD) is a professor of music education at NTNU Norwegian University of Science and Technology, in the Department of Teacher Education and the Department of Music, and a visiting professor at Nord University, Norway, Faculty of Education and Arts. Her research interests include music teacher education, higher music education, and music and art schools. Further information: https://www.ntnu.edu/ employees/elin.angelo

Jorge Salgado Correia $(\mathrm{PhD})$ is an associate professor at the University of Aveiro, Portugal. Correia has a background in philosophy and music, and has studied in Portugal, Holland and England. His specialist performance area is contemporary music. Correia has published articles and book chapters on performance and artistic research, and he is coordinator of the research group Creation, Performance and Artistic Research at INET-md (the Instituto de Etnomusicologia - Centro de Estudos em Música e Dança) and president of the Portuguese Flute Association. Jorge is also founder and editor of IMPAR-Online Journal for Artistic Research. Further information: http://www.inetmd.pt/index.php/en/ people/doutoradosen/242-jorge-manuel-salgado-de-castro-correia-en

Randi Margrethe Eidsaa $(\mathrm{PhD})$ is a professor of music education at the Faculty of Fine Arts, University of Agder, Norway. She teaches musicology, concert production and music didactics. Eidsaa holds a $\mathrm{PhD}$ in music pedagogy from Danish School of Education in Copenhagen. Further information: https://www.uia.no/kk/profil/randie

Frida Forsgren $(\mathrm{PhD})$ is an associate professor of art history at the University of Agder, Norway. Her PhD is in Renaissance studies, but she works predominantly with American and Nordic Modernism. Forsgren's 
publications include San Francisco Beat Art in Norway (2008), Beat Lives (2013), Out of the Shadows (2015), and Beatgenerasjonen og kjønnsroller (2017). Further information: https://www.uia.no/kk/profil/ingvilff

Rolf Lislevand (Dr phil h c) is a professor at the University of Agder, Norway; a professor of lute, improvisation and historically informed performance practice at the Staatliche Hochschule für Musik, Trossingen, Germany; and a professor of lute, improvisation and chamber music at the Lyon Conservatoire National Supérieur Musique et Danse, France. Lislevand was granted an honorary doctorate by the Royal Swedish Academy of Music in 2018, and he is considered one of the foremost early music performers of our time. Further information: https://www.uia. no/om-uia/fakultet/fakultet-for-kunstfag/institutter/institutt-for-klassisk-musikk-og-musikkpedagogikk/utoevende-klassisk-musikk/ rolf-lislevand

Inga Marie Nesmann-Aas (MMus, MA) is a research fellow at the University of Agder, Norway. She holds an MA in English literature and MMus in classical singing. Her PhD project 'Reconfiguring Dido' investigates new approaches towards textual and musical analysis, post-HIP, interpretation, embodied musical performance and realisations of text and music. Further information: https://www.uia.no/kk/profil/ingamn

Robin Rolfhamre $(\mathrm{PhD})$ is a professor of music education at the University of Agder, Norway, Department of Classical Music and Music Education. His research is rooted in music pedagogy, early music performance studies, and organology. As a performer, Rolfhamre has released several full albums and performed concerts worldwide. Further information: www. rolfhamre.com

Daniel Henry Øvrebø $(\mathrm{PhD})$, a research fellow at the University of Agder at the time the chapters were written, is currently working as research adviser at Oslo Metropolitan University, Norway. He has studied music performance at the University of Agder and the University of Music Wuerzburg, Germany. He also studied art history, German language 
and culture, and musicology at the University of Bergen, Norway. His $\mathrm{PhD}$ project 'Performative Arts Based Audience Research' investigates audience reception through his own performances of high modernist flute music. Further information: https://www.oslomet.no/om/ansatt/ danielhe/

\section{Review Panel}

- James Cook (PhD), lecturer in early music, University of Edinburgh, Scotland

- Øyvind Johan Eiksund (PhD), associate professor of music, NTNU - Norwegian University of Science and Technology, Norway

- Martha Elliott (MMus), of the performance faculty (voice), Department of Music, Princeton University, USA

- Anne Jordhus-Lier (PhD), associate professor, Inland Norway University of Applied Sciences

- Alexis Luko (PhD), director and professor, School of Music, University of Victoria, Canada

- Mattias Lundberg (PhD), professor, Department of Musicology, Uppsala University, Sweden

- Rose Martin (PhD), professor of arts education, NTNU - Norwegian University of Science and Technology

- Kate Maxwell (PhD), professor, UiT The Arctic University of Norway

- Nadia Moberg, research fellow in musicology, Örebro University, Sweden

- Hanne Rinholm (PhD), associate professor, Oslo Metropolitan University, Norway

- Ragnhild Sandberg-Jurström (PhD), senior lecturer in music education, Ingesund School of Music, Karlstad University, Sweden

- Rachel E. Scott (PhD), associate dean for information assets, Milner Library, Illinois State University, USA

- Ola Buan Øien (PhD), associate professor, Nord University, Norway

- anonymous peer reviewer 
